CEVIN STIEHL

Beitrag zur Vorbemessung der Biegeverstärkung von Stahlbetonbauteilen mit Rechteckquerschnitt mittels aufgeklebten CFK-Lamellen 

CEVIN STIEHL

Beitrag zur Vorbemessung der

Biegeverstärkung von

Stahlbetonbauteilen mit

Rechteckquerschnitt mittels

aufgeklebten CFK-Lamellen 


\section{Über den Autor}

Cevin Stiehl studierte bis 2014 Bauingenieurwesen an der Hochschule Magdeburg-Stendal. Als Werkstudent sammelte er erste Erfahrungen im Projektmanagement. Dem Bachelorstudium folgte ein Masterstudium an der HTWK Leipzig, mit den Schwerpunkten Hochbau und Bauwerkserhaltung, in dessen Rahmen das vorliegende Werk als Abschlussarbeit verfasst wurde. Seit dem erfolgreichen Studienabschluss im August 2017 war er als Bauleiter tätig. Ab 2020 wird er als wissenschaftlicher Mitarbeiter an der HTWK Leipzig angestellt.

Bibliografische Information der Deutschen Nationalbibliothek

Die Deutsche Nationalbibliothek verzeichnet diese Publikation in der Deutschen Nationalbibliografie. Detaillierte bibliografische Daten sind im Internet unter http://dnb.de abrufbar.

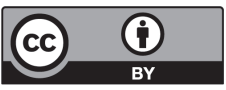

Der Text dieses Werks ist unter der Creative-Commons-Lizenz CC BY 4.0

International veröffentlicht. Den Vertragstext der Lizenz finden Sie unter https://creativecommons.org/licenses/by/4.0/. Die Abbildungen sind von dieser Lizenz ausgenommen, hier liegt das Urheberrecht beim jeweiligen Rechteinhaber.

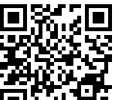

Die Online-Version dieser Publikation ist abrufbar unter

http://doi.org/10.33968/9783966270021-00

\section{(C) 2019 Cevin Stiehl}

\section{Herausgeber}

Open-Access-Hochschulverlag

Hochschule für Technik, Wirtschaft und Kultur Leipzig

Karl-Liebknecht-Str. 132

04277 Leipzig

Deutschland

Druck und Bindung in Deutschland und den Niederlanden Gedruckt auf säurefreiem Papier

ISBN (Hardcover) 978-3-96627-000-7

ISBN (Softcover) 978-3-96627-001-4

ISBN (ePub) 978-3-96627-003-8

ISBN (PDF) 978-3-96627-002-1 


\section{Kurzfassung}

Das nachträgliche Verstärken von Stahlbetonbauteilen mit geklebter Bewehrung ist seit 2012 in einer eigenen Richtlinie geregelt. Darin sind u.a. die erforderlichen Nachweise für aufgeklebte Lamellen aus kohlenstofffaserverstärktem Kunststoff (CFK) geregelt, welche neben der aufwendigen iterativen Biegebemessung ein sehr komplexes Verbundverhalten aufweisen. Dafür wurde vom Deutschen Ausschuss für Stahlbeton anhand von Versuchsauswertungen ein Modell zur Nachweisführung erarbeitet, wobei die auftretenden Zugkräfte zum Teil über Zwischenrisselemente (Teilstrecken zwischen Biegerissen) in das Bauteil übertragen werden. Aufgrund des Umfangs und der Komplexität der Nachweisführung wurden gleichzeitig vereinfachte, aber ungenauere Nachweisformate darin zur Verfügung gestellt. Um eine frühzeitige Abschätzung über den Einsatz von aufgeklebten CFK-Lamellen zu ermöglichen, wurden in dieser Arbeit unterschiedliche Hilfsmittel für Stahlbetonbauteile mit Rechteckquerschnitt in Abhängigkeit der unterschiedlichen Nachweisformate erarbeitet. Dazu wurden die Bemessungsgrundlagen getrennt nach reiner Biegetragfähigkeit und dem Verbundverhalten betrachtet. Für eine einfache Handrechnung ergaben sich analog zum Stahlbetonbau Bemessungstafeln mit dimensionslosen Beiwerten mit denen anhand einer Grenzdehnung aus dem vereinfachten Nachweis der Biegetragfähigkeit die erforderliche Lamellenfläche bestimmt werden kann. Für eine wirtschaftlichere Lösung wurde der genauere Nachweis der Lamellenkraftänderung am Zwischenrisselement in einer Excel-Arbeitsmappe konfiguriert, da hierbei ein außerordentlicher iterativer Berechnungsaufwand entsteht.

\section{Abstract}

Since 2012, the subsequent reinforcement of reinforced concrete components with bonded reinforcement has been regulated in a separate guideline. This includes the dimensioning of the adhesively bonded strips made of carbon-fiber reinforced plastic (CFRP), which, in addition to the complex iterative bending design, have a very complex bonding behavior. For this purpose, the German Committee for Structural Concrete developed a model for the verification based on experimental evaluations, in which the occurring tensile forces are partly transferred into the component via intermediate elements (partial distances between flexural cracks). Simultaneously, simplified but more inaccurate verification formats were made available to reduce the complexity of the verification. For an early assessment of the use of bonded CFRP strips, different tools have been developed in this paper for reinforced concrete components with a rectangular cross-section depending on the different verification formats. For this purpose, the design parameters were considered separately for pure bending strength and bonding behavior. For a simple calculation, tables for the design with dimensionless coefficients were obtained by analogy with the reinforced concrete construction, with which the required cross-section area for the CFRP strips can be determined by means of a limited 
stretching from the simplified verification of the flexural load-bearing capacity. For a more economical solution, the more precise verification of the force transmission on the intermediate elements was configured in an Excel workbook, because this results in an extraordinary iterative calculation effort. 


\section{Inhaltsverzeichnis}

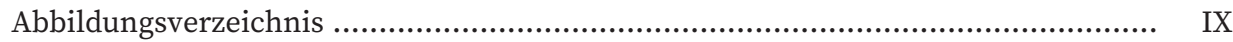

Tabellenverzeichnis ................................................................................ XII

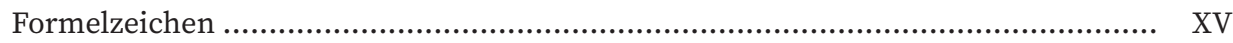

Abkürzungsverzeichnis............................................................................ XV

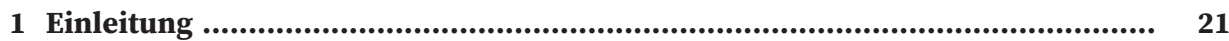

1.1 Einführung in die Thematik .............................................................. 21

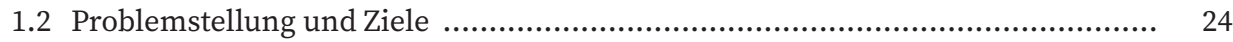

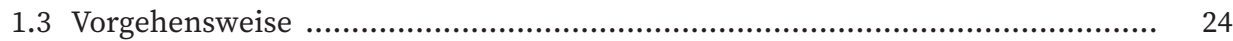

2 Theoretische Grundlagen ....................................................................... 27

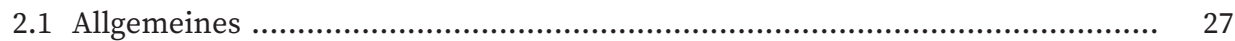

2.2 Voraussetzungen für die Bemessung ................................................... 27

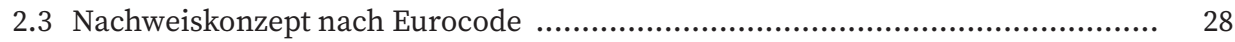

2.4 Materialkennwerte ............................................................................ 30

2.4.1 Beton ................................................................................... $\quad 30$

2.4.2 Betonstahl ............................................................................... 34

2.4.3 Kohlenstofffaserverstärkter Kunststoff - CFK ......................................... 35

2.5 Schnittgrößenermittlung .................................................................. 38

2.6 Bemessung Stahlbetonquerschnitt ........................................................ 39

2.7 Verstärkung mit aufgeklebten CFK-Lamellen ............................................ 46

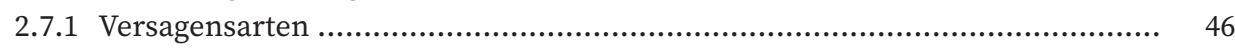

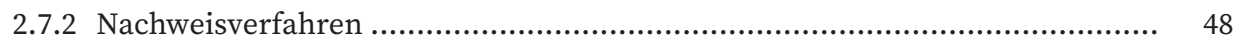

2.7.3 Abgrenzung der Arbeit ...................................................................... 49

2.7.4 Nachweis der Biegetragfähigkeit ........................................................ 50

2.7.5 Nachweis der Verbundkraftübertragung ............................................. 57

2.7.6 Vereinfachter Nachweis ohne Verbundbetrachtung ................................ 74

3 Vorbemessung der Verstärkung mit aufgeklebten CFK-Lamellen .................... 77

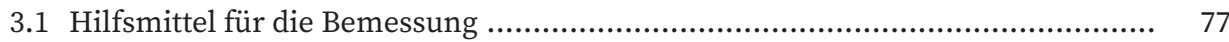

3.2 Vereinfachung des reinen Biegenachweises ............................................. 78

3.2.1 Bemessungstafeln ohne Druckbewehrung ............................................ 78

3.2.2 Bemessungstafeln mit Druckbewehrung ............................................. 90

3.3 Nachweis der Verbundkraftübertragung am ZRE .................................... 96

3.3.1 Excel-Arbeitsmappe für die Nachweisführung ....................................... 96

3.3.2 Konfiguration der Excel-Arbeitsmappe .............................................. 98 


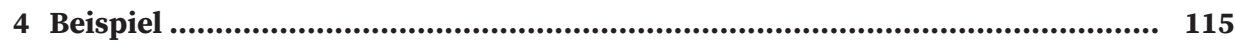

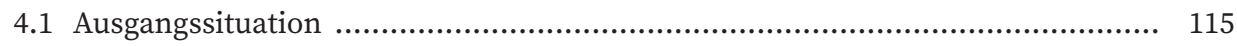

4.1.1 Statisches System mit Einwirkungen ................................................ 115

4.1.2 Materialkennwerte .................................................................. 116

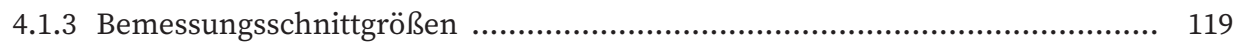

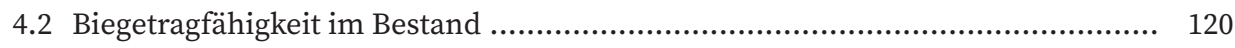

4.3 Dehnungen zum Zeitpunkt der Verstärkung ............................................. 121

4.4 Vereinfachter Nachweis ohne Verbundbetrachtung ................................. 121

4.4.1 Zulässige Grenzdehnung ................................................................ 122

4.4.2 Erforderliche Lamellenfläche .......................................................... 123

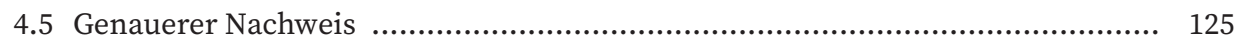

4.5.1 Nachweis der Biegetragfähigkeit ..................................................... 125

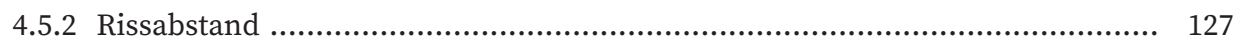

4.5.3 Iterative Ermittlung der Lamellenkraft ............................................... 129

4.5.4 Nachweis der Verbundkraftübertragung ............................................. 134

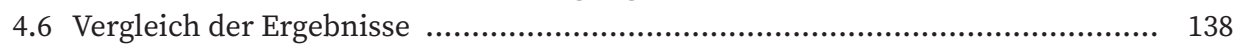

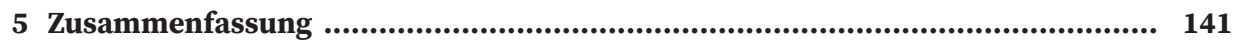

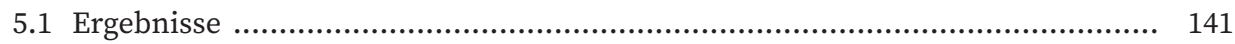

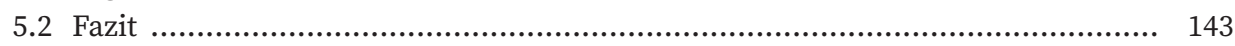

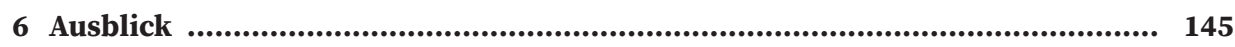

Literaturverzeichnis ........................................................................ 147

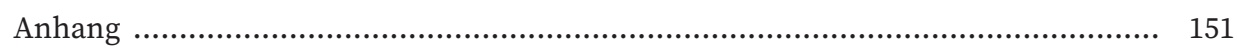

Anhang A Anwendung der Bemessungstafeln ohne Druckbewehrung .................. 153

Anhang B Anwendung der Bemessungstafeln mit Druckbewehrung ..................... 157

Anhang C Bemessungstafeln .................................................................. 161

Anhang D innerer Hebelarm ...................................................................... 195

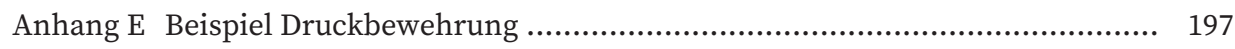

Anhang F Newton-Verfahren .............................................................. 201

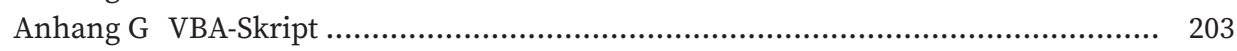

Anhang H Fehlerbehebung Excel-Arbeitsmappe ........................................... 245 


\section{Abbildungsverzeichnis}

Abb. 1 Verstärkung eines Stahlbetonunterzugs mit aufgeklebten CFK-Lamellen 22

Abb. 2 Verstärkung einer Stahlbetondecke mit aufgeklebten CFK-Lamellen ....... 23

Abb. 3 Spannungs-Dehnungs-Linie für die Schnittgrößenermittlung

(nichtlinear) ........................................................................ 30

Abb. $4 \quad$ Parabel-Rechteck-Diagramm …..................................................... 33

Abb. 5 Rechnerische Spannungs-Dehnungs-Linie des Betonstahls ................... 35

Abb. 6 Versagen von CFK unter Biegung und Zug ..................................... 36

Abb. 7 Spannungs-Dehnungs-Linie von CFK-Lamellen für die Bemessung ......... 36

Abb. 8 Idealisierung der Spannungs-Dehnungs-Linie nach Elastizitätstheorie .... 39

Abb. 9 zulässige Dehnungszustände am Stahlbetonquerschnitt ...................... 40

Abb. 10 Dehnungs- und Spannungsverteilung am Stahlbetonquerschnitt ........... 40

Abb. 11 Dehnungsverteilung bei reiner Biegung ........................................... 43

Abb. 12 Iterationsvorgang Biegetragfähigkeit im Bestand .............................. 45

Abb. 13 Fachwerkprinzip mit CFK-Lamelle ............................................ 47

Abb. 14 Versatzbruch ......................................................................... 47

Abb. 15 Ablaufschema des Nachweisverfahrens bei aufgeklebten CFK-Lamellen . 48

Abb. 16 zulässige Dehnungszustände am verstärkten Stahlbetonquerschnitt (A) .. 51

Abb. 17 zulässige Dehnungszustände am verstärkten Stahlbetonquerschnitt (B) .. 51

Abb. 18 Dehnungs- und Spannungsverteilung am verstärkten Querschnitt ......... 53

Abb. 19 Iterationsschema verstärkter Querschnitt ...................................... 55

Abb. 20 Verbundversagen bei aufgeklebten CFK-Lamellen ............................... 57

Abb. 21 Prinzip des Zugkraftverlaufs über Zwischenrisselemente ..................... 58

Abb. 22 bilineare Verbundspannungsschlupfbeziehung .................................. 59

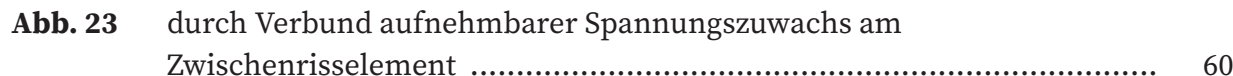

Abb. 24 bilinearer Verbundansatz erweitert um Reibung am ZRE ..................... 62

Abb. 25 bilinearer Verbundansatz erweitert um Reibung und Krümmung

Abb. 26 aufnehmbare Lamellenkraftänderung am ZRE .................................. 65

Abb. 27 Rissabstand und Zwischenrisselemente ....................................... 70

Abb. 28 Bezeichnungen am verstärkten Querschnitt (ohne Druckbewehrung) .... 79

Abb. 29 Bereich der zulässigen Stahldehnung für die Bemessungstafeln ............. 80

Abb. 30 zulässige Dehnungszustände für Bemessungstafeln ohne

Druckbewehrung ...................................................................... 82

Abb. 31 beispielhafter Ausschnitt einer Bemessungstafel $(10 \% 0)$..................... 83

Abb. 32 Diagramm zur Bestimmung der Lamellengesamtdehnung .................... 86

Abb. 33 Dehnungen und Spannungen zum Zeitpunkt „0“ ohne Druckbewehrung . 87

Abb. 34 Bezeichnungen am verstärkten Querschnitt (mit Druckbewehrung) ....... 90 
Abb. 35 zulässige Dehnung der Druckbewehrung für die Bemessungstafeln ........ 91

Abb. 36 zulässige Dehnungszustände für Bemessungstafeln mit

Druckbewehrung ........................................................................ 93

Abb. 37 Dehnungen und Spannungen zum Zeitpunkt „0“ mit Druckbewehrung ... 95

Abb. 38 Ausnutzungsgrad Verbundnachweis in Abhängigkeit des

Nachweisformats ...................................................................... 96

Abb. 39 Schaltfläche „Inhalt aktivieren“ ..................................................... 98

Abb. 40 Userform Startseite ................................................................... 99

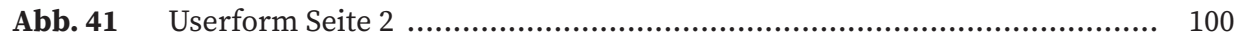

Abb. 42 Userform Seite 3 (Biegebalken) .................................................... 101

Abb. 43 Userform Seite 3 Ausschnitt (einachsig gespannte Platte) .................... 102

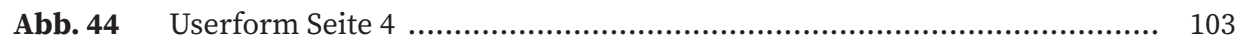

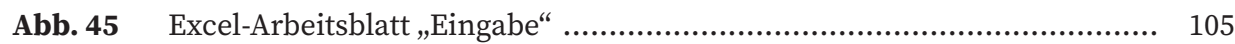

Abb. 46 Excel-Arbeitsblatt „Daten“ ........................................................... 107

Abb. 47 maximal zulässige Lamellenbreite .............................................. 108

Abb. 48 Konfigurationsschema der Excel-Arbeitsmappe ................................. 109

Abb. 49 Ablaufschema des Verbundnachweises am ZRE (Iteration 3) ................ 113

Abb. 50 statisches System mit Belastung ................................................ 115

Abb. 51 Querschnittsabmessungen ....................................................... 116

Abb. 52 qualitative Darstellung des Biegemoments ...................................... 119

Abb. 53 Zugkraftverlauf der einbetonierten und aufgeklebten Bewehrung ......... 133

Abb. 54 erforderliche Lamellenfläche in Abhängigkeit des Nachweisformats ...... 138

Abb. 55 Ablaufschema des Nachweisverfahrens bei aufgeklebten CFK-Lamellen . 141

Abb. 56 zulässige Bereiche der Bemessungstafeln in Bezug zur

Betonstahlspannung ............................................................. 142

Abb. 57 Umfang der integrierten und der zu führenden Nachweise .................. 144

Abb. A.1 Dehnungs- und Spannungsverteilung am Stahlbetonquerschnitt bei linear-elastischem Materialverhalten ohne Druckbewehrung ............... 153

Abb. A.2 Dehnungs- und Spannungsverteilung am verstärkten Querschnitt ohne Druckbewehrung ............................................................. 154

Abb. B.1 Dehnungs- und Spannungsverteilung am Stahlbetonquerschnitt bei linear-elastischem Materialverhalten mit Druckbewehrung ................. 157

Abb. B.2 Dehnungs- und Spannungsverteilung am verstärkten Querschnitt mit Druckbewehrung .............................................................. 158

Abb. D.1 Dehnungs- und Spannungsverteilung am Stahlbetonquerschnitt bei linear-elastischem Materialverhalten .............................................. 195

Abb. E.1 Dehnungsverteilung bei großen Einwirkungen ohne Druckbewehrung ... 197

Abb. E.2 Dehnungsverteilung bei großen Einwirkungen mit Druckbewehrung ..... 197

Abb. E.3 beispielhafter Stahlbetonquerschnitt .......................................... 198

Abb. F.1 Newton-Verfahren .................................................................. 201

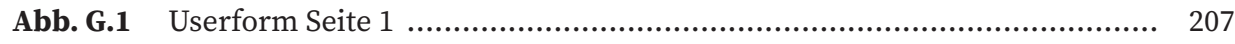

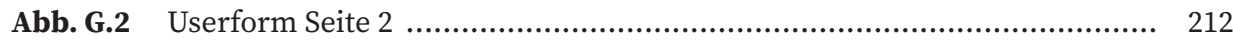

Abb. G.3 Userform Seite 3.1 ............................................................... 218 
Abb. G.4 Userform Seite 3.2 ................................................................. 218

Abb. G.5 Userform Seite 4 ..................................................................... 231

Abb. H.1 Fehlermeldung (Solver Add-in nicht installiert) .............................. 245

Abb. H.2 Excel-Add-Ins ......................................................................... 246

Abb. H.3 Solver aktivieren ...................................................................... 247

Abb. H.4 Fehlermeldung (VBA Solver-Verweis fehlt) .................................... 247

Abb. H.5 Makro stoppen .................................................................. 248

Abb. H.6 VBA-Verweise öffnen .................................................................. 248

Abb. H.7 Solver-Verweis setzen ......................................................... 248

Abb. H.8 automatische Arbeitsmappenberechnung aktivieren ........................... 249

Abb. H.9 Fehlermeldung Zielzelle ...................................................... 250 


\section{Tabellenverzeichnis}

Tab. 1 Teilsicherheitsbeiwerte für Baustoffe im GZT ….............................. 29

Tab. 2 Festigkeits- und Formänderungskennwerte für Normalbeton ................ 32

Tab. 3 Versagensarten von Querschnitten mit aufgeklebten CFK-Lamellen ....... 46

Tab. 4 Beiwerte zur Berechnung der Verbundspannung .............................. 72

Tab. 5 Solver-Iteration Biegetragfähigkeit (Bestand) ............................... 111

Tab. 6 Solver-Iteration verstärkter Querschnitt ....................................... 112

Tab. 7 Solver-Iteration Lamellenkraft ............................................... 113

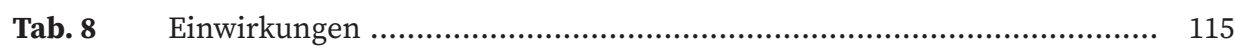

Tab. 9 Schnittgrößen und Dehnungen ...................................................... 132

Tab. 10 Lamellenkraftdifferenz an den Zwischenrisselementen $\quad$....................... 134

Tab. C.1 Bemessungstafel für Rechteckquerschnitte mit und ohne Druckbewehrung (Normalbeton C12/16 - C50/60 | Betonstahl B500 |

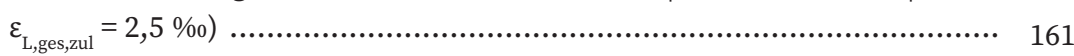

Tab. C.2 Bemessungstafel für Rechteckquerschnitte mit und ohne Druckbewehrung (Normalbeton C12/16 - C50/60 | Betonstahl B500 |

$\varepsilon_{\mathrm{L}, \mathrm{ges}, \mathrm{zul}}=3 \% 0$ ) 162

Tab. C.3 Bemessungstafel für Rechteckquerschnitte mit und ohne Druckbewehrung (Normalbeton C12/16 - C50/60 | Betonstahl B500 | $\varepsilon_{\text {L,ges,zul }}=3,5 \% 0$ )

Tab. C.4 Bemessungstafel für Rechteckquerschnitte mit und ohne Druckbewehrung (Normalbeton C12/16 - C50/60 | Betonstahl B500 | $\varepsilon_{\mathrm{L}, \mathrm{ges}, \mathrm{zul}}=4 \% 0$ ) 164

Tab. C.5 Bemessungstafel für Rechteckquerschnitte mit und ohne Druckbewehrung (Normalbeton C12/16 - C50/60 | Betonstahl B500 | $\varepsilon_{\text {L,ges,zul }}=4,5 \% 0$ ) 165

Tab. C.6 Bemessungstafel für Rechteckquerschnitte mit und ohne Druckbewehrung (Normalbeton C12/16 - C50/60 | Betonstahl B500 | $\left.\varepsilon_{\mathrm{L}, \mathrm{ges}, \mathrm{zul}}=5 \% 0\right)$. 166

Tab. C.7 Bemessungstafel für Rechteckquerschnitte mit und ohne Druckbewehrung (Normalbeton C12/16 - C50/60 | Betonstahl B500 | $\varepsilon_{\text {L,ges,zul }}=5,5 \%$ )

Tab. C.8 Bemessungstafel für Rechteckquerschnitte mit und ohne Druckbewehrung (Normalbeton C12/16 - C50/60 | Betonstahl B500 | $\varepsilon_{\mathrm{L}, \mathrm{ges}, \mathrm{zul}}=6 \% 0$ ) 
Tab. C.9 Bemessungstafel für Rechteckquerschnitte mit und ohne Druckbewehrung (Normalbeton C12/16 - C50/60 | Betonstahl B500 |

$\varepsilon_{\text {L,ges,zul }}=6,5 \% 0$ )

Tab. C.10 Bemessungstafel für Rechteckquerschnitte mit und ohne Druckbewehrung (Normalbeton C12/16 - C50/60 | Betonstahl B500 | $\varepsilon_{\mathrm{L}, \mathrm{ges}, \mathrm{zul}}=7 \% 0$ )

Tab. C.11 Bemessungstafel für Rechteckquerschnitte mit und ohne Druckbewehrung (Normalbeton C12/16 - C50/60 | Betonstahl B500 | $\varepsilon_{\text {L,ges,zul }}=7,5 \% 0$ )

Tab. C.12 Bemessungstafel für Rechteckquerschnitte mit und ohne Druckbewehrung (Normalbeton C12/16 - C50/60 | Betonstahl B500 | $\varepsilon_{\mathrm{L}, \mathrm{ges}, \mathrm{zul}}=8 \% 0$ )

Tab. C.13 Bemessungstafel für Rechteckquerschnitte mit und ohne Druckbewehrung (Normalbeton C12/16 - C50/60 | Betonstahl B500 | $\varepsilon_{\text {L,ges,zul }}=8,5 \% 0$ )

Tab. C.14 Bemessungstafel für Rechteckquerschnitte mit und ohne Druckbewehrung (Normalbeton C12/16 - C50/60 | Betonstahl B500 |

$\varepsilon_{\mathrm{L}, \mathrm{ges}, \mathrm{zul}}=9 \%$ ) 174

Tab. C.15 Bemessungstafel für Rechteckquerschnitte mit und ohne Druckbewehrung (Normalbeton C12/16 - C50/60 | Betonstahl B500 | $\left.\varepsilon_{\mathrm{L}, \mathrm{ges}, \mathrm{zul}}=9,5 \% 0\right)$

Tab. C.16 Bemessungstafel für Rechteckquerschnitte mit und ohne Druckbewehrung (Normalbeton C12/16 - C50/60 | Betonstahl B500 | $\left.\varepsilon_{\mathrm{L}, \mathrm{ges}, \mathrm{zul}}=10 \% 0\right)$ 176

Tab. C.17 Bemessungstafel für Rechteckquerschnitte mit und ohne Druckbewehrung (Normalbeton C12/16 - C50/60 | Betonstahl B500 | $\varepsilon_{\text {L,ges,zul }}=10,5 \% 0$ )

Tab. C.18 Bemessungstafel für Rechteckquerschnitte mit und ohne Druckbewehrung (Normalbeton C12/16 - C50/60 | Betonstahl B500 | $\left.\varepsilon_{\mathrm{L}, \text { ges }, \mathrm{zul}}=11 \% 0\right)$ 178

Tab. C.19 Bemessungstafel für Rechteckquerschnitte mit und ohne Druckbewehrung (Normalbeton C12/16 - C50/60 | Betonstahl B500 | $\varepsilon_{\text {L,ges,zul }}=11,5 \% 0$ )

Tab. C.20 Bemessungstafel für Rechteckquerschnitte mit und ohne Druckbewehrung (Normalbeton C12/16 - C50/60 | Betonstahl B500 | $\varepsilon_{\mathrm{L}, \text { ges,zul }}=12 \% 0$ )

Tab. C.21 Bemessungstafel für Rechteckquerschnitte mit und ohne Druckbewehrung (Normalbeton C12/16 - C50/60 | Betonstahl B500 | $\varepsilon_{\text {L,ges,zul }}=12,5 \% 0$ ) 
Tab. C.22 Bemessungstafel für Rechteckquerschnitte mit und ohne Druckbewehrung (Normalbeton C12/16 - C50/60 | Betonstahl B500 |

$\left.\varepsilon_{\mathrm{L}, \mathrm{ges}, \mathrm{zul}}=13 \% 0\right)$ 182

Tab. C.23 Bemessungstafel für Rechteckquerschnitte mit und ohne Druckbewehrung (Normalbeton C12/16 - C50/60 | Betonstahl B500 | $\varepsilon_{\text {L,ges,zul }}=13,5 \% 0$ )

Tab. C.24 Bemessungstafel für Rechteckquerschnitte mit und ohne Druckbewehrung (Normalbeton C12/16 - C50/60 | Betonstahl B500 | $\varepsilon_{\mathrm{L}, \text { ges }, \mathrm{zul}}=14 \% 0$ ) 184

Tab. C.25 Bemessungstafel für Rechteckquerschnitte mit und ohne Druckbewehrung (Normalbeton C12/16 - C50/60 | Betonstahl B500 | $\varepsilon_{\text {L,ges,zul }}=14,5 \% 0$ )

Tab. C.26 Bemessungstafel für Rechteckquerschnitte mit und ohne Druckbewehrung (Normalbeton C12/16 - C50/60 | Betonstahl B500 | $\varepsilon_{\mathrm{L}, \text { ges,zul }}=15 \% 0$ ) 186

Tab. C.27 Bemessungstafel für Rechteckquerschnitte mit und ohne Druckbewehrung (Normalbeton C12/16 - C50/60 | Betonstahl B500 | $\varepsilon_{\mathrm{L}, \mathrm{ges}, \mathrm{zul}}=15,5 \%$ )

Tab. C.28 Bemessungstafel für Rechteckquerschnitte mit und ohne Druckbewehrung (Normalbeton C12/16 - C50/60 | Betonstahl B500 | $\varepsilon_{\mathrm{L}, \text { ges,zul }}=16 \% 0$ )

Tab. C.29 Bemessungstafel für Rechteckquerschnitte mit und ohne Druckbewehrung (Normalbeton C12/16 - C50/60 | Betonstahl B500 | $\varepsilon_{\mathrm{L}, \mathrm{ges}, \mathrm{zul}}=16,5 \% 0$ ) 189

Tab. C.30 Bemessungstafel für Rechteckquerschnitte mit und ohne Druckbewehrung (Normalbeton C12/16 - C50/60 | Betonstahl B500 | $\varepsilon_{\mathrm{L}, \text { ges,zul }}=17 \%$ ) 190

Tab. C.31 Bemessungstafel für Rechteckquerschnitte mit und ohne Druckbewehrung (Normalbeton C12/16 - C50/60 | Betonstahl B500 | $\varepsilon_{\mathrm{L}, \mathrm{ges}, \mathrm{zul}}=17,5 \% 0$ )

Tab. C.32 Bemessungstafel für Rechteckquerschnitte mit und ohne Druckbewehrung (Normalbeton C12/16 - C50/60 | Betonstahl B500 | $\varepsilon_{\mathrm{L}, \text { ges,zul }}=18 \% 0$ )

Tab. C.33 Bemessungstafel für Rechteckquerschnitte mit und ohne Druckbewehrung (Normalbeton C12/16 - C50/60 | Betonstahl B500 | $\left.\varepsilon_{\mathrm{L}, \mathrm{ges}, \mathrm{zul}}=\infty \% 0\right)$ 


\section{Formelzeichen}

\section{Große lateinische Buchstaben}

A $\quad$ Querschnittsfläche des Bewehrungsstahls

$A_{L}$ Querschnittsfläche der aufgeklebten CFK-Lamelle

$\mathrm{E}_{\mathrm{cm}}$ mittlerer Elastizitätsmodul des Betons

$E_{d}$ Bemessungswert der Einwirkung

$\mathrm{E}_{\mathrm{Lm}}$ Mittelwert des Elastizitätsmoduls der aufgeklebten CFK-Lamelle

$\mathrm{E}_{\mathrm{s}}$

$\mathrm{F}_{\mathrm{bsm}}$ Bemessungswert des Elastizitätsmoduls von Betonstahl

$\mathrm{F}_{\mathrm{cd}}$ mittlere Verbundkraft

$\mathrm{F}_{\mathrm{Ld}}$ Bemessungswert der Betondruckkraft

$\mathrm{F}_{\text {LEd }}$

$\Delta \mathrm{F}_{\mathrm{LEd}}$

$\Delta \mathrm{F}_{\mathrm{Lk}, \mathrm{BF}}$

$\Delta \mathrm{F}_{\text {Lk,BL }}$

$\mathrm{F}_{\mathrm{Lk}, \mathrm{BL}}^{\mathrm{D}}$

$\Delta \mathrm{F}_{\mathrm{Lk}, \mathrm{BL}}^{\mathrm{D}}$

$\Delta \mathrm{F}_{\mathrm{Lk}, \mathrm{BL}}^{\mathrm{G}}$

$\Delta \mathrm{F}_{\mathrm{Lk}, \mathrm{KF}}$

$\Delta \mathrm{F}_{\text {LRd }}$

$\mathrm{F}_{\text {Lud }}$

$\mathrm{F}_{\text {s1d }}$

$\mathrm{F}_{\text {s2d }}$

$\mathrm{G}_{\mathrm{F}}$

$\mathrm{G}_{\mathrm{k}}$

$\mathrm{M}_{\mathrm{cr}}$

$\mathrm{M}_{\mathrm{Ed}}$

$\mathrm{M}_{\mathrm{Ed}, \mathrm{L}}$

$\mathrm{M}_{\mathrm{Ed}, \mathrm{s}}$

$\mathrm{M}_{\mathrm{Rd}, \mathrm{s}, 0}$

Bemessungswert der Lamellenzugkraft

Bemessungswert der einwirkenden Lamellenkraft

Bemessungswert der einwirkenden Lamellenkraftänderung

Verbundkraftwiderstand am ZRE aufgrund Reibung

Grundwert des Verbundkraftwiderstandes am ZRE

Lamellenkraft am geringer beanspruchten Rissufer am Punkt D

aufnehmbare Lamellenkraftdifferenz am Punkt D

aufnehmbare Lamellenkraftdifferenz am Punkt G

Verbundkraftwiderstand am ZRE aufgrund Krümmung

Bemessungswert des Widerstandes der Lamellenkraftänderung

Bemessungswert der Lamellenbruchkraft

Bemessungswert der Stahlzugkraft

Bemessungswert der Stahldruckkraft

Verbundbruchenergie

charakteristischer Wert einer ständigen Einwirkung

Rissmoment

Bemessungswert des einwirkenden Moments

einwirkendes Moment bezogen auf die Achse der Lamellenzugkraft

einwirkendes Moment bezogen auf die Achse der unteren

Bewehrungslage

Bemessungswiderstand der Biegetragfähigkeit vor der Verstärkung (bezogen auf den Schwerpunkt der Stahlzugbewehrung) 


$\begin{array}{ll}\mathrm{M}_{\mathrm{Rd}, \mathrm{L}, \mathrm{V}} & \begin{array}{l}\text { Bemessungswiderstand der Biegetragfähigkeit nach der Verstärkung } \\ \text { (bezogen auf den Schwerpunkt der aufgeklebten CFK-Lamellen) } \\ \text { vorhandenes Moment nach Umlagerung }\end{array} \\ \mathrm{M}_{\mathrm{vorh}} & \begin{array}{l}\text { Bemessungswert der einwirkenden Normalkraft } \\ \mathrm{N}_{\mathrm{Ed}}\end{array} \\ \mathrm{N}_{\mathrm{Rd}, 0} & \begin{array}{l}\text { Bemessungswiderstand der Normalkrafttragfähigkeit vor der } \\ \text { Verstärkung }\end{array} \\ \mathrm{N}_{\mathrm{Rd}, \mathrm{V}} & \begin{array}{l}\text { Bemessungswiderstand der Normalkrafttragfähigkeit nach der } \\ \text { Verstärkung }\end{array} \\ \mathrm{Q}_{\mathrm{k}} & \text { charakteristischer Wert einer veränderlichen Einwirkung } \\ \mathrm{R}_{\mathrm{d}} & \text { Bemessungswert des Tragwiderstands } \\ \mathrm{W}_{\mathrm{c}, 0} & \text { Widerstandsmoment des Betonquerschnitts im ungerissenen Zustand }\end{array}$

\section{Kleine lateinische Buchstaben}

a

b

$b_{L}$

d

$\mathrm{d}_{\mathrm{L}}$

$d_{s 2}$

$\mathrm{f}_{\mathrm{bLk} \text {,max }}$

$\mathrm{f}_{\mathrm{bLk}}\left(\mathrm{S}_{\mathrm{r}}\right)$

$f_{b s m}$

$\mathrm{f}_{\mathrm{cd}}$

$\mathrm{f}_{\mathrm{ck}}$

$f_{\text {ck,cube }}$

$\mathrm{f}_{\mathrm{cm}}$

$\mathrm{f}_{\mathrm{ctm}}$

$\mathrm{f}_{\text {ctm,surf }}$

$\mathrm{f}_{\text {Luk }}$

$\mathrm{f}_{\text {Lud }}$

$\mathrm{f}_{\text {tk,cal }}$

$\mathrm{f}_{\text {tk,cal }}$

$\mathrm{f}_{\mathrm{yd}}$

$\mathrm{f}_{\mathrm{yk}}$

$\mathrm{h}$
Angriffspunkt der Betondruckkraft (Abstand vom oberen

Querschnittsrand)

Breite des Querschnitts

Lamellenbreite

statische Höhe der Biegezugbewehrung

statische Höhe der aufgeklebten CFK-Lamelle

statische Höhe der Druckbewehrung

charakteristischer Wert der maximalen Verbundfestigkeit der

Verstärkung am Endverankerungspunkt

charakteristische Verbundfestigkeit der Verstärkung

mittlere Verbundspannung des Betonstahls

Bemessungswert der Betondruckfestigkeit

charakteristische Zylinderdruckfestigkeit des Betons

charakteristische Würfeldruckfestigkeit des Betons

Mittelwert der Zylinderdruckfestigkeit des Betons

Mittelwert der zentrischen Zugfestigkeit des Betons

Mittelwert der Oberflächenzugfestigkeit des Betons

Bemessungswert der Zugfestigkeit der aufgeklebten CFK-Lamelle

charakteristischer Wert der Zugfestigkeit der aufgeklebten CFK-

Lamelle

charakteristischer Wert der Zugfestigkeit des Betonstahls

charakteristischer Wert der Zugfestigkeit des Betonstahls

Bemessungswert der Streckgrenze des Betonstahls

charakteristischer Wert der Streckgrenze des Betonstahls

Querschnittshöhe 
$\mathrm{k}$

$\mathrm{k}_{\mathrm{a}}$

1

$1_{\mathrm{bL}, \text { max }}$

$1_{e, 0}$

$\mathrm{n}_{\mathrm{s}, \mathrm{i}}$

$\mathrm{p}_{\mathrm{d}}$

$\mathrm{p}_{\mathrm{d}}$

$\mathrm{S}_{\mathrm{L}}$

$\mathrm{S}_{\text {Lok }}$

$\mathrm{S}_{\mathrm{r}}$

$t_{\mathrm{L}}$

$\mathrm{x}$

$\mathrm{x}_{\mathrm{A}}$

$\mathrm{z}_{\mathrm{L}}$

$\mathrm{z}_{\mathrm{s} 1}$

empirischer Faktor (eingeführt von Niedermeier) $=\kappa_{\mathrm{Lb}}$

Beiwert des Randabstandes der resultierenden Betondruckkraft

effektive Stützweite

effektive Verbundlänge

Eintragungslänge des Betonstahls

Anzahl der Stäbe mit gleichem Durchmesser

Bemessungseinwirkung

Bemessungseinwirkung

Lamellenschlupf

maximaler Schlupf nach dem bilinearen Verbundansatz

Rissabstand

Lamellendicke

Höhe der Betondruckzone

Abstand zum Auflager

innerer Hebelarm der aufgeklebten Bewehrung

innerer Hebelarm der einbetonierten Biegezugbewehrung

\section{Griechische Buchstaben}

$a_{c c} \quad$ Beiwert zur Berücksichtigung von Langzeitauswirkungen auf die Betondruckfestigkeit

$a_{c t} \quad$ Beiwert zur Berücksichtigung von Langzeitauswirkungen auf die Betonzugfestigkeit

$a_{\mathrm{R}} \quad$ Völligkeitsbeiwert

$a_{s} \quad$ Verhältniswert der Elastizitätsmoduln

$a_{\text {zeit }} \quad$ Dauerstandminderungsfaktor

$\gamma_{\mathrm{BA}}$

Teilsicherheitsbeiwert für den Verbund bei aufgeklebten CFK-

Lamellen

$\gamma_{\mathrm{C}} \quad$ Teilsicherheitsbeiwert für Beton

$\gamma_{\mathrm{G}} \quad$ Teilsicherheitsbeiwert für ständige Einwirkungen

$\gamma_{\mathrm{LL}} \quad$ Teilsicherheitsbeiwert für CFK-Lamellen

$\gamma_{\mathrm{Q}}$

Teilsicherheitsbeiwert für veränderliche Einwirkungen

Teilsicherheitsbeiwert für Betonstahl

Wichte von Stahlbeton

$\gamma_{\mathrm{Stb}}$

Umlagerungsfaktor

Betondehnung bei Erreichen der Maximalfestigkeit (nichtlinear)

$\varepsilon_{\mathrm{c} 1}$

Betondehnung bei Erreichen der Maximalfestigkeit (Parabel-Rechteck-

Diagramm) 
$\varepsilon_{\mathrm{cR} 1}$

$\varepsilon_{\mathrm{cR} 2}$

$\varepsilon_{\text {cr1 }}$

$\varepsilon_{\text {cu2 }}$

$\varepsilon_{\mathrm{L}}$

$\varepsilon_{L, 0}$

$\varepsilon_{\text {L,ges }}$

$\varepsilon_{\text {L,ges,zul }}$

$\varepsilon_{\text {LRd,max }}$

$\varepsilon_{\text {Lr1 }}$

$\varepsilon_{\text {Lud }}$

$\varepsilon_{\text {Luk }}$

$\varepsilon_{\mathrm{s}}$

$\varepsilon_{\mathrm{s} 1}$

$\varepsilon_{\mathrm{s} 2}$

$\varepsilon_{\text {ud }}$

$\eta$

$\kappa$

$\kappa_{\mathrm{fl}}$

$\kappa_{h}$

$\kappa_{\mathrm{k}}$

$\kappa_{\text {L1 }}$

$\kappa_{\text {LF }}$

$\mu_{\mathrm{Ed}, \mathrm{L}}$

$\xi_{\mathrm{L}}$

$\rho_{\mathrm{s}} \quad$ Bewehrungsgrad

$\sigma_{\mathrm{c}} \quad$ Druckspannung im Beton

$\sigma_{\mathrm{s}} \quad$ Spannung im Betonstahl

$\sigma_{\mathrm{L}}$

Verstärkung

verstärkten Zustand

Dehnung des Betonstahls

Dehnung der Druckbewehrung

Krümmung

Zugfestigkeit

Lamellenkraftänderung am ZRE)

Lamelle

Betondehnung am unteren Querschnittsrand

Betondehnung am oberen Querschnittsrand

Betondehnung am niedriger beanspruchten Rissufer

Bruchdehnung des Betons (Parabel-Rechteck-Diagramm)

mittlere Dehnung der aufgeklebten CFK-Lamelle

Dehnung am unteren Querschnittsrand zum Zeitpunkt der

Gesamtdehnung am unteren Querschnittsrand im verstärkten Zustand

zulässige Gesamtdehnung am unteren Querschnittsrand im

maximal zulässige Dehnung der aufgeklebten CFK-Lamelle

Lamellendehnung am niedriger beanspruchten Rissufer

Dehnung der CFK-Lamelle bei Erreichen der Bemessungszugfestigkeit

charakteristische Bruchdehnung der aufgeklebten CFK-Lamelle

Dehnung der Biegezugbewehrung

rechnerische Bruchdehnung des Betonstahls

Beiwert zur Bestimmung der effektiven Festigkeit

Umrechnungsbeiwert zw. Biegezugfestigkeit und zentrischer

Beiwert zur Berechnung der am ZRE aufnehmbaren

Lamellenkraftdifferenz aus Bauteilkrümmung (vereinfachter

Nachweis der Lamellenkraftänderung am ZRE)

Beiwert zur Berechnung der am ZRE aufnehmbaren

Lamellenkraftdifferenz aus Krümmung (genauerer Nachweis der

Beiwert zur Berechnung der am ZRE aufnehmbaren

Lamellenkraftdifferenz aus Klebeverbund

Beiwert zur Berechnung der am ZRE aufnehmbaren

Lamellenkraftdifferenz aus Verbundreibung

dimensionsloses bezogenes Bemessungsmoment

Verhältnisbeiwert für Druckzonenhöhe zu statischer Höhe der CFK-

Spannung in der aufgeklebten CFK-Lamelle 


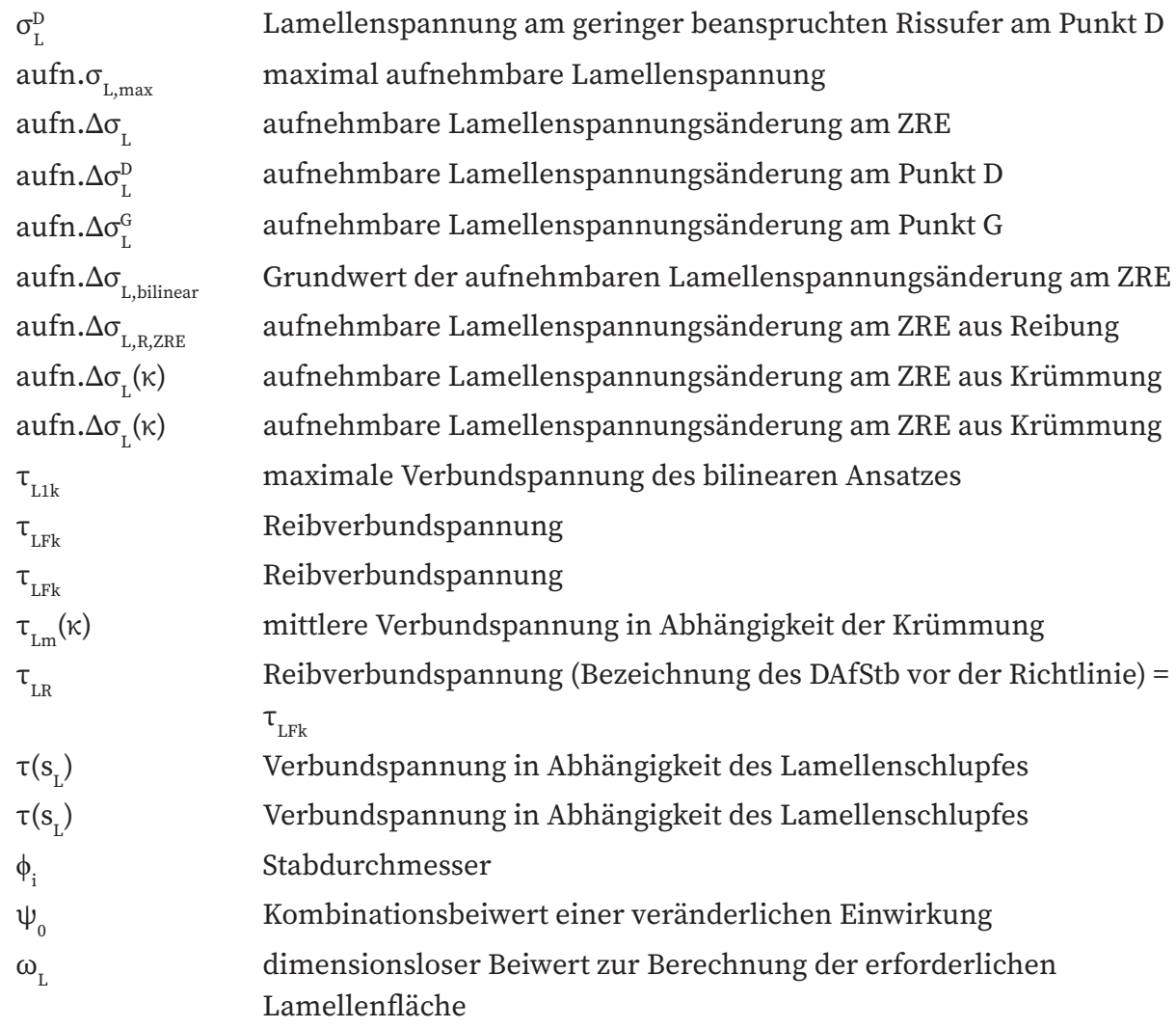




\section{Abkürzungsverzeichnis}

$\begin{array}{ll}\text { Abs. } & \text { Abschnitt (in Bezug auf Normen und Regelwerke) } \\ \text { CFK } & \text { Kohlenstofffaserverstärkter Kunststoff } \\ \text { DAfStb } & \text { Deutscher Ausschuss für Stahlbeton } \\ \text { DGL } & \text { Differentialgleichung } \\ \text { DIBt } & \text { Deutsches Institut für Bautechnik } \\ \text { EC0 } & \text { Eurocode 0 (DIN EN 1990:2010-12) } \\ \text { EC2 } & \text { Eurocode 2 (DIN EN 1992-1-1:2011-01) } \\ \text { E-Modul } & \text { Elastizitätsmodul } \\ \text { Gl. } & \text { Gleichung } \\ \text { GZG } & \text { Grenzzustand der Gebrauchstauglichkeit } \\ \text { GZT } & \text { Grenzzustand der Tragfähigkeit } \\ \text { NA } & \text { Nationaler Anhang } \\ \text { NW } & \text { Nachweis } \\ \text { ZRE } & \text { Zwischenrisselement }\end{array}$




\section{Einleitung}

\subsection{Einführung in die Thematik}

In der heutigen Zeit steigt die Bedeutung des Bauens im Bestand stetig an. Resultierend aus dem sinkenden Bedarf an Neubauten, aufgrund des demografischen Wandels und der vorhandenen Bausubstanz, kommt es vermehrt zu Umnutzungen, Instandsetzungen und Sanierungen von bestehenden Bauwerken ([Küchler 2013] S. 347 ff.). Dabei kann es notwendig sein ein Bauteil zu verstärken, sofern dessen Bemessungswiderstand durch die neue Bemessungseinwirkung überschritten wird. Diese Überschreitungen des Bemessungswiderstandes können aus unterschiedlichsten Gründen hervorgerufen werden. Einige mögliche Beispiele dafür sind:

- Lasterhöhungen in Bestandsgebäuden

- Beschädigung der vorhandenen Bewehrung (Korrosion / physische Schäden)

- Bemessung mit erhöhtem Sicherheitsniveau

- Veränderung des statischen Systems

Doch nicht nur Bestandsbauwerke erfordern Verstärkungsmaßnahmen. Es kann auch vorkommen, dass durch Fehler und Änderungen in der Planung bzw. Statik oder eine mangelhafte Ausführung ein Bauteil verstärkt werden muss. Außerdem ermöglicht der moderne Planungs- und Bauprozess ganzheitliche Änderungen des Nutzungskonzepts während der Bauphase. Daraus können ebenfalls ergänzende Maßnahmen zur Verstärkung eines bereits fertiggestellten Bauteils resultieren. Da in Deutschland der Massivbau die überwiegende Bauart darstellt, sind insbesondere Stahlbetonbauteile von Verstärkungsmaßnahmen aus den o.g. Gründen betroffen. Dafür wurden bereits vielfache Möglichkeiten zur nachträglichen Verstärkung entwickelt (vgl. bspw. [Küchler 2013] S. 442 ff.). Unter anderem sind folgende Maßnahmen möglich:

- Querschnittsergänzung (bspw. Aufbeton zur Vergrößerung der Druckzone)

- Änderung des statischen Systems (bspw. Abfangung mit Stahlträgern und Stützen)

- Ersetzen von beschädigter Bewehrung

- Ergänzen von Bewehrungslagen: 
- Betonstahl in einer zusätzlichen Ortbetonschicht

- Aufkleben von Stahllaschen

- in Schlitzen eingeklebte CFK-Lamellen

- Aufkleben von CFK-Lamellen und CF-Gelegen

Seit etwa 20 Jahren sind kohlenstofffaserverstärkte Kunststoffe (CFK) zur Verstärkung von Stahlbetonbauteilen national bauaufsichtlich zugelassen [Otto 2017]. Obwohl aufgeklebte CFK-Lamellen als verhältnismäßig neuer Werkstoff im Bauwesen zu betrachten sind, stellen diese bereits die häufigste Form der Biegeverstärkung dar ([Zilch et al. 2013] S. 478). Die dabei verwendeten CFK-Lamellen bestehen aus unidirektional angeordneten Kohlenstofffasern (Carbonfasern) und einer Kunststoffmatrix, die mittels Epoxidharzen auf die Betonoberfläche geklebt werden. Durch die einheitliche Ausrichtung der Fasern weist der Verbundwerkstoff sehr hohe Zugfestigkeiten auf (vgl. [Dehn et al. 2005]). Daher eignen sich CFK-Lamellen hervorragend als ergänzende Biegezugbewehrung für die nachträgliche Tragwerksverstärkung. Da das Material verhältnismäßig teuer ist, wurde der Einsatz anfangs eher skeptisch betrachtet ([Dehn et al. 2005] S. 19 ff.). Im Laufe der Jahre hat sich jedoch herausgestellt, dass die Vorteile überwiegen. Durch geringe Ausführungszeiten sowie die erleichterte Baulogistik gegenüber anderen Verstärkungsmaßnahmen wird der finanzielle Nachteil des Materials ausgeglichen. Die Lamellen lassen sich aufgrund des geringen Gewichts leicht transportieren und applizieren. Eine geringe Aushärtungszeit des Klebers ermöglicht die Wiederaufnahme der Nutzung nach nur etwa zwei Tagen [Otto 2017]. Außerdem hebt sich diese Verstärkungsmaßnahme durch ihre geringe Dicke gegenüber allen anderen Möglichkeiten ab. Im Nachhinein gibt es nahezu keine Einschränkung der lichten Höhe, die jede alternative Verstärkungsmaßnahme nach sich ziehen würde. Die Abbildungen 1 und 2 stellen beispielhaft zwei Verstärkungen von Stahlbetonbauteilen mit aufgeklebten CFK-Lamellen dar, um die vorangegangenen Aspekte nochmals zu verdeutlichen. 


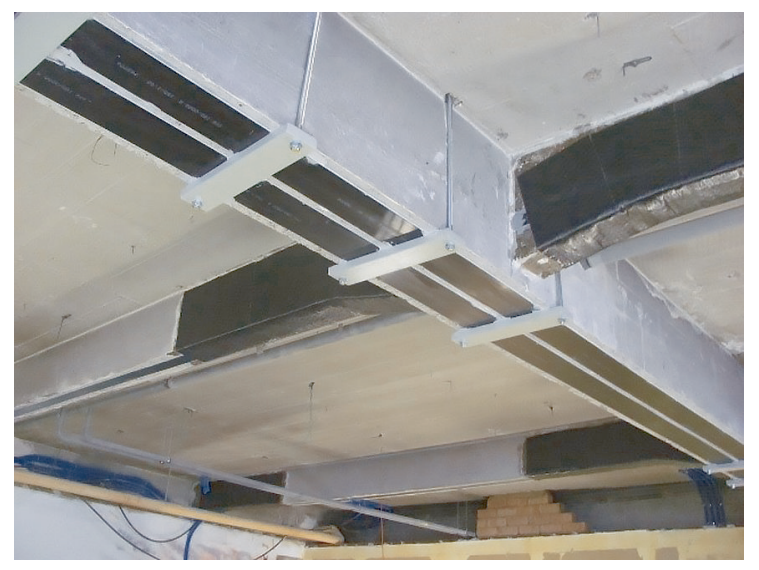

Abb. 1 Verstärkung eines Stahlbetonunterzugs mit aufgeklebten CFK-Lamellen (Quelle: [S\&P 2017]) (http://doi.org/10.33968/9783966270021-01-A-01)

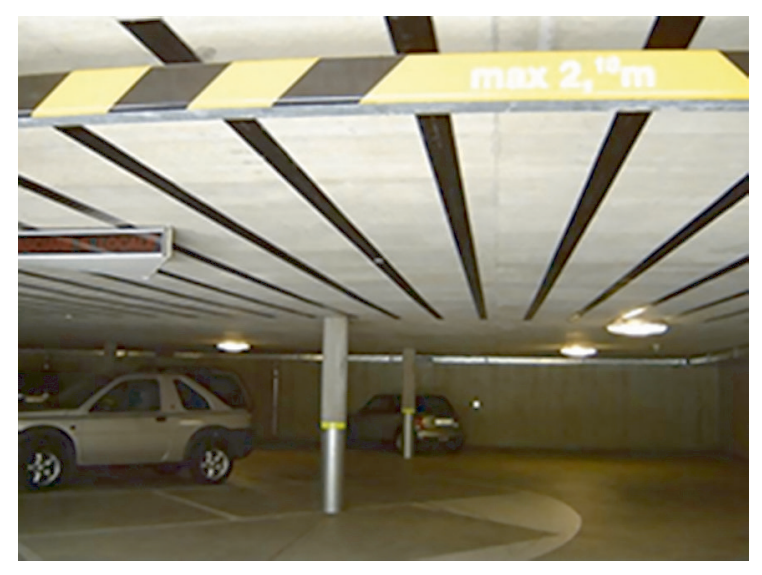

Abb. 2 Verstärkung einer Stahlbetondecke mit aufgeklebten CFK-Lamellen (Quelle: [bm engineering 2017]) (http://doi.org/10.33968/9783966270021-01-A-02)

Selbstverständlich gibt es auch Nachteile beim Einsatz von CFK-Lamellen. Dazu zählt vor allem der Ausfall der aufgeklebten Bewehrung im Brandfall. Dabei versagt der Kleber ab einer verhältnismäßig geringen Temperatur, sodass die einbetonierte Bewehrung für die Bemessung im Brandfall ausreichen muss. Alternativ sind dafür entsprechende Brandschutzsysteme entwickelt worden. Außerdem darf die Verstärkung nicht an Bauteilen erfolgen, die dauerhaft eine Grenztemperatur übersteigen. Die genaue Temperatur ist für das jeweilige System in der zugehöri- 
gen bauaufsichtlichen Zulassung des Deutschen Instituts für Bautechnik (DIBt) geregelt [Z-36.12- 84/85/86]. Zum aktuellen Zeitpunkt sind drei Systeme mit aufgeklebten CFK-Lamellen unterschiedlicher Hersteller durch das Deutsche Institut für Bautechnik (DIBt) allgemein bauaufsichtlich zugelassen [DIBt 2017].

\subsection{Problemstellung und Ziele}

Eine nachträgliche Bauteilverstärkung mit aufgeklebten CFK-Lamellen muss hinsichtlich ihrer Tragfähigkeit bemessen werden. Seit März 2012 ist die Bemessung in der Richtlinie "Verstärken von Betonbauteilen mit geklebter Bewehrung" des Deutschen Ausschusses für Stahlbeton (DAfStb) geregelt. Im Folgenden wird diese nur noch als "DAfStb-Richtlinie" bezeichnet. Auf die Richtlinie bezieht sich auch die jüngste Generation der bauaufsichtlichen Zulassungen der Hersteller. Diese Richtlinie ermöglicht unterschiedliche Genauigkeitsstufen in der Nachweisführung (vgl. Abbildung 15). Dabei besteht der größte Aufwand in den iterativen Berechnungsvorgängen, die aus den Bemessungsansätzen des Stahlbetonbaus und der Erweiterung um die aufgeklebten CFK-Lamellen resultieren. Außerdem weisen aufgeklebte CFK-Lamellen ein sprödes Verbundverhalten auf, das zur Nachweisführung in der DAfStb-Richtlinie mithilfe eines komplexen Ingenieurmodells beschrieben wird. Hierfür sollen Lösungsansätze entwickelt werden, die eine einfachere Abschätzung über den wirtschaftlichen Einsatz von aufgeklebten CFK-Lamellen anhand der erforderlichen Querschnittsfläche mit möglichst geringem Aufwand zulassen. Dabei sollen geeignete Hilfsmittel erarbeitet werden, die zweckmäßig für die unterschiedlichen Nachweisformate sind und gleichzeitig eine möglichst große Allgemeingültigkeit besitzen. Insbesondere in der Baubranche spielen Zeit und Geld eine übergeordnete Rolle. Deshalb soll eine Möglichkeit zur ersten überschlägigen Ermittlung der erforderlichen Lamellenfläche geschaffen werden, um bereits frühzeitig durch jeden Bauingenieur die Realisierung einer Biegeverstärkung mit aufgeklebten CFK-Lamellen beurteilen zu können.

\subsection{Vorgehensweise}

Um die Biegeverstärkung von Stahlbetonbauteilen zu bemessen, werden zunächst die theoretischen Grundlagen des reinen Stahlbetonbaus erläutert. Dazu wird auf das Nachweiskonzept nach Eurocode, die Schnittgrößenermittlung sowie auf die Grundvoraussetzungen für die Querschnittsbemessung eingegangen. Es wird das für die Bemessung anzunehmende jeweilige Materialverhalten beschrieben. An dieser Stelle werden auch die Bemessungseigenschaften der CFK-Lamellen analog zum Eurocode mit einer geeigneten Spannungs-Dehnungs-Linie dargestellt. Anschließend wird die Bemessung des Bestandsquerschnitts erläutert. Dieser wird im Zuge der Biegeverstärkung um die aufgeklebte CFK-Lamelle erweitert und die Ermittlung der erforderlichen Lamellenfläche beschrieben. Weiterhin ist eine spezifische Betrachtung des Verbundverhaltens bei aufgeklebter Bewehrung erforder- 
lich, da sich dieses vom Verbundverhalten des Stahlbetons mit der einbetonierten Bewehrung stark unterscheidet.

Die Hilfsmittel sollen sich an denen des Stahlbetonbaus orientieren. Dabei wird die Vorgehensweise zur Ermittlung der etablierten Bemessungshilfen, wie dem allgemeinen Bemessungsdiagramm oder den Bemessungstafeln mit dimensionslosen Beiwerten, auf die Biegeverstärkung angewendet. Zunächst sollen die Hilfsmittel für die reine Biegeverstärkung an Stahlbetonrechteckquerschnitten ohne Druckbewehrung erstellt werden. Danach können diese Ansätze um den Anteil der Druckbewehrung ergänzt werden. Aufgrund des hohen iterativen Rechenaufwandes bei der Verbundbetrachtung von aufgeklebten CFK-Lamellen werden hierfür computergestützte Bemessungshilfen entwickelt. Abschließend soll an einem Beispiel die Nachweisführung der Richtlinie demonstriert werden. Dieses Beispiel integriert die erarbeiteten Hilfsmittel zur reinen Biegeverstärkung. Außerdem eignet sich ein Beispiel sehr gut, um die Funktionsweise und die Berechnungsvorgänge EDV-basierter Bemessungshilfsmittel zu erläutern. 



\section{Theoretische Grundlagen}

\section{$2.1 \quad$ Allgemeines}

Da im Voraus nicht bekannt ist, ob die Biegetragfähigkeit eines Bauteils durch die neue Bemessungseinwirkung nach einer Umnutzung oder Ertüchtigung überschritten wird, muss diese zunächst bestimmt werden. Anschließend kann überprüft werden, inwiefern eine Verstärkungsmaßnahme notwendig ist. Ist die Bemessungseinwirkung tatsächlich größer als die vorhandene Biegetragfähigkeit, muss die Verstärkungsmaßnahme bemessen werden. Bei aufgeklebten CFK-Lamellen gehört zum Nachweis der Biegetragfähigkeit auch eine Verbundbetrachtung. Nähere Erläuterungen dazu folgen in den anschließenden Kapiteln. Für die nachträgliche Verstärkung mit aufgeklebten CFK-Lamellen ist somit folgende Vorgehensweise vorzusehen:

1. Biegetragfähigkeit des Bestandsbauteils bestimmen

2. Überschreitung durch die neue Bemessungseinwirkung prüfen

3. Bemessung der Verstärkungsmaßnahme

a) Biegetragfähigkeit - Bestimmen der erforderlichen Lamellenfläche

b) Weitere Nachweise gemäß DAfStb-Richtlinie

\subsection{Voraussetzungen für die Bemessung}

Alle Berechnungen beruhen auf Ingenieurmodellen, die die Realität annähernd numerisch darstellen sollen. Diese Theorien dienen der Bemessung der Bauteile und stellen deren reales Verhalten stark vereinfacht dar. Um einen Stahlbetonquerschnitt zu bemessen, gelten in der technischen Biegelehre bestimmte Annahmen ([Bindseil 2008] S. 43). Diese sind im Folgenden sowohl für die Bemessung des Ausgangsquerschnitts, als auch für die Bemessung der nachträglichen Verstärkung zugrunde gelegt. Im EC2 ([EC2-1-1 2011-01] Abs. 6.1) sind diese für den Grenzzustand der Tragfähigkeit aufgelistet:

- Ebenbleiben der Querschnitte (Hypothese von Bernoulli)

- Vollkommener Verbund

- Betonzugfestigkeit bleibt unberücksichtigt

- Betondruckspannungsverteilung nach Parabel-Rechteck-Diagramm (Kapitel 2.4.1)

- Betonstahlspannungen gemäß Spannungs-Dehnungs-Linien (Kapitel 2.4.2) 
Die Hypothese von Bernoulli besagt, dass bei schlanken Stahlbetonbauteilen, deren Querschnittsabmessungen deutlich geringer als deren Länge sind, die Querschnitte nach der Verformung weiterhin senkrecht zur Balkenachse sowie in sich eben bleiben ([Wommelsdorff u. Albert 2011] S. 110). Mit dem vollkommenen oder auch starren Verbund wird beschrieben, dass alle Querschnittsfasern, die den gleichen Abstand zur Nulllinie besitzen, die gleichen Dehnungen aufweisen ([Bindseil 2008] S. 43). Dadurch lässt sich eine lineare Verteilung der Dehnungen über die Querschnittshöhe festhalten. Des Weiteren wird die Zugfestigkeit des Betons nicht angesetzt, wodurch sich das betrachtete Bauteil unter Biegung im gerissenen Zustand (Zustand II) befindet. Daraus lässt sich schließen, dass sämtliche Zugkräfte vom Bewehrungsstahl aufgenommen werden müssen, da der Querschnitt ab der Nulllinie als gerissen zu betrachten ist. Außerdem sollen an dieser Stelle bereits die spezifischen Einschränkungen und Annahmen, welche ausschließlich in dieser Arbeit Anwendung finden, benannt werden. Diese ergeben sich aus der DAfStbRichtlinie [DAfStb 2012-03] und aus den Abgrenzungen dieser Arbeit. Eine Erläuterung folgt in den anschließenden Kapiteln. Zusammenfassend sind diese spezifischen Festlegungen hier für eine vereinfachte Übersicht aufgeführt:

- Betrachtung von Stahlbetonrechteckquerschnitten

- Bemessung für Normalbeton (C12/15 - C50/60)

- Einwirkung vorwiegend ruhender Belastung

- Querschnitt zum Zeitpunkt der Verstärkung unter reiner Biegung

- Verstärkung für positive Feldmomente

\subsection{Nachweiskonzept nach Eurocode}

Die Tragfähigkeit eines Querschnitts wird in der Regel nachgewiesen indem seine Bemessungswiderstandsfähigkeit größer oder mindestens gleich der Bemessungseinwirkung ist ([Bindseil 2008] S. 43). Im EC0 ([EC0 2010-12] Abs. 6.4.2) wird dafür folgende Formulierung angegeben.

$E_{d} \leq R_{d}$

Mit:

$E_{d} \quad$ Bemessungswert der Einwirkung

$R_{d} \quad$ Bemessungswert des Tragwiderstands

Aus dem EC0 ergeben sich die anzusetzenden Widerstände für die Bemessung nach Gl. (2-2) (vgl. [Holschemacher et al. 2012] S. 7 ff.).

$R_{d}=R\left(\alpha_{c c} \cdot \frac{f_{c k}}{\gamma_{C}} ; \frac{f_{y k}}{\gamma_{S}} ; \alpha_{Z e i t} \cdot \frac{f_{L u k}}{\gamma_{L L}}\right)$ 
Mit:

$\alpha_{c c} \quad$ Beiwert zur Berücksichtigung von Langzeitauswirkungen auf die Betondruckfestigkeit (im Allgemeinen gilt: $\alpha_{c c}=0,85$ [EC2-1-1 NA 2013-04] NDP zu 3.1.6)

$f_{c k} \quad$ charakteristische Zylinderdruckfestigkeit des Betons gemäß Tabelle 2

$\gamma_{C} \quad$ Teilsicherheitsbeiwert für Beton (aus Tab. 2.1DE [EC2-1-1 NA 2013-04])

$f_{y k} \quad$ charakteristischer Wert der Streckgrenze des Betonstahls

$\gamma_{S} \quad$ Teilsicherheitsbeiwert für Betonstahl (aus Tab. 2.1DE [EC2-1-1 NA 2013-04])

$\alpha_{\text {Zeit }} \quad$ Dauerstandminderungsfaktor für CFK-Lamellen gemäß Zulassung

$f_{\text {Luk }}^{\text {Leit }}$ charakteristischer Wert der Materialfestigkeit der CFK-Lamelle (aus Zulassung)

$\gamma_{L L} \quad$ Teilsicherheitsbeiwert für CFK-Lamellen ([DAfStb 2012-03] Tabelle RV 2.1)

Dabei sind die Widerstände auf diese Arbeit angepasst und um die Formulierung für aufgeklebte CFK-Lamellen ergänzt, wie es im Kapitel 2.4.3 beschrieben wird. Die folgende Tabelle fasst die entsprechenden Teilsicherheitsbeiwerte im Grenzzustand der Tragfähigkeit für die Baustoffe zusammen, die in dieser Arbeit Anwendung finden. Diese stammen aus dem EC2 in Zusammenhang mit dem NA und der DAfStb-Richtlinie.

Tab. 1 Teilsicherheitsbeiwerte für Baustoffe im GZT (http://doi.org/10.33968/9783966270021-02-T-01)

\begin{tabular}{llll} 
Bemessungssituation & Beton & Betonstahl & CFK-Lamellen \\
& $\mathbf{V}_{\mathrm{c}}$ & $\mathbf{V}_{\mathrm{s}}$ & $\mathbf{V}_{\mathrm{LL}}$ \\
\hline $\begin{array}{l}\text { ständig und } \\
\text { vorübergehend }\end{array}$ & 1,5 & 1,15 & 1,2 \\
\hline
\end{tabular}

Laut EC0 und dem zugehörigen Nationalen Anhang [EC0 NA 2010-12] sind die Bemessungswerte der Einwirkungen in Abhängigkeit der zugrunde gelegten Bemessungssituation mit Teilsicherheitsbeiwerten $\mathrm{zu}$ versehen und entsprechend $\mathrm{zu}$ kombinieren. In dieser Arbeit wird ausschließlich die ständige und vorübergehende Bemessungssituation betrachtet. Für anderweitige Bemessungssituationen sind die Kombinationen nach EC0 zu verwenden.

$E_{d}=E\left\{\sum_{j \geq 1} \gamma_{G, j} \cdot G_{k, j} \oplus \gamma_{Q, 1} \cdot Q_{k, 1} \oplus \sum_{i>1} \gamma_{Q, i} \cdot \psi_{0, i} \cdot Q_{k, i}\right\}$ 
Mit:

$\gamma_{G} \quad$ Teilsicherheitsbeiwert für ständige Einwirkungen

$\gamma_{Q} \quad$ Teilsicherheitsbeiwert für veränderliche Einwirkungen

$G_{k} \quad$ charakteristischer Wert einer ständigen Einwirkung

$Q_{k} \quad$ charakteristischer Wert einer veränderlichen Einwirkung

$\psi_{0} \quad$ Kombinationsbeiwert einer veränderlichen Einwirkung

\subsection{Materialkennwerte}

\subsubsection{Beton}

Als Grundlage zur Bemessung sind in diesem und den folgenden Kapiteln die bei der Bemessung zu verwendenden Materialkennwerte für Beton, Betonstahl und CFK beschrieben. Der DAfStb legt in seiner Richtlinie für die Bemessung den EC2 [EC2-1-1 2011-01] zugrunde. Dabei wird an dieser Stelle darauf verwiesen, dass es sich um die Bemessung von bestehenden Bauteilen handelt. Aus diesem Grund sind mit geeigneten Methoden die Materialkennwerte des vorhandenen Bauteils zu verifizieren. Für den Beton eignen sich dazu beispielsweise Bohrkerne, um Kenntnisse über die Festigkeit des Betons zu erlangen ([Stahr 2015] S. 195). Die benötigten Materialkennwerte für den Beton, die sich aus der ermittelten Festigkeitsklasse ergeben, wurden dem EC2 entnommen und sind in Tabelle 2 aufgeführt. Darin sind lediglich die Kennwerte für Normalbetone enthalten, welche ausschließlich Gegenstand der Betrachtungen dieser Arbeit sowie der DAfStb-Richtlinie [DAfStb 2012-03] sind. Bei Beton sind die Verformungen unter Lasteinwirkung maßgeblich von dessen Zusammensetzung abhängig. Der EC2 bietet dafür Richtwerte, die das Verformungsverhalten vereinfachend beschreiben sollen, um Abschätzungen der auftretenden Verformungen vornehmen zu können ([Baar u. Ebeling 2017] S. 64). Diese Abschätzungen, die der Schnittgrößenermittlung zugrunde gelegt werden, sind in Abbildung 3 dargestellt ([EC2-1-1 2011-01] Abs. 3.1.5). 


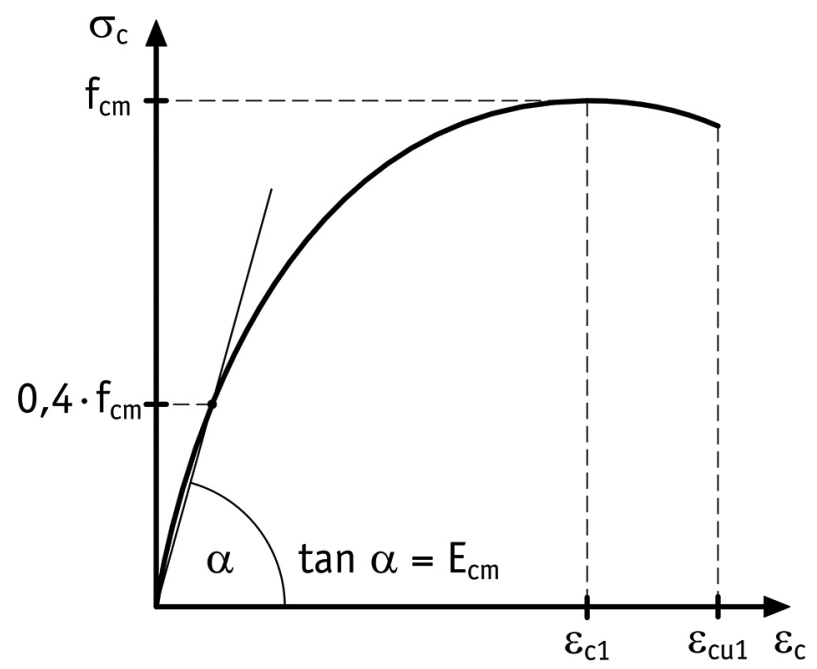

Abb. 3 Spannungs-Dehnungs-Linie für die Schnittgrößenermittlung (nichtlinear) (Quelle: [EC2-1-1 2011-01] Bild 3.2) (http://doi.org/10.33968/9783966270021-02-A-01)

Für die Berechnung der Druckspannung in Abhängigkeit zur Betonstauchung wird im EC2 folgende Formulierung angegeben:

$\frac{\sigma_{c}}{f_{c m}}=\frac{k \cdot \eta-\eta^{2}}{1+(k-2) \cdot \eta}$

Mit:
$\sigma_{c} \quad$ Betondruckspannung
$f_{c m}^{c} \quad$ Mittelwert der Zylinderdruckfestigkeit des Betons
$k \quad$ Faktor zur Beschreibung der Form des Spannungs-Dehnungsverlaufs (vgl. [Mehlhorn et al. 2002] S. 14)
$\eta \quad$ Beiwert zur Bestimmung der effektiven Festigkeit

Diese Gleichung gilt im Bereich $0 \leq\left|\varepsilon_{c}\right| \leq\left|\varepsilon_{c u l}\right|$. Für die rechnerische Bruchdehnung $\varepsilon_{c u l}$ sind die Werte in Tabelle 2 angegeben. Dabei gilt:

$\eta=\frac{\varepsilon_{c}}{\varepsilon_{c 1}}$

Mit:

$\varepsilon_{c} \quad$ Betonstauchung 
$\varepsilon_{c 1} \quad$ Betonstauchung bei Erreichen der Maximalfestigkeit gemäß Tabelle 2

$k=1,05 \cdot E_{c m} \cdot \frac{\left|\varepsilon_{c 1}\right|}{f_{c m}}$

Mit:

$\varepsilon_{c m} \quad$ mittlerer Elastizitätsmodul als Sekantenwert des Betons

Der E-Modul als mittlerer Sekantenwert berechnet sich in Abhängigkeit der mittleren Zylinderdruckfestigkeit des Betons gemäß Gleichung (2-7).

$E_{c m}=22 \cdot\left(\frac{f_{c m}}{10}\right)^{0,3}$

Mit:

$E_{c m} \quad$ mittlerer Elastizitätsmodul als Sekantenwert des Betons

$f_{c m}^{c m} \quad$ Mittelwert der Zylinderdruckfestigkeit des Betons (in $\left[\mathrm{N} / \mathrm{mm}^{2}\right]$ )

Tab. 2 Festigkeits- und Formänderungskennwerte für Normalbeton (Quelle: [EC2-1-1 2011-01] Tabelle 3.1) (http://doi.org/10.33968/9783966270021-02-T-02)

\begin{tabular}{|c|c|c|c|c|c|c|c|c|c|}
\hline \multirow{2}{*}{$\begin{array}{l}\text { Kenn- } \\
\text { werte }\end{array}$} & \multicolumn{9}{|c|}{ Betonfestigkeitsklassen $\left(f_{c k}\left[\mathrm{~N} / \mathrm{mm}^{2}\right] / f_{c k, c u b e}\left[\mathrm{~N} / \mathrm{mm}^{2}\right]\right)$} \\
\hline & C12/15 & $\mathrm{C} 16 / 20$ & C20/25 & $\mathrm{C} 25 / 30$ & C30/37 & C35/45 & $\mathrm{C} 40 / 50$ & $\mathrm{C} 45 / 55$ & $\mathrm{C} 50 / 60$ \\
\hline $\begin{array}{c}f_{\mathrm{cm}} \\
{\left[\mathrm{N} / \mathrm{mm}^{2}\right]}\end{array}$ & 20 & 24 & 28 & 33 & 38 & 43 & 48 & 53 & 58 \\
\hline $\begin{array}{c}\mathrm{f}_{\mathrm{ctm}} \\
{\left[\mathrm{N} / \mathrm{mm}^{2}\right]}\end{array}$ & 1,6 & 1,9 & 2,2 & 2,6 & 2,9 & 3,2 & 3,5 & 3,8 & 4,1 \\
\hline $\begin{array}{c}E_{\mathrm{cm}} \\
{\left[\mathrm{N} / \mathrm{mm}^{2}\right]}\end{array}$ & 27.000 & 29.000 & 30.000 & 31.000 & 33.000 & 34.000 & 35.000 & 36.000 & 37.000 \\
\hline $\begin{array}{c}\varepsilon_{\mathrm{c} 1} \\
{[\%]}\end{array}$ & $-1,8$ & $-1,9$ & $-2,0$ & $-2,1$ & $-2,2$ & $-2,25$ & $-2,3$ & $-2,4$ & $-2,45$ \\
\hline $\begin{array}{l}\varepsilon_{\text {cu1 }} \\
{[\% \circ]}\end{array}$ & \multicolumn{9}{|c|}{$-3,5$} \\
\hline $\begin{array}{c}\varepsilon_{\mathrm{c} 2} \\
{[\%]}\end{array}$ & \multicolumn{9}{|c|}{$-2,0$} \\
\hline $\begin{array}{l}\varepsilon_{\mathrm{cu} 2} \\
{[\% 0]}\end{array}$ & \multicolumn{9}{|c|}{$-3,5$} \\
\hline $\begin{array}{c}n \\
{[-]}\end{array}$ & \multicolumn{9}{|c|}{2,0} \\
\hline
\end{tabular}

Für den Beton gilt bei allen folgenden Bemessungsansätzen der Bemessungswert der Betondruckfestigkeit. Dieser ergibt sich in Abhängigkeit des Beiwertes zur Be- 
rücksichtigung von Langzeitauswirkungen und dem Teilsicherheitsbeiwert für Beton auf Grundlage der charakteristischen Betondruckfestigkeit gemäß folgender Gleichung ([EC2-1-1 2011-01] Abs. 3.1.6).

$$
f_{c d}=\alpha_{c c} \cdot \frac{f_{c k}}{\gamma_{C}}
$$

Mit:

$\alpha_{c c} \quad$ Beiwert zur Berücksichtigung von Langzeitauswirkungen auf die Betondruckfestigkeit (im Allgemeinen gilt: $\alpha_{c c}=0,85$ [EC2-1-1 NA 2013-04] NDP zu 3.1.6)

$f_{c k} \quad$ charakteristische Zylinderdruckfestigkeit des Betons gemäß Tabelle 2

$\gamma_{C}$ Teilsicherheitsbeiwert für Beton (gemäß Tabelle 2.1DE [EC2-1-1 NA 2013-04])

Der EC2 bietet drei unterschiedliche Möglichkeiten zur Beschreibung des Spannungs-Dehnungs- Verhaltens von Beton unter Druckbeanspruchung für die Querschnittsbemessung ([EC2-1-1 2011-01] Abs. 3.1.7). Dabei werden die Stauchungen als positive Werte dargestellt. Als primärer Lösungsansatz wird das Parabel-Rechteck-Diagramm (Abbildung 4) empfohlen. Der Spannungsverlauf wird dabei mit den folgenden Gleichungen beschrieben.

$$
\begin{array}{ll}
\sigma_{c}=f_{c d} \cdot\left[1-\left(1-\frac{\varepsilon_{c}}{\varepsilon_{c 2}}\right)^{n}\right] & \text { für } 0 \leq\left|\varepsilon_{c}\right| \leq\left|\varepsilon_{c 2}\right| \\
\sigma_{c}=f_{c d} & \text { für }\left|\varepsilon_{c 2}\right| \leq\left|\varepsilon_{c}\right| \leq\left|\varepsilon_{c u 2}\right|
\end{array}
$$

Mit:

$\begin{array}{ll}\sigma_{c} & \text { Druckspannung im Beton } \\ f_{c d} & \text { Bemessungswert der Betondruckfestigkeit nach Gl. (2-8) } \\ \varepsilon_{c} & \text { Betonstauchung } \\ \varepsilon_{c 2} & \text { Betonstauchung bei Erreichen der Maximalfestigkeit gemäß Tabelle } 2 \\ \varepsilon_{c u 2} & \text { Bruchdehnung gemäß Tabelle 2 } \\ n & \text { Exponent gemäß Tabelle 2 }\end{array}$




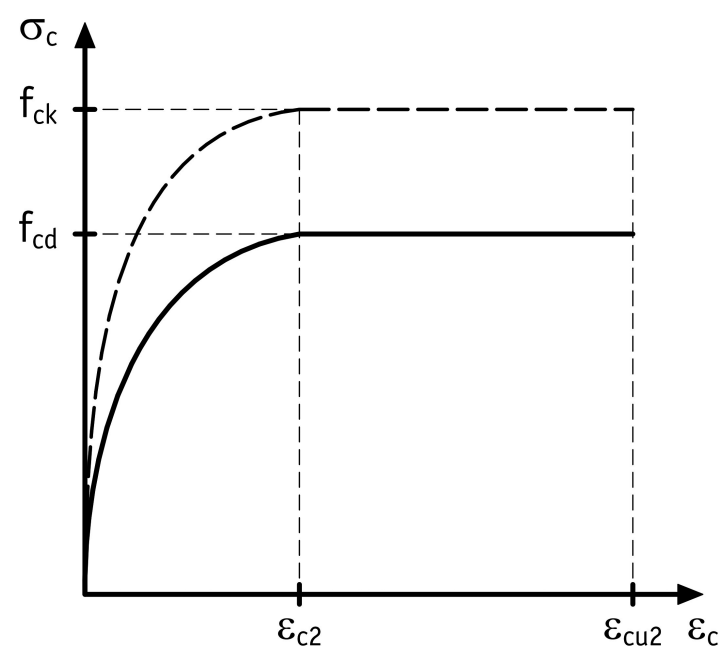

Abb. 4 Parabel-Rechteck-Diagramm (Quelle: [EC2-1-1 2011-01] Bild 3.3) (http://doi.org/10.33968/9783966270021-02-A-02)

Alternativ ist es gemäß EC2 zulässig vereinfachte, aber dem Parabel-Rechteck-Diagramm gleichwertige bzw. konservativere Bemessungsansätze zu verwenden. Zwei mögliche Ansätze dafür sind bereits im EC2 (Abs. 3.1.7) aufgeführt. Das sind die bilineare Spannungs-Dehnungs-Linie und der Spannungsblock. Aus Gründen der Vollständigkeit werden diese erwähnt, im Folgenden findet in dieser Arbeit jedoch ausschließlich das Parabel-Rechteck-Diagramm Anwendung.

Die Zugfestigkeit des Betons ist wesentlich geringer als seine Druckfestigkeit und beträgt diese nur ungefähr 10\% der jeweiligen Betondruckfestigkeit [Bindseil 2008]. Wie die Druckfestigkeit des Betons ist auch dessen Zugfestigkeit von der Spannungsverteilung abhängig. Für die hier betrachteten Normalbetone wird die mittlere zentrische Zugfestigkeit gemäß EC2 (Tabelle 3.1) wie folgt berechnet:

$f_{c t m}=0,3 \cdot f_{c k} \frac{2}{3}$

Mit:

$f_{c t m} \quad$ Mittelwert der zentrischen Zugfestigkeit des Betons

$f_{c k} \quad$ charakteristische Zylinderdruckfestigkeit des Betons gemäß Tabelle 2

\subsubsection{Betonstahl}

Für den Betonstahl dürfen gemäß EC2 zwei unterschiedliche bilineare Bemessungsansätze angenommen werden, die aus dem tatsächlichen Materialverhalten 
abgeleitet wurden. Diese werden durch den Nationalen Anhang spezifiziert. Es besteht die Möglichkeit von einem linear ansteigenden Funktionsast ab Erreichen des Bemessungswerts der Streckgrenze des Betonstahls auszugehen. Vereinfachend darf ein horizontaler Verlauf ab diesem Punkt angenommen werden (vgl. Abbildung 5).

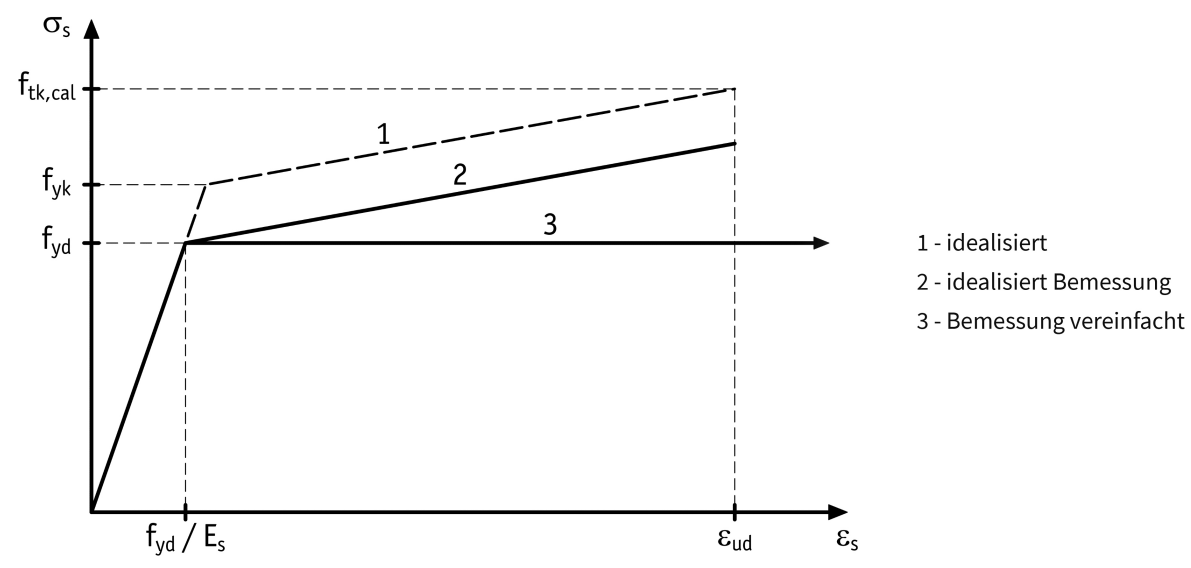

Abb. 5 Rechnerische Spannungs-Dehnungs-Linie des Betonstahls (Quelle: [EC2-1-1 2011-01] Bild 3.5 mit Anpassungen aus dem NA) (http://doi.org/10.33968/9783966270021-02-A-03)

Diese Ansätze gelten für den Betonstahl unter Zug- und Druckbeanspruchung. Der Bemessungswert der Streckgrenze des Betonstahls wird mit Gleichung (2-12) ermittelt.

$f_{y d}=\frac{f_{y k}}{\gamma_{S}}$

Mit:

$f_{y k} \quad$ charakteristischer Wert der Streckgrenze des Betonstahls

$\gamma_{s}$ Teilsicherheitsbeiwert für Betonstahl (Tab. 2.1DE [EC2-1-1 NA 2013-04])

Durch den Nationalen Anhang wird für den ansteigenden Funktionsast eine Bemessungsdehnungsgrenze von $25 \%$ angegeben (vgl. [EC2-1-1 NA 2013-04] NDP zu 3.2.7 (2)). Diese soll bei der Querschnittsbemessung auch für den horizontalen Ast angenommen werden ([BVPI 2016] S. 34), der im Folgenden für die Bemessung der Querschnitte herangezogen wird. 


\subsubsection{Kohlenstofffaserverstärkter Kunststoff - CFK}

Die folgenden Ausführungen beziehen sich ausschließlich auf die in der DAfStbRichtlinie erwähnten aufgeklebten CFK-Lamellen. Die Richtlinie des DAfStb zum Verstärken von Betonbauteilen mit geklebter Bewehrung ist so aufgebaut, dass Sie den Eurocode 2 mit notwendigen Regelungen an den entsprechenden Stellen ergänzt. Damit ist die Gliederung zum EC2 identisch, weshalb die zugehörigen Bemessungsansätze für Kohlenstofffaserverstärkten Kunststoff (CFK) im Kapitel Baustoffe zu finden sein sollten. Solche Regelungen fehlen an dieser Stelle. Es wird als empfehlenswert erachtet, eine Spannungs-Dehnungs-Linie für die Bemessung, analog zum Beton und Betonstahl einzuführen. Diese ergibt sich aus dem Materialverhalten von CFK, wobei dem Werkstoff ein linear-elastisches Verhalten bis zum Bruch (Abbildung 6) für die Querschnittsbemessung unter Zugbeanspruchung unterstellt wird ([Dehn et al. 2005] S. 11). Daraus ergibt sich unter Berücksichtigung des Sicherheitskonzeptes gemäß EC0 die Spannungs-Dehnungs-Linie für CFK nach Abbildung 7.

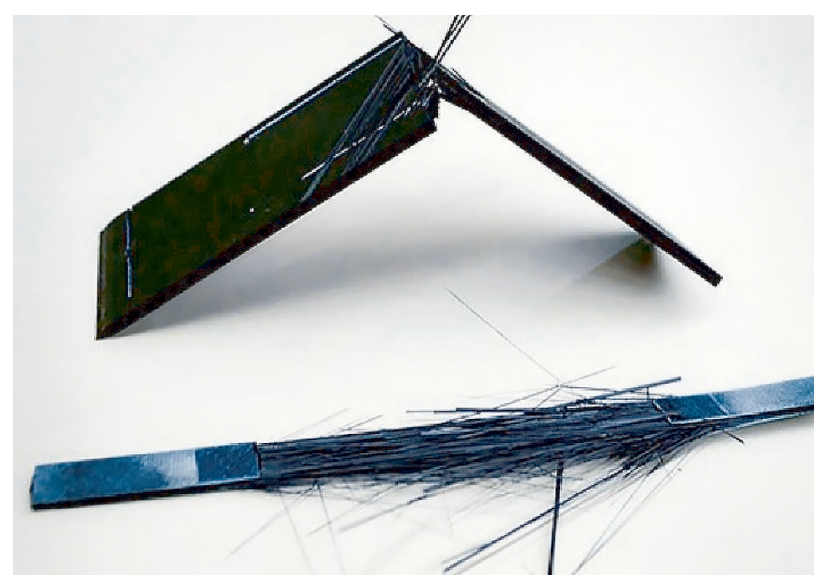

Abb. 6 Versagen von CFK unter Biegung und Zug (Quelle: [CTQ GmbH 2017]) (http://doi.org/10.33968/9783966270021-02-A-04) 


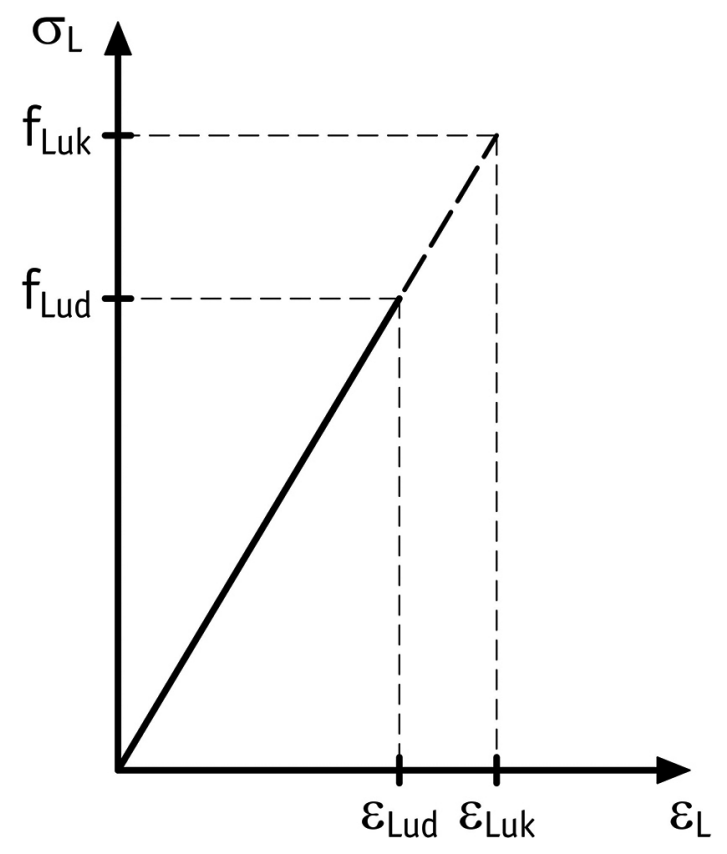

Abb. 7 Spannungs-Dehnungs-Linie von CFK-Lamellen für die Bemessung (http://doi.org/10.33968/9783966270021-02-A-05)

Auch weitere Formulierungen fehlen in der Richtlinie für eine konsequente Ergänzung des EC2. Erst aus den Erläuterungen und Beispielen zur DAfStb-Richtlinie geht die Ermittlung des Bemessungswertes der Zugfestigkeit der Lamelle, analog zum Bemessungswert der Streckgrenze des Betonstahls, hervor (Gleichung (2-13) [DAfStb-Heft 595] S. 48). Der entsprechende Teilsicherheitsbeiwert ist dagegen unter dem $\mathrm{zu}$ erwartenden Gliederungspunkt der Richtlinie zu finden ([DAfStb 2012-03] Tabelle RV 2.1).

$f_{L u d}=\frac{f_{L u k}}{\gamma_{L L}}$

Mit:

$f_{\text {Luk }} \quad$ charakteristischer Wert der Materialfestigkeit der CFK-Lamelle (aus Zulassung)

$\gamma_{L L} \quad$ Teilsicherheitsbeiwert für CFK-Lamellen ([DAfStb 2012-03] Tabelle RV 2.1)

Aus der Bemessungszugfestigkeit für die Querschnittsbemessung ergibt sich damit die Grenzdehnung für den Bemessungsfall nach Gleichung (2-14) (vgl. [Finckh 2012] S. 211). Laut den Erläuterungen zur DAfStb-Richtlinie darf für die Berech- 
nungen der mittlere E-Modul angesetzt werden ([DAfStb-Heft 595] S. 13). Dieser ist abhängig von der verwendeten Lamelle und dementsprechend aus der jeweiligen bauaufsichtlichen Zulassung des Herstellers zu entnehmen.

$\varepsilon_{\text {Lud }}=\frac{f_{L u d}}{E_{L m}}$

Mit:

$f_{\text {Lud }} \quad$ Bemessungswert der Zugfestigkeit der Lamelle nach Gl. (2-13)

$E_{L m} \quad$ Mittelwert des E-Moduls der geklebten Bewehrung (gemäß Zulassung)

Unter Berücksichtigung der aktuellen Zulassungen des DIBt müssen für die Nachweisführung abweichende Formulierungen zur Berechnung der Bemessungszugfestigkeit verwendet werden. Dabei wird Gleichung (2-13) um einen Dauerstandminderungsfaktor erweitert ([Z-36.12- 84/85/86] Abs. 3.2). Die Werte sind der jeweiligen Zulassung zu entnehmen.

$f_{L u d}=\alpha_{Z e i t} \cdot \frac{f_{L u k}}{\gamma_{L L}}$

Mit:

$\alpha_{\text {zeit }} \quad$ Dauerstandminderungsfaktor für die CFK-Lamellen

Auch die Werte der Bruchdehnungen entsprechen in den Zulassungen nicht den Ergebnissen der Berechnung mit Gl. (2-14). In Abhängigkeit des verwendeten Systems fällt die zulässige Bruchdehnung größer oder kleiner aus (vgl. [Z-36.12-84/85/86]). Daher sind für die Bemessung in jedem Fall die entsprechenden Zulassungen der aufgeklebten CFK-Lamellen heranzuziehen.

\subsection{Schnittgrößenermittlung}

Bei der Anwendung des Bemessungskonzeptes nach EC2 werden vereinfachte Verfahren mit idealisierter Tragwerksgeometrie und idealisiertem Tragwerksverhalten für die Schnittgrößenermittlung verwendet ([EC2-1-1 2011-01] Abs. 5). Zu den möglichen idealisierten Tragwerksverhalten gehören:

- linear-elastisches Verhalten

- linear-elastisches Verhalten mit begrenzter Umlagerung

- plastisches Verhalten

- nichtlineares Verhalten

Für die folgende Bearbeitung wird ausschließlich die Vereinfachung des linearelastischen Verhaltens benötigt. In Abbildung 8 ist schematisch die Abweichung 
zwischen tatsächlichem und idealisiertem Verhalten des Stahlbetonquerschnitts unter Lasteinwirkung dargestellt (vgl. bspw. [Baar u. Ebeling 2017] S. 176).

\section{reales Verhalten}

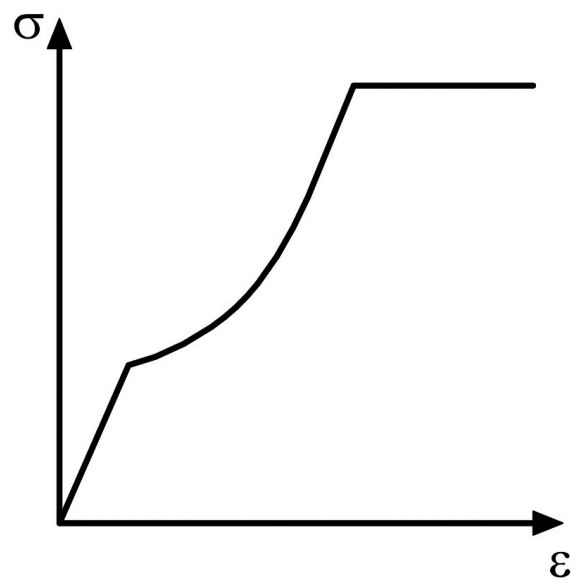

Elastizitätstheorie

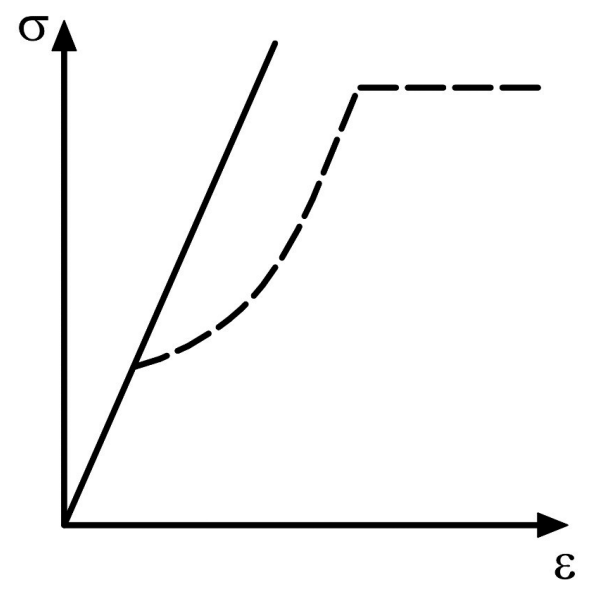

Abb. 8 Idealisierung der Spannungs-Dehnungs-Linie nach Elastizitätstheorie (Quelle: Eigene Darstellung in Anlehnung an [Baar u. Ebeling 2017] S. 176, Bild 5.1) (http://doi.org/10.33968/9783966270021-02-A-06)

Die Elastizitätstheorie darf für den Grenzzustand der Tragfähigkeit sowie für den Grenzzustand der Gebrauchstauglichkeit angewendet werden. Dabei werden Annahmen getroffen die durch den Nationalen Anhang zum Eurocode 2 ergänzt werden:

- ungerissene Querschnitte (NA: Zustand II ebenfalls zulässig)

- lineare Spannungs-Dehnungs-Linien (vgl. schematische Abbildung 8)

- Mittelwert des Elastizitätsmoduls

Sofern keine konstruktiven Maßnahmen ergriffen werden, ist für Normalbeton der Grenzwert $\mathrm{x} / \mathrm{d} \leq 0,45$ einzuhalten.

Hierbei werden für den Querschnitt konstante Steifigkeiten angenommen. Diese sind unabhängig von der Einwirkung, wodurch die Reduzierung der Steifigkeiten aufgrund von plastischen Verformungen nicht berücksichtigt werden. Daher kann das Superpositionsprinzip angewendet werden. Das Verfahren liegt stets auf der sicheren Seite, jedoch wird die mangelnde Aussagekraft über die reale Verformung des Tragwerks sowie die Überschätzung der Schnittgrößen als nachteilig eingestuft (vgl. [Mehlhorn et al. 2002] S. 60). 


\subsection{Bemessung Stahlbetonquerschnitt}

Wie bereits in Kapitel 2.1 erwähnt, ist es erforderlich die Tragfähigkeit eines Bauteils im ursprünglichen Zustand zu kennen, um zu ermitteln, ob es einer Verstärkungsmaßnahme bedarf. Dazu müssen die rechnerischen Zustände bekannt sein, bei denen dem Bauteil in der Querschnittsbemessung ein Versagen unterstellt wird. Diese gehen aus den Werkstoffgesetzen hervor (vgl. Abschnitt 2.4). Ein rechnerisches Versagen des Querschnitts bei Biegung mit oder ohne Normalkraft tritt ein, sofern ein Material voll ausgenutzt ist. Für den Beton ergeben sich die rechnerischen Grenzwerte aus Tabelle 2 und für den Betonstahl anhand der Formulierungen des EC2 mit den Ergänzungen des Nationalen Anhangs (vgl. Abs. 2.4.2). Schematisch sind die zulässigen Dehnungszustände gemäß EC2 ([EC2-1-1 2011-01] Abs. 6.1) in Abbildung 9 dargestellt.

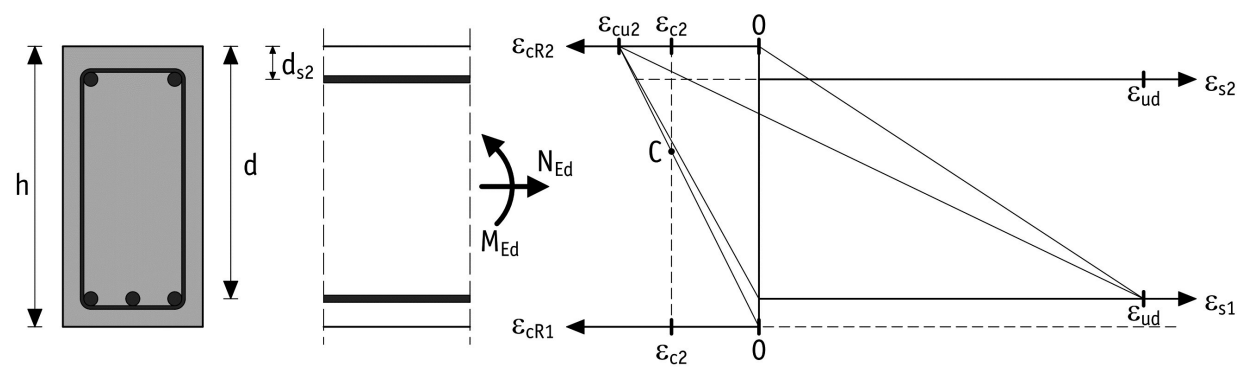

Abb. 9 zulässige Dehnungszustände am Stahlbetonquerschnitt (Quelle: Eigene Darstellung in Anlehnung an [Mehlhorn et al. 2002] Bild 8-3, S. 243)

(http://doi.org/10.33968/9783966270021-02-A-07)

Resultierend aus der Anwendung des Parabel-Rechteck-Diagramms (Abbildung 4) und der Spannungs- Dehnungs-Linie für die Querschnittsbemessung von Betonstahl (Abbildung 5) ergeben sich die Dehnungs- und Spannungszustände am ursprünglichen unverstärkten Stahlbetonquerschnitt unter Biegung und Normalkraft gemäß Abbildung 10. 


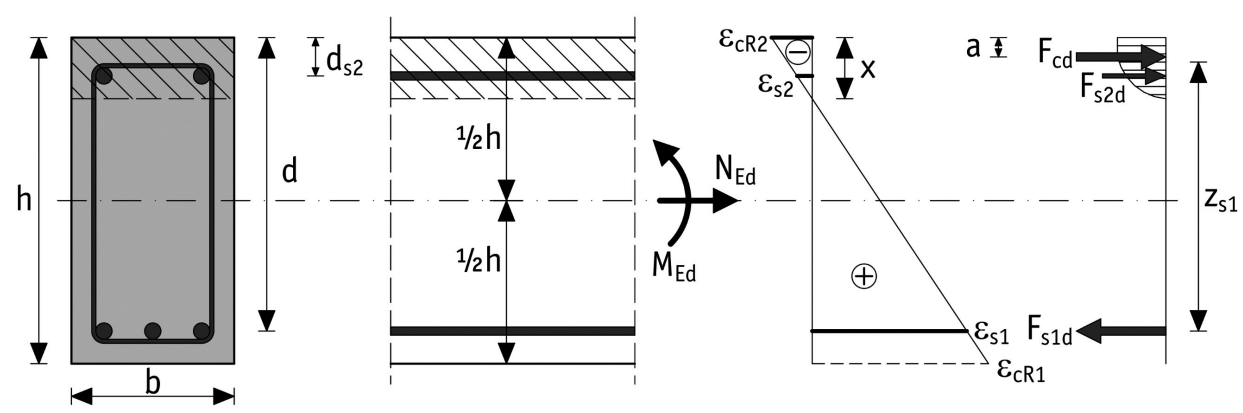

Abb. 10 Dehnungs- und Spannungsverteilung am Stahlbetonquerschnitt (Quelle: Eigene Darstellung in Anlehnung an [Mehlhorn et al. 2002] Bild 8-12, S. 249)

(http://doi.org/10.33968/9783966270021-02-A-08)

Aufgrund der Einwirkungen treten im Querschnitt innere Kräfte auf. Aus den Materialgesetzen (Kapitel 2.4) lassen sich diese resultierenden inneren Kräfte bestimmen. Die Betondruckkraft ergibt sich als Integral der Spannungsverteilung über die Betondruckzone ([Bindseil 2008] S. 48). Das Integral wurde bereits vielfach gelöst, wobei der sogenannte Völligkeitsbeiwert eingeführt wird, der die Lösung des Integrals in Abhängigkeit der Betonrandstauchung enthält (vgl. bspw. [Leonhardt u. Mönnig 1984] S. 155, [Mehlhorn et al. 2002] S. 249 ff.). Diese Betonrandstauchung am druckbeanspruchten oberen Querschnittsrand wird in dieser Arbeit mit $\varepsilon_{c R 2}$ bezeichnet. Somit ergibt sich die Betondruckkraft nach Gleichung (2-16).

$F_{c d}=b \int_{0}^{x} \sigma_{c}(x) d x=b \cdot x \cdot f_{c d} \cdot \alpha_{R}$

Mit:

$F_{c d} \quad$ Bemessungswert der Betondruckkraft

b Breite des Querschnitts

$\sigma_{c} \quad$ Druckspannung im Beton

$x \quad$ Höhe der Druckzone

$f_{c d} \quad$ Bemessungswert der Betondruckfestigkeit nach Gl. (2-8)

$\alpha_{R} \quad$ Völligkeitsbeiwert nach Gl. (2-17)

Dabei nimmt $\alpha_{R}$ für normalfeste Betone folgende Werte an $\left(\left|\varepsilon_{\mathrm{cR} 2}\right|\right.$ in \%o): 


$$
\alpha_{R}= \begin{cases}\frac{\left|\varepsilon_{c R 2}\right| \cdot\left(6-\left|\varepsilon_{c R 2}\right|\right)}{12} & \left(0 \% \leq\left|\varepsilon_{c R 2}\right|<2 \% 0\right) \\ \frac{3 \cdot\left|\varepsilon_{c R 2}\right|-2}{3 \cdot\left|\varepsilon_{c R 2}\right|} & \left(2 \% \leq\left|\varepsilon_{c R 2}\right| \leq 3,5 \% 0\right)\end{cases}
$$

Mit:

$\alpha_{R} \quad$ Völligkeitsbeiwert

$\varepsilon_{c R 2} \quad$ Betonrandstauchung am druchbeanspruchten oberen

Querschnittsrand

Da sich die DAfStb-Richtlinie auf die Betonfestigkeitsklassen C12/15 bis C50/60 beschränkt, erübrigt sich an dieser Stelle eine Betrachtung über diese Festigkeitsklassen hinaus (vgl. [DAfStb 2012-03] Teil 1 Abs. RV 3.6 (RV1)). Des Weiteren kann mittels des aufgelösten Integrals der Beiwert für den bezogenen Randabstand der resultierenden Betondruckkraft ermittelt werden ([Leonhardt u. Mönnig 1984] S. 155). Damit kann anschließend der Angriffspunkt der Betondruckkraft sowie der innere Hebelarm der Bewehrung bestimmt werden $\left(\left|\varepsilon_{\mathrm{cR} 2}\right|\right.$ in \%o $)$.

$$
k_{a}=\left\{\begin{array}{cl}
\frac{8-\left|\varepsilon_{c R 2}\right|}{4 \cdot\left(6-\left|\varepsilon_{c R 2}\right|\right)} & \left(0 \% \leq\left|\varepsilon_{c R 2}\right|<2 \%\right) \\
\frac{\left|\varepsilon_{c R 2}\right| \cdot\left(3 \cdot\left|\varepsilon_{c R 2}\right|-4\right)+2}{2 \cdot\left|\varepsilon_{c R 2}\right| \cdot\left(3 \cdot\left|\varepsilon_{c R 2}\right|-2\right)} & \left(2 \% \leq\left|\varepsilon_{c R 2}\right| \leq 3,5 \%\right)
\end{array}\right.
$$

Mit:

$k_{a} \quad$ Beiwert des Randabstandes der resultierenden Betondruckkraft

$\varepsilon_{c R 2} \quad$ Betonrandstauchung am druchbeanspruchten oberen

Querschnittsrand

$a=k_{a} \cdot x$

Mit:

a Angriffspunkt der Betondruckkraft (Abstand vom oberen

Querschnittsrand)

$x$ Höhe der Druckzone

$z_{s 1}=d-a$

Mit:

$z_{s 1} \quad$ innerer Hebelarm der Biegezugbewehrung

d statische Höhe der Biegezugbewehrung 
Unter Berücksichtigung der Hypothese von Bernoulli und der Annahme des vollkommenen Verbundes lässt sich auch die Druckzonenhöhe, über die Dehnungszustände und die statische Höhe, berechnen (Gl. (2-21)).
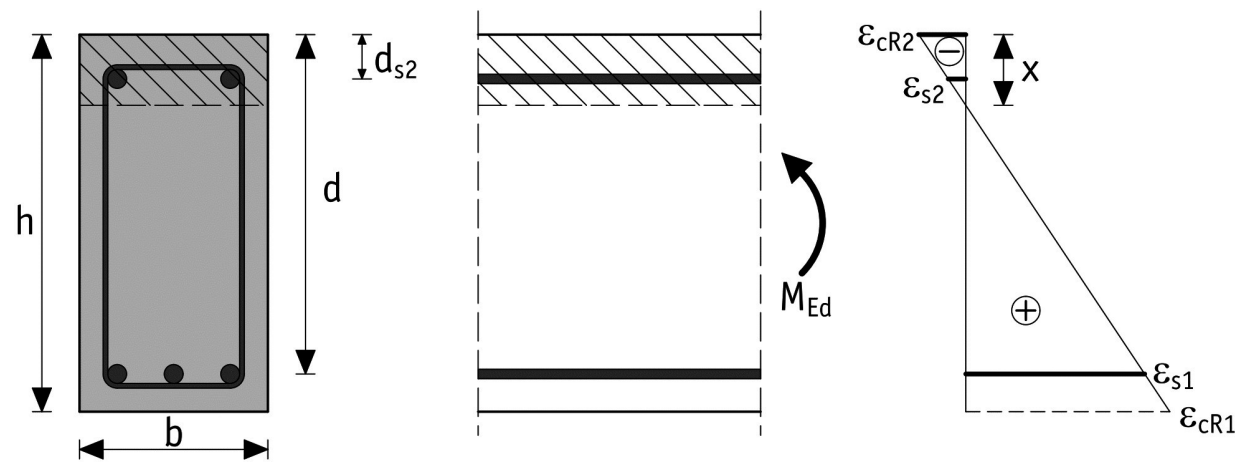

Abb. 11 Dehnungsverteilung bei reiner Biegung

(http://doi.org/10.33968/9783966270021-02-A-09)

$x=\frac{\varepsilon_{c R 2}}{\varepsilon_{c R 2}-\varepsilon_{s 1}} \cdot d$

Mit:

$\begin{array}{ll}x & \text { Höhe der Druckzone } \\ d & \text { statische Höhe der Biegezugbewehrung } \\ \varepsilon_{c R 2} & \text { Betonrandstauchung am druckbeanspruchten oberen } \\ & \text { Querschnittsrand } \\ \varepsilon_{s 1} & \text { Dehnung der Biegezugbewehrung }\end{array}$

Für den Betonstahl ergibt sich die zugehörige Kraft nach Gleichung (2-22) [Zilch et al. 2013]. Dieser rechnerische Ansatz gilt gleichermaßen für Druck- und Zugkräfte. An dieser Stelle soll noch einmal darauf verwiesen werden, dass der Beton, gemäß den Voraussetzungen für die Bemessung, planmäßig keine Zugkräfte aufnimmt und damit in der Zugzone als gerissen betrachtet wird. Sämtliche Zugkräfte sind durch den Bewehrungsstahl aufzunehmen. Gemäß dem bilinearen Bemessungsansatz werden ab dem Bemessungswert der Streckgrenze keine weiteren Spannungen durch den Betonstahl aufgenommen (vgl. Kapitel 2.4.2). Das bedeutet, dass sich der Dehnungszustand der Bewehrung zwar betragsmäßig bis zur rechnerischen Bruchdehnung vergrößern kann, dabei jedoch keine weiteren Spannungen, bzw. daraus resultierende Kräfte, rechnerisch angesetzt werden dürfen. Gleichung (2-22) gilt aufgrund des Werkstoffverhaltens von Stahl (vgl. Kapitel 2.4.2 Abbildung 5) sowohl für Zugkräfte, als auch für Druckkräfte. 


$$
F_{s d}=\sigma_{s} \cdot A_{s}=\varepsilon_{s} \cdot E_{s} \cdot A_{s} \leq f_{y d} \cdot A_{s}
$$

Mit:

$F_{\text {sd }} \quad$ Bemessungswert der Stahlzug- bzw. Stahldruckkraft

$\sigma_{s} \quad$ Betonstahlspannung

$A_{s} \quad$ Querschnittsfläche des Betonstahls

$\varepsilon_{s} \quad$ Dehnung / Stauchung der Bewehrung

$E_{s} \quad$ Bemessungswert des Elastizitätsmoduls für Betonstahl

$f_{y d} \quad$ Bemessungswert der Streckgrenze des Betonstahls

Über die Gleichgewichtsbedingungen kann der Querschnittswiderstand berechnet werden. Das Gleichgewicht der Momente wird hier um den Schwerpunkt der Zugbewehrung (Index ,„“) aufgestellt. Eine einwirkende Normalkraft ist als Zugkraft positiv anzusetzen und als Druckkraft mit negativem Vorzeichen zu versehen. Um zu verdeutlichen, dass es sich um den Zeitpunkt vor bzw. während der Verstärkung handelt, wird bei den Bemessungswiderständen der Index „0“ ergänzt.

$N_{R d, 0}=F_{c d}-F_{s 1 d}+F_{s 2 d}$

$M_{R d, s, 0}=F_{c d} \cdot z_{s 1}+F_{s 2 d} \cdot\left(d-d_{s 2}\right)$

Mit:

$\begin{array}{ll}F_{c d} & \text { Bemessungswert der Betondruckkraft } \\ F_{s 1 d} & \text { Bemessungswert der Stahlzugkraft } \\ F_{s 2 d} & \text { Bemessungswert der Stahldruckkraft } \\ N_{R d, 0} & \text { Bemessungswiderstand der Normalkrafttragfähigkeit vor der } \\ M_{R d, s, 0} & \text { Verstärkung } \\ z_{s 1} & \text { Bemessungswiderstand der Biegetragfähigkeit vor der Verstärkung } \\ d & \text { innerer Hebelarm der Biegezugbewehrung } \\ d_{s 2} & \text { statische Höhe der Biegezugbewehrung }\end{array}$

Das einwirkende Moment auf Höhe der unteren Bewehrungslage berechnet sich aus dem einwirkenden Moment zuzüglich des Anteils der einwirkenden Normalkraft.

$M_{E d, s}=M_{E d}-N_{E d} \cdot\left(d-\frac{h}{2}\right)$

Mit:

$M_{E d, s} \quad$ einwirkendes Moment bezogen auf die Achse der unteren

Bewehrungslage

$M_{E d} \quad$ Bemessungswert des einwirkenden Moments 
$N_{E d} \quad$ Bemessungswert der einwirkenden Normalkraft

d statische Höhe der Biegezugbewehrung

h Querschnittshöhe

Die Einwirkungen werden als bekannte Größen vorausgesetzt, da diese mit statischen Berechnungen für jede Stelle eines Systems berechnet werden können. Damit erfolgt in der Regel eine Bemessung von Stahlbetonquerschnitten so, dass mittels einer gesuchten Bewehrungsfläche die Einwirkungen vom Querschnitt aufgenommen werden können und gleich dem Bauteilwiderstand sind ([Bindseil 2008] S. 43). Einige Parameter werden dabei bauseits vorgegeben. Dazu zählen die Abmessungen des Querschnitts sowie die Betondruckfestigkeitsklasse ([Bindseil 2008] S. 57). Anschließend folgt ein iterativer Vorgang bei dem die Dehnungszustände in den zulässigen Grenzen variiert werden, um das Gleichgewicht der inneren und äußeren Schnittgrößen herzustellen.

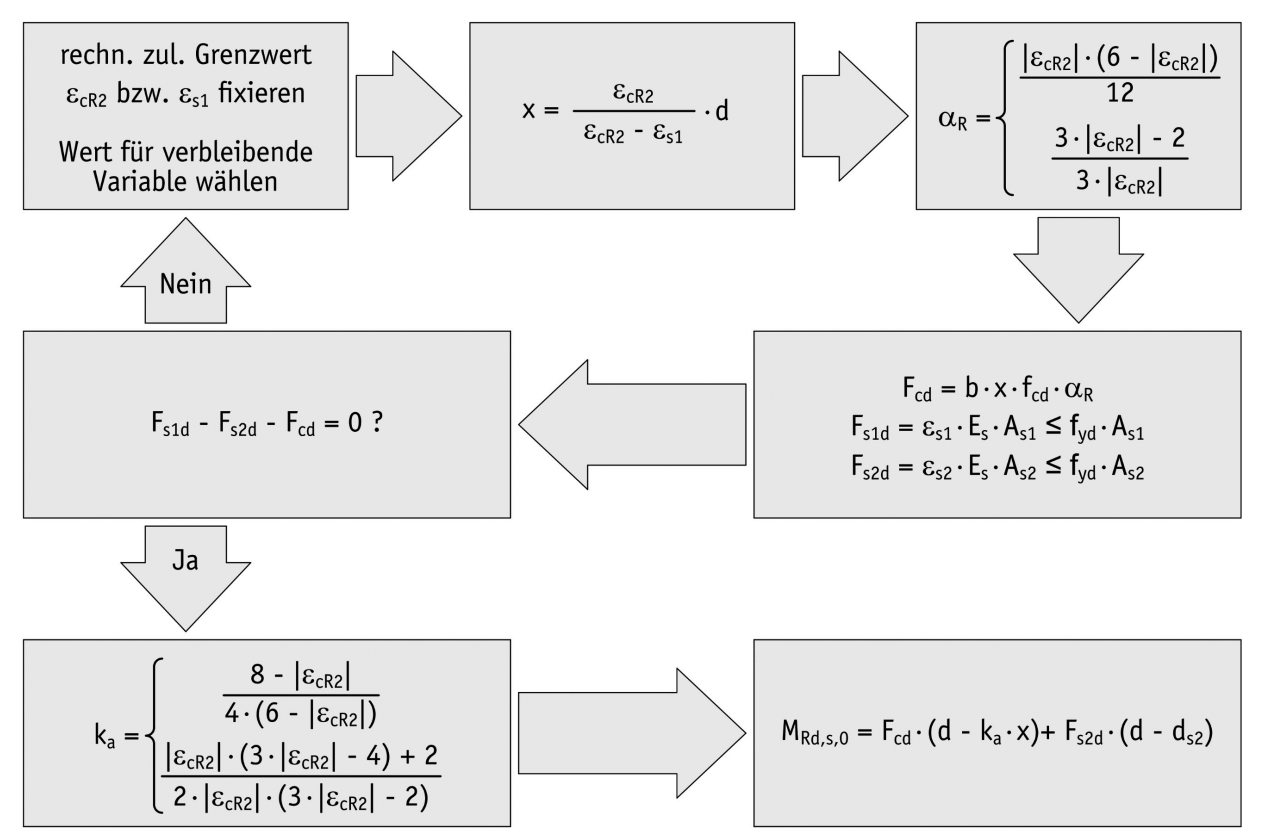

Abb. 12 Iterationsvorgang Biegetragfähigkeit im Bestand (http://doi.org/10.33968/9783966270021-02-A-10)

Da in der normalen Bemessung für Stahlbeton an dieser Stelle die Stahlfläche unbekannt ist, muss zuerst das Gleichgewicht der Momente aufgestellt werden, um anschließend über die Summe der horizontalen Kräfte die erforderliche Fläche der Stahlzugbewehrung bestimmen zu können. Dafür gibt es bereits unterschiedlichste Bemessungshilfen, wie bspw. die Bemessungstafeln mit dimensionslosen Bei- 
werten (vgl. bspw. [Schneider et al. 2012]). Weil es sich in dieser Arbeit um die Bemessung im Bestand handelt, werden diese Ansätze auf das Bestandsbauteil übertragen. Hierbei ist die Bewehrungsfläche bereits aus Planunterlagen oder Bauteiluntersuchungen bekannt, sodass direkt durch Iteration der Dehnungen bis zum Gleichgewicht der inneren Kräfte die Biegetragfähigkeit mit Gleichung (2-24) berechnet werden kann. Dieser Vorgang ist zur Verdeutlichung als Iterationsschema in Abbildung 12 dargestellt. Damit ist die Tragfähigkeit des Bestands bekannt und es kann geprüft werden, ob die neue Einwirkung die vorhandene Tragfähigkeit übersteigt.

\subsection{Verstärkung mit aufgeklebten CFK-Lamellen}

\subsubsection{Versagensarten}

Für den Fall, dass die Tragfähigkeit des vorhandenen Querschnitts unter der neuen Einwirkung überschritten wird und somit das Bauteil nach dem aktuell gültigen Sicherheitskonzept nicht nachgewiesen werden kann, sind Ertüchtigungsmaßnahmen vorzusehen. In diesem Kapitel soll die Bemessung von Verstärkungsmaßnahmen zur Erhöhung der Biegetragfähigkeit eines Stahlbetonbauteils mit aufgeklebten CFK-Lamellen erläutert werden. Dafür ist eine grundsätzliche Kenntnis der Versagensarten zum Verständnis der Nachweisführung bei einer solchen Verstärkungsmaßnahme erforderlich. Im Sachstandbericht des DAfStb sind diese zusammenfassend aufgeführt ([DAfStb-Heft 591] S. 19 f.). Dabei treten herkömmliche Versagensarten des Stahlbetons auf. Hinzu kommen weitere Versagensarten, die durch das Aufkleben der Lamelle hervorgerufen werden. Die Versagensarten sind in Tabelle 3 aufgeführt.

Tab. 3 Versagensarten von Querschnitten mit aufgeklebten CFK-Lamellen (http://doi.org/10.33968/9783966270021-02-T-03)

Versagensarten bei aufgeklebten CFK-Lamellen

Analog zum Stahlbeton

- Versagen der Betondruckzone

- Betonbruch infolge Fließen der inneren Bewehrung

- Lamellenbruch infolge Fließen der inneren

Bewehrung

- Querkraftversagen

\section{Spezifisch für aufgeklebte CFK-Lamellen}

- Versatzbruch am Lamellenende

- Verbundversagen am Lamellenende

- Verbundversagen am Zwischenrisselement

In der Regel treten die spezifischen Versagensarten bei aufgeklebten CFK-Lamellen vor denen des Stahlbetons ein und werden maßgebend ([DAfStb-Heft 591] S. 
20). Ausgehend von der CFK-Lamelle kann das Fachwerkprinzip analog zum Stahlbeton angenommen werden ([Zilch et al. 2013] S. 491). Beim Versatzbruch löst sich der Beton unterhalb der Bewehrung am Lamellenende. Dieser Vorgang resultiert aus dem vertikalen Versatz zwischen zugbeanspruchter Lamelle und der Bügelbewehrung ([DAfStb-Heft 594] S. 19). Dieses Prinzip ist in Abbildung 13 schematisch dargestellt. Daneben ist die entsprechende Versagensart bei einem Versuch am Stahlbetonbiegebalken abgebildet (Abbildung 14).

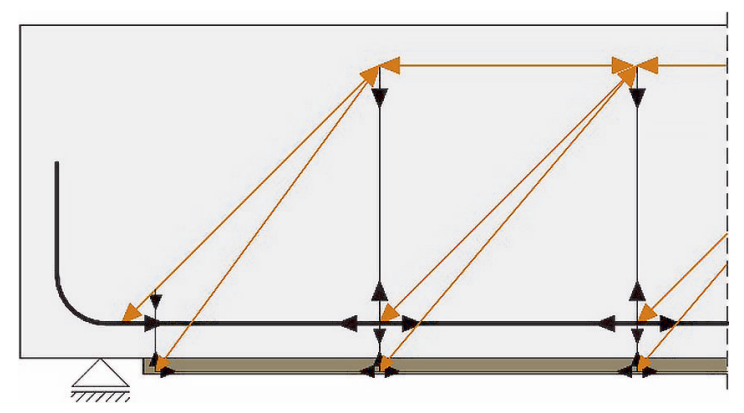

Abb. 13 Fachwerkprinzip mit CFK-Lamelle (Quelle: Eigene Darstellung in Anlehnung an [Finckh 2012] Bild 6.2, S. 176) (http://doi.org/10.33968/9783966270021-02-A-11)

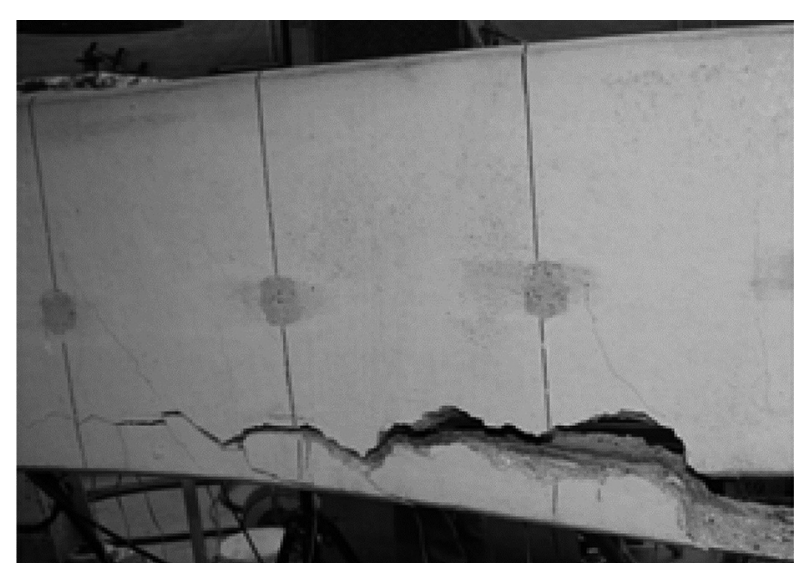

Abb. 14 Versatzbruch (Quelle: [Finckh 2012] Ausschnitt Bild 2.2, S. 7) (http://doi.org/10.33968/9783966270021-02-A-12)

Das Verbundversagen beschreibt das Ausbrechen oberflächennaher Betonschichten, sobald an der betrachteten Stelle die Betonzugfestigkeit überschritten wird ([DAfStb-Heft 591] S. 20). Dies tritt entweder am Ende der Lamelle oder an einem 
Abschnitt zwischen den Rissen des Stahlbetons (Zwischenrisselemente) auf. Dabei werden die Zugkräfte aus der Lamelle über den Verbund teilweise in den Beton eingeleitet. Auf diese Versagensart wird im Kapitel 2.7.5.1 explizit eingegangen.

\subsubsection{Nachweisverfahren}

Um die vorab genannten Versagensarten zu vermeiden, sind in der DAfStb-Richtlinie für das „Verstärken von Betonbauteilen mit geklebter Bewehrung“ im GZT folgende Nachweise bei überwiegend biegebeanspruchten Bauteilen für aufgeklebte CFK-Lamellen vorgesehen ([DAfStb 2012-03] Teil 1 Abs. RV 6.1.1.1):

- Nachweis der Biegetragfähigkeit (zuzüglich Verbundnachweis)

- Nachweis der Querkrafttragfähigkeit

- Nachweis des Versatzbruches

Zum Nachweis der Biegetragfähigkeit zählt neben dem reinen Biegenachweis bei aufgeklebten CFK-Lamellen der Nachweis des Verbundes ([DAfStb 2012-03] Teil 1 Abs. RV 6.1.1.3.1). Damit wird das Verbundverhalten zwischen der aufgeklebten Lamelle und dem Stahlbeton abgebildet. Es soll gewährleistet werden, dass die auftretenden Versagensarten vermieden und die Kräfte durch den Verbund aufgenommen werden können. Dieses Problem wurde vielfach durch Versuche betrachtet und mit unterschiedlichen Ingenieurmodellen beschrieben. Die verschiedenen Ansätze und Ergebnisse sind in dem Sachstandbericht, der unter anderem als Grundlage zur DAfStb- Richtlinie diente, zusammengetragen, beschrieben und bewertet worden [DAfStb-Heft 591]. Wie bereits erwähnt, stellt das Verbundversagen die maßgebende Ursache für das Versagen von verstärkten Querschnitten mit aufgeklebten CFK-Lamellen dar ([DAfStb-Heft 591] S. 20). Daher ist es zwingend erforderlich die mögliche Verbundkraftübertragung rechnerisch zu beurteilen. Gemäß der DAfStb-Richtlinie werden deshalb die Betrachtung der Verbundkraftübertragung am Zwischenrisselement (ZRE), ein Endverankerungsnachweis der aufgeklebten Lamellen und die Vermeidung des Versatzbruches gefordert ([DAfStb 2012-03] Teil 1 RV 6.1.1).

Alternativ bietet die Richtlinie die Möglichkeit eines stark vereinfachten Nachweises ([DAfStb 2012-03] Teil 1 RV 6.1.1.2). Dieser ermöglicht es die Verbundbetrachtung entfallen zu lassen, da dieser Nachweis auf Untersuchungen beruht, die den genaueren Nachweis der Lamellenkraftänderung am ZRE sowie den Endverankerungsnachweis einbeziehen ([DAfStb-Heft 595] S. 17). Dabei werden gewisse Randbedingungen vorausgesetzt (vgl. Abs. 2.7.6) und die Dehnungen für den Biegenachweis im GZT auf der sicheren Seite liegend begrenzt. Jedoch ist die Ausnutzung der CFK-Lamellen hinsichtlich deren Bemessungszugfestigkeit bei diesem Nachweisformat äußerst gering. Das gesamte Nachweisverfahren für aufgeklebte CFK-Lamellen mit seinen unterschiedlichen Möglichkeiten der Nachweisführung ist schematisch in Abbildung 15 dargestellt. 


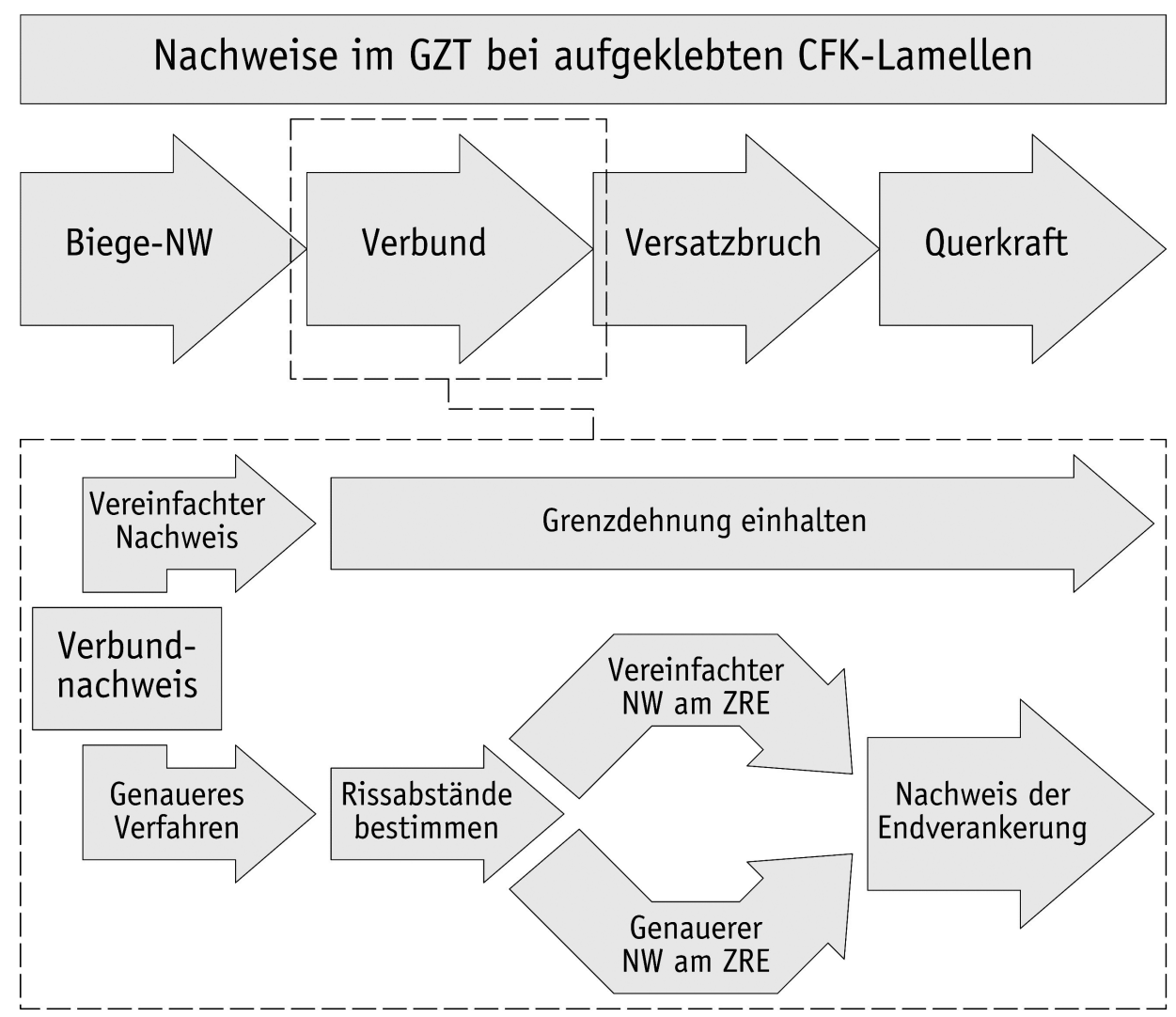

Abb. 15 Ablaufschema des Nachweisverfahrens bei aufgeklebten CFK-Lamellen (Quelle: Eigene Darstellung in Anlehnung an [DAfStb-Heft 595] Bild H.8, S. 17) (http://doi.org/10.33968/9783966270021-02-A-13)

\subsubsection{Abgrenzung der Arbeit}

Aufgrund der Komplexität der Nachweisführung in der DAfStb-Richtlinie ist es erforderlich diese Arbeit in bestimmten Punkten abzugrenzen. Es handelt sich somit in den Ergebnissen um eine erste Vorbemessung für die aufgeklebten CFK-Lamellen, die unbedingt eine weitere Nachweisführung nach sich ziehen muss. Die Ergebnisse dienen aber dazu, diese Nachweisführung zu vereinfachen bzw. zu erleichtern.

Im Rahmen dieser Arbeit soll der Nachweis der Biegetragfähigkeit ([DAfStb 2012-03] Teil 1 RV 6.1.1.3.2) betrachtet werden, um daraus entsprechende Hilfsmittel zu entwickeln. Die Richtlinie zählt zu diesem Nachweis die Verbundnachweise. 
Damit sind für den Nachweis der Biegetragfähigkeit nachstehende Nachweise zu führen.

- Nachweis der Biegetragfähigkeit (RV 6.1.1.3.2)

- Nachweis der Lamellenkraftänderung am ZRE (RV 6.1.1.3.5 bzw. RV 6.1.1.3.6)

- Endverankerungsnachweis (RV 6.1.1.4)

Eine Betrachtung der Querkraft ist in dieser Arbeit nicht vorgesehen. Daher wird auch auf den Nachweis zur Vermeidung des Versatzbruches ([DAfStb 2012-03] Teil 1 RV 6.2.7) verzichtet, der sich bei der Anordnung einer konstruktiven Endverbügelung ohnehin erübrigt ([DAfStb 2012- 03] Teil 1 RV 6.1.1.1 (RV 2)). Außerdem wird in Folge dieses Aspektes der Endverankerungsnachweis in dieser Arbeit nicht betrachtet, da sich hierbei unterschiedlichste Berechnungsansätze in Abhängigkeit der Verankerungsart ergeben.

Es wird explizit darauf hingewiesen, dass es sich bei der vorliegenden Arbeit um die Entwicklung von Hilfsmitteln zur Vorbemessung handelt und sämtliche Nachweise gemäß den geltenden Normen und technischen Regelwerken im Rahmen einer Verstärkungsmaßnahme mit aufgeklebten CFK-Lamellen zu führen sind, auch wenn sie nicht Gegenstand dieser Arbeit sind.

\subsubsection{Nachweis der Biegetragfähigkeit}

Um die Biegetragfähigkeit im verstärkten Zustand nachzuweisen, wird der Stahlbetonquerschnitt um die CFK-Lamelle erweitert. Dabei wird kohlenstofffaserverstärktem Kunststoff für die Bemessung ein linear-elastisches Materialverhalten bis zum Bruch unterstellt (vgl. Kapitel 2.4.3). Damit ist die Spannung direkt proportional zur Dehnung und das Hookesche Gesetz kann für CFK-Lamellen bis zum Bruch uneingeschränkt angewendet werden (vgl. [Stroppe 2012] S. 105).

$\sigma_{L}=\varepsilon_{L} \cdot E_{L m}$

Mit:

$\sigma_{L} \quad$ Spannung in der aufgeklebten CFK-Lamelle

$\varepsilon_{L} \quad$ Dehnung der aufgeklebten CFK-Lamelle

$E_{L m} \quad$ Mittelwert des E-Moduls der geklebten Bewehrung (gemäß Zulassung)

Dabei darf der Bemessungswert der Zugfestigkeit der Lamelle nicht überschritten werden ([DAfStb 2012-03] Teil 1 RV 6.1.1.3.2). Somit ergibt sich die Lamellenkraft wie in Gl. (2-27) beschrieben (vgl. [Zilch et al. 2013] S. 479).

$F_{L d}=\varepsilon_{L} \cdot E_{L m} \cdot A_{L} \leq f_{L u d} \cdot A_{L}$ 
Mit:

$$
\begin{array}{ll}
F_{L d} & \text { Bemessungswert der Lamellenzugkraft } \\
\varepsilon_{L} & \text { Dehnung der aufgeklebten CFK-Lamelle } \\
E_{L m} & \text { Mittelwert des E-Moduls der geklebten Bewehrung (gemäß } \\
& \text { Zulassung) } \\
A_{L} & \text { Querschnittsfläche der aufgeklebten CFK-Lamelle } \\
f_{L u d} & \text { Bemessung der Zugfestigkeit der Lamelle nach Gl. (2-13) }
\end{array}
$$

Da sich die Kraft über die Dehnung berechnet, ist bei der Lamelle zu beachten, dass der Querschnitt bereits einer Belastung ausgesetzt ist, wenn diese appliziert wird. Die Belastung zum Zeitpunkt der Verstärkung darf entweder realitätsnah mit den tatsächlichen Einwirkungen, oder auf vereinfachte Weise mit der quasi-ständigen Belastungskombination auf Gebrauchstauglichkeitsniveau ermittelt werden ([DAfStb 2012-03] Teil 1 Abs. 5.1.1 (RV19)). Daraus ergeben sich die Dehnungen zum Zeitpunkt der Verstärkung, die sich aufgrund der Hypothese von Bernoulli linear über den Querschnitt verteilen. Diese können anhand der linear-elastischen Schnittgrößenermittlung über das einwirkende Moment abgeleitet werden. Eine genaue Beschreibung der Vorgehensweise für die Berechnung folgt im Kapitel 3.2.1.3.

Mit den vorangegangenen Erläuterungen können die rechnerischen Dehnungszustände aus Abbildung 9, bei denen ein Versagen des Querschnitts unterstellt wird, um die Lamelle erweitert werden. Hierbei können theoretisch zwei unterschiedliche Fälle eintreten:

A Lamellenversagen - Lamellengrenzdehnung wird maßgebend

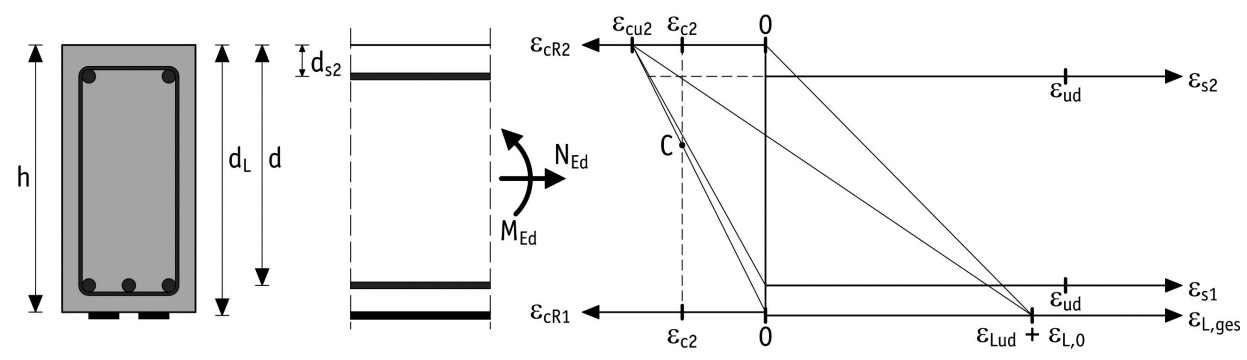

Abb. 16 zulässige Dehnungszustände am verstärkten Stahlbetonquerschnitt (A) (http://doi.org/10.33968/9783966270021-02-A-14) 
B Stahlversagen - Stahlgrenzdehnung wird maßgebend

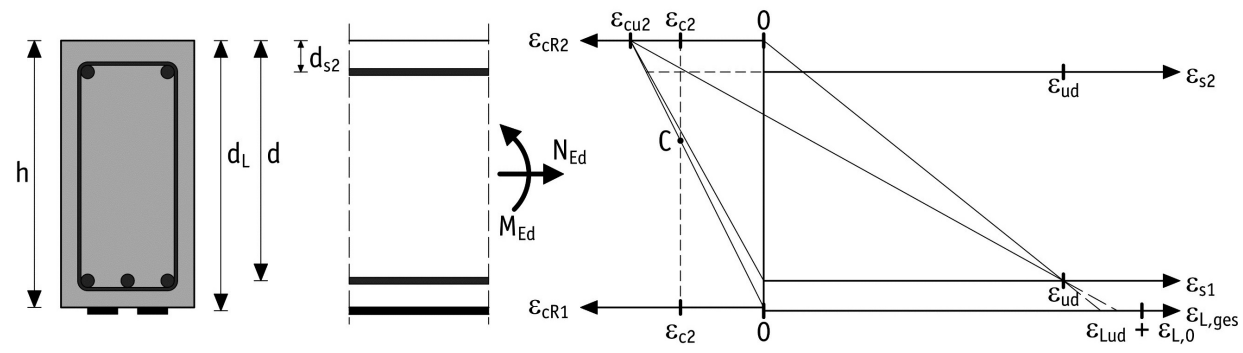

Abb. 17 zulässige Dehnungszustände am verstärkten Stahlbetonquerschnitt (B) (http://doi.org/10.33968/9783966270021-02-A-15)

Rechnerisch lassen sich diese beiden Fälle wie folgt unterscheiden:

\section{Fall A:}

$\varepsilon_{L, g e s} \cdot \frac{d-x}{d_{L}-x}<\varepsilon_{u d}$

\section{Fall B:}

$\varepsilon_{L, g e s} \cdot \frac{d-x}{d_{L}-x} \geq \varepsilon_{u d}$

Mit:

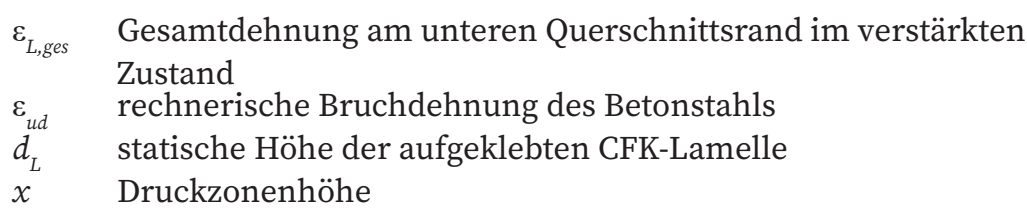

Der Fall B tritt nur in der Theorie auf, da die rechnerisch zulässigen Lamellengrenzdehnungen der aktuellen bauaufsichtlichen Zulassungen deutlich unter der Bemessungsgrenzdehnung des Betonstahls gemäß EC2 liegen (vgl. dazu [Z-36.12-84/85/86]).

Aufgrund der geringen Dicke der Lamellen, die maximal $3 \mathrm{~mm}$ zuzüglich Klebeschichtdicke betragen darf, kann vereinfachend angenommen werden, dass sich die Lamellendehnung auf einer Ebene mit der untersten Querschnittsfaser befindet ([DAfStb 2012-03] Teil 1 RV 3.7). Aus diesem Grund wird für die Dehnung der untersten Querschnittsfaser zum Zeitpunkt der Verstärkung die Bezeichnung $\varepsilon_{\mathrm{L}, 0}$ eingeführt ([DAfStb-Heft 595] S. 50 u. 89). Die Gesamtdehnung am unteren Quer- 
schnittsrand wird als $\varepsilon_{\mathrm{L}, \mathrm{ges}}$ bezeichnet. Diese setzt sich aus der Dehnung zum Zeitpunkt der Verstärkung und der reinen Lamellendehnung unter der neuen Bemessungseinwirkung zusammen ([DAfStb-Heft 595] S. 50). Somit gilt vereinfachend für die Bemessung der Biegetragfähigkeit im verstärkten Zustand:

$d_{L} \approx h$

Mit:

$d_{L} \quad$ statische Höhe der aufgeklebten CFK-Lamelle

h Querschnittshöhe

$\varepsilon_{L, 0} \approx \varepsilon_{C R 1,0}$

Mit:

$\varepsilon_{L, 0} \quad$ Dehnung am unteren Querschnittsrand zum Zeitpunkt der Verstärkung

$\varepsilon_{c r 1,0} \quad$ Betondehnung am unteren Querschnittsrand zum Zeitpunkt der Verstärkung

$\varepsilon_{L, g e s} \approx \varepsilon_{C R 1}$

Mit:

$\varepsilon_{L, g e s} \quad$ Gesamtdehnung am unteren Querschnittsrand im verstärkten

$\varepsilon_{c r 1} \quad$ Betondehnung am unteren Querschnittsrand

Damit ergibt sich die reine Dehnung der aufgeklebten CFK-Lamellen zur Ermittlung der Lamellenkraft gemäß Gl. (2-33).

$\varepsilon_{L}=\varepsilon_{L, g e s}-\varepsilon_{L, 0}$

Mit:

$\varepsilon_{L} \quad$ Dehnung der aufgeklebten Lamelle

$\varepsilon_{L, \text { ges }} \quad$ Gesamtdehnung am unteren Querschnittsrand im verstärkten

Zustand

$\varepsilon_{L, 0} \quad$ Dehnung am unteren Querschnittsrand zum Zeitpunkt der Verstärkung

Die Betondruckkraft sowie die Kräfte in der Betonstahlbewehrung werden weiterhin nach Kapitel 2.6 bestimmt. Aus den vorangegangenen Erläuterungen ergeben sich die Dehnungs- und Spannungsverteilungen am verstärkten Querschnitt (Abbildung 18). 


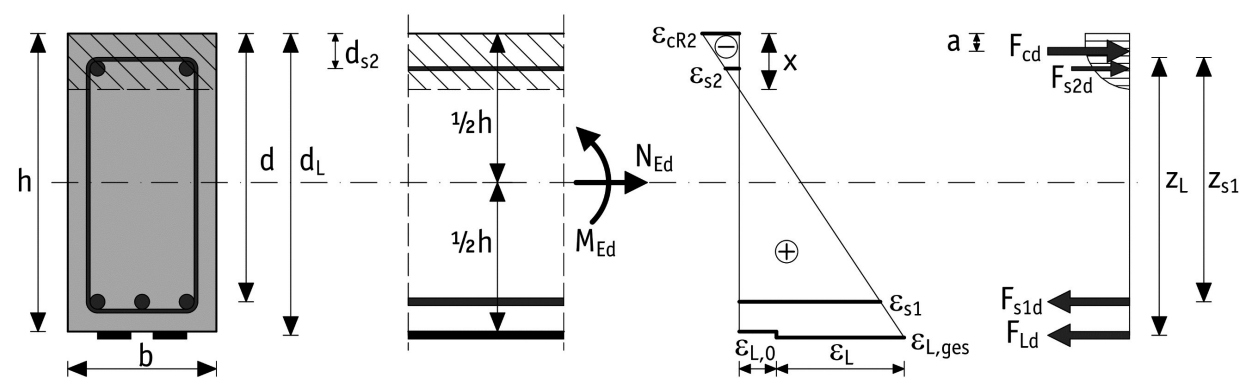

Abb. 18 Dehnungs- und Spannungsverteilung am verstärkten Querschnitt (http://doi.org/10.33968/9783966270021-02-A-16)

Analog zu reinen Stahlbetonquerschnitten kann anhand der Gleichgewichtsbedingungen die Bemessung erfolgen. Dazu werden die Formeln um den Anteil der Lamelle ergänzt, wie es bereits in verschiedenen Veröffentlichungen durchgeführt wurde (vgl. [FIB 2001] S. 35 / [Onken u. Vom Berg 2001] S. 65). Hier wird das Gleichgewicht der Momente um die Schwerachse der aufgeklebten CFK-Lamellen gebildet (vgl. dazu Abbildung 18).

$\Sigma N=0: \quad N_{E d}=N_{R d, V}$

$\Sigma M_{L}=0: \quad M_{E d, L}=M_{R d, L, V}$

Mit:

$\begin{array}{ll}N_{E d} & \text { Bemessungswert der einwirkenden Normalkraft } \\ N_{R d, V} & \text { Bemessungswiderstand der Normalkrafttragfähigkeit nach der } \\ M_{E d, L} & \begin{array}{l}\text { Verstärkung } \\ \text { einwirkendes Moment bezogen auf die Achse der } \\ \text { Lamellenzugkraft }\end{array} \\ M_{R d, L, V} & \begin{array}{l}\text { Bemessungswiderstand der Biegetragfähigkeit nach der } \\ \text { Verstärkung }\end{array}\end{array}$

Das einwirkende Moment muss in der Folge auf die Schwerachse der Lamellenzugkraft bezogen werden. Unter Berücksichtigung von Gleichung (2-30) ergibt sich Gleichung (-36).

$M_{E d, L}=M_{E d}-N_{E d} \cdot\left(d_{L}-\frac{h}{2}\right) \approx M_{E d}-N_{E d} \cdot \frac{h}{2}$

Mit:

$M_{E d} \quad$ Bemessungswert des einwirkenden Moments 
$d_{L} \quad$ statische Höhe der aufgeklebten CFK-Lamellen

h Querschnittshöhe

Anhand der Gleichgewichtsbedingungen können analog zum Stahlbetonquerschnitt die Querschnittswiderstände beschrieben werden.

$N_{R d, V}=F_{c d}+F_{s 2 d}-F_{s 1 d}-F_{L d}$

$M_{R d, L, V}=F_{c d} \cdot z_{L}-F_{s 1 d} \cdot(h-d)+F_{s 2 d} \cdot\left(h-d_{s 2}\right)$

Mit:

$\begin{array}{ll}F_{L d} & \text { Bemessungswert der Lamellenzugkraft } \\ F_{s 1 d} & \text { Bemessungswert der Stahlzugkraft } \\ F_{s 3 d} & \text { Bemessungswert der Stahldruckkraft } \\ F_{c d} & \text { Bemessungswert der Betondruckkraft } \\ N_{R d, V} & \text { Bemessungswiderstand der Normalkrafttragfähigkeit nach der } \\ M_{R d, L, V} & \text { Verstärkung } \\ z_{L} & \text { Bemessungswiderstand der Biegetragfähigkeit nach der } \\ h & \text { Verstärkung } \\ d & \text { Querschnittshöhe } \\ d_{s 2} & \text { statische Höhe der Biegezugbewehrung } \\ & \text { statische Höhe Druckbewehrung }\end{array}$

Mit dem vorhandenen Formelapparat lassen sich die Gleichgewichtsbedingungen durch Iteration der Betonstauchung auswerten ([Rostásy et al. 1996] S. 565). Sofern die Lamellenbruchdehnung bekannt ist, kann analog zum Stahlbeton vorgegangen werden. Der Vorgang ist in Abbildung 19 als Iterationsschema dargestellt. 


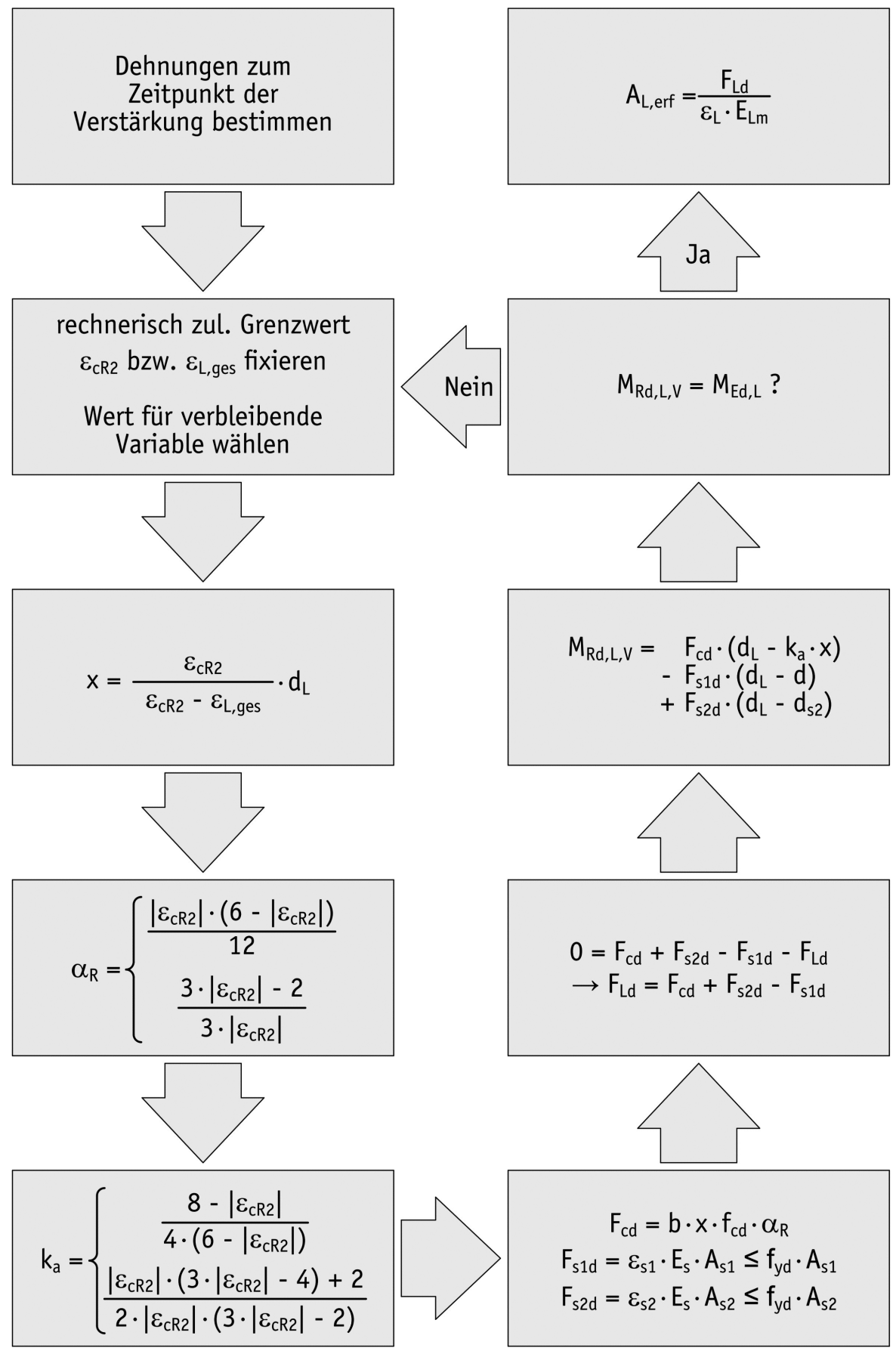

Abb. 19 Iterationsschema verstärkter Querschnitt (http://doi.org/10.33968/9783966270021-02-A-17) 


\subsubsection{Nachweis der Verbundkraftübertragung}

\subsubsection{Verbundversagen}

Beim Verbundversagen handelt es sich, wie im Kapitel 2.7.1 schon kurz beschrieben, um einen Bruch in der oberflächennahen Betonschicht. Dieses Versagen ist in Abbildung 20 schematisch dargestellt. In Bauteilversuchen wurde vom DAfStb festgestellt, dass ein mit aufgeklebten CFK-Lamellen verstärktes Bauteil signifikant mehr Zugkräfte aufnehmen kann, als es allein durch die Endverankerung möglich wäre. Daraus resultiert, dass die Kräfte über den Verbund in das Bauteil eingeleitet werden. Sofern die eingeleiteten Kräfte Spannungen erzeugen, die die Zugfestigkeit des Betons übersteigen, brechen die oberflächennahen Betonschichten aus. Nach lokaler Entkopplung tritt bei weiterer Laststeigerung ein „Reißverschlusseffekt" ([Zilch et al. 2013] S. 477) auf, da intakte Bereiche mit ebenfalls geringer Betonzugfestigkeit die zusätzlich wirkenden Kräfte nicht aufnehmen können. Beginnt das Bauteil an einer Stelle zu versagen, wird also infolge weiterer Lasterhöhung der gesamte Verbund versagen (vgl. [Zilch et al. 2013] S. 480).

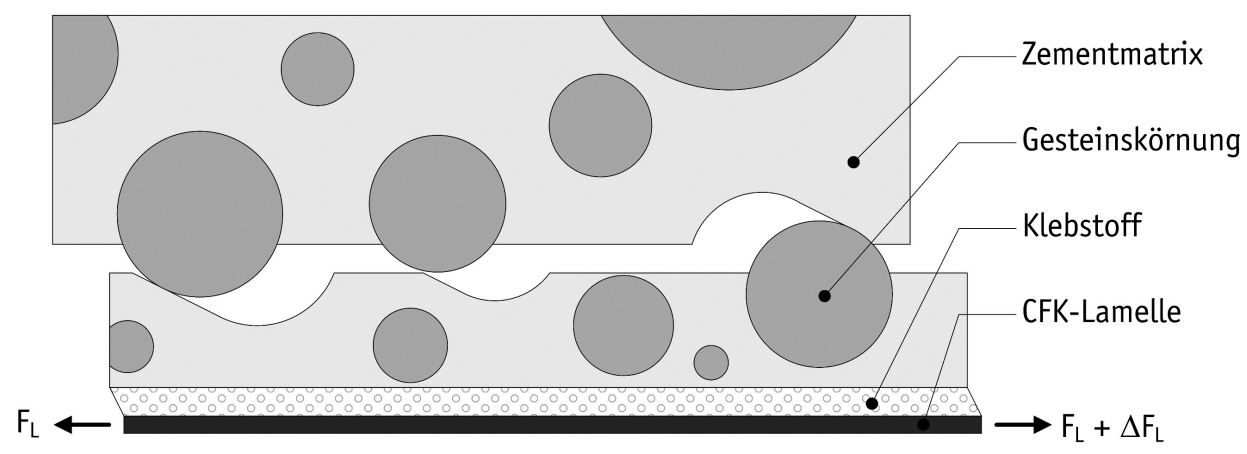

Abb. 20 Verbundversagen bei aufgeklebten CFK-Lamellen (Quelle: Eigene Darstellung in Anlehnung an [Ulaga 2003] Bild 4.2, S. 51)

(http://doi.org/10.33968/9783966270021-02-A-18)

Um sicherzustellen, dass kein Bruch in der Klebefuge entsteht, sind in der DAfStbRichtlinie entsprechende Anforderungen an die Verstärkungssysteme und den verwendeten Kleber enthalten. Diese Anforderungen sind notwendig, da das Bemessungsmodell ausschließlich darauf beruht, dass die oberflächennahen Betonschichten versagen ([DAfStb 2012-03] Teil 2 Abs. 3.2). 


\subsubsection{Verbundkraftübertragung am ZRE}

Aus dem vorab beschriebenen Verhalten geht hervor, dass ein reiner Endverankerungsnachweis äußerst unwirtschaftlich wäre, da weitere Kräfte über den Verbund aufgenommen werden können. Je nach Anforderung an die Genauigkeit der Bemessung bietet die Richtlinie aufgrund der komplexen Berechnung zwei Alternativen für den Nachweis des Verbundes ([Zilch et al. 2013] S. 478 ff.). Dabei geht der vereinfachte Nachweis der Lamellenkraftänderung am ZRE auf eine Vereinfachung des genaueren Nachweises zurück ([DAfStb-Heft 595] S. 19 f.). Die Verbundkräfte bzw. -spannungen werden bei den Nachweisen an Zwischenrisselementen in das Bauteil übertragen. Als ZRE werden die Abschnitte zwischen den Biegerissen des Bauteils bezeichnet. Aufgrund des Lamellenzugkraftverlaufs tritt an jedem ZRE ein höher und ein niedriger beanspruchtes Rissufer auf. Über den Verbund muss bei dem Nachweis, die daraus resultierende Differenz der Lamellenkraft am ZRE in das Bauteil übertragen werden. Dabei wird allmählich die Zugkraft der Lamelle bis zum letzten Biegeriss abgebaut (vgl. Abbildung 21). An diesem Biegeriss wird dann der Endverankerungsnachweis mit der verbleibenden Lamellenkraft geführt ([Zilch et al. 2013] S. 480).
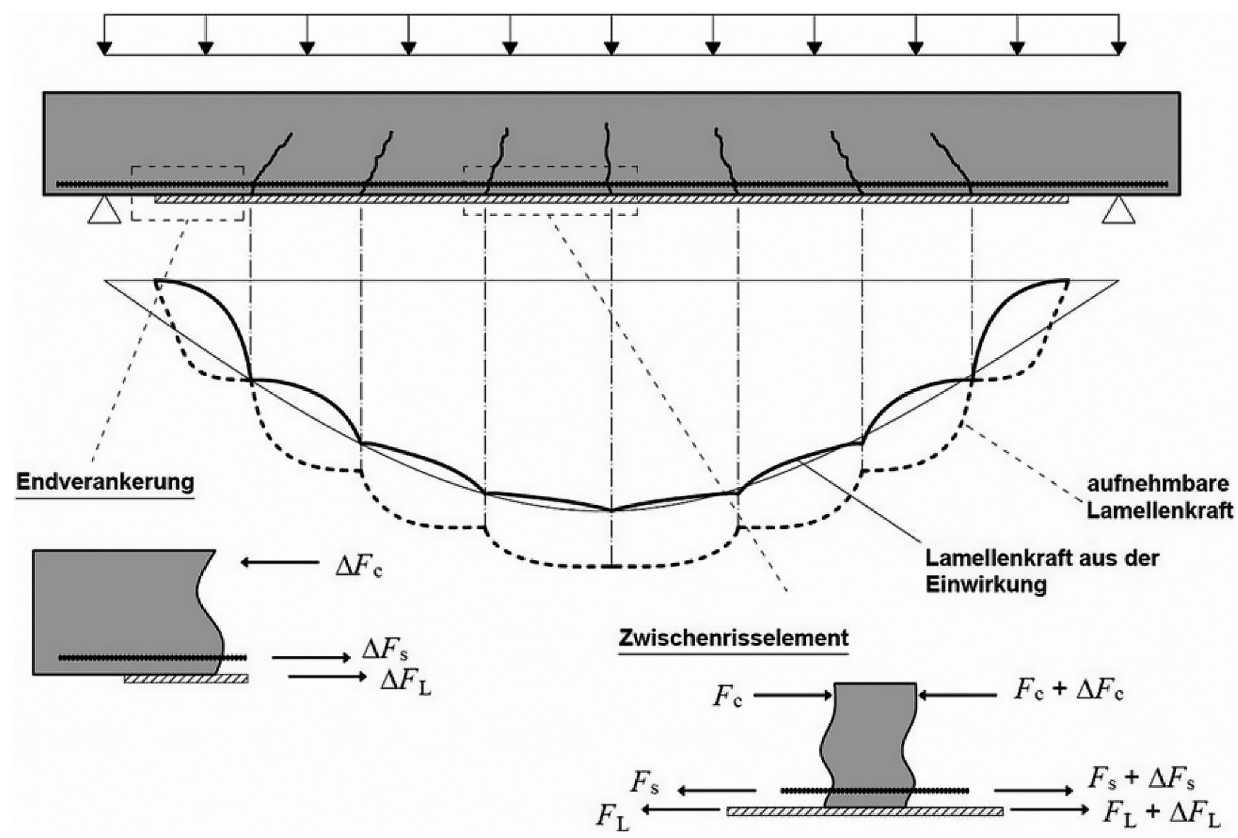

Abb. 21 Prinzip des Zugkraftverlaufs über Zwischenrisselemente (Quelle: [Finckh 2012] Bild 2.10, S. 20) (http://doi.org/10.33968/9783966270021-02-A-19) 
Zur Lösung des hieraus entstehenden mathematischen Problems verwendet der DAfStb im Heft 592 die Differentialgleichung (DGL) des verschieblichen Verbundes (Gleichung (2-39)).

$s_{L}^{\prime \prime}-\frac{1}{E_{L} \cdot t_{L}} \cdot \tau\left(s_{L}\right)=0$

Mit:
$S_{L} \quad$ Lamellenschlupf
$E_{L} \quad$ Elastizitätsmodul der aufgeklebten CFK-Lamelle
$t_{L} \quad$ Lamellendicke
$\tau\left(s_{L}\right) \quad$ Verbundspannung in Abhängigkeit des Lamellenschlupfes

Mit den Randbedingungen des ZRE wird die DGL mit der Verbundspannungsschlupfbeziehung gelöst, die über idealisierte Endverankerungsversuche ermittelt wird (vgl. [DAfStb-Heft 592] S. 13 ff.). Anhand der Endverankerungsversuche konnte festgestellt werden, dass sich die Verbundspannungsschlupfbeziehung annähernd bilinear verhält (vgl. Abbildung 22).

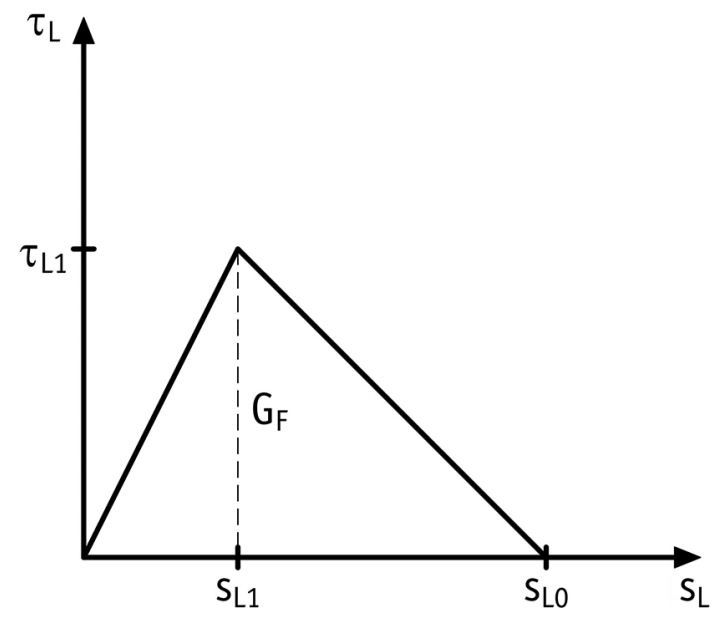

Abb. 22 bilineare Verbundspannungsschlupfbeziehung (Quelle: [DAfStb-Heft 592] Bild 2.2, S. 13) (http://doi.org/10.33968/9783966270021-02-A-20)

Der DAfStb gibt eine Lösung an, die sich in zwei Bereiche aufteilt. Im Bereich 1 hat der Rissabstand bei geringen Lamellenspannungen einen ausschlaggebenden Einfluss. Dagegen entfällt dieser Einfluss im Bereich 2, da die effektive Verbundlänge kleiner als der Rissabstand ist ([DAfStb-Heft 592] S. 18 f.). Die aufnehmbare Spannungsdifferenz am ZRE ist dabei immer von der Grundlamellenspannung abhängig. Außerdem darf die Bemessungszugfestigkeit der Lamelle nicht überschritten 
werden. Dieses Verhalten ist in Abbildung 23 grafisch dargestellt, wobei der Punkt D den Übergang von Bereich 1 zu Bereich 2 kennzeichnet.

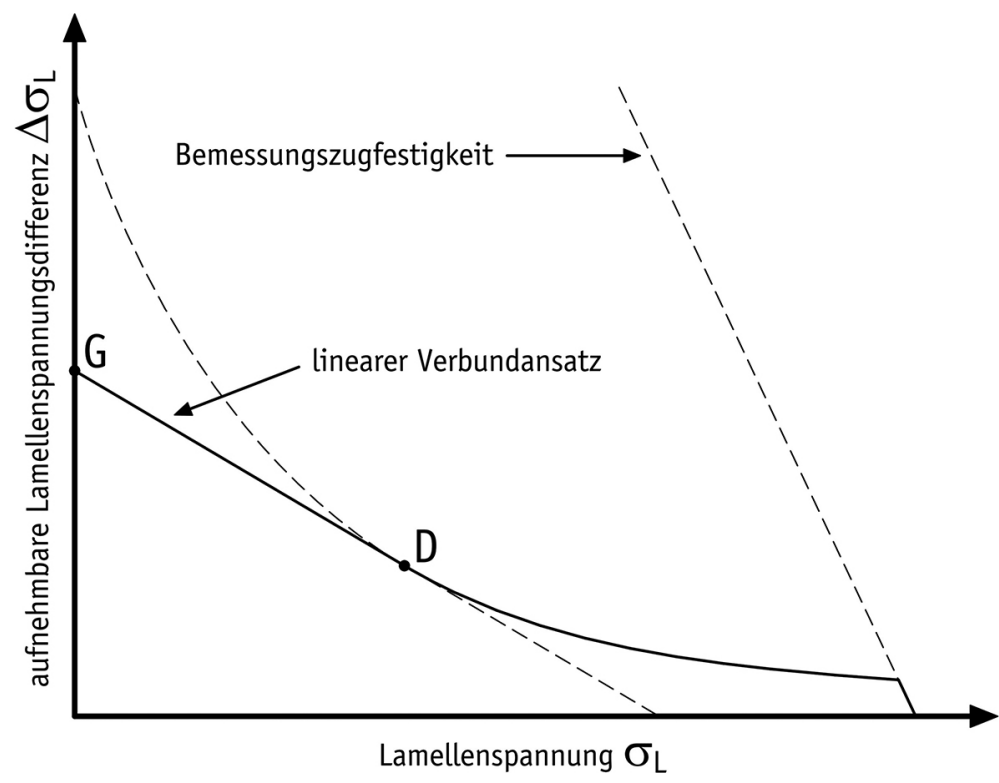

Abb. 23 durch Verbund aufnehmbarer Spannungszuwachs am Zwischenrisselement (Quelle: Eigene Darstellung in Anlehnung an [DAfStb-Heft 592] Bild 2.4, S. 18) (http://doi.org/10.33968/9783966270021-02-A-21)

Die Lösung des DAfStb ergibt dabei die folgenden Gleichungen für die aufnehmbare Lamellenspannungsdifferenz am ZRE des jeweiligen Bereichs ([DAfStb-Heft 592] S. $18 \mathrm{f}$.).

\section{Bereich 1:}

aufn. $\Delta \sigma_{L}=$ aufn. $\Delta \sigma_{L}^{G}-\frac{a u f n \cdot \Delta \sigma_{L}^{G}-a u f n \cdot \Delta \sigma_{L}^{D}}{\sigma_{L}^{D}} \cdot \sigma_{L}$

Mit:

aufn. $\Delta \sigma_{L} \quad$ aufnehmbare Lamellenspannungsänderung am ZRE aufn. $\Delta \sigma_{L}^{G} \quad$ aufnehmbare Lamellenspannungsänderung am Punkt G aufn. $\Delta \sigma_{L}^{D} \quad$ aufnehmbare Lamellenspannungsänderung am Punkt D $\sigma_{L}^{D}$ Lamellenspannung am geringer beanspruchten Rissufer am Punkt D

$\sigma_{L} \quad$ einwirkende Lamellenspannung 
Dabei ergibt sich aus den Ausführungen des DAfStb im Heft 592 die aufnehmbare Lamellenspannungsänderung am Punkt G gemäß Gleichung (2-41), wobei diese von der maximal aufnehmbaren Lamellenspannung nach Gleichung (2-42) abhängt.

aufn. $\Delta \sigma_{L}^{G}=\left\{\begin{array}{cl}\text { aufn. } \sigma_{L, \max } \cdot \frac{s_{r}}{l_{b L, \max }} \cdot\left(2-\frac{s_{r}}{l_{b L, \max }}\right) & \text { für } s_{r}<l_{b L, \max } \\ \text { aufn. } \sigma_{L, \max } & \text { für } s_{r} \geq l_{b L, \text { max }}\end{array}\right.$

Mit:

aufn. $\Delta \sigma_{L}^{G} \quad$ aufnehmbare Lamellenspannungsänderung am Punkt G

aufn. $\sigma_{L, \max }$ maximal aufnehmbare Lamellenspannung

$s_{r} \quad$ Rissabstand

$l_{b L, \max }^{r} \quad$ maximale effektive Verbundlänge

aufn. $\sigma_{L, \max }=\sqrt{\frac{E_{L} \cdot \tau_{L 1 k} \cdot s_{L 0 k}}{t_{L}}}$

Mit:

$E_{L} \quad$ Elastizitätsmodul der Lamelle

$\tau_{\text {L1k }} \quad$ maximale Verbundspannung des bilinearen Ansatzes

$s_{L O k} \quad$ maximaler Schlupf nach dem bilinearen Verbundansatz

$t_{L} \quad$ Lamellendicke

Die effektive Verbundlänge ergibt sich über die Verbundspannungsschlupfbeziehung. Sobald diese Länge überschritten wird, können keine weiteren Spannungen durch den Verbund aufgenommen werden. Vom DAfStb wurde zur Anpassung der ermittelten Formel an deren Versuchsergebnisse ein empirischer Faktor eingeführt.

$l_{b L, \max }=\frac{2}{k} \cdot \sqrt{\frac{E_{L} \cdot t_{L} \cdot s_{L 0 k}}{\tau_{L 1 k}}}$

Mit:

$k=1,128 \quad$ empirischer Faktor (eingeführt von Niedermeier)

\section{Bereich 2:}

Der Punkt D markiert den Übergang zwischen den Bereichen, ab dem der Rissabstand keinen Einfluss mehr auf die aufnehmbare Lamellenkraftdifferenz an einem 
ZRE hat. Zur Ermittlung der Spannung an diesem Punkt wird Gleichung (2-44) angegeben. Für die Berechnung der aufnehmbaren Lamellenspannungsänderung am Punkt D verwendet der DAfStb die Gleichung (2-45) (vgl. [DAfStb-Heft 592] S. 18 f.).

$\sigma_{L}^{D}=\frac{s_{L 0 k} \cdot E_{L}}{s_{r}}-\tau_{L 1 k} \cdot \frac{s_{r}}{4 \cdot t_{L}}$

Mit:

$S_{L O k} \quad$ maximaler Schlupf nach dem bilinearen Verbundansatz

$E_{L} \quad$ Elastizitätsmodul der Lamelle

$s_{r} \quad$ Rissabstand

$\tau_{\text {L1k }} \quad$ maximale Verbundspannung des bilinearen Ansatzes

$t_{L} \quad$ Lamellendicke

aufn. $\Delta \sigma_{L}=\sqrt{\frac{2 \cdot G_{F} \cdot E_{L}}{t_{L}}+\sigma_{L}^{2}}-\sigma_{L}$

Mit:

aufn. $\sigma_{L} \quad$ aufnehmbare Lamellenspannungsänderung am ZRE

$G_{F} \quad$ Verbundbruchenergie nach Gleichung (2-46)

$\sigma_{L} \quad$ einwirkende Lamellenspannung

$G_{F}=\frac{S_{L 0 k} \cdot \tau_{L 1 k}}{2}$

Durch Auswertung zahlreicher Versuche hat der DAfStb festgestellt, dass sich die Verbundkraftübertragung mit diesen Gleichungen nur unzureichend genau modellieren lässt. Aus den Versuchsbetrachtungen wird abgeleitet, dass weitere Verbundspannungen infolge von Reibung aufgenommen werden können. Um die Bemessung wirtschaftlich zu gestalten, wird diese Erkenntnis in den bilinearen Verbundansatz überführt (Abbildung 24) und damit die DGL des verschieblichen Verbundes gelöst (vgl. [DAfStb-Heft 592] S. 67 f.). Dadurch kann der zusätzlich aufnehmbare Anteil der Verbundspannungen aufgrund von Reibung beschrieben werden. Diese Lösung ist in bilinearer Verbundansatz erweitert um Reibung am ZRE (Quelle: [DAfStb-Heft 592] Bild 4.10, S. 67) wiedergegeben. 


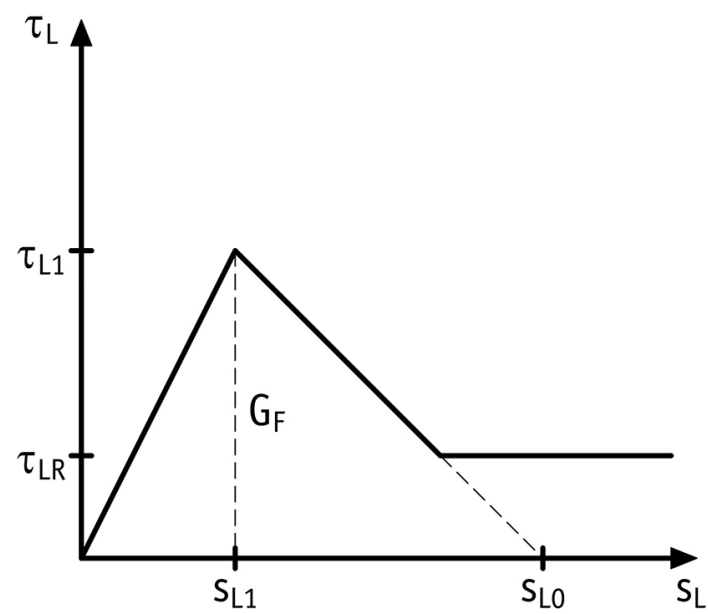

Abb. 24 bilinearer Verbundansatz erweitert um Reibung am ZRE (Quelle: [DAfStb-Heft 592] Bild 4.10, S. 67) (http://doi.org/10.33968/9783966270021-02-A-22)

aufn. $\Delta \sigma_{L, R, Z R E}=\frac{\tau_{L R} \cdot\left(s_{r}-\frac{2 \cdot t_{L} \cdot E_{L}}{\tau_{L 1 k}} \cdot\left(\sqrt{\frac{\tau_{L 1 k} \cdot s_{L 0 k}}{t_{L} \cdot E_{L}}+\frac{\sigma_{L}{ }^{2}}{E_{L}{ }^{2}}-\frac{\sigma_{L}}{E_{L}}}\right)\right)}{t_{L}}$

Mit:

$\begin{array}{ll}\text { aufn. } \Delta \sigma_{L, R, Z R E} & \text { aufnehmbare Lamellenspannungsänderung am ZRE aus } \\ \tau_{L R} & \text { Reibung } \\ s_{r} & \text { Reibverbundspannung } \\ t_{L} & \text { Rissabstand } \\ E_{L} & \text { Lamellendicke } \\ \tau_{L 1 k} & \text { Elastizitätsmodul der aufgeklebten CFK-Lamelle } \\ s_{L 0 k} & \text { maximale Verbundspannung des bilinearen Ansatzes } \\ \sigma_{L} & \text { maximaler Schlupf nach dem bilinearen Verbundansatz } \\ & \text { einwirkende Lamellenspannung }\end{array}$

Weiterhin erfolgt im DAfStb-Heft 592 eine Berücksichtigung der Krümmung des Bauteils, wie von Finckh [Finckh 2012] beschrieben wurde. Wirkt auf die aufgeklebte Bewehrung eine Zugkraft, strebt diese einen ebenen Zustand an. Dabei entsteht ein selbstinduzierter Anpressdruck, der es ermöglicht weitere Verbundspannungen bei entsprechender Krümmung aufzunehmen. Daraus folgt eine weitere Anpassung des bilinearen Verbundansatzes ([DAfStb-Heft 592] S. 79 f.). Die endgültig resultierende Verbundspannungsschlupfbeziehung ist in Abbildung 25 dargestellt. 


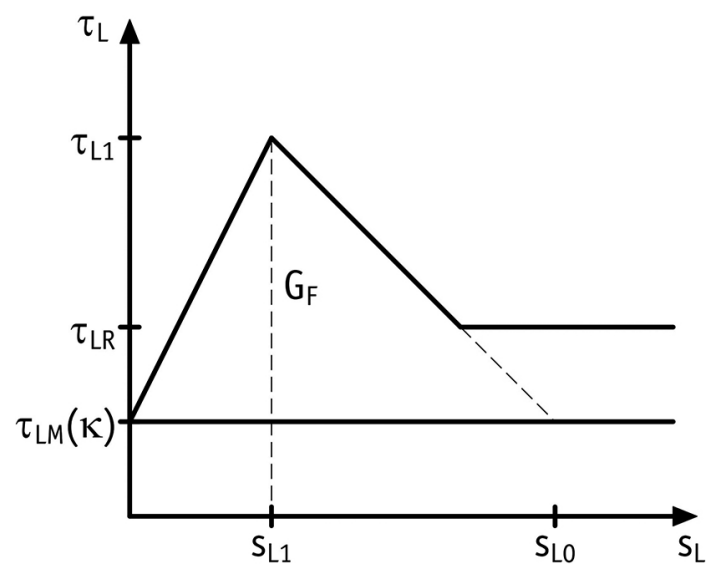

Abb. 25 bilinearer Verbundansatz erweitert um Reibung und Krümmung am ZRE (Quelle: [DAfStb-Heft 592] Bild 4.25, S. 80) (http://doi.org/10.33968/9783966270021-02-A-23)

Auch hierfür wird vom DAfStb im Heft 592 eine Formulierung vorgeschlagen, die auf Versuchen und theoretischen Betrachtungen basiert. Je nachdem, ob eine positive (konvexe) oder negative (konkave) Krümmung vorliegt, können weitere Verbundspannungen aufgenommen werden oder müssen von den bisher theoretisch aufnehmbaren Spannungsdifferenzen abgezogen werden ([DAfStb-Heft 592] S. 76 ff.), um den Versuchsergebnissen näher zu kommen. Die aufnehmbare Lamellenspannungsdifferenz aufgrund von Krümmungseffekten wird mit Gleichung (2-48) beschrieben.

aufn. $\Delta \sigma_{L}(\kappa)=\frac{s_{r} \cdot \tau_{L m}(\kappa) \cdot \kappa}{t_{L}}$

Mit:

aufn. $\Delta \sigma_{L}(\kappa) \quad$ aufnehmbare Lamellenspannungsänderung am ZRE aus

$\begin{array}{ll}s_{r} & \text { Krümmung } \\ \tau_{L m}(\kappa) & \text { Rissabstand } \\ \kappa & \text { mittlere Verbundspannung in Abhängigkeit der Krümmung } \\ t_{L} & \text { Krümmung }\end{array}$

Aus den beschriebenen Verbundansätzen wird vom DAfStb die Gleichung (2-49) für die letztlich resultierende aufnehmbare Lamellenspannungsänderung am ZRE formuliert ([DAfStb-Heft 592] S. 100). Die Gleichung setzt sich aus den vorab beschriebenen drei Anteilen der Verbundspannungsschlupfbeziehung zusammen:

- Grundwert des bilinearen Verbundansatzes aus Endverankerungsversuchen 
- Anteil der Reibverbundspannung

- Anteil aus Bauteilkrümmung

aufn. $\Delta \sigma_{L}=$ aufn. $\Delta \sigma_{L, \text { bilinear }}+$ aufn. $\Delta \sigma_{L, R, Z R E} \pm$ aufn. $\Delta \sigma_{L}(\kappa)$

Mit:
aufn. $\Delta \sigma_{L}$
aufnehmbare Lamellenspannungsänderung am ZRE
aufn. $\Delta \sigma_{L, \text { bilinear }}$
Grundwert der aufnehmbaren
aufn. $\Delta \sigma_{L, R, Z R E}$
Lamellenspannungsänderung am ZRE
aufn. $\Delta \sigma_{L}(\kappa)$
aufnehmbare Lamellenspannungsänderung am ZRE aus
Reibung
aufnehmbare Lamellenspannungsänderung am ZRE aus
Krümmung

Für die Nachweisführung in der Richtlinie sind die aufnehmbaren Spannungsdifferenzen vom DAfStb in Kraftdifferenzen umgeformt worden. Damit ergibt sich die durch Verbund aufnehmbare Lamellenkraftänderung am ZRE gemäß Gleichung (2-50). Der Teilsicherheitsbeiwert für den Verbund wurde ergänzt, um ein der aktuellen Normung entsprechendes Sicherheitsniveau zu erreichen. In der Richtlinie und im DAfStb-Heft 592 unterscheiden sich die Bezeichnungen und Indizes der Formelzeichen. Ab dieser Stelle werden die Formulierungen der Richtlinie übernommen, da diese als technisches Regelwerk gilt und als Grundlage für die weitere Bemessung dient.

$\Delta F_{L R d}=\frac{\Delta F_{L k, B L}+\Delta F_{L k, B F}+\Delta F_{L k, K F}}{\gamma_{B A}}$

Mit:
$\triangle F_{L R d}$
$\Delta F_{L k, B L}$
Bemessungswert des Widerstandes der Lamellenkraftänderung
$\Delta F_{L k, B F}$
$\Delta F_{L k, K F}$
Grundwert des Verbundkraftwiderstandes am ZRE
$\gamma_{B A}$
Verbundkraftwiderstand am ZRE aufgrund der Reibung
Verbundkraftwiderstand am ZRE aufgrund der Krümmung
Teilsicherheitsbeiwert für den Verbund bei aufgeklebten CFK-
Lamellen 


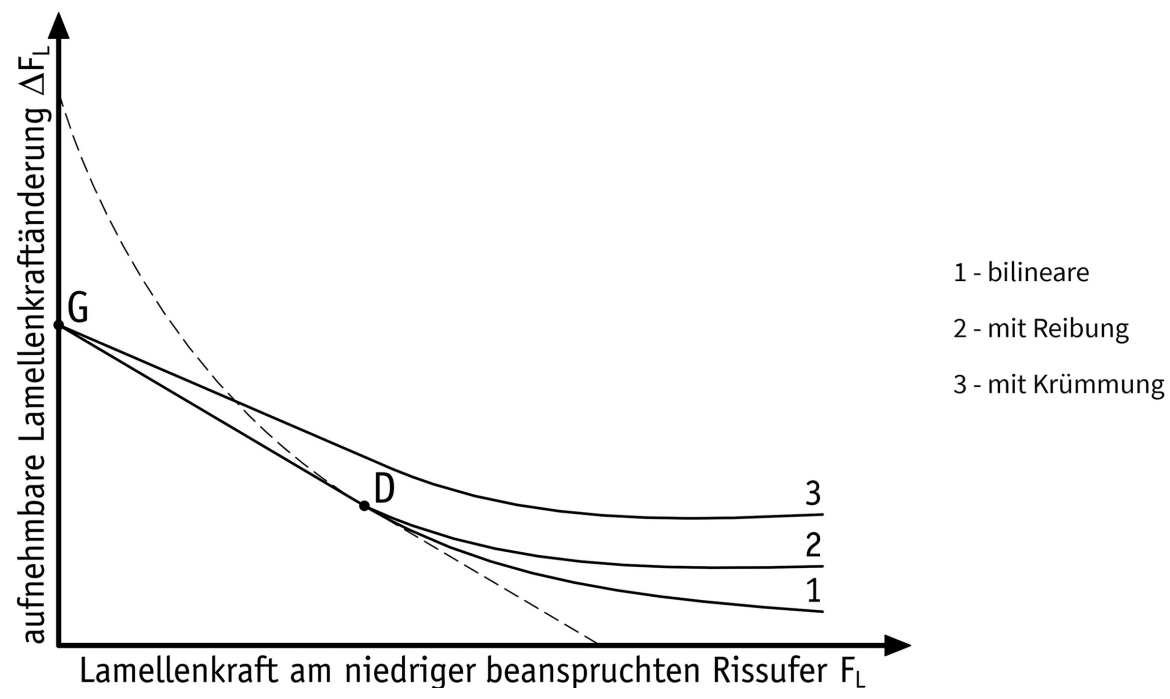

Abb. 26 aufnehmbare Lamellenkraftänderung am ZRE (Quelle: Eigene Darstellung in Anlehnung an [Zilch et al. 2013] Bild 8, S. 483)

(http://doi.org/10.33968/9783966270021-02-A-24)

Aus den Gleichungen (2-40) bis (2-46) folgt durch die Umformung von Spannungen in Kräfte die Ermittlung des Grundwertes des Verbundkraftwiderstandes am ZRE gemäß den Gleichungen (2-51) bis (2-56) (vgl. dazu [DAfStb 2012-03] RV 6.1.1.3.6). Daraus folgt für die aufnehmbare Lamellenkraftdifferenz ebenfalls eine Fallunterscheidung in Abhängigkeit der einwirkenden Lamellenkraft. Dabei wird der Einfluss des Rissabstandes nur berücksichtigt, sofern dieser kleiner als die effektive Verbundlänge ist ([DAfStb-Heft 595 S. 21). Ansonsten hat der Rissabstand keinen Einfluss auf die aufnehmbare Lamellenkraftdifferenz am ZRE mehr. Der Übergang zwischen den beiden Bereichen erfolgt, analog zu den Spannungen, am Punkt D. Für die Lamellenkräfte ist die Abhängigkeit der aufnehmbaren Lamellenkraftdifferenz von der einwirkenden Lamellenkraft am geringer beanspruchten Rissufer des ZRE in Abbildung 26 dargestellt, in der die Punkte D und G nochmals verdeutlicht werden.

$$
\Delta F_{L k, B L}=\left\{\begin{array}{cl}
\Delta F_{L k, B L}^{G}-\frac{\Delta F_{L k, B L}^{G}-\Delta F_{L k, B L}^{D} \cdot F_{L E d}}{F_{L k, B L}^{D}} & \text { für } F_{L E d} \leq F_{L k, B L}^{D} \\
\sqrt{b_{L}{ }^{2} \cdot \tau_{L 1 k} \cdot s_{L 0 k} \cdot E_{L m} \cdot t_{L}+F_{L E d}^{2}}-F_{L E d} & \text { für } F_{L k, B L}^{D}<F_{L E d} \leq F_{L u d}
\end{array}\right.
$$


Mit:

$\Delta F_{L k, B L}^{G} \quad$ aufnehmbare Lamellenkraftdifferenz am Punkt G

$\Delta F_{L k, B L}^{D} \quad$ aufnehmbare Lamellenkraftdifferenz am Punkt D

$F_{L k, B L}^{D} \quad$ Lamellenkraftdifferenz am geringer beanspruchten Rissufer am Punkt D

$F_{\text {Lud }} \quad$ Bemessungswert der Lamellenbruchkraft

$F_{L E d} \quad$ Bemessungswert der einwirkenden Lamellenkraft am geringer beanspruchten Rissufer des ZRE

$\Delta F_{L k, B L}^{G}=f_{b L k}\left(s_{r}\right) \cdot b_{L} \cdot t_{L}$

Mit:

$f_{b L k}\left(s_{r}\right) \quad$ charakteristische Verbundfestigkeit der Verstärkung

$b_{L} \quad$ Lamellenbreite

$t_{L} \quad$ Lamellendicke

$f_{b L k}\left(s_{r}\right)=\left\{\begin{array}{cl}f_{b L k, \text { max }} \cdot \frac{s_{r}}{l_{b L, \text { max }}} \cdot\left(2-\frac{s_{r}}{l_{b L, \text { max }}}\right) & \text { für } s_{r}<l_{b L, \text { max }} \\ f_{b L k, \text { max }} & \text { für } s_{r} \geq l_{b L, \text { max }}\end{array}\right.$

Mit:

$f_{b L k, \max } \quad$ maximale charakteristische Verbundfestigkeit der Verstärkung am Endverankerungspunkt

$s_{r} \quad$ Rissabstand

$l_{b L \text {, } \operatorname{rax}}^{r} \quad$ effektive Verbundlänge nach Gl. (2-43)

$f_{b L k, \text { max }}=\sqrt{\frac{E_{L m} \cdot s_{L 0 k} \cdot \tau_{L 1 k}}{t_{L}}}$

Mit:

$E_{L m} \quad$ Mittelwert des E-Moduls der aufgeklebten CFK-Lamelle

$S_{\text {Lok }} \quad$ maximaler Schlupf nach dem linearen Verbundansatz

$\tau_{\text {L1k }} \quad$ maximale Verbundspannung des bilinearen Ansatzes

$F_{L k, B L}^{D}=\frac{E_{L m} \cdot s_{L 0 k} \cdot b_{L} \cdot t_{L}}{s_{r}}-\tau_{L 1 k} \cdot \frac{s_{r} \cdot b_{L}}{4}$

$\Delta F_{L k, B L}^{D}=\sqrt{b_{L}^{2} \cdot \tau_{L 1 k} \cdot s_{L 0 k} \cdot E_{L m} \cdot t_{L}+F_{L k, B L}^{D}{ }^{2}}-F_{L k, B L}^{D}$ 
$\Delta F_{L k, B L}^{D}=\sqrt{b_{L}{ }^{2} \cdot \tau_{L 1 k} \cdot s_{L 0 k} \cdot E_{L m} \cdot t_{L}+F_{L k, B L}^{D}{ }^{2}}-F_{L k, B L}^{D}$

Analog zum Grundwert des Verbundkraftwiderstands wird der aufnehmbare Anteil der Lamellenkraftdifferenz aus Reibungseffekten in der Richtlinie direkt aus dem DAfStb-Heft 592 übernommen. Die Formulierung wird dahingehend ergänzt, dass keine Reibungseffekte auftreten bevor die einwirkende Lamellenkraft den Wert am Punkt D übersteigt (vgl. [DAfStb 2012-03] RV 6.1.1.3.6).

Für $F_{L E d} \leq F_{L k, B L}^{D}$ gilt:

$\Delta F_{L k, B F}=0$

Für $F_{L k, B L}^{D}<F_{L E d} \leq F_{L u d}$ gilt: gilt:

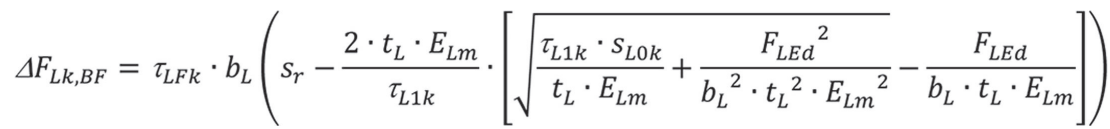

Mit:

$\begin{array}{ll}\Delta F_{L k, B F} & \text { Verbundkraftwiderstand am ZRE aufgrund Reibung } \\ \tau_{L F k} & \text { Reibverbundspannung }\end{array}$

Im Anhang RV K der DAfStb-Richtlinie sind empfohlene Verbundbeiwerte für die Gleichungen (2-51) bis (2-58) enthalten. Diese basieren auf den Systemen zur Bauteilverstärkung mit aufgeklebten CFK-Lamellen, welche zum Zeitpunkt der Erarbeitung der Richtlinie bauaufsichtlich zugelassen waren. Im Anwendungsfall ist jedoch unbedingt darauf zu achten, ob die jeweiligen bauaufsichtlichen Zulassungen der unterschiedlichen Hersteller abweichende Systembeiwerte enthalten ([Zilch et al. 2013] S. 481 f.). Die empfohlenen Verbundbeiwerte aus dem Anhang zur Richtlinie sind in den Gleichungen (2-59) bis (2-61) angegeben. Aktuell existieren keine nationalen allgemeinen bauaufsichtlichen Zulassungen die abweichende Verbundwerte für die Nachweisführung angeben (vgl. [Z-36.12-84/85/86 Abs. 3.1).

$\tau_{L 1 k}=0,366 \cdot \sqrt{\alpha_{c c} \cdot f_{c m} \cdot \alpha_{c t} \cdot f_{c t m, s u r f}}$

Mit:

$\tau_{L 1 k} \quad$ maximale Verbundspannung des bilinearen Ansatzes

$\alpha_{c c} \quad$ Beiwert zur Berücksichtigung von Langzeitauswirkungen auf die Betondruckfestigkeit (i. A. $\alpha_{c c}=0,85$ [EC2-1-1 NA 2013-04] NDP zu 3.1.6) 
$\alpha_{c t} \quad$ Beiwert zur Berücksichtigung von Langzeitauswirkungen auf die Betonzugfestigkeit (i. A. $\alpha_{c t}=0,85$ [EC2-1-1 NA 2013-04] NDP zu 3.1.6) $f_{c m} \quad$ Mittelwert der Zylinderdruckfestigkeit

$f_{c t m, \text { surf }} \quad$ Mittelwert der Oberflächenzugfestigkeit

$s_{L 0 k}=0,201 \mathrm{~mm}$

Mit:

$S_{\text {Lok }} \quad$ maximaler Schlupf nach dem bilinearen Ansatz

$\tau_{L F k}=10,8 \cdot \alpha_{c c} \cdot f_{c m}^{-0,89}$

Mit:

$\tau_{L F k} \quad$ Reibverbundspannung

Wie in den Gleichungen (2-59) und (2-61) zu erkennen, gehen die Verbundbeiwerte aus Bauteilkenngrößen hervor, die daher mit ausreichender Genauigkeit vor Ort zu bestimmen sind. Dazu zählen die Oberflächenzugfestigkeit und die mittlere Zylinderdruckfestigkeit des Betons ([Zilch et al. 2013] S. 482). Für die Oberflächenzugfestigkeit wird eine entsprechend sichere statistische Auswertung gefordert. Diese ist im Anhang A zum Teil 4 der DAfStb-Richtlinie vorgegeben [DAfStb 2012-03]. Außerdem gilt die Richtlinie nur für Oberflächenzugfestigkeiten von maximal 4,0 N/mm² ([DAfStb 2012-03] Teil 1 RV 3.6). Weiterhin soll der Wert 1,0 N/mm² nicht unterschreiten ([DAfStb 2012-03] Teil 3 Abs. 4.4.1).

Als dritter Anteil geht die Krümmung in die Bemessung ein. Der Ansatz aus dem DAfStb-Heft 592 wurde in der Richtlinie leicht vereinfacht (vgl. dazu [DAfStbHeft 595] S. 21). Damit ergibt sich der Anteil der aufnehmbaren Lamellenkraftdifferenz aus Krümmungseffekten nach Gleichung (2-62).

$$
\begin{aligned}
& \Delta F_{L k, K F}=s_{r} \cdot \kappa_{k} \cdot \frac{\varepsilon_{L r 1}-\varepsilon_{c r 1}}{h} \cdot b_{L} \\
& \kappa_{k}=24,3 \cdot 10^{3} \mathrm{~N} / \mathrm{mm}
\end{aligned}
$$

Mit:

$$
\begin{array}{ll}
\Delta F_{L k, K F} & \text { Verbundkraftwiderstand am ZRE aufgrund Krümmung } \\
s_{r} & \text { Rissabstand } \\
\kappa_{k} & \text { Krümmungsbeiwert } \\
\varepsilon_{L r 1} & \text { Lamellendehnung am niedriger beanspruchten Rissufer } \\
\varepsilon_{c r 1} & \text { Betondehnung am niedriger beanspruchten Rissufer }
\end{array}
$$




$\begin{array}{ll}h & \text { Querschnittshöhe } \\ b_{L} & \text { Lamellenbreite }\end{array}$

\subsubsection{Ermittlung des Rissabstandes}

Als nächstes soll die Ermittlung der Rissabstände beschrieben werden, da die Risse das Bauteil in die Zwischenrisselemente unterteilen an denen die Nachweise zur Vermeidung des Verbundversagens geführt werden (s. Abbildung 27).
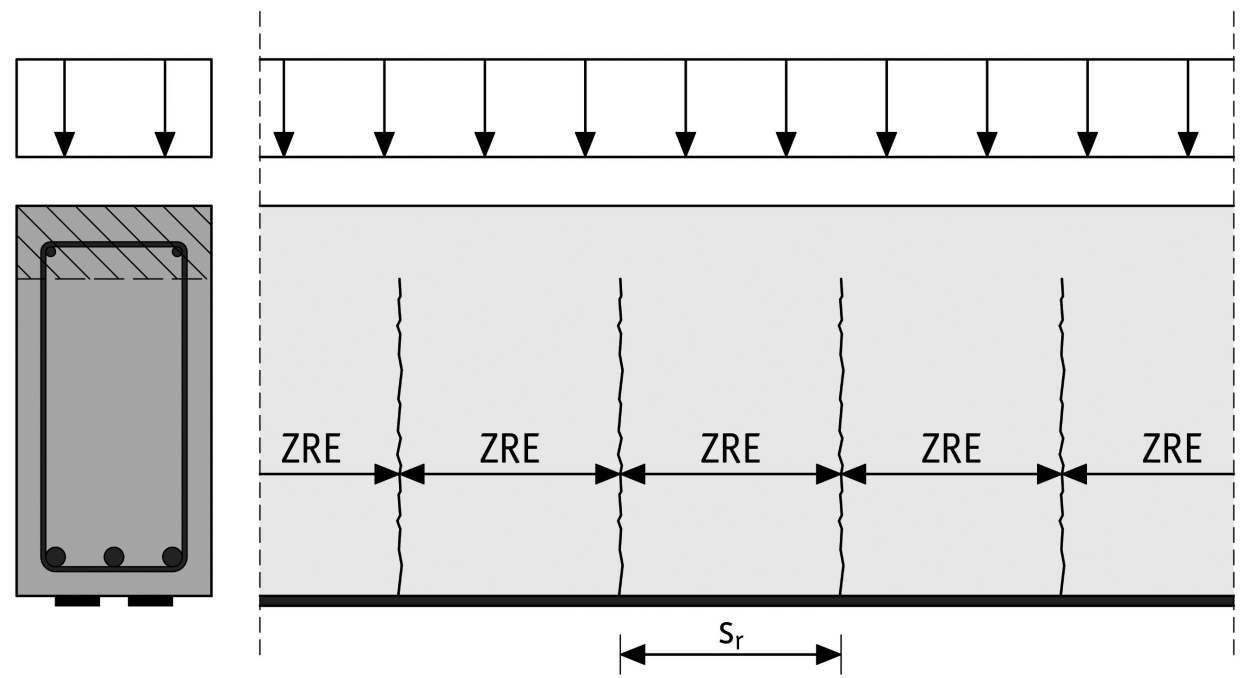

Abb. 27 Rissabstand und Zwischenrisselemente (http://doi.org/10.33968/9783966270021-02-A-25)

Aufgrund der Vielzahl von Parametern, die einen Einfluss auf den Rissabstand ausüben und weil dieser außerdem einer erheblichen Streuung unterliegt, ist in der DAfStb-Richtlinie eine auf der sicheren Seite liegende Abschätzung als Formulierung gewählt worden ([DAfStb-Heft 595] S. 17). Anhand der Eintragungslänge des Betonstahls ergibt sich der Rissabstand wie folgt:

$s_{r}=1,5 \cdot l_{e, 0}$

Mit:

$$
\begin{array}{ll}
s_{r} & \text { Rissabstand } \\
l_{e, 0} & \text { Eintragungslänge des Betonstahls }
\end{array}
$$

Dabei wird die Eintragungslänge des Betonstahls über das Rissmoment, den inneren Hebelarm und die mittlere Verbundkraft bestimmt. Dieser Ansatz wurde vom 
DAfStb in Anlehnung an Piotr Noakowski gewählt ([Zilch et al. 2013] S. 482), der im DAfStb-Heft 394 geeignete Nachweisverfahren für die Verankerung, Verformung, Zwangsbeanspruchung und Rissbreite beschrieben hat (vgl. dazu [DAfStb-Heft 394]).

$l_{e, 0}=\frac{M_{c r}}{z_{s 1} \cdot F_{b s m}}$

Mit:
$M_{c r} \quad$ Rissmoment
$z_{s 1} \quad$ innerer Hebelarm der Stahlzugbewehrung
$F_{b s m} \quad$ mittlere Verbundkraft

Aufgrund der Tatsache, dass die Oberflächenzugfestigkeit bei Verstärkungsmaßnahmen direkt am Betonbauteil bestimmt wird, soll auch das Rissmoment damit berechnet werden. Damit erfolgt die Berechnung über die Oberflächenzugfestigkeit und das Widerstandsmoment des ungerissenen Betonquerschnitts. Um eine Anpassung zwischen ermittelter Oberflächenzugfestigkeit und der zentrischen Zugfestigkeit in zu erreichen, wurde der Umrechnungsbeiwert aus dem EC2 (Abs. 3.1.8) übernommen ([Zilch et al. 2013] S. 482).

$M_{c r}=\kappa_{f l} \cdot f_{c t m, s u r f} \cdot W_{c, 0}$

Mit:

$\kappa_{f l} \quad$ Umrechnungsbeiwert zwischen Biegezugfestigkeit und zentrischer Zugfestigkeit des Betons

$f_{c t m, \text { surf }} \quad$ Mittelwert der Oberflächenzugfestigkeit des Betons

$W_{c, 0} \quad$ Widerstandsmoment des Betonquerschnitts im ungerissenen Zustand

Dabei ergibt sich der Umrechnungsbeiwert zwischen Biegezugfestigkeit und zentrischer Zugfestigkeit in Abhängigkeit der Querschnittshöhe gemäß Gleichung (2-66).

$\kappa_{f l}=(1,6-h / 1000) \geq 1,0$

Mit:

h Querschnittshöhe [mm]

Für die mittlere Verbundkraft erfolgt die Berechnung anhand des Umfangs sowie der Verbundspannung des Betonstahls. 
$F_{b s m}=\sum_{i=1}^{n} n_{s, i} \cdot \phi_{i} \cdot \pi \cdot f_{b s m}$

Mit:

$n_{s, i} \quad$ Anzahl der Stäbe mit gleichem Durchmesser

$\phi_{i} \quad$ Stabdurchmesser

$f_{b s m} \quad$ mittlere Verbundspannung des Betonstahls

Bei Doppelstäben ist ein Ersatzstabdurchmesser einzusetzen, der die zwei direkt nebeneinanderliegenden Stäbe rechnerisch als einen Stab betrachtet, da der Umfang für die Verbundwirkung ausschlaggebend ist.

$\phi_{n}=\sqrt{2} \cdot \phi_{i}$

Die mittlere Verbundspannung ist abhängig von dem einbetonierten Betonstahl. Da es sich um ein Bestandsbauteil handelt, können unterschiedlichste Arten des Betonstahls vorliegen. In der DAfStb-Richtlinie wird dabei zwischen glattem und geripptem Betonstahl unterschieden. Außerdem werden mit den Verbundbeiwerten die jeweiligen Verbundbedingungen in den Formulierungen berücksichtigt ([DAfStb 2012-03] RV 6.1.1.3.3).

$f_{b s m}=\left\{\begin{array}{l}\kappa_{v b 1} \cdot 0,43 \cdot f_{c m}{ }^{2 / 3} \\ \kappa_{v b 2} \cdot 0,28 \cdot \sqrt{f_{c m}}\end{array}\right.$

für gerippten Betonstahl

für glatten Betonstahl

Mit:

$\kappa_{v b} \quad$ Beiwert zur Berechnung der Verbundspannung des Betonstahls in Abhängigkeit der Verbundbedingungen

$f_{c m} \quad$ Mittelwert der Zylinderdruckfestigkeit des Betons

In Tabelle 4 sind die entsprechenden Beiwerte in Abhängigkeit des Betonstahls sowie der jeweiligen Verbundbedingungen aufgeführt. Eine Abschätzung der Verbundbedingungen kann mittels EC2 [EC2-1-1 2011-01] Bild 8.2 erfolgen. 
Tab. 4 Beiwerte zur Berechnung der Verbundspannung (http://doi.org/10.33968/9783966270021-02-T-04)

\begin{tabular}{llll} 
Betonstahl & Beiwert & guter Verbund & mäßiger Verbund \\
\hline gerippt & $\kappa_{v b 1}$ & 1,0 & 0,7 \\
Gemerameramo & & \\
\hline glatt & $\kappa_{v b 2}$ & 1,0 & 0,5 \\
\hline
\end{tabular}

Wird bei der Betrachtung des Rissabstandes lediglich der Betonstahl angesetzt, führt dies zu einer Überschätzung des tatsächlich auftretenden Abstandes in Verbindung mit aufgeklebten CFK-Lamellen. Durch den erheblich steigenden Rechenaufwand, der durch die Berücksichtigung der Lamellen entstehen würde, hat der DAfStb beschlossen diese für die Berechnung des Rissabstandes unberücksichtigt zu lassen. Durch die daraus folgenden rechnerisch größeren Rissabstände werden auf der sicheren Seite liegende Ergebnisse für die Bemessung erzielt, wodurch die Annahme legitimiert wird ([Zilch et al. 2013] S. 482 f.).

\subsubsection{Vereinfachung des Verbundnachweises am ZRE}

Aufgrund der Komplexität des Verbundnachweises ist dieser meist nur noch mit Rechentechnik zu bewältigen. Deshalb hat der DAfStb versucht durch Zufallsanalysen des genauen Verbundnachweises eine Vereinfachung herzuleiten ([DAfStbHeft 592] S. 101 ff.). Dieses Ziel wurde erreicht, indem gewisse Randbedingungen in der Nachweisführung eingeführt wurden. Im Gegensatz zum genaueren Nachweis der Lamellenkraftänderung am ZRE ist der Widerstand unabhängig von der einwirkenden Lamellenkraft. Daher wird hier auch eine konstante aufnehmbare Lamellenkraft am ZRE in der Richtlinie aus den Betrachtungen des DAfStb im Heft 592 formuliert. Damit kann das Superpositionsprinzip wieder für die Bemessung verwendet werden [Zilch et al. 2013]. Die aufnehmbare Lamellenkraftänderung am ZRE ist weiterhin abhängig von den Verbundbeiwerten, dem Rissabstand und einem Krümmungsanteil.

$\Delta F_{L R d}=\frac{\tau_{L 1 k} \cdot \kappa_{L 1} \cdot \sqrt{s_{r}}+\tau_{L F k} \cdot \kappa_{L F} \cdot s_{r}{ }^{4 / 3}+\frac{\kappa_{h}}{h} \cdot s_{r}{ }^{1 / 3}}{\gamma_{B A}} \cdot b_{L}$

Mit:

$\tau_{L 1 k} \quad$ maximale Verbundspannung des bilinearen Ansatzes

$\kappa_{L 1} \quad$ Beiwert zur Berechnung der am ZRE aufnehmbaren

Lamellenkraftänderung aus Klebeverbund

$s_{r} \quad$ Rissabstand

$\tau_{L F K} \quad$ Reibverbundspannung 


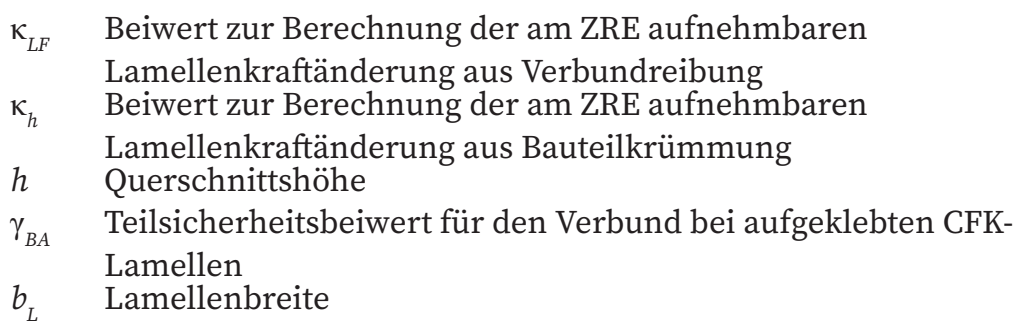

Die Umrechnungsbeiwerte sind aus den numerischen Betrachtungen ermittelt worden [DAfStb-Heft 592] und wie folgt anzunehmen:

$\kappa_{L 1}=2,3 \quad \kappa_{L F}=0,1 \quad \kappa_{h}=\left\{\begin{array}{cl}2000 & \text { für ebene Stahlbetonbauteile } \\ 0 & \text { für Spannbetonbauteile }\end{array}\right.$

Da die Gleichung (2-70) nicht dimensionsrein ist, müssen alle Werte in $[\mathrm{N}]$ und $[\mathrm{mm}]$ bzw. $\left[\mathrm{N} / \mathrm{mm}^{2}\right]$ eingesetzt werden. Die Randbedingungen des vereinfachten Nachweises der Lamellenkraftänderung am ZRE sind in der DAfStb-Richtlinie wie folgt definiert:

- Lamellendehnung $\varepsilon_{\mathrm{L}} \leq \varepsilon_{\mathrm{LRd}, \max }=10 \% 0$

- Lamellenspannung $\sigma_{\mathrm{L}} \leq \mathrm{f}_{\text {Lud }}$

- Rissabstand $\mathrm{s}_{\mathrm{r}} \leq 400 \mathrm{~mm}$

- Bauteilhöhe $\mathrm{h} \geq 100 \mathrm{~mm}$

Sofern der Rissabstand von $400 \mathrm{~mm}$ überschritten wird, ist dieser auf den Maximalwert zu begrenzen. Genauso ist bei Unterschreitung des Minimalwertes der Bauteilhöhe zu verfahren. Im Anhang RV L.3 zur Richtlinie sind vom DAfStb auch Formeln zur Ermittlung der einwirkenden Lamellenkraft für eine äußerst vereinfachte Handrechnung angegeben, die zwar auf der sicheren Seite liegen, dagegen aber in hohem Maße unwirtschaftlich sind ([DAfStb-Heft 595] S. 20). Diese dürfen für den vereinfachten Nachweis der Lamellenkraftänderung am ZRE herangezogen werden.

\subsubsection{Vereinfachter Nachweis ohne Verbundbetrachtung}

Wie bereits in Abschnitt 2.7.2 erwähnt, besteht die alternative Möglichkeit den Biegenachweis ohne Betrachtung der Verbundkraftübertragung zu führen ([DAfStb 2012-03] Abs. RV 6.1.1.2). Dazu muss lediglich nachgewiesen werden, dass die aufgeklebte CFK-Lamelle eine maximale Grenzdehnung nicht übersteigt. Diese ergibt sich wie folgt (vgl. [DAfStb 2012-03] RV 6.1.1.2): 


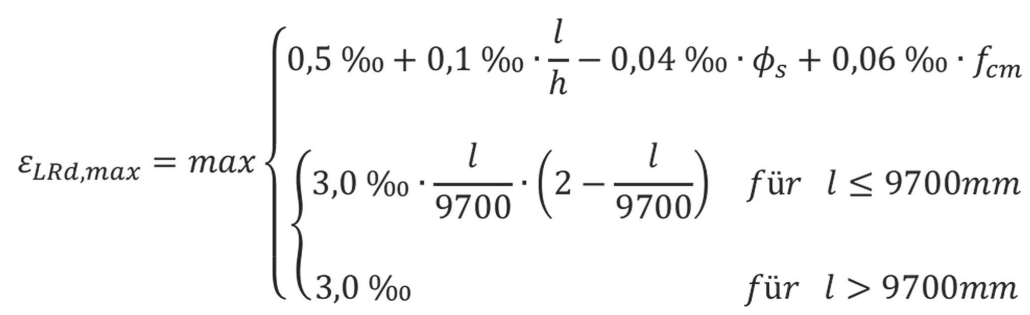

Mit:

$\begin{array}{ll}\varepsilon_{L R d, \max } & \text { maximal zulässige Dehnung der aufgeklebten CFK-Lamelle } \\ l & \text { effektive Stützweite in } \mathrm{mm} \\ h & \text { Querschnittshöhe in } \mathrm{mm} \\ \phi_{s} & \text { größter Betonstahldurchmesser in } \mathrm{mm} \\ f_{c m} & \text { Mittelwert der Zylinderdruckfestigkeit des Betons in } \mathrm{N} / \mathrm{mm}^{2}\end{array}$

Diese Vereinfachung geht aus der Dissertation von Finckh hervor. Darin wurden unterschiedliche Ansätze für die Vereinfachung der Verbundkraftübertragung untersucht (vgl. [Finckh 2012] Abs. 7.2.5, S. 223 ff.). Folgende Voraussetzungen sind bei dem vereinfachten Nachweis einzuhalten:

- positive Feldmomente

- nicht vorgespannte Bauteile

Außerdem wird gefordert, dass die Betondruck- und Betonzugfestigkeit miteinander korrelieren ([DAfStb-Heft 595] S. 17). Diese Forderung ist in der Richtlinie in Gleichung (RV 6.2) enthalten, die der Formulierung aus Gleichung (2-72) in dieser Arbeit entspricht.

$f_{c t m, s u r f} \geq 0,26 \cdot f_{c m} \frac{2}{3}$

Mit:

$\begin{array}{ll}f_{c t m, s u r f} & \text { Mittelwert der Oberflächenzugfestigkeit des Betons } \\ f_{c m} & \text { Mittelwert der Zylinderdruckfestigkeit des Betons }\end{array}$

Wird diese Bedingung nicht erfüllt, muss bei dem vereinfachten Nachweis mit verminderter mittlerer Zylinderdruckfestigkeit gerechnet werden ([DAfStb-Heft 595] S. 50). Diese ergibt sich dann durch Umstellen gemäß folgender Formulierung:

$f_{c m, \text { vorh }}=\left(\frac{f_{c t m, \text { surf }}}{0,26}\right)^{\frac{3}{2}}$ 
Weiterhin kann gemäß Richtlinie auf den Nachweis der Endverankerung verzichtet werden, sofern:

- die Lamelle bis mind. $50 \mathrm{~mm}$ vor die Auflagerkante geführt wird,

- gerippter Betonstahl verwendet wurde,

- der Betonstahl nicht abgestuft ist und

- die Lamellenstärke insgesamt maximal 1,4 mm beträgt.

Sind diese Bedingungen erfüllt, kann mittels des vereinfachten Nachweises das Nachweisverfahren stark abgekürzt werden. Sollten diese Punkte nicht eingehalten werden, kann bei Gleichlast ein ergänzender Endverankerungsnachweis geführt werden, der zu auf der sicheren Seite liegenden Ergebnissen führt ([DAfStbHeft 595] S. 17). Abschließend ist bei diesem Nachweisformat anzumerken, dass es sich dabei um "[...] die realitätsfremdeste und somit unwirtschaftlichste Nachweismöglichkeit [...]" ([Finckh 2012] S. 223) für aufgeklebte CFK-Lamellen handelt, da die Vielzahl an Parametern, die das Verbundverhalten beeinflussen unberücksichtigt bleibt (vgl. [Finckh 2012]). 


\section{Vorbemessung der Verstärkung mit aufgeklebten CFK-Lamellen}

\subsection{Hilfsmittel für die Bemessung}

Bemessungshilfsmittel sollen allgemein Vereinfachungen der komplexen und iterativen Berechnungen im Stahlbetonbau herbeiführen. Sie sollen dem Anwender eine aufwendige Berechnung ersparen und schneller zum Ergebnis führen. Bereits die Bemessungsansätze der Werkstoffe sind Vereinfachungen, da sich das tatsächliche Verhalten mathematisch nur abschätzen lässt ([Holschemacher et al. 2012] S. 1). Im Stahlbetonbau gibt es seit der Entwicklung dieser Bauweise bereits Hilfsmittel, die mit dem Fortschreiten der Normung und der Technik stetig angepasst wurden. Dazu zählen u.a.

- Diagramme

- Tabellen

- Vereinfachungen von Formeln

- EDV-gestützte Berechnungen

- Interaktionen aus diesen Hilfsmitteln

Aufgrund der Komplexität basiert die Bemessung in der heutigen Zeit fast ausschließlich auf computergestützten Berechnungen. Dabei können Bemessungshilfen für eine überschlägige Überprüfung der Ergebnisse von Berechnungssoftware verwendet werden. Außerdem sollte jeder Ingenieur ein grundlegendes Verständnis des Bemessungsapparates besitzen, um auch die Anwendungsgrenzen einer solchen Software beurteilen zu können ([Holschemacher et al. 2012] S. 1). Trotz der großen Verbreitung von Bemessungssoftware, sind Plausibilitätskontrollen durch Handrechnungen unabdingbar um eventuelle Fehleingaben oder Anwendungsgrenzen zu identifizieren. Daher scheinen explizit für die iterative Berechnung bei aufgeklebten CFK-Lamellen Bemessungshilfsmittel äußerst sinnvoll, denn damit kann bereits im Voraus die Realisierbarkeit einer solchen Maßnahme beurteilt werden.

Ziel eines solchen Hilfsmittels sollte eine möglichst große Allgemeingültigkeit sein, ohne dabei die Wirtschaftlichkeit zu sehr zu beeinträchtigen. Für Stahlbetonquerschnitte, die mit CFK-Lamellen verstärkt werden, soll eine möglichst große Unabhängigkeit der Bemessungshilfsmittel von den Bemessungsparametern erzielt werden. Dazu wird in den folgenden Betrachtungen zwischen dem reinen Biegenachweis und dem Nachweis der Verbundkraftübertragung am ZRE unter- 
schieden. Als häufig verwendetes Hilfsmittel mit äußerst hoher Allgemeingültigkeit gelten die Bemessungstafeln mit dimensionslosen Beiwerten ( $\mu_{\mathrm{s}}$-Tafeln u.a. [Holschemacher et al. 2012] S. 67 ff.). Diese sind zwar jeweils auf eine Querschnittsform (Rechteck / Plattenbalken) begrenzt, dabei aber unabhängig von den Abmessungen des Querschnitts sowie für alle Festigkeitsklassen von Normalbetonen anzuwenden. Es entsteht lediglich eine zusätzliche Abhängigkeit zur Druckbewehrung, die eine weitere Unterscheidung notwendig macht.

\subsection{Vereinfachung des reinen Biegenachweises}

\subsubsection{Bemessungstafeln ohne Druckbewehrung}

\subsubsection{Ermittlung der Eingangswerte}

Die Bemessungstafeln mit dimensionslosen Beiwerten haben sich im Laufe der Jahre in der überschlägigen Bemessung im Stahlbetonbau etabliert. Daher wird in diesem Abschnitt analog dazu ein ähnlicher Ansatz für aufgeklebte CFK-Lamellen entwickelt, der es ermöglicht aus den errechneten Werten die Lamellenfläche abzuleiten. Dazu werden die Bezeichnungen am verstärkten Stahlbetonquerschnitt gemäß Abbildung 28 verwendet. In diesem Abschnitt wird die Betrachtung vorerst ohne Druckbewehrung durchgeführt. Anschließend erfolgt eine Erweiterung um die Druckbewehrung.

Die Berechnung erfolgt mit der Summe der Momente um die Schwerachse der aufgeklebten CFK-Lamelle (Index „L“). Dabei stehen innere und äußere Schnittgrößen im Gleichgewicht. Das einwirkende Moment ist gemäß Gleichung (2-36) zu ermitteln.

$M_{E d, L}=M_{R d, L, V}$

Wird die Berechnung des Tragwiderstands aus Gleichung (2-38) (vgl. Kapitel 2.7.4) ohne den Anteil der Druckbewehrung in (3-1) eingesetzt, ergibt sich (3-2).

$M_{E d, L}=F_{c d} \cdot z_{L}-F_{s 1 d} \cdot\left(d_{L}-d\right)$

Durch Ersetzen der Kräfte mit den Gleichungen (2-16) und (2-22) sowie den inneren Hebelarmen gilt:

$M_{E d, L}=\alpha_{R} \cdot b \cdot x \cdot f_{c d} \cdot\left(d_{L}-k_{a} \cdot x\right)-\sigma_{s 1 d} \cdot A_{s 1} \cdot\left(d_{L}-d\right)$

Dabei wird aufgrund der geringen Lamellendicke für die Berechnung unterstellt, dass die statische Höhe der aufgeklebten CFK-Lamelle in etwa der Querschnittshöhe entspricht. 
$d_{L} \approx h$

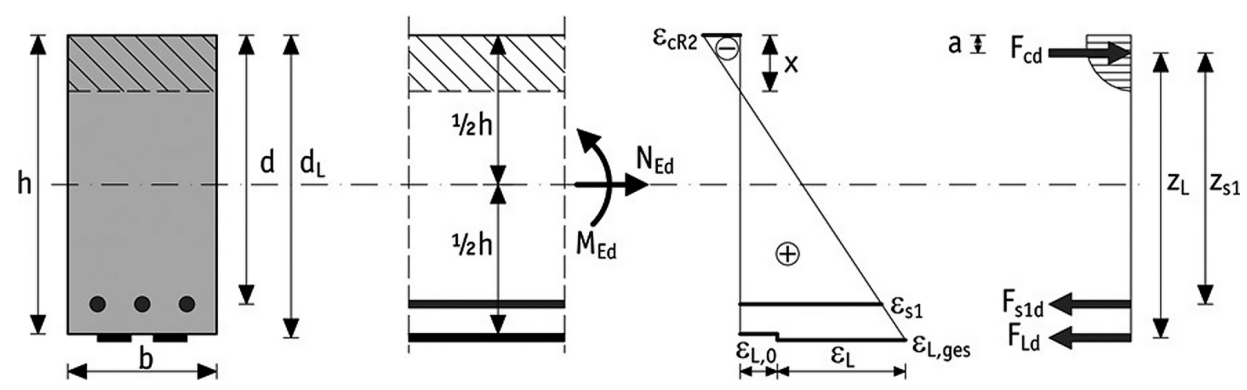

Abb. 28 Bezeichnungen am verstärkten Querschnitt (ohne Druckbewehrung) (http://doi.org/10.33968/9783966270021-03-A-01)

Für eine weitere Vereinfachung wird für die Fläche des Betonstahls in der weiteren Berechnung eine querschnittsabhängige Formulierung benötigt. Dazu wird an dieser Stelle der Bewehrungsgrad eingeführt, der sich aus dem Verhältnis von Betonstahlfläche zur Bruttoquerschnittsfläche ergibt. Durch Umstellen ergibt sich für die Bewehrungsfläche folgende Formulierung:

$A_{s 1}=\rho_{s 1} \cdot b \cdot h$

Mit:

$\rho_{s 1} \quad$ Bewehrungsgrad der Stahlzugbewehrung

Weiterhin ist es erforderlich die unbekannte Druckzonenhöhe in Gl. (3-3) zu ersetzen. Dazu wird über Umstellen des Verhältnisses der Druckzonenhöhe zur Betonrandstauchung der Beiwert $\xi_{\mathrm{L}}$ eingeführt ([Mehlhorn et al. 2002] S. 250). Im Gegensatz zum Stahlbetonbau wird hier das Verhältnis mit Hilfe der statischen Höhe der Lamelle beschrieben, da diese der Querschnittshöhe entspricht und für die anschließende Berechnung benötigt wird. Deshalb wird der Beiwert um den Index „L“ erweitert. Folgende Beziehung liegt dem zugrunde (vgl. Abbildung 28):

$\frac{x}{\varepsilon_{c R 2}}=\frac{d_{L}}{\varepsilon_{c R 2}-\varepsilon_{L, g e s}}$

Nach dem Umstellen kann der Beiwert für die weitere Berechnung gemäß Gl. (3-7)eingeführt werden. Dabei sei bereits an dieser Stelle erwähnt, dass sich hierin die Gesamtdehnung am unteren Querschnittsrand bzw. auf Lamellenhöhe wiederfindet. Für die Berechnung der Lamellenkraft wird aber die reine Lamellendehnung benötigt, welche sich aus der Gesamtdehnung und der Dehnung zum Zeit- 
punkt der Verstärkung (Index „0“) ergibt. Eine Erläuterung zur Ermittlung der Dehnungen zum Zeitpunkt „0“ folgt in Abschnitt 3.2.2.3.

$\frac{x}{d_{L}}=\frac{\varepsilon_{C R 2}}{\varepsilon_{c R 2}-\varepsilon_{L, g e s}}=\xi_{L}$

Mit:

$\xi_{L} \quad$ Verhältnisbeiwert von Druckzonenhöhe zu statischer Höhe der CFKLamelle

Für die Berechnung der Druckzonenhöhe bzw. den Abstand der Nulllinie vom oberen Querschnittsrand gilt somit folgende Formulierung:

$x=\frac{\varepsilon_{C R 2}}{\varepsilon_{C R 2}-\varepsilon_{L, g e s}} \cdot d_{L}=\xi_{L} \cdot d_{L} \approx \xi_{L} \cdot h$

In die Gleichung (3-3) geht die Stahlzugspannung ein. Da diese unterschiedliche Werte annehmen kann, wäre die Bemessung weiterhin iterativ. Ab der Streckgrenze kann die Stahlspannung als konstant betrachtet werden, deshalb wird dieser Wert für die Bemessungstafeln fixiert.

$\sigma_{s 1 d}=f_{y d}$

Mit dieser Annahme lässt sich ein relativ großer Bereich abdecken, der im Allgemeinen für die Bemessung der aufgeklebten CFK-Lamellen am Momentenmaximum zutreffen sollte. Aufgrund der großen zulässigen Lamellendehnungen (vgl. [Z-36.12-84/85/86) wird die Annahme als gerechtfertigt betrachtet. Es ist aber bei der Verwendung der Bemessungshilfen in jedem Fall zu prüfen, ob sich die Bewehrung tatsächlich im Fließen befindet. Sofern dieser Fall eintritt, wird durch die Bemessungstafeln ohne Druckbewehrung ein verhältnismäßig großer Bereich abgedeckt (vgl. Abbildung 29). Andernfalls erfolgt die Bemessung iterativ. 


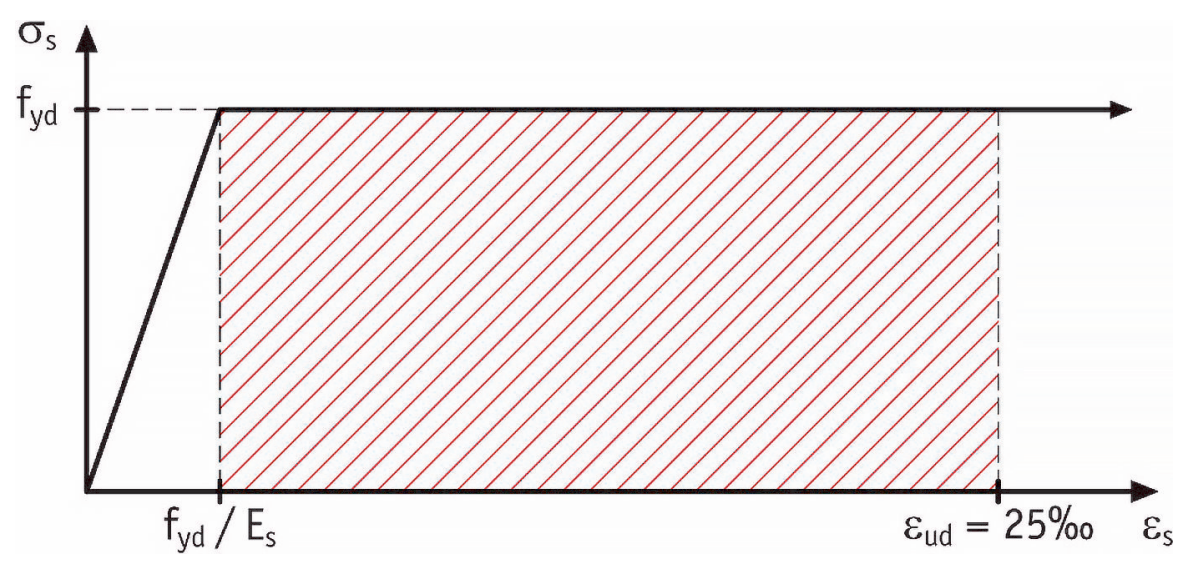

Abb. 29 Bereich der zulässigen Stahldehnung für die Bemessungstafeln (http://doi.org/10.33968/9783966270021-03-A-02)

Mit den Annahmen und Festlegungen aus den Gleichungen (3-4) bis (3-9) kann folgender Ausdruck formuliert werden:

$M_{E d, L}=\alpha_{R} \cdot b \cdot \xi_{L} \cdot h \cdot f_{c d} \cdot\left(h-k_{a} \cdot \xi_{L} \cdot h\right)-f_{y d} \cdot \rho_{s 1} \cdot b \cdot h \cdot(h-d)$

Durch Umformen ergibt sich Gleichung (3-11).

$M_{E d, L}=\alpha_{R} \cdot b \cdot \xi_{L} \cdot h^{2} \cdot f_{c d} \cdot\left(1-k_{a} \cdot \xi_{L}\right)-f_{y d} \cdot \rho_{s 1} \cdot b \cdot h^{2} \cdot\left(1-\frac{d}{h}\right)$

Im Folgenden werden die Querschnittswerte durch weiteres Umstellen auf die Einwirkungsseite gebracht. Somit ergibt sich wie bei Stahlbetonquerschnitten der einwirkungs- und querschnittsabhängige Eingangswert $\mu_{\mathrm{Ed}, \mathrm{L}}$ für die Bemessungstafeln.

$\frac{M_{E d, L}}{b \cdot h^{2} \cdot f_{c d}}+\frac{f_{y d}}{f_{c d}} \cdot \rho_{s 1} \cdot\left(1-\frac{d}{h}\right)=\alpha_{R} \cdot \xi_{L} \cdot\left(1-k_{a} \cdot \xi_{L}\right)=\mu_{E d, L}$

Mit:

$\mu_{E d, L} \quad$ dimensionsloses bezogenes Bemessungsmoment

Durch die Umformung wurde eine Allgemeingültigkeit für Rechteckquerschnitte mit variablen Abmessungen, Einwirkungen und Festigkeitsklassen erreicht. Wie aus (3-12) hervorgeht, kann somit für festgelegte $\mu_{E d, L}$-Werte der Dehnungszustand iterativ bestimmt werden. Als iterative Größen ergeben sich die Betonstauchung am druckbeanspruchten oberen Querschnittsrand und die Lamellengesamtdehnung. Durch die Überführung der Begrenzung der zulässigen Stahlzugspannung 
(Abbildung 29) auf die rechnerisch zulässigen Dehnungszustände aus Abbildung 16, ergeben sich für diese Iteration die rechnerisch zulässigen Dehnungszustände gemäß Abbildung 30. Die Betrachtung erfolgt nur für den Fall A, der in Kapitel 2.7.4 bereits erläutert wurde.

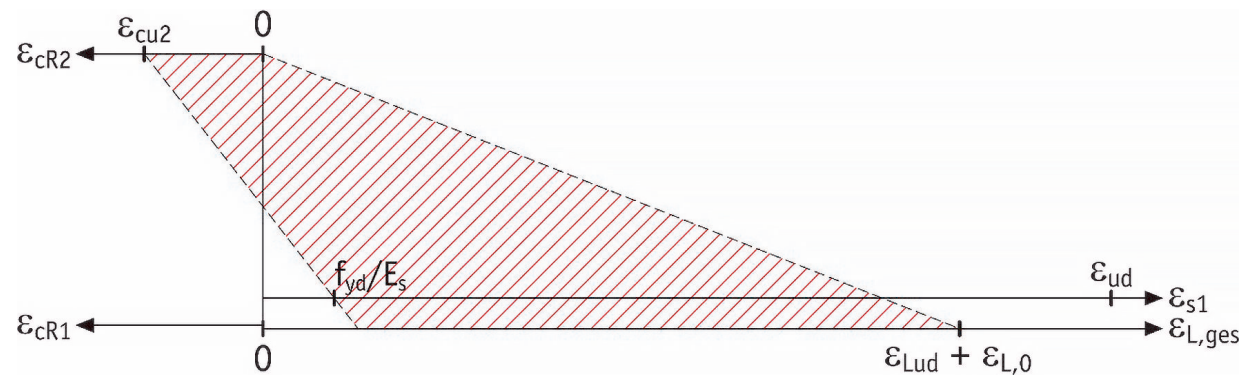

Abb. 30 zulässige Dehnungszustände für Bemessungstafeln ohne Druckbewehrung (http://doi.org/10.33968/9783966270021-03-A-03)

Beim reinen Stahlbeton sind die rechnerisch zulässigen Dehnungsgrenzen für die Bemessung eindeutig geregelt und bekannt. Hier ist aber die zulässige Gesamtdehnung im Voraus unbekannt, da sie sich aus der noch unbekannten Dehnung zum Zeitpunkt „0“ und der zulässigen Bruchdehnung der Lamelle zusammensetzt, die wiederum vom verwendeten Verstärkungssystem abhängt. Zur Lösung dieses Problems wurden mehrere Bemessungstafeln mit unterschiedlichen maximalen Gesamtdehnungen erstellt werden, zwischen denen mit der konkreten Gesamtdehnung interpoliert oder auf der sicheren Seite liegend gerechnet werden kann.

\subsubsection{Ermittlung der Lamellenfläche}

Als nächstes soll die Berechnung der Lamellenfläche beschrieben werden. Dazu werden der Völligkeitsbeiwert und der Beiwert zur Berechnung der Druckzonenhöhe zusammengefasst.

$\alpha_{R} \cdot \xi_{L}=\omega_{L}$

Mit:

$\omega_{L} \quad$ dimensionsloser Beiwert zur Berechnung der erforderlichen Lamellenfläche

Die Bestimmung der Lamellenfläche erfolgt über das Gleichgewicht der inneren und äußeren Kräfte am verstärkten Querschnitt vorerst ohne Druckbewehrung (vgl. (2-37)). 
$0=F_{c d}-F_{s 1 d}-F_{L d}+N_{E d}$

Als nächstes wird (3-14) nach der Lamellenkraft umgestellt:

$F_{L d}=F_{c d}-F_{s 1 d}+N_{E d}$

Wie auch im vorherigen Kapitel werden die Kräfte durch die entsprechenden Formulierungen aus den Abschnitten 2.6 und 2.7 ersetzt. Außerdem wird die Formulierung für die Druckzonenhöhe gemäß (3-8) verwendet und die Stahlzugspannung auf den Wert der Bemessungsstreckgrenze fixiert.

$\varepsilon_{L} \cdot E_{L m} \cdot A_{L}=\alpha_{R} \cdot b \cdot \xi_{L} \cdot h \cdot f_{c d}-f_{y d} \cdot \rho_{s 1} \cdot b \cdot h+N_{E d}$

Damit ergibt sich durch Umformen und Einsetzen von $\omega_{\mathrm{L}}$ aus (3-13) die Gleichung (3-17) zur Berechnung der erforderlichen Lamellenfläche. Der Wert $\omega_{\mathrm{L}}$ kann in Abhängigkeit von $\mu_{\mathrm{Ed}, \mathrm{L}}$ aus den Bemessungstafeln abgelesen werden.

$A_{L}=\frac{\left(\omega_{L} \cdot f_{c d}-f_{y d} \cdot \rho_{s 1}\right) \cdot b \cdot h+N_{E d}}{\varepsilon_{L} \cdot E_{L m}}$

Für die erforderliche Lamellenfläche wird die reine Lamellendehnung benötigt. Dazu können unterschiedliche Ansätze gewählt werden. Es besteht u.a. die Möglichkeit die Bruchdehnung der jeweiligen Lamelle aus den bauaufsichtlichen Zulassungen der Hersteller zu entnehmen oder die Grenzdehnung aus dem vereinfachten Nachweis gemäß Kapitel 2.7.6 zu verwenden. Für die Vorbemessung wird letztere Methode empfohlen. Die Bruchdehnung würde zu unrealistischen Ergebnissen führen, denn dabei wird der Verbundnachweis in keiner Weise berücksichtigt. Damit kann der Gesamtdehnungszustand am unteren Querschnittsrand bestimmt werden, der sich aus den Dehnungen zum Zeitpunkt der Verstärkung und der reinen Lamellendehnung zusammensetzt. Dieser dient gleichzeitig als Eingangswert für die Bemessungstafeln.

Damit können unterschiedliche Gesamtdehnungszustände am unteren Querschnittsrand auftreten. Deshalb wurden mehrere Bemessungstafeln mit zulässigen Gesamtdehnungen von 2,5\%o bis 18\%o erstellt. Aus den Berechnungen geht hervor, dass eine Abstufung von jeweils 0,5\% zwischen den einzelnen Bemessungstafeln als sinnvoll zu erachten ist, weil hierbei geringe, aber dennoch ausschlaggebende Änderungen zwischen den Tafelwerten zu verzeichnen sind. Aufgrund der Vielzahl der Bemessungstafeln sind diese im „Anhang C - Bemessungstafeln“ abgedruckt. Beispielhaft stellt Abbildung 31 einen Ausschnitt der Bemessungstafel mit einem zulässigen Gesamtdehnungszustand von $10 \%$ dar. 
Bemessungstafel für Rechteckquerschnitte mit und ohne Druckbewehrung (Normalbeton C12/16 - C50/60 | Betonstahl B500 | a,ges,zul = $10 \%$ )

\begin{tabular}{|c|c|c|c|c|c|}
\hline$\mu_{\mathrm{Ed}, \mathrm{L}}$ & $\omega_{\mathrm{L}}$ & $\varepsilon_{c R 2}$ & $\varepsilon_{L, \text { ges }}$ & $\xi_{L}$ & $\max . \mathrm{d}_{2} / \mathrm{h}$ \\
\hline 0,01 & 0,0102 & $-0,48$ & 10,00 & 0,0459 & \multirow{10}{*}{ 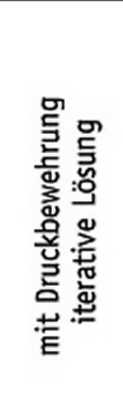 } \\
\hline 0,02 & 0,0205 & $-0,70$ & 10,00 & 0,0658 & \\
\hline 0,03 & 0,0309 & $-0,89$ & 10,00 & 0,0816 & \\
\hline 0,04 & 0,0414 & $-1,05$ & 10,00 & 0,0953 & \\
\hline 0,05 & 0,0520 & $-1,21$ & 10,00 & 0,1078 & \\
\hline 0,06 & 0,0627 & $-1,36$ & 10,00 & 0,1194 & \\
\hline 0,07 & 0,0735 & $-1,50$ & 10,00 & 0,1305 & \\
\hline 0,08 & 0,0843 & $-1,65$ & 10,00 & 0,1413 & \\
\hline 0,09 & 0,0953 & $-1,79$ & 10,00 & 0,1518 & \\
\hline 0,10 & 0,1064 & $-1,94$ & 10,00 & 0,1623 & \\
\hline
\end{tabular}

Abb. 31 beispielhafter Ausschnitt einer Bemessungstafel (10\%) (http://doi.org/10.33968/9783966270021-03-A-04)

Die Begrenzung der Bemessungstafeln auf einen minimalen Wert der zulässigen Gesamtdehnung am unteren Querschnittsrand von 2,5\% ergibt sich aus der Begrenzung der Betonstahlspannung. Bei der nächsten Abstufung würde die Spannung des Betonstahls definitiv unterhalb der Bemessungsstreckgrenze der heute gängigen Betonstähle B500A und B500B liegen. Selbst bei dieser unteren Grenze ist es zwar möglich aber dennoch fraglich, ob sich der Betonstahl im Fließen befindet. Dieser Sachverhalt ist in jedem Fall zu überprüfen. Das lässt sich unmittelbar über die Dehnungen erreichen.

$\varepsilon_{S 1}=\frac{d}{d_{L}} \cdot\left(\varepsilon_{L, g e s}-\varepsilon_{C R 2}\right)+\varepsilon_{C R 2}$

Die Dehnungen können aus den Bemessungstafeln abgelesen bzw. interpoliert werden. Um die Bemessungsstreckgrenze zu erreichen, muss folgende Bedingung für die Dehnung erfüllt sein:

$\varepsilon_{s 1} \geq \frac{f_{y d}}{E_{s}} !$

Bei geringen Dehnungen sind die Lamellen im Allgemeinen nur äußerst schlecht ausgenutzt (vgl. [Z-36.12-84/85/86), dennoch werden auch solche geringen Werte in die Bemessungstafeln aufgenommen, um auch den vereinfachten Nachweis der Richtlinie gemäß Abschnitt 2.7.6 zu ermöglichen. Bei diesem Nachweis werden oftmals nur geringe zulässige Dehnungen der Lamelle erzielt, jedoch erübrigt sich da- 
durch der enorme Nachweisaufwand der Verbundbetrachtung (vgl. Kapitel 2.7.6). Das Maximum wurde auf 18\%o festgelegt, weil damit die aktuell in Deutschland bauaufsichtlich zugelassenen Systeme für aufgeklebte CFK-Lamellen abgedeckt sind (vgl. aktuell zugelassene Systeme [DIBt 2017]).

Bei der Berechnung der einzelnen Bemessungstafeln wurde festgestellt, dass sich die Lamellengesamtdehnung als Funktion von $\mu_{\mathrm{Ed}, \mathrm{L}}$ darstellen lässt. So kann mit Hilfe dieser Funktion ein Diagramm ausgegeben werden. Daraus kann direkt abgelesen werden, ob die gewählte CFK-Lamelle voll ausgenutzt ist oder rechnerisches Betonversagen maßgebend wird. Die Funktion ergibt sich aus der Umkehrfunktion des zweiten Teils der Gleichung (3-12). Die quadratische Ausgangsfunktion lautet somit wie folgt:

$\mu_{E d, L}\left(\xi_{L}\right)=\alpha_{R} \cdot \xi_{L} \cdot\left(1-k_{a} \cdot \xi_{L}\right)=\alpha_{R} \cdot \xi_{L}-\alpha_{R} \cdot k_{a} \cdot \xi_{L}^{2}$

Die dazugehörige Umkehrfunktion ergibt sich zu:

$\xi_{L}\left(\mu_{E d, L}\right)=\frac{1}{2 \cdot k_{a}}-\sqrt{\frac{\mu_{E d, L}}{-\alpha_{R} \cdot k_{a}}+\frac{1}{4 \cdot k_{a}^{2}}}$

Durch Ersetzen des Beiwertes der Druckzonenhöhe mit der Formulierung aus G1. (3-7) und weiterem Umstellen, kann die Funktion der Gesamtdehnung der aufgeklebten CFK-Lamelle in Abhängigkeit von $\mu_{\mathrm{Ed}, \mathrm{L}}$ aufgestellt werden:

$\varepsilon_{L, g e s}\left(\mu_{E d, L}\right)=\varepsilon_{c R 2}-\varepsilon_{c R 2} \cdot\left(\frac{1}{2 \cdot k_{a}}-\sqrt{\frac{\mu_{E d, L}}{-\alpha_{R} \cdot k_{a}}+\frac{1}{4 \cdot k_{a}^{2}}}\right)^{-1}$

Durch Einführung der Randbedingung, dass der Beton voll ausgenutzt sein soll, werden mehrere Unbekannte in der Gleichung reduziert. Damit wird für die Betonstauchung am druckbeanspruchten oberen Querschnittsrand der maximal zulässige Betrag für Normalbeton von 3,5\%o eingesetzt. Dadurch sind gleichzeitig der Völligkeitsbeiwert und der Beiwert für den Randabstand bekannt. Es bleibt ausschließlich eine Abhängigkeit zu $\mu_{\mathrm{Ed}, \mathrm{L}}$ bestehen, die durch den Funktionsverlauf in Abbildung 32 grafisch dargestellt werden kann.

Die Funktion gilt theoretisch für unendlich große Gesamtdehnungszustände am unteren Querschnittsrand im verstärkten Zustand. Um zwischen dem rechnerischen Beton- und Lamellenversagen mit dem zulässigen Gesamtdehnungszustand zu unterscheiden, muss eine weitere Bedingung eingeführt werden. Diese lässt sich als lineare Funktion mit der Gleichung (3-23) beschreiben, die parallel zur xAchse verläuft. 
$\varepsilon_{L, g e s}\left(\mu_{E d, L}\right) \leq \varepsilon_{L, g e s, z u l}$

Mit:

$$
\begin{array}{ll}
\varepsilon_{L, g e s, z u l} & \text { zulässige Gesamtdehnung am unteren Querschnittsrand im } \\
\text { verstärkten Zustand }
\end{array}
$$

Im Bereich vom Schnittpunkt mit der y-Achse bis zum Schnittpunkt mit der quadratischen Funktion tritt also ein rechnerisches Versagen der aufgeklebten CFKLamelle ein. Ab dem Schnittpunkt mit der quadratischen Funktion reduziert sich der Gesamtdehnungszustand am unteren Querschnittsrand dem Funktionsverlauf von Gl. (3-22) folgend und es tritt ein rechnerisches Versagen der Betondruckzone ein. Somit kann der rechnerische Gesamtdehnungszustand je nach Querschnitt und Belastung abgelesen oder direkt mit (3-22) berechnet werden. Um die tatsächliche Lamellendehnung zu erhalten, müssen nur noch die Vordehnungen subtrahiert werden, die während der Verstärkung auftreten.

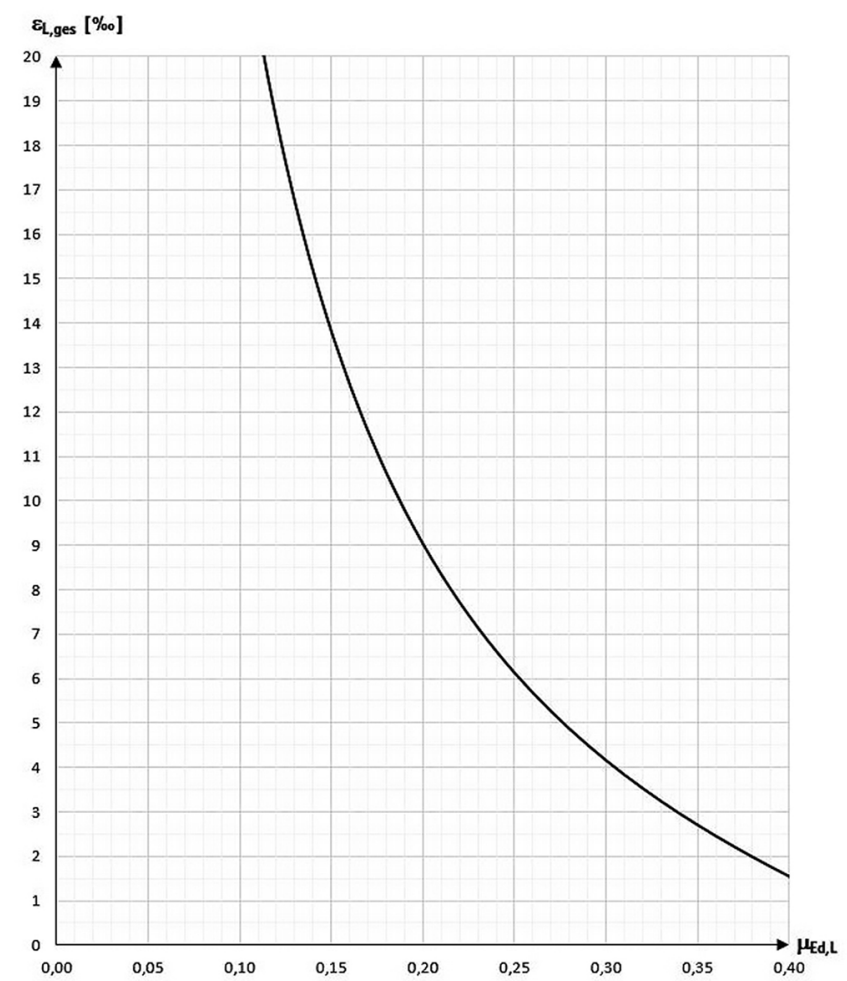

Abb. 32 Diagramm zur Bestimmung der Lamellengesamtdehnung (http://doi.org/10.33968/9783966270021-03-A-05) 


\subsubsection{Dehnungen zum Zeitpunkt der Verstärkung}

In diesem Abschnitt werden alle Größen, die sich vor und nach der Verstärkung in ihren Beträgen unterscheiden können, mit dem Index „,“" versehen, um zu verdeutlichen, dass es sich um den Zeitpunkt vor bzw. während des Verstärkens handelt. Für die Bemessungstafeln werden die Schnittgrößen linear-elastisch ermittelt, um daraus die entsprechenden Dehnungszustände abzuleiten. Unter Gebrauchslasten ist diese Annahme gerechtfertigt. Außerdem dienen die Bemessungstafeln als Instrument zur Vorbemessung, somit wird diese Annahme als hinreichend genau betrachtet. Für eine genauere Bemessung wird empfohlen die Dehnungen mit entsprechenden nichtlinearen Verfahren zu berechnen oder direkt am Bauteil durch geeignete Messmethoden zu überprüfen. Insbesondere bei intensiver Belastungsvorgeschichte sollten Messwerte in Betracht gezogen werden. Aus Kapitel 2.5 geht hervor, dass bei der linearen Schnittgrößenermittlung lineare Spannungs-Dehnungs-Linien für das Werkstoffverhalten angenommen werden. Damit gilt das Hookesche Gesetz gemäß Gleichung (3-24), sowohl für den Beton, als auch für die Stahlzugbewehrung. Weiterhin gilt in der Physik die Definition der Spannung als Kraft pro Fläche, woraus sich die Gleichung für die Kraft ableiten lässt (vgl. [Stroppe 2012] S. 104 f.).

$\sigma=\varepsilon \cdot E$

$\sigma=\frac{F}{A}$

$F=\varepsilon \cdot E \cdot A$

Mit diesen Voraussetzungen lassen sich die Dehnungs- und Spannungszustände am Stahlbetonquerschnitt für die Ermittlung der Schnittgrößen und Dehnungen gemäß Abbildung 33 für Rechteckquerschnitte ohne Druckbewehrung darstellen. Dabei ist für die nachfolgende Berechnung wichtig, dass zum Zeitpunkt „0“ keine Normalkraft auf den Querschnitt wirkt, weil dadurch die Dehnungen und Spannungen verschoben würden. 


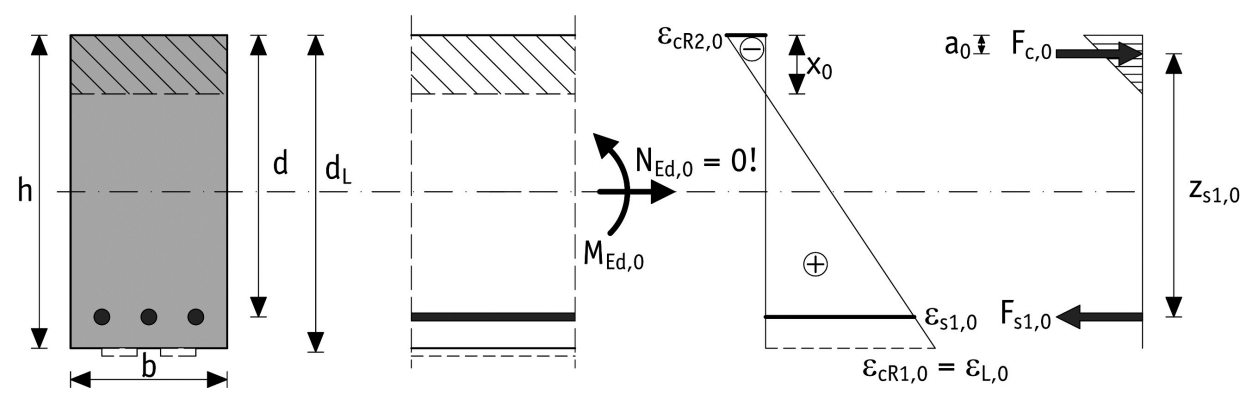

Abb. 33 Dehnungen und Spannungen zum Zeitpunkt „0“ ohne Druckbewehrung (http://doi.org/10.33968/9783966270021-03-A-06)

Wie im Bild zu erkennen, verteilt sich aufgrund des idealisierten Verhaltens für die Schnittgrößenermittlung die Betondruckspannung linear über die Druckzone. Um die resultierende Kraft zu ermitteln, kann die Spannung gemittelt und mit der Fläche multipliziert werden. Dabei wirkt die Druckspannung über die Betondruckzonenhöhe und die volle Breite des Querschnitts. Somit kann der Ausdruck für die Betondruckkraft gemäß (3-27) formuliert werden.

$F_{c, 0}=\frac{\varepsilon_{c R 2,0} \cdot E_{c m}}{2} \cdot b \cdot x_{0}$

Analog kann über die Stahlfläche die Kraft in der Bewehrung mit der mittleren Dehnung errechnet werden. Die Stahlfläche wird wieder durch eine querschnittsabhängige Formulierung nach Gleichung (3-5) ersetzt.

$F_{s 1,0}=\varepsilon_{s 1,0} \cdot E_{s} \cdot \rho_{s 1} \cdot b \cdot h$

Über das Gleichgewicht der horizontalen Kräfte können die Betondruckkraft und die Stahlzugkraft gleichgesetzt werden, da zu diesem Zeitpunkt keine weiteren Kräfte auf den Querschnitt wirken.

$\frac{-\varepsilon_{c R 2,0} \cdot E_{c m}}{2} \cdot b \cdot x_{0}=\varepsilon_{s 1,0} \cdot E_{s} \cdot \rho_{s 1} \cdot b \cdot h$

Anhand von Abbildung 33 kann folgendes Verhältnis aufgestellt werden:

$\frac{-\varepsilon_{c R 2,0}}{x_{0}}=\frac{\varepsilon_{s 1,0}}{d-x_{0}}$

Durch Umstellen wird eine Formulierung erzielt, mit der es möglich ist die Dehnungen aus Gleichung (3-29) zu eliminieren. 
$\frac{d-x_{0}}{x_{0}}=\frac{\varepsilon_{S 1,0}}{-\varepsilon_{c R 2,0}}$

Um den entsprechenden Bezeichnungen der DAfStb-Richtlinie zu folgen und eine verbesserte Übersichtlichkeit der Gleichungen zu erreichen, wird an dieser Stelle für das Verhältnis der E-Moduln der folgende Beiwert für die weitere Berechnung eingeführt.

$\alpha_{s}=\frac{E_{s}}{E_{c m}}$

Mit:

$\alpha_{s} \quad$ Verhältniswert der Elastizitätsmoduln

Nach dem Umstellen und anschließendem Einsetzen der Gleichungen (3-31) und (3-32) in die aus Gleichung (3-29) entstehende Formulierung, ergibt sich eine quadratische Gleichung, die von der Druckzonenhöhe abhängig ist. Eine Nullstelle davon entspricht der Lösung für die Druckzonenhöhe. Die Normalform dieser Gleichung lautet:

$0=x_{0}^{2}+2 \cdot \alpha_{s} \cdot \rho_{s 1} \cdot h \cdot x_{0}-2 \cdot \alpha_{s} \cdot \rho_{s 1} \cdot d \cdot h$

Über die p-q-Formel (vgl. [Papula 2014] S. 10) können zwei Lösungen für $\mathrm{x}_{0}$ ermittelt werden, wobei die positive Lösung der Druckzonenhöhe entspricht. Damit gilt für die Druckzonenhöhe zum Zeitpunkt der Verstärkung bei linear-elastischem Werkstoffverhalten unter reiner Biegung folgender Ausdruck:

$x_{0}=\left(-\alpha_{s} \cdot \rho_{s 1}+\sqrt{\left(\alpha_{s} \cdot \rho_{s 1}\right)^{2}+2 \cdot \alpha_{s} \cdot \rho_{s 1} \cdot \frac{d}{h}}\right) \cdot h$

Ohne Druckbewehrung und unter reiner Biegung ist der Angriffspunkt der Betondruckkraft mit dem Schwerpunkt des Spannungsdreiecks aus Abbildung 33 gleichzusetzen. Dieser liegt bei einem Drittel der Druckzonenhöhe unterhalb des oberen Querschnittsrands. Somit ergibt sich für den Hebelarm der inneren Kräfte:

$z_{s 1,0}=d-a_{0}=d-k_{a} \cdot x_{0}=d-\frac{1}{3} \cdot x_{0}$

Anschließend kann über das einwirkende Moment zum Zeitpunkt der Verstärkung und den inneren Hebelarm die Zugkraft der Bewehrung berechnet werden. Dabei darf gemäß DAfStb-Richtlinie das Moment realitätsnah oder mit der quasi-ständigen Belastungskombination auf Gebrauchstauglichkeitsniveau ermittelt werden, 
wie es bereits im Abschnitt 2.7.4 erörtert wurde (vgl. dazu [DAfStb 2012-03] Teil 1 Abs. 5.1.1 (RV19)).

$F_{S 1,0}=\frac{M_{E d, 0}}{Z_{S 1,0}}$

Darüber kann im linear-elastischen Bereich, resultierend aus Gleichung (3-28), die Stahldehnung berechnet werden.

$\varepsilon_{s 1,0}=\frac{F_{s 1,0}}{E_{s} \cdot \rho_{s 1} \cdot b \cdot h}$

Über das Verhältnis der Abstände zur Nulllinie ergibt sich aus der Stahldehnung die Dehnung am unteren Querschnittsrand zum Zeitpunkt „0“, die aufgrund Festlegungen aus Kapitel 2.7.4, auf Höhe der zu applizierenden Lamelle liegt.

$\varepsilon_{L, 0}=\varepsilon_{s 1,0} \cdot \frac{d_{L}-x_{0}}{d-x_{0}}$

Damit können zum Zweck der Vorbemessung die Dehnungen während des Verstärkens bestimmt werden. Anschließend kann eine beliebige (bauaufsichtlich zugelassene) CFK-Lamelle gewählt werden und mit der entsprechenden Bemessungsbruchdehnung die erforderliche Lamellenfläche mithilfe der Bemessungstafeln ermittelt werden. Alternativ können geringere Lamellendehnungen gewählt werden, mit denen in die Bemessungstafeln eingestiegen wird. Beispielsweise könnte eine solche geringere zulässige Dehnung aus dem vereinfachten Nachweis der Biegetragfähigkeit (vgl. Kapitel 2.7.6) resultieren, wodurch die aufwendige Verbundbetrachtung entfallen könnte. Mit der Gesamtdehnung kann aus den Bemessungstafeln der $\omega_{\mathrm{L}}$-Wert abgelesen und für die Berechnung der Lamellenfläche verwendet werden. Für eine genaue Berechnung kann zwischen den Tafelwerten linear interpoliert werden. Zum Zweck der Vorbemessung kann auf der sicheren Seite liegend mit dem geringeren Wert der zulässigen Gesamtdehnung gerechnet werden.

\subsubsection{Bemessungstafeln mit Druckbewehrung}

\subsubsection{Ermittlung der Eingangswerte}

Zusätzliche Druckbewehrung wird bei Stahlbetonquerschnitten eingesetzt, um sprödes Versagen der Druckzone auszuschließen. Ein Beispiel zur Erläuterung des Einsatzes von Druckbewehrung für eine wirtschaftliche Bemessung ist im Anhang E enthalten. Darin wird erläutert wie sich der Querschnitt bei starker Beanspruchung mit und ohne Druckbewehrung verhält. 


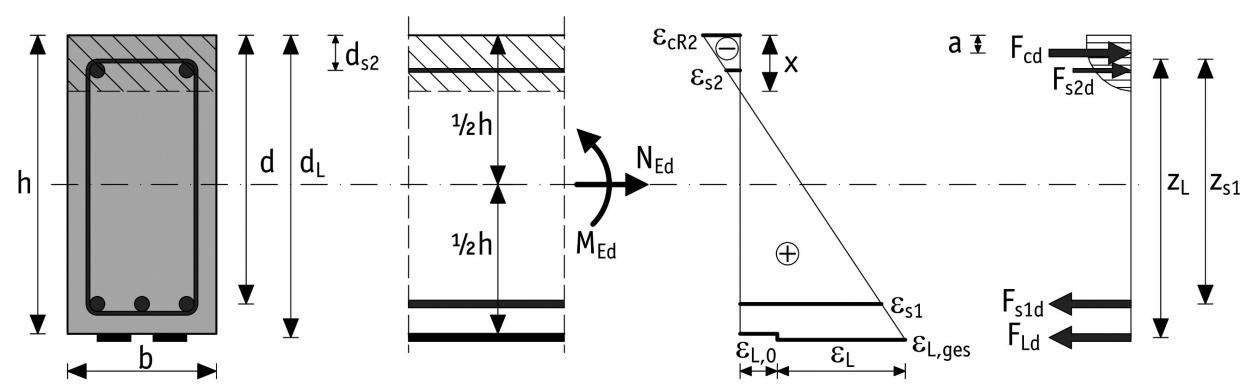

Abb. 34 Bezeichnungen am verstärkten Querschnitt (mit Druckbewehrung) (http://doi.org/10.33968/9783966270021-03-A-07)

In den folgenden Abschnitten handelt es sich lediglich um eine Erweiterung der Berechnungsansätze aus den vorherigen Kapiteln 3.2.1.1 bis 3.2.1.3 um die Anteile der Druckbewehrung. Dadurch ergibt sich aus den Gleichungen (3-1) bis (3-3) unter Berücksichtigung der Kraft in der Druckbewehrung folgender Ausdruck:

$$
\begin{aligned}
M_{E d, L}= & \alpha_{R} \cdot b \cdot x \cdot f_{c d} \cdot\left(d_{L}-k_{a} \cdot x\right)-\sigma_{s 1 d} \cdot A_{s 1} \cdot\left(d_{L}-d\right) \\
& +\sigma_{s 2 d} \cdot A_{s 2} \cdot\left(d_{L}-d_{s 2}\right)
\end{aligned}
$$

Auch für die Querschnittsfläche der Druckbewehrung wird die querschnittsabhängige Formulierung entsprechend Gleichung (3-5) für die anschließenden Berechnungen eingeführt. Ebenso wird auch an dieser Stelle der Verhältnisbeiwert nach Gleichung (3-7) aufgenommen. Weiterhin gilt auch hier die Annahme, dass die Stahlspannung die Bemessungsstreckgrenze übersteigt und somit die Druckspannung im Stahl als konstant angenommen werden kann. Daraus resultieren jedoch deutlich ungünstigere Anwendungsgrenzen für die Bemessungstafeln, weil die Stahldehnung der Druckbewehrung, aufgrund des rechnerischen Versagens der Betondruckzone bei $\varepsilon_{\text {cu2 }}=3,5 \%$ für Normalbeton, stark begrenzt ist. Im Gegensatz zur Stahlzugbewehrung, für die auch hier die Annahmen und Einschränkungen gemäß Abschnitt 3.2.1 gelten, ergibt sich dadurch ein deutlich geringerer Bereich der zulässigen bzw. möglichen Stahldehnungen für die Bemessungstafeln mit Druckbewehrung, wie in Abbildung 35 dargestellt. 


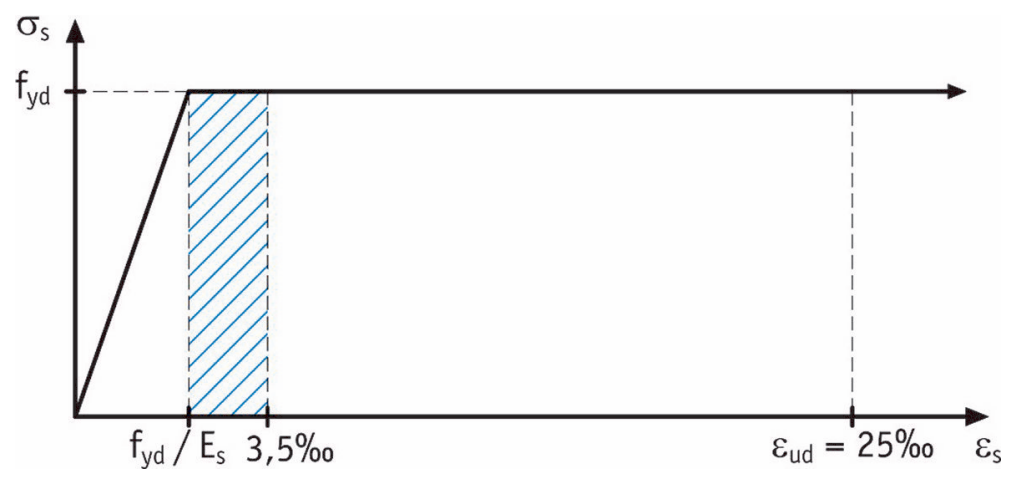

Abb. 35 zulässige Dehnung der Druckbewehrung für die Bemessungstafeln (http://doi.org/10.33968/9783966270021-03-A-08)

Außerdem kann die hier dargestellte maximale Stauchung von 3,5\%o nur in der Theorie erreicht werden, da sie am oberen Querschnittsrand auftritt. Praktisch wird die Dehnung der Druckbewehrung bei linearer Dehnungsverteilung diesen Wert nie annehmen können, da mit der Betonüberdeckung die Dauerhaftigkeit des Bauteils sichergestellt werden muss (vgl. [EC2-1-1 2011- 01] Abs. 4). Da bei den Bemessungstafeln ohne Druckbewehrung die Wahrscheinlichkeit durch den relativ großen Bereich der zulässigen Stahldehnung und die großen Lamellendehnungen äußerst hoch ist, dass sich der Stahl im Fließen befindet, wird dort eine nachträgliche Überprüfung über die Dehnungszustände als ausreichend erachtet. Aufgrund der Tatsache, dass der Bereich für die Druckbewehrung so gering ausfällt, werden die Bemessungstafeln mit Druckbewehrung um eine Spalte ergänzt, die bereits frühzeitig eine Beurteilung über die grundlegende Anwendbarkeit der Bemessungstafeln zulässt. Ein rechnerischer Ausdruck für diese Beurteilung lässt sich unmittelbar über das Dehnungsverhältnis erzielen (vgl. dazu Abbildung 34).

$\frac{\varepsilon_{c R 2}}{x}=\frac{\varepsilon_{C R 2}-\varepsilon_{s 2}}{d_{s 2}}$

Dabei ist das Ziel, dass die Dehnung der Druckbewehrung kleiner bzw. gleich der Dehnung bei Erreichen der Bemessungsstreckgrenze ist. Da es sich um eine Druckbeanspruchung handelt, ist die Bemessungsstreckgrenze negativ anzusetzen.

$\varepsilon_{s 2} \leq-\frac{f_{y d}}{E_{s}}$

Um einen Wert zu erhalten, der über die Querschnittsgeometrie zum gewünschten Ergebnis führt, wird die Höhe der Betondruckzone wieder durch die Formulierung aus Gleichung (3-8) ersetzt. Dadurch ergibt sich nach dem Umformen ein Grenz- 
wert für das Verhältnis von statischer Höhe der Druckbewehrung zur Querschnittshöhe, der nicht überschritten werden darf.

$\frac{d_{s 2}}{h} \leq \xi_{L} \cdot\left(1+\frac{f_{y d}}{E_{s} \cdot \varepsilon_{c R 2}}\right)$

Wird diese Bedingung erfüllt, können die Bemessungstafeln auch für Druckbewehrung aufgestellt werden. Die erforderlichen Werte zur Berechnung des Grenzwertes ergeben sich bei der Iteration der Dehnungszustände. Dazu kann mit den genannten Voraussetzungen, analog zu Gleichung (3-11) die folgende Formulierung aufgestellt werden:

$$
\begin{aligned}
M_{E d, L}= & \alpha_{R} \cdot b \cdot \xi_{L} \cdot h^{2} \cdot f_{c d} \cdot\left(1-k_{a} \cdot \xi_{L}\right)-f_{y d} \cdot \rho_{s 1} \cdot b \cdot h^{2} \cdot\left(1-\frac{d}{h}\right) \\
& +f_{y d} \cdot \rho_{s 2} \cdot b \cdot h^{2} \cdot\left(1-\frac{d_{s 2}}{h}\right)
\end{aligned}
$$

Durch weiteres Umformen ergibt sich (3-44).

$\frac{M_{E d, L}}{b \cdot h^{2} \cdot f_{c d}}+\frac{f_{y d}}{f_{c d}} \cdot\left(\rho_{s 1} \cdot\left(1-\frac{d}{h}\right)-\rho_{s 2} \cdot\left(1-\frac{d_{s 2}}{h}\right)\right)=\alpha_{R} \cdot \xi_{L} \cdot\left(1-k_{a} \cdot \xi_{L}\right)$

Damit kann wieder der erste Teil der Gleichung als Wert fixiert und die zugehörigen Dehnungszustände bestimmt werden. Es ist festzustellen, dass der zweite Teil aus Gleichung (3-12) identisch zum zweiten Teil dieser Gleichung ist. Damit gelten die Bemessungstafeln sowohl mit, als auch ohne Druckbewehrung und es ändert sich lediglich die Berechnung des Eingangswertes für die Bemessungstafeln sowie die Ermittlung der erforderlichen Lamellenfläche.

$\mu_{E d, L}=\frac{M_{E d, L}}{b \cdot h^{2} \cdot f_{c d}}+\frac{f_{y d}}{f_{c d}} \cdot\left(\rho_{s 1} \cdot\left(1-\frac{d}{h}\right)-\rho_{s 2} \cdot\left(1-\frac{d_{s 2}}{h}\right)\right)$

Somit lassen sich, durch Ergänzung einer Spalte für den Grenzwert $d_{s 2} / h$, die bereits berechneten Bemessungstafeln ebenso für verstärkte Stahlbetonquerschnitte mit Druckbewehrung anwenden. Dabei werden die zulässigen Dehnungszustände aus Abbildung 30 durch die zusätzliche Begrenzung der Stahldehnung noch weiter spezifiziert. Abbildung 36 stellt die endgültigen zulässigen Dehnungszustände bei Anwendung der Bemessungstafeln mit Druckbewehrung dar. An dieser Stelle wurde angenommen, dass die rechnerische Grenzdehnung der Stahlzugbewehrung nicht erreicht wird, wie es der Fall A im Kapitel 2.7.4 beschreibt. 


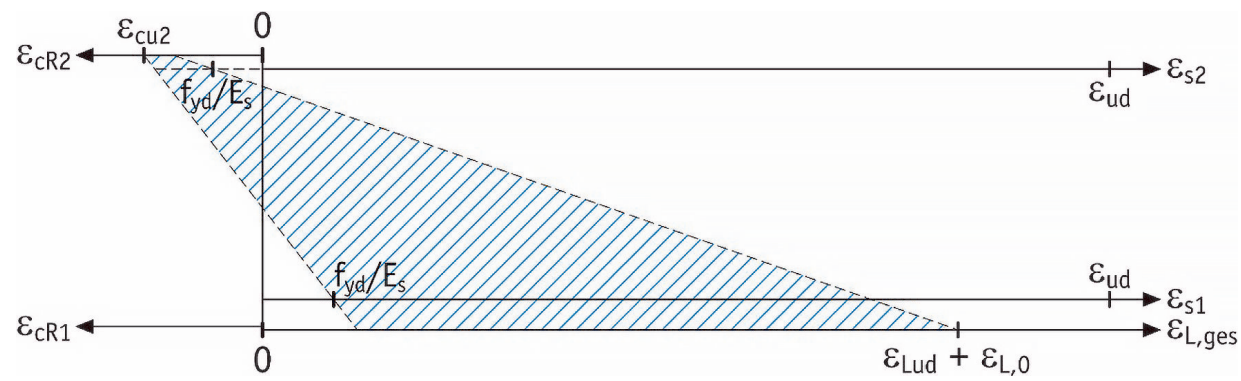

Abb. 36 zulässige Dehnungszustände für Bemessungstafeln mit Druckbewehrung (http://doi.org/10.33968/9783966270021-03-A-09)

\subsubsection{Ermittlung der Lamellenfläche}

Prinzipiell entspricht das Vorgehen an dieser Stelle der vorangegangenen Verfahrensweise zur Bestimmung der Eingangswerte. Für die Berechnung der erforderlichen Lamellenfläche erfolgt die Erweiterung der Gleichungen (3-14) bis (3-16) um den Kraftanteil der Druckbewehrung.

$\varepsilon_{L} \cdot E_{L m} \cdot A_{L}=\alpha_{R} \cdot b \cdot \xi_{L} \cdot h \cdot f_{c d}-f_{y d} \cdot \rho_{s 1} \cdot b \cdot h+f_{y d} \cdot \rho_{s 2} \cdot b \cdot h+N_{E d}$

Nach Einfügen des Beiwertes $\omega_{\mathrm{L}}$ aus Gleichung (3-13) berechnet sich die erforderliche Lamellenfläche nach (3-47).

$A_{L}=\frac{\left(\omega_{L} \cdot f_{c d}-f_{y d} \cdot\left(\rho_{s 1}-\rho_{s 2}\right)\right) \cdot b \cdot h+N_{E d}}{\varepsilon_{L} \cdot E_{L m}}$

Auch hier ist zwingend das Überschreiten der Bemessungsstreckgrenze der Biegezugbewehrung über die Dehnungszustände gemäß den Gleichungen (3-18) und (3-19) zu überprüfen. Es wird aber ebenfalls aufgrund der großen Lamellendehnungen vermutet, dass diese Annahme gerechtfertigt ist. Abschließend muss die Dehnung zum Zeitpunkt der Verstärkung ermittelt werden. .

\subsubsection{Dehnungen zum Zeitpunkt der Verstärkung}

Es wird wieder der Index „,“ bei allen veränderlichen Größen zur Verdeutlichung des Zeitpunktes vor und während der Verstärkung ergänzt. Die Berechnung der Dehnungen zu diesem Zeitpunkt erfolgt wieder über die linear-elastische Schnittgrößenermittlung mit den entsprechenden Vereinfachungen, die für eine Vorbemessung als gerechtfertigt erachtet werden. Somit stellt die Abbildung 37 die ver- 
einfachten Dehnungs- und Spannungszustände am unverstärkten Querschnitt bei linear-elastischer Schnittgrößenermittlung dar.

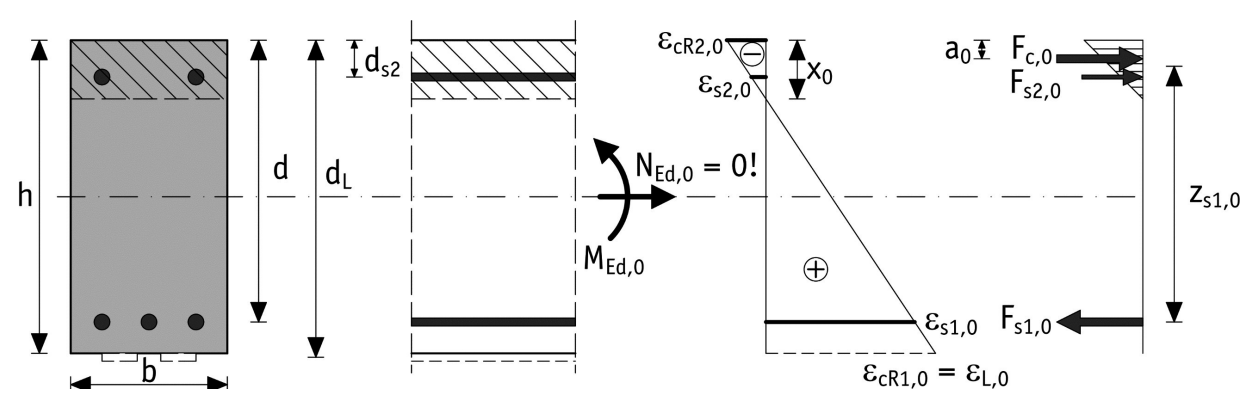

Abb. 37 Dehnungen und Spannungen zum Zeitpunkt „0“ mit Druckbewehrung (http://doi.org/10.33968/9783966270021-03-A-10)

Über das Gleichgewicht der Kräfte und mit der Voraussetzung, dass zu diesem Zeitpunkt keine Normalkraft wirkt, kann die Druckzonenhöhe berechnet werden. Die Druckkraft in der oberen Bewehrungslage ergibt sich analog der Stahlzugkraft nach (3-28). Damit kann resultierend aus dem Kräftegleichgewicht die folgende Formulierung aufgestellt werden:

$\frac{-\varepsilon_{c R 2,0} \cdot E_{c m}}{2} \cdot b \cdot x_{0}-\varepsilon_{s 2,0} \cdot E_{s} \cdot \rho_{s 2} \cdot b \cdot h=\varepsilon_{s 1,0} \cdot E_{s} \cdot \rho_{s 1} \cdot b \cdot h$

Um wieder die Dehnungen aus der Gleichung zu eliminieren, wird die Dehnung bzw. Stauchung der Druckbewehrung ins Verhältnis zur Betonrandstauchung gesetzt und in der Gleichung durch Umformen ersetzt.

$\frac{\varepsilon_{s 2,0}}{\varepsilon_{c R 2,0}}=\frac{x_{0}-d_{s 2}}{x_{0}}$

Der Verhältniswert der E-Moduln kann direkt aus (3-32) übernommen werden, da gemäß EC2 der E-Modul für Betonstahl festgelegt ist (vgl. [EC2-1-1 2011-01] Abs. 3.2.7) und die gesamte Vorbemessung in dieser Arbeit darauf beruht. Durch Umformen von (3-48) und Einsetzen der genannten Vereinfachungen entsteht wieder eine quadratische Gleichung, deren Lösung die Druckzonenhöhe enthält.

$0=x_{0}^{2}+2 \cdot \alpha_{s} \cdot\left(\rho_{s 1}+\rho_{s 2}\right) \cdot h \cdot x_{0}-2 \cdot \alpha_{s} \cdot\left(\rho_{s 1} \cdot d+\rho_{s 2} \cdot d_{s 2}\right) \cdot h$

Daraus ergibt sich die Druckzonenhöhe wie folgt: 
$x_{0}=\left(-\alpha_{s} \cdot\left(\rho_{s 1}+\rho_{s 2}\right)+\sqrt{\left(\alpha_{s} \cdot\left(\rho_{s 1}+\rho_{s 2}\right)\right)^{2}+2 \cdot \alpha_{s} \cdot\left(\rho_{s 1} \cdot \frac{d}{h}+\rho_{s 2} \cdot \frac{d_{s 2}}{h}\right)}\right) \cdot h$

Die Dehnung soll wieder über die Stahlzugkraft und den inneren Hebelarm ermittelt werden. Es ergibt sich aber ein abweichender innerer Hebelarm zu Kapitel 3.2.1.3. Dieser lässt sich nicht ausschließlich über den Schwerpunkt des Spannungsdreiecks der Betondruckkraft ermitteln, da sich die Druckkraft als Resultierende der Betondruckkraft und Stahldruckkraft ergibt. Hierfür kann die vereinfachte Annahme des DAfStb aus dem Anhang RV L.1 zur Richtlinie übernommen werden, die sich bei probeweisen Rechnungen als ausreichend genau für den Zweck einer Vorbemessung erwiesen hat.

$z_{s 1,0} \approx d-0,4 \cdot x_{0}$

Eine genauere Berechnung bei linear-elastischer Schnittgrößenermittlung ist mit den idealisierten Spannungs-Dehnungs-Linien durchaus möglich. Dadurch steigt aber der Rechenaufwand an, wobei die Genauigkeit aufgrund der Vereinfachungen nicht maßgebend gesteigert werden kann. Diese genauere Berechnung des inneren Hebelarms ist informativ im Anhang D beschrieben. Anschließend können mit dem inneren Hebelarm unter Verwendung der Gleichungen (3-36) bis (3-38) die Dehnungen zum Zeitpunkt der Verstärkung bestimmt werden, wobei keine weitere Anpassung für die Druckbewehrung erforderlich ist, da diese bereits über den inneren Hebelarm integriert ist.

Zusammenfassend sind alle erforderlichen Formeln für die Eingangswerte und Berechnungen der Bemessungstafeln in Anhang A (ohne Druckbewehrung) und Anhang B (mit Druckbewehrung) aufgeführt. Daran schließen sich die gesamten Bemessungstafeln im Anhang $\mathrm{C}$ an.

\subsection{Nachweis der Verbundkraftübertragung am ZRE}

\subsubsection{Excel-Arbeitsmappe für die Nachweisführung}

Nachdem im vorangegangen Kapitel die reine Biegebemessung behandelt wurde, soll nun eine Vereinfachung des Verbundnachweises folgen. Eine weitgehende Vereinfachung der Formeln wurde bereits vom DAfStb vorgenommen (vgl. Kapitel 2.7.5.4 und 2.7.6). Hierbei handelt es sich jeweils um Vereinfachungen der Ausgangsgleichungen des genaueren Nachweises der Lamellenkraftänderung am ZRE (vgl. Abs. 2.7.5.2), wobei die Genauigkeit und somit die Wirtschaftlichkeit abnimmt ([Finckh 2012] S. 223). Zur Verdeutlichung ist dies einmal am Ausnutzungsgrad des Verbundnachweises je nach Nachweisverfahren für einen Stahlbetonrechteckquerschnitt in Abbildung 38 dargestellt. 


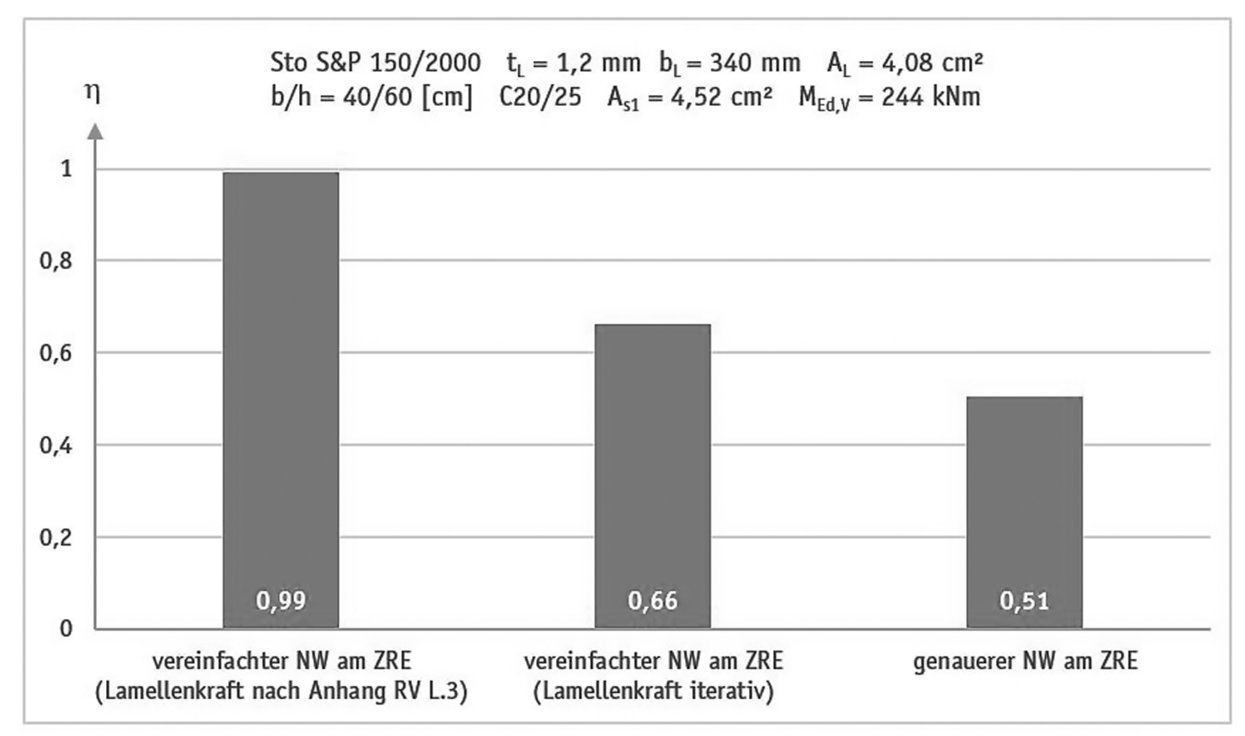

Abb. 38 Ausnutzungsgrad Verbundnachweis in Abhängigkeit des Nachweisformats (http://doi.org/10.33968/9783966270021-03-A-11)

Die Problematik besteht jedoch weniger in der komplexen Nachweisführung gemäß DAfStb- Richtlinie, als in der iterativen Berechnung der Lamellenkraft an jedem Biegeriss des Bauteils. Beispielhaft ist diese aufwendige Berechnung an einer Stahlbetondecke in Abschnitt 4.5 dargestellt. Eine Vereinfachung analog zur Biegebemessung müsste es zulassen die Lamellenkraft an jedem Riss bestimmen zu können, ohne dass ein Werkstoff an seine rechnerische Grenzdehnung stößt. Eine solche Vereinfachung und ein derart hoher Rechenaufwand lässt sich in der Praxis nur noch mittels computergestützter Rechentechnik lösen. Ein Tabellenkalkulationsprogramm, wie Microsoft Excel, genügt dazu. Der Vorteil von Excel liegt darin, dass bereits der Solver zur Lösung von iterativen Problemen als Add-In werkseitig mitgeliefert wird. Der Solver löst komplexe Iterationsvorgänge mit einer festgelegten maximalen Anzahl an Nebenbedingungen in relativ kurzer Zeit, abhängig von der zur Verfügung stehenden Rechenleistung. Es wird zwar als nachteilig erachtet, dass die Programmierung und der hinterlegte Algorithmus nicht einsehbar sind, jedoch ist der Solver in den Berechnungen signifikant schneller als jedes von Hand konfigurierte Annäherungsverfahren. Weiterhin ist bekannt, dass der Solver mit dem Newton-Verfahren arbeitet, um näherungsweise zum Ergebnis zu gelangen. Die Vorgehensweise des Newton- Verfahrens ist im Anhang F beschrieben. Außerdem lässt sich mit Microsoft Visual Basic for Applications (VBA) eine Excel-Arbeitsmappe dahingehend aufbereiten, dass der potentielle Nutzer nur noch die Systemund Baustoffkennwerte eingeben muss und die Berechnung dann automatisiert durchgeführt wird. 
In den folgenden Kapiteln wird das Vorgehen verdeutlicht. Aufgrund der Größe der Arbeitsblätter wird empfohlen die Excel-Arbeitsmappe „Verbundnachweis_aufgeklebte_CFK-Lamellen.xlsm“ separat zu öffnen und zum besseren Verständnis heranzuziehen. Diese befindet sich auf dem beiliegenden Datenträger. Zur Bearbeitung wurde die aktuellste Excel-Version 2016 verwendet.

\subsubsection{Konfiguration der Excel-Arbeitsmappe}

\subsubsection{Einschränkungen}

Im Folgenden wird die Konfiguration der Excel-Tabelle für die gesicherte Nachweisführung der Verbundkraftübertragung am Zwischenrisselement vorgestellt. Dazu sind an dieser Stelle wiederum einige Einschränkungen erforderlich, um das Ausmaß dieser Arbeit zu begrenzen. Unter anderem sind folgende Festlegungen für die weitere Bearbeitung getroffen worden:

- statisches System: Einfeldträger auf zwei Stützen (nicht eingespannt)

- ausschließlich konstante Streckenlasten

- nur eine veränderliche Einwirkung

- Stahlbeton-Rechteckquerschnitt: Biegebalken oder einachsig gespannte Platte

- ständige und vorübergehende Bemessungssituation im GZT

Dabei soll der genauere Verbundnachweis am ZRE für die aufgeklebten CFK-Lamellen (gemäß Abschnitt 2.7.5.2) geführt werden. Das ergibt sich aus der größtmöglichen Wirtschaftlichkeit dieses Nachweisformats, wie Abbildung 38 beispielhaft darstellt. Ein Nachweis der Endverankerung erfolgt aufgrund der in 2.7.3 genannten Aspekte nicht.

\subsubsection{Userform - Eingangswerte für den Verbundnachweis am ZRE}

In diesem Abschnitt wird zuerst die erstellte Eingabemaske beschrieben, um im anschließenden Kapitel zu erklären, welche Rechenschritte in der Excel-Arbeitsmappe zur Nachweisführung umgesetzt werden. Zum besseren Verständnis wird empfohlen die Excel-Arbeitsmappe heranzuziehen. Diese befindet sich auf dem beiliegenden Datenträger. Mit dem VBA-Editor wurde eine Userform (Eingabemaske) erstellt, über die der Anwender sämtliche Eingaben in der Arbeitsmappe tätigt. Die Arbeitsblätter sind für den Benutzer gesperrt, um zu verhindern, dass Änderungen an den Formeln in den einzelnen Zellen vorgenommen werden können. Beim Start der Excel-Tabelle startet die Userform automatisch, sofern die Inhalte aktiviert sind. Werden die Makros beim Start nicht über die Schaltfläche „Inhalt aktivieren“ zugelassen (vgl. Abbildung 39), kann an der gesamten Tabellenkalkulation keine Änderung vorgenommen werden. 


\section{SICHERHEITSWARNUNG Makros wurden deaktiviert. Inhalt aktivieren}

Abb. 39 Schaltfläche „Inhalt aktivieren“ (http://doi.org/10.33968/9783966270021-03-A-12)

Sobald die Schaltfläche bestätigt wird, startet die vierseitige Eingabemaske automatisch. Auf der ersten Seite werden grundsätzliche Kennwerte zur Bauteilgeometrie und die effektive Stützweite abgefragt. Diese ersten Eingaben sind durch die Einschränkungen gemäß Abschnitt 3.3.2.1 begrenzt. Daraus resultiert außerdem die Auswahlmöglichkeit zwischen einem Biegebalken und einer einachsig gespannten Platte. Hinzu kommen die Einwirkungen, die ausschließlich als Gleichstreckenlasten auf den Einfeldträger wirken. Dabei können die Lasten in Abhängigkeit vom Zeitpunkt des Auftretens eingegeben werden.

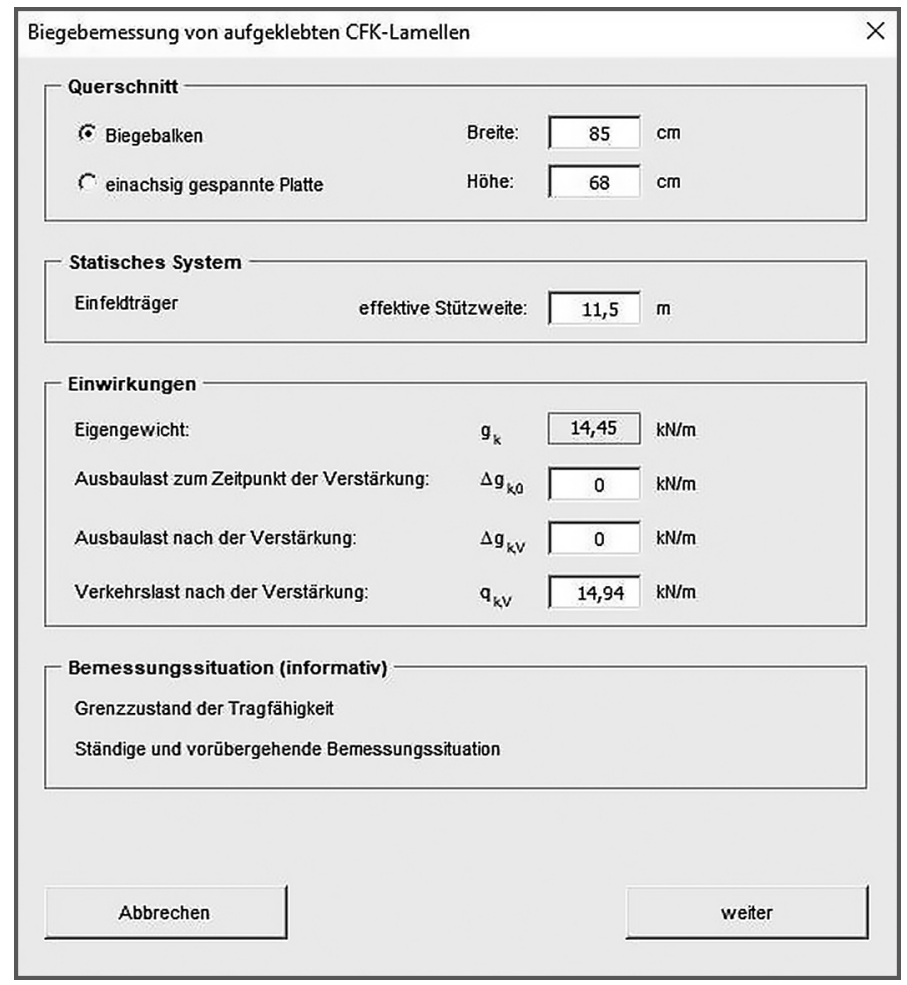

Abb. 40 Userform Startseite (http://doi.org/10.33968/9783966270021-03-A-13)

Das Eigengewicht wirkt sowohl vor, als auch nach der Verstärkungsmaßnahme und errechnet sich aus den Querschnittsabmessungen gemäß Gleichung (3-53). 


$$
g_{k}=b \cdot h \cdot \gamma_{S t b}
$$

Mit:

$\gamma_{\text {Stb }} \quad$ Wichte des Stahlbetons $\left(25 \mathrm{kN} / \mathrm{m}^{3}\right.$ [Schneider et al. 2012])

Im Allgemeinen sollten sämtliche Ausbauten zumindest temporär zurückgebaut werden, um die Dehnungen zum Zeitpunkt der Verstärkung so gering wie möglich zu halten. Für den Fall, dass Teile des Ausbaus nicht zurückgebaut werden, besteht die Möglichkeit in der Eingabemaske eine Ausbaulast zum Zeitpunkt der Verstärkung zu berücksichtigen. Verkehrslasten oder andere veränderliche Einwirkungen sollen während der Verstärkung nicht auf den Querschnitt wirken. Anschließend können die neuen Lasten, die auf das Tragwerk im endgültigen verstärkten Zustand wirken, eingegeben werden. Dazu wurde eine Ausbaulast und eine veränderliche Verkehrslast berücksichtigt. Informativ wird im unteren Teil auf die Bemessungssituation hingewiesen (Abbildung 40).

Auf der folgenden Seite werden die Materialkennwerte des Betons eingegeben (Abbildung 41). Dazu muss insbesondere die Festigkeitsklasse des Betons bekannt sein, die am Bauteil zu ermitteln ist. Daraus werden die folgenden Werte abgeleitet, die sich aus dem EC2 ergeben, wie es im Kapitel 2.4.1 bereits beschrieben ist. Da es sich oftmals um Bestandsbauteile handelt, sind die Beiwerte der Langzeitauswirkungen veränderlich, um dem Anwender die Eingabe anderer Werte in den Grenzen des EC2 (zuzüglich NA) zu ermöglichen. Es wird empfohlen die voreingestellten Werte gemäß den gültigen Normen $\mathrm{zu}$ verwenden. Abschließend muss auf dieser Seite die Oberflächenzugfestigkeit des Betons eingetragen werden, die einen maßgebenden Einfluss auf den Nachweis der Verbundkraftübertragung hat, wie aus Kapitel 2.7.5.2 hervorgeht. Gemäß DAfStb-Richtlinie darf diese nur zwischen 1,0-4,0 N/mm² liegen und ist am Bauteil zu ermitteln. 


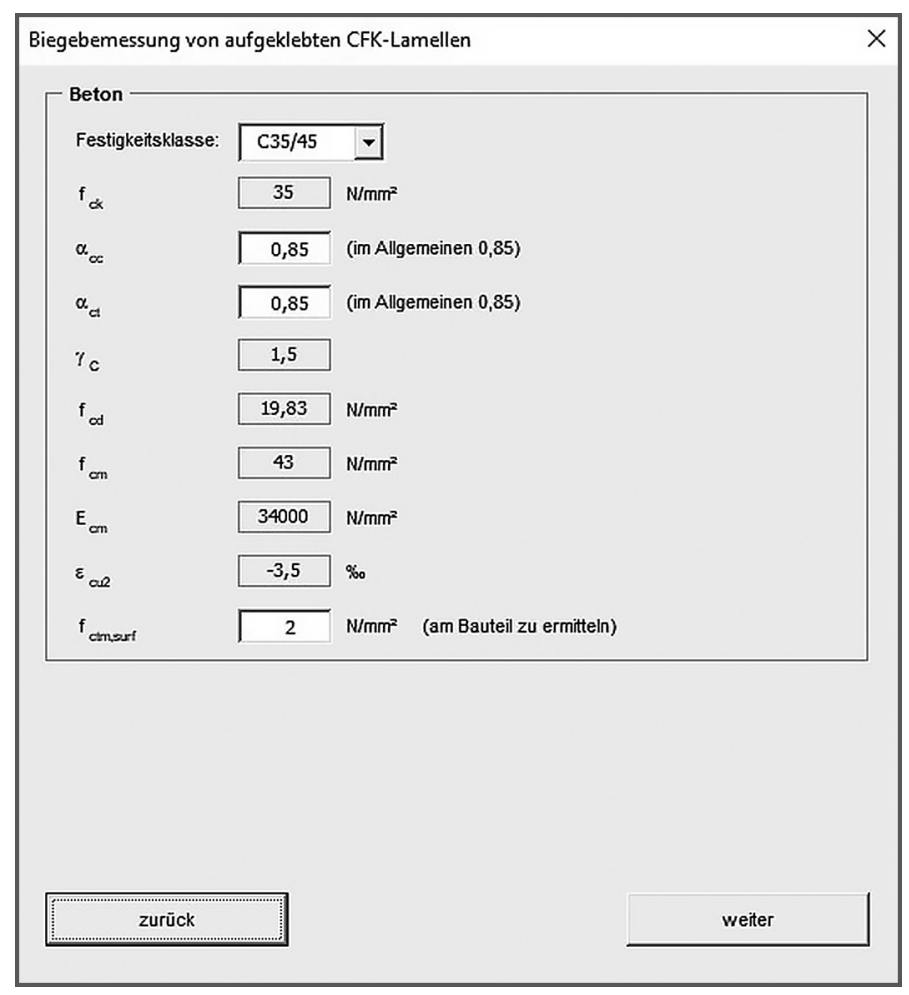

Abb. 41 Userform Seite 2 (http://doi.org/10.33968/9783966270021-03-A-14)

Anschließend folgen die Kennwerte des Betonstahls. Laut DAfStb-Richtlinie dürfen auch ältere Betonstähle angesetzt werden. Dabei können die Eigenschaften der verwendeten Bewehrung von den aktuell gültigen Bemessungsansätzen des EC2 abweichen (vgl. [DAfStb 2012-03] Teil 1 Abs. 3.2). In der Richtlinie wird dazu auf das DBV-Merkblatt „Bauen im Bestand - Beton und Betonstahl“ verwiesen (vgl. [DAfStb 2012-03] Abs. 3.2.2). Für den Verbundnachweis, bzw. für die Ermittlung des Rissabstandes, sind die Verbundbedingungen sowie die Oberflächenbeschaffenheit der einbetonierten Bewehrung von entscheidender Bedeutung (vgl. Kapitel 2.7.5.3). Die weiteren Eigenschaften und geometrischen Angaben können in den dafür vorgesehenen Feldern eingetragen werden. Sollten die Eigenschaften des Betonstahls von der Bemessung nach EC2 abweichen, wird der Nutzer in Form eines informativen Pop-Ups nach Betätigen der Schaltfläche „weiter“ darauf aufmerksam gemacht, um versehentliche Änderungen zu vermeiden. Sofern dann durch den Nutzer keine Änderung erfolgt, bleiben diese Werte erhalten. Insgesamt können bei Biegebalken bis zu drei Stabdurchmesser berücksichtigt werden (Abbildung 42). 


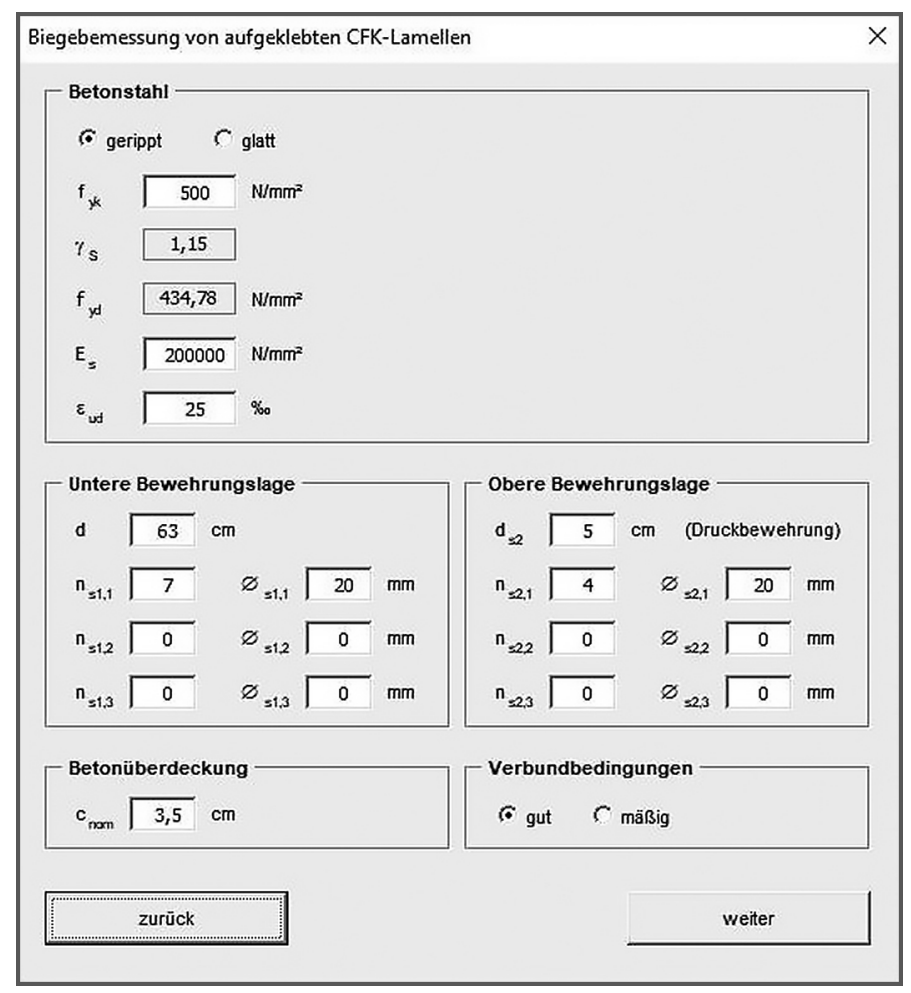

Abb. 42 Userform Seite 3 (Biegebalken) (http://doi.org/10.33968/9783966270021-03-A-15)

Alternativ besteht die Möglichkeit einen Stabdurchmesser und den Achsabstand jeweils für die Druck- und Zugbewehrung einzugeben, sofern auf der ersten Seite die Option „einachsig gespannte Platte“ ausgewählt wurde. Dabei weicht die Darstellung der Seite 3 nur im Bereich der Bewehrungslagen von der vorherigen Variante ab. In Abbildung 43 ist der entsprechende abweichende Ausschnitt dargestellt. 


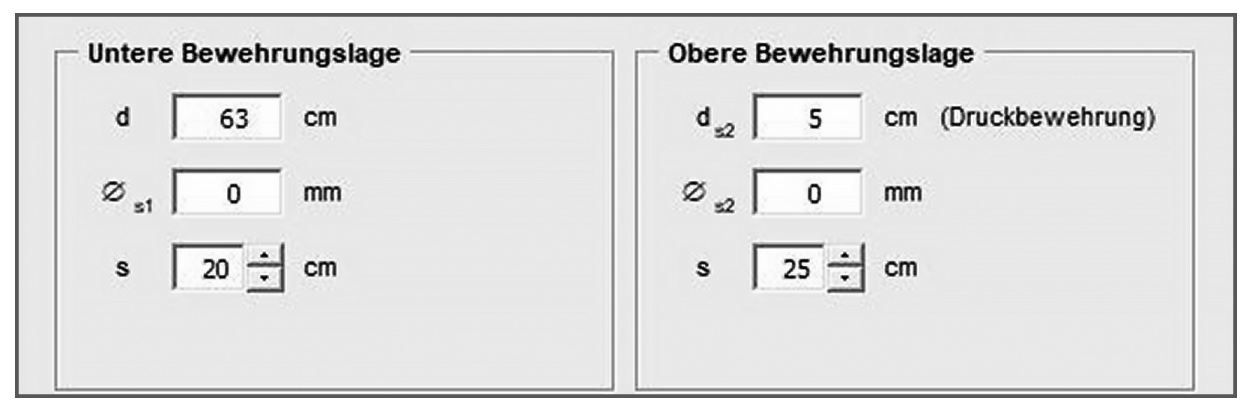

Abb. 43 Userform Seite 3 Ausschnitt (einachsig gespannte Platte)

(http://doi.org/10.33968/9783966270021-03-A-16)

Auf der letzten Seite hat der Nutzer die Möglichkeit ein Lamellensystem zu wählen. Hier sind alle aktuell durch das DIBt in Deutschland zugelassenen Systeme für aufgeklebte CFK-Lamellen mit den entsprechenden Kennwerten hinterlegt. Danach kann die statische Höhe der CFK-Lamelle angepasst werden, die jedoch in etwa der Querschnittshöhe entsprechen sollte. Durch die Vorgabe der DAfStb-Richtlinie von maximal doppelt übereinander verklebten CFK-Lamellen mit einer Gesamtdicke von höchstens 3,0 mm (zuzüglich Klebeschichtdicke von jeweils 0,5 cm) darf der Wert maximal 1,3 cm von der Querschnittshöhe abweichen, wodurch eine Begrenzung für das Eingabefeld resultiert. 


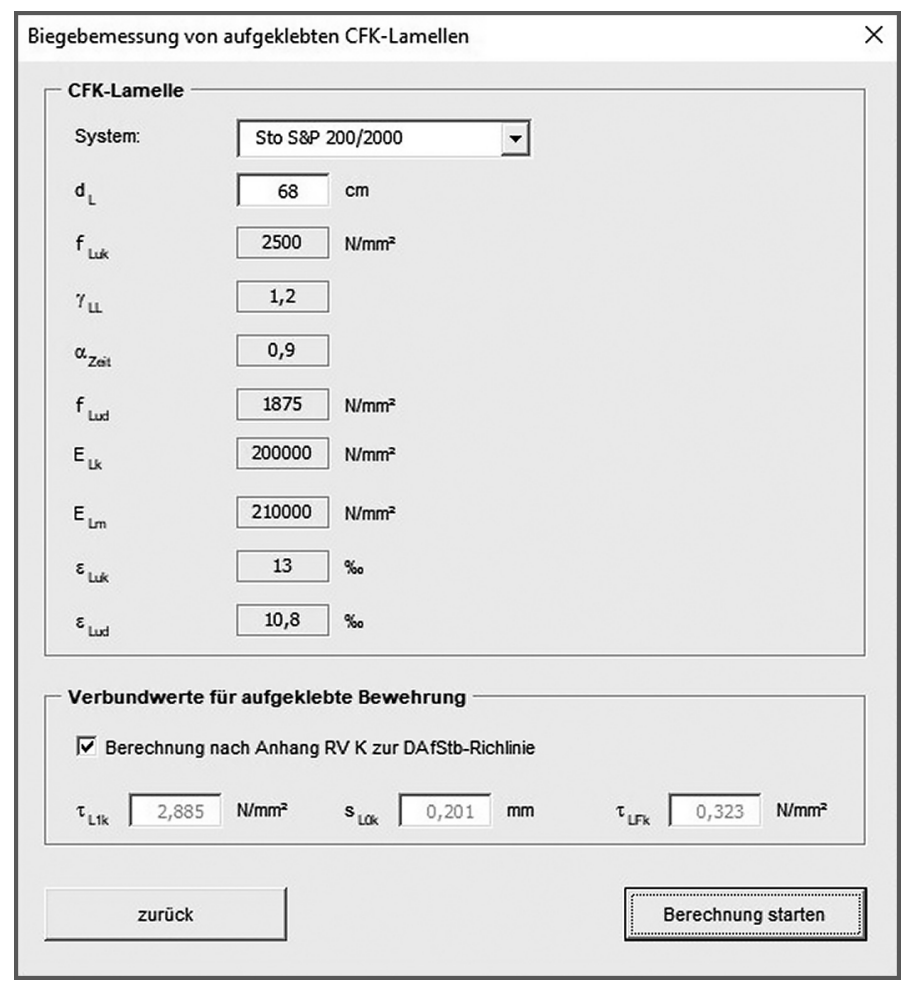

Abb. 44 Userform Seite 4 (http://doi.org/10.33968/9783966270021-03-A-17)

Im unteren Teil dieser Seite sind die Verbundwerte des bilinearen Ansatzes der aufgeklebten Bewehrung inklusive des Anteils der Reibverbundspannung aufgeführt, die sich aus den Bauteilkennwerten ergeben (vgl. Kapitel 2.7.5.2). An dieser Stelle wird empfohlen die vorgegebenen Werte nach Anhang RV K zur DAfStbRichtlinie zu verwenden. Es steht jedem Nutzer frei die Systembeiwerte nach bestem Wissen abzuändern, sofern sich andere Ansätze dafür ergeben. Mit dem Betätigen der Schaltfläche „Berechnung starten“ beginnt der Berechnungsvorgang. Vorher wird noch ein Pop-Up-Fenster geöffnet, um darauf hinzuweisen, dass die Berechnung aufgrund des iterativen Vorgangs einige Minuten dauern kann.

\subsubsection{Aufbau der Excel-Arbeitsmappe}

Um den Berechnungsvorgang zu erläutern, muss der Aufbau der Excel-Arbeitsmappe bekannt sein, die aus den folgenden fünf Arbeitsblättern besteht:

- Eingabe

- Biegenachweis 
- Rissabstand

- Genauerer_NW

- Daten

Das erste Arbeitsblatt „Eingabe“ gibt alle eingegebenen Werte der Userform aus (Abbildung 45). Sobald eine Eingabe in der Userform geändert wird, erscheint diese entweder direkt oder nachdem betätigen der Schaltfläche „weiter“ in den gelb hinterlegten Feldern. Sämtliche Felder ohne farbliche Hervorhebung sind mit entsprechenden Formeln versehen und ergeben sich aus den Eingabewerten. Außerdem lässt sich von diesem Arbeitsblatt aus die Eingabemaske erneut über die Schaltfläche „Eingabe starten“ öffnen. Die angezeigten Werte dienen als Ausgangswerte für alle folgenden Berechnungsvorgänge in der Arbeitsmappe. Alle zugehörigen Formelzeichen und Einheiten sind in den direkt angrenzenden Zellen enthalten. Außerdem enthalten die folgenden Arbeitsblätter in den oberen Zeilen jeweils eine Verknüpfung zu den erforderlichen Werten aus dem Arbeitsblatt „Eingabe“. Damit sollen die Berechnungen und die Nachweisführung auf jedem Arbeitsblatt möglichst transparent und nachvollziehbar sein.

Das Eigengewicht des Stahlbetonbalkenquerschnitts ergibt sich nach (3-53). Da es sich um einen Einfeldträger mit gleichmäßiger Streckenlast handelt, kann das maximale einwirkende Moment wie folgt berechnet werden ([Schneider et al. 2012]):

$M_{E d}=\frac{p_{d} \cdot l^{2}}{8}$

Mit:

$p_{d} \quad$ Bemessungseinwirkung

$l \quad$ effektive Stützweite

Die Bemessungseinwirkung ergibt sich dabei für die ständige und vorübergehende Bemessungssituation gemäß Kapitel 2.3. Allerdings werden die Lasten zum Zeitpunkt der Verstärkung (Index „0“) auf Gebrauchstauglichkeitsniveau angesetzt, wie es von der DAfStb-Richtlinie vorgegeben wird (siehe dazu Kapitel 2.7.4). 


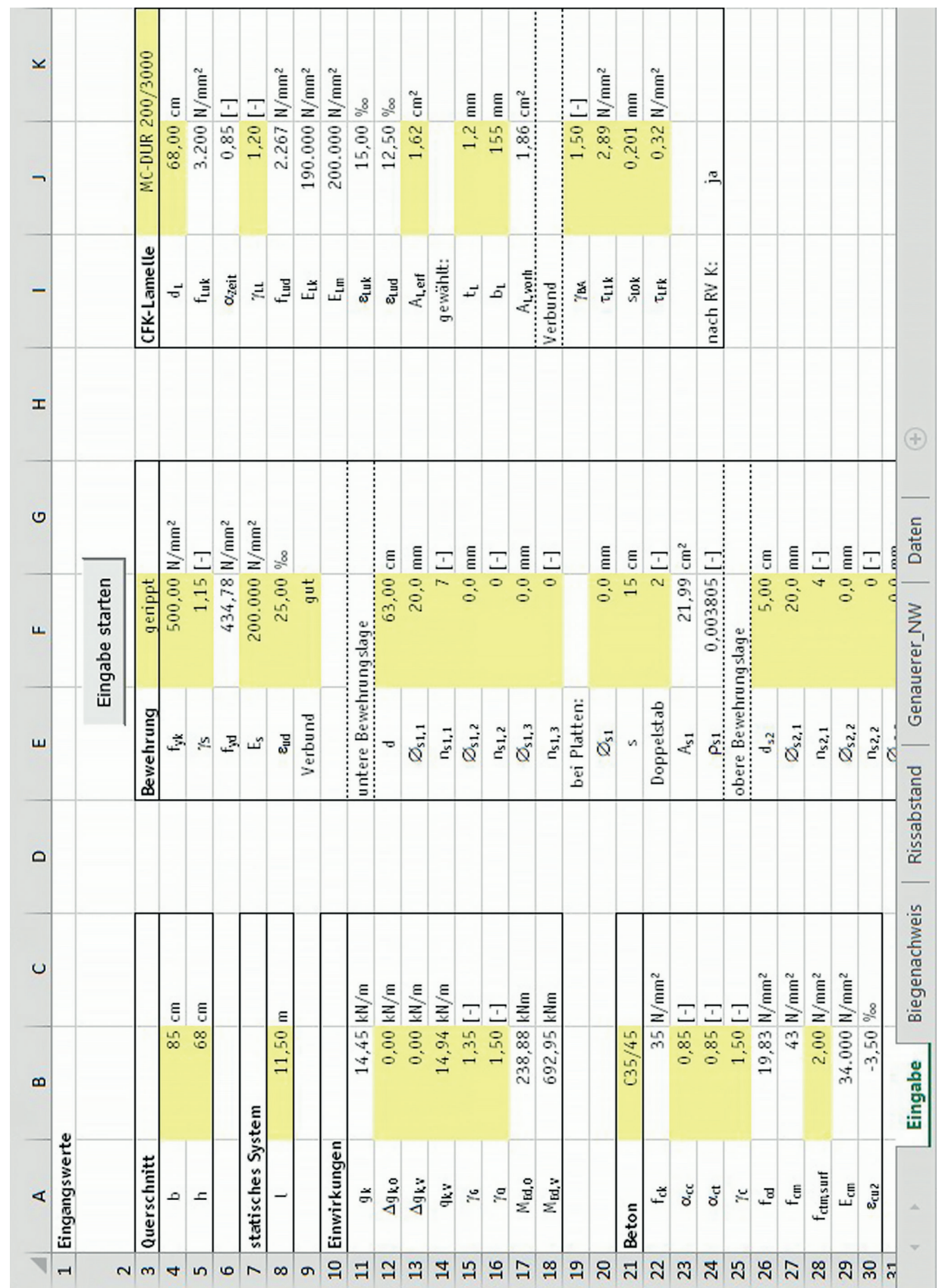

Abb. 45 Excel-Arbeitsblatt „Eingabe“ (http://doi.org/10.33968/9783966270021-03-A-18) 
Die Kennwerte des Betons, der Bewehrung und der aufgeklebten CFK-Lamellen ergeben sich aus den Kapiteln 2.4.1 bis 2.4.3. Dabei sind für die Betonfestigkeitsklassen sowie für die Lamellensysteme die zugehörigen Kennwerte des EC2 bzw. der aktuell gültigen DIBt-Zulassungen im Arbeitsblatt „Daten“ hinterlegt (vgl. Abbildung 46). Somit steht dem Anwender eine vorkonfigurierte Auswahl zur Verfügung.

\begin{tabular}{|c|c|c|c|c|c|c|c|}
\hline 4 & A & B & C & D & $\mathrm{E}$ & $\mathrm{F}$ & G \\
\hline 1 & Daten & & & & & & \\
\hline \multicolumn{8}{|l|}{2} \\
\hline 3 & Beton & & & & & & \\
\hline 4 & Festigkeitskl. & $f_{c k}$ & $\varepsilon_{\mathrm{cu2}}$ & & & & \\
\hline 5 & $\mathrm{C} 12 / 15$ & 12 & $-3,5$ & & & & \\
\hline 6 & $\mathrm{C} 16 / 20$ & 16 & $-3,5$ & & & & \\
\hline 7 & $\mathrm{C} 20 / 25$ & 20 & $-3,5$ & & & & \\
\hline 8 & $\mathrm{C} 25 / 30$ & 25 & $-3,5$ & & & & \\
\hline 9 & $\mathrm{C} 30 / 37$ & 30 & $-3,5$ & & & & \\
\hline 10 & $\mathrm{C} 35 / 45$ & 35 & $-3,5$ & & & & \\
\hline 11 & $C 40 / 50$ & 40 & $-3,5$ & & & & \\
\hline 12 & $C 45 / 55$ & 45 & $-3,5$ & & & & \\
\hline 13 & $\mathrm{C} 50 / 60$ & 50 & $-3,5$ & & & & \\
\hline \multicolumn{8}{|c|}{14} \\
\hline 15 & Verbund & gerippt & glatt & & & & \\
\hline 16 & \multirow[b]{2}{*}{ gut } & $\kappa_{f b 1}$ & $\kappa_{1 \mathrm{~b} 2}$ & & & & \\
\hline 17 & & 1,0 & 1,0 & & & & \\
\hline 18 & mäßiq & 0,7 & 0,5 & & & & \\
\hline \multicolumn{8}{|c|}{19} \\
\hline 20 & \multicolumn{2}{|c|}{ zugelassene Lamellensysteme } & & & & & \\
\hline 21 & Systemname & $f_{\text {Luk }}$ & $E_{L k}$ & $E_{\mathrm{Lm}}$ & $\varepsilon_{\text {Luk }}$ & $\alpha_{\text {zeit }}$ & \\
\hline 22 & Carboplus $^{\theta} 160 / 2400$ & 2.800 & 160.000 & 162.000 & 16,0 & 0,85 & für $\mathrm{pH} 7-11$ \\
\hline 23 & Carboplus ${ }^{\theta} 160 / 2800$ & 3.200 & 164.000 & 168.000 & 18,0 & 0,85 & für $\mathrm{pH} 7-11$ \\
\hline 24 & Carboplus $^{\theta} 200 / 3000$ & 3.200 & 190.000 & 200.000 & 15,0 & 0,85 & für $\mathrm{pH} 7-11$ \\
\hline 25 & MC-DUR $160 / 2400$ & 2.800 & 160.000 & 162.000 & 16,0 & 0,85 & für $\mathrm{pH} 7-11$ \\
\hline 26 & MC-DUR $160 / 2800$ & 3.200 & 164.000 & 168.000 & 18,0 & 0,85 & für $\mathrm{pH} 7-11$ \\
\hline 27 & MC-DUR $200 / 3000$ & 3.200 & 190.000 & 200.000 & 15,0 & 0,85 & für $\mathrm{pH} 7-11$ \\
\hline 28 & Sto S\&P $150 / 2000$ & 2.350 & 160.000 & 168.000 & 15,0 & 0,90 & für $\mathrm{pH} 7-13,7$ \\
\hline 29 & Sto S\&P $200 / 2000$ & 2.500 & 200.000 & 210.000 & 13,0 & 0,90 & für $\mathrm{pH} 7-13,7$ \\
\hline 30 & & & & & & & \\
\hline & Eingabe & Bieger & weis & abstand & Genauerer_NW & Daten & ( \\
\hline
\end{tabular}

Abb. 46 Excel-Arbeitsblatt „Daten“ (http://doi.org/10.33968/9783966270021-03-A-19)

Außerdem sind die unterschiedlichen Beiwerte des Verbundes zwischen einbetonierter Bewehrung und dem Beton in Abhängigkeit der Oberflächenbeschaffenheit und der Verbundbedingungen enthalten, die durch den Anwender in der Eingabemaske ausgewählt werden können. Diese sind für die Berechnung des Rissabstandes erforderlich, der im gleichnamigen Arbeitsblatt nach Kapitel 2.7.5.3 berechnet wird. Anstelle der näherungsweisen Berechnung der DAfStb-Richtlinie wird dabei der innere Hebelarm aus der Biegebemessung des Bestands übernommen. Diese Anpassung wird eingeführt, da der innere Hebelarm in Beispielrechnungen, insbe- 
sondere bei Platten, zum Teil zu groß wurde und in einigen Fällen sogar die statische Höhe der Bewehrung überschritten hätte.

\subsubsection{Berechnungen zur Nachweisführung}

Zu Beginn der Berechnung erfolgt der reine Biegenachweis. Dazu wird die Grenztragfähigkeit des Bestandes nach Abbildung 12 bestimmt und geprüft, ob diese von dem neuen einwirkenden Bemessungsmoment überschritten wird. Sofern dieser Fall eintritt, wird mit dem Iterationsschema aus Abbildung 19 die erforderliche Lamellenfläche für das neue Bemessungsmoment bestimmt. Dabei wird in dieser ersten Berechnung die Bemessungsbruchdehnung der Lamelle angesetzt, um die kleinstmögliche Fläche aus dem Biegenachweis zu erhalten. Anschließend wird der Verbundnachweis aus Kapitel 2.7.5.2 an jedem Zwischenrisselement geführt, wobei für jeden einzelnen Riss die einwirkende Lamellenkraft iterativ bestimmt werden muss.

Da hier kein Werkstoff vollständig ausgenutzt ist (diese Möglichkeit besteht ausschließlich am Momentenmaximum), werden zwei Dehnungen gleichzeitig zu variablen Größen. Die Iteration erfolgt in Anlehnung an die Ermittlung der erforderlichen Lamellenfläche, wobei aber die Lamellenkraft über die Dehnung und die vorgegebene Lamellenfläche berechnet wird. Es werden im Einzelnen die Werte der Lamellenbreite und Dicke benötigt (vgl. Abs. 2.7.5). Dazu wird aus der Biegebemessung mittels der erforderlichen Fläche ein Anfangsquerschnitt abgeleitet. Als Ausgangswert für die Lamellendicke wurde die kleinste lieferbare Dicke von 1,2 mm der aktuell gültigen DIBt-Zulassungen gewählt, um den praktischen Gegebenheiten gerecht zu werden. Um den Biegenachweis in jedem Fall zu erfüllen, wird die daraus hervorgehende Lamellenbreite auf $5 \mathrm{~mm}$ genau aufgerundet. Darüber hinaus ist in den Zulassungen eine Mindestbreite von $50 \mathrm{~mm}$ angegeben, wodurch dieser Wert auch nicht unterschritten werden kann ([Z-36.12-84/85/86 Abs. 2.1.1). Damit kann der Verbundnachweis am ZRE geführt werden. Dann wird geprüft, ob die einwirkende Lamellenkraftdifferenz im Verhältnis zur aufnehmbaren Lamellenkraftdifferenz den Ausnutzungsgrad von $100 \%$ überschreitet. Sollte dieser Fall eintreten, wird die Lamellenfläche erhöht und der Verbundnachweis beginnend am ersten ZRE erneut durchgeführt. In erster Instanz wird die Breite um jeweils 5 mm gesteigert, bis diese an ihre Grenzen stößt. Gemäß Richtlinie muss die Lamellenlängskante mindestens den Abstand der Betonüberdeckung zu beiden Querschnittsrändern einhalten ([DAfStb 2012-03] Teil 1 Abs. RV 8.2.1.1), woraus sich die maximal zulässige Lamellenbreite ergibt (vgl. Abbildung 47). 


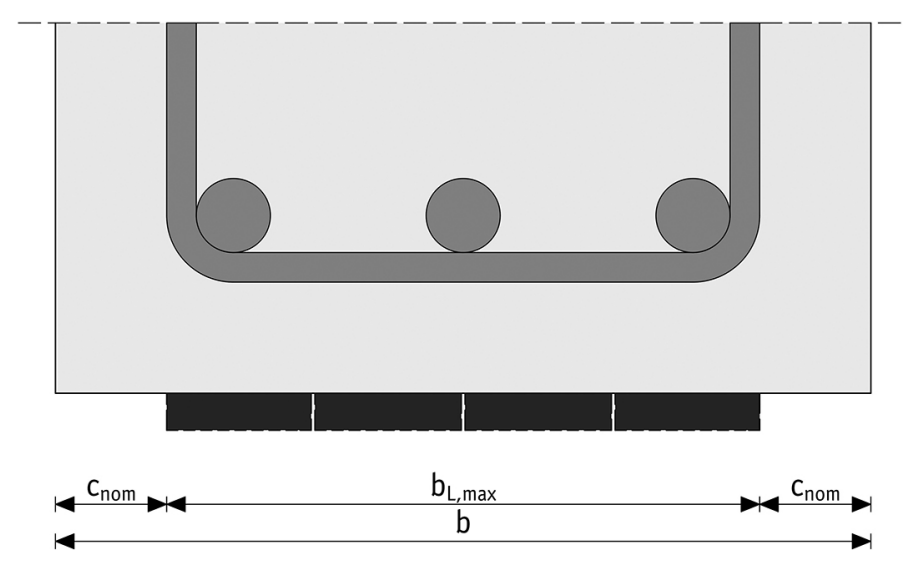

Abb. 47 maximal zulässige Lamellenbreite (http://doi.org/10.33968/9783966270021-03-A-20)

Wenn der Nachweis damit nicht erfüllt werden kann, wird die Lamellendicke um jeweils $0,1 \mathrm{~mm}$ erhöht, bis diese ebenfalls ihr Maximum erreicht. Sollte diese den maximal zulässigen Wert von 3,0 $\mathrm{mm}$ erreichen und der Nachweis noch immer nicht erfüllt werden können, kann der Nachweis für diesen Querschnitt mit dieser Einwirkung und dem gewählten Lamellensystem nicht geführt werden ([DAfStb 2012-03] Teil 1 Abs. RV 3.7). Dieser Fall kann bei sehr großen Einwirkungen oder auch großen Rissabständen durchaus eintreten. Somit wären alternative Verstärkungsmaßnahmen erforderlich. Sofern der Nachweis aber an dem betrachteten ZRE erfüllt ist, wird mit dem nächsten ZRE fortgefahren bis der letzte Biegeriss erreicht ist. Das Konfigurationsschema (Abbildung 48) verdeutlicht den Berechnungsvorgang zur Nachweisführung in der Excel-Arbeitsmappe. 


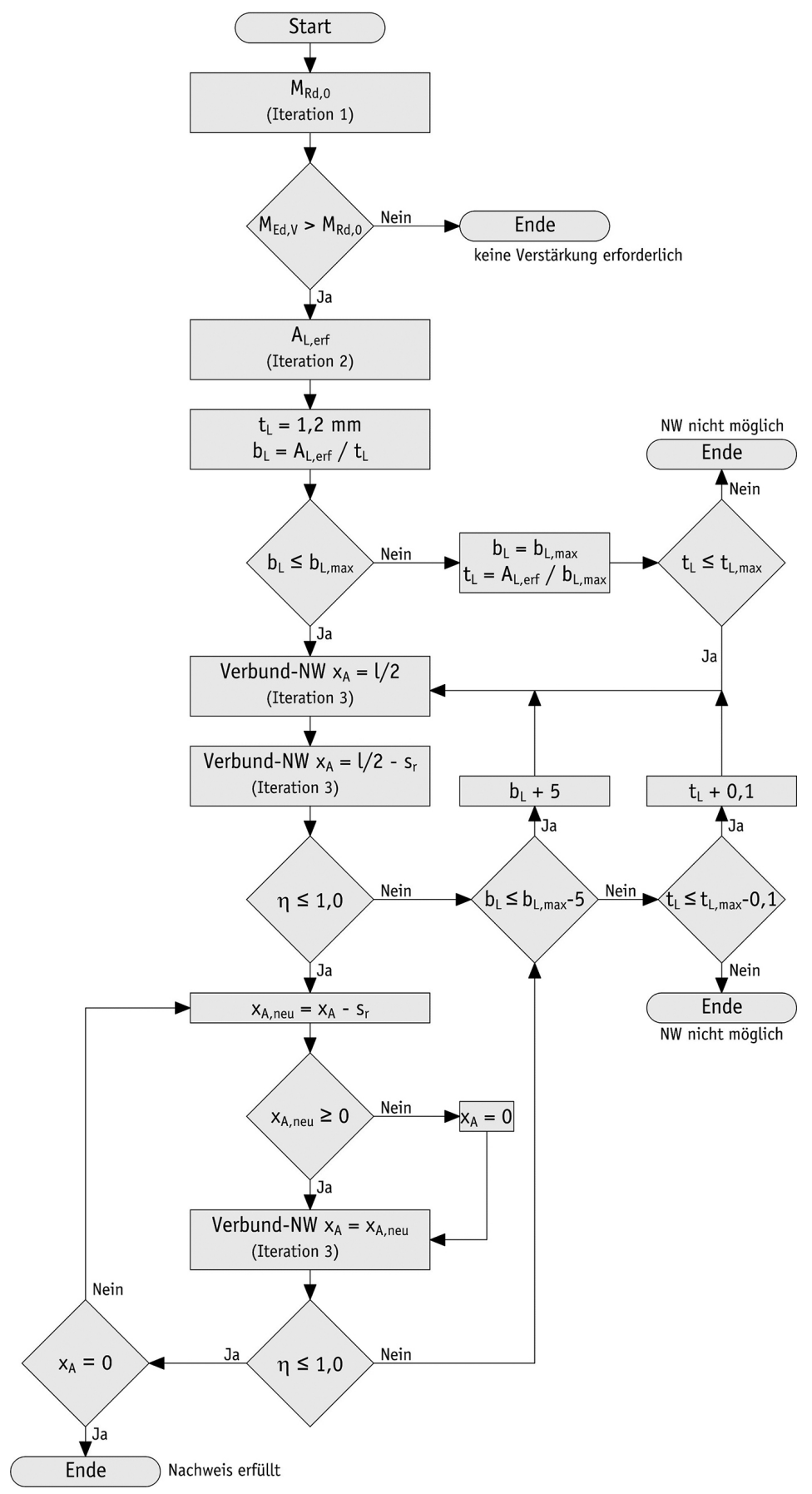

Abb. 48 Konfigurationsschema der Excel-Arbeitsmappe (http://doi.org/10.33968/9783966270021-03-A-21) 
Um die Übersichtlichkeit zu erhalten, wurden die einzelnen Iterationen aus dem Konfigurationsschema extrahiert. Die Berechnung der Tragfähigkeit im Bestand (Iteration 1) erfolgt anhand des Iterationsschemas aus Abbildung 12. An dieser Stelle wird der Solver in der Excel-Arbeitsmappe zur Lösung verwendet und mit VBA die Berechnung automatisiert (siehe Anhang G). Dabei wird anfangs ein Stahlversagen unterstellt und somit die Stahldehnung auf die maximal zulässige Bemessungsgrenzdehnung fixiert. Sofern sich damit durch Iteration der Betonrandstauchung am oberen Querschnittsrand unter den gesetzten Nebenbedingungen eine Lösung erzielen lässt, wird zum nächsten Berechnungsschritt übergegangen. Sollte der Solver keine Lösung für die Nebenbedingung des Kräftegleichgewichts finden, wird dieser Vorgang für Betonversagen wiederholt. Da im Laufe der Bearbeitung teilweise Probleme bei der Iteration mit negativen Werten auftraten (Betonrandstauchung), wurde hier ein Umweg über den Betrag der Betonrandstauchung gewählt. Tabelle 5 verzeichnet die Eingaben, die vom Solver für die Iteration übernommen werden.

Tab. 5 Solver-Iteration Biegetragfähigkeit (Bestand)

(http://doi.org/10.33968/9783966270021-03-T-01)

\begin{tabular}{lll} 
& Stahlversagen & Betonversagen \\
\hline Ziel & $\left|\varepsilon_{\mathrm{cr} 2}\right|$ maximieren & $\varepsilon_{\mathrm{s} 1}$ maximieren \\
\hline variable Zellen & $\left|\varepsilon_{\mathrm{cr} 2}\right|$ & $\varepsilon_{\mathrm{s} 1}$ \\
\hline Nebenbedingungen & $\sum \mathrm{F}=0$ & $\Sigma \mathrm{F}=0$ \\
& $\left|\varepsilon_{\mathrm{cr} 2}\right| \geq 0$ & $\varepsilon_{\mathrm{s} 1} \geq 0$ \\
& $\left|\varepsilon_{\mathrm{cr} 2}\right| \leq\left|\varepsilon_{\mathrm{cu} 2}\right|$ & $\varepsilon_{\mathrm{s} 1} \leq \varepsilon_{\mathrm{ud}}$ \\
\hline
\end{tabular}

Hieraus geht auch die in dieser Arbeit am häufigsten verwendete Funktion des VBA-Editors hervor: die If-Abfrage. Dabei wird bei der Ausführung des Makros geprüft, ob ein vorgegebener Fall eintritt und was in der Folge zu tun ist. Sofern dieser Fall nicht eintritt, wird gemäß den dafür vorgesehenen Anweisungen fortgefahren. Hat der Solver die Lösung für die Biegetragfähigkeit des Bestands errechnet, folgt die Abfrage, ob das einwirkende Bemessungsmoment diese Tragfähigkeit überschreitet. Wenn das einwirkende Moment tatsächlich geringer sein sollte, endet die Berechnung mit einem Hinweisfenster, dass keine Verstärkung notwendig ist. Andernfalls wird die Ermittlung der erforderlichen Lamellenfläche eingeleitet. Dazu erfolgt im Arbeitsblatt „Biegenachweis“ die Berechnung der Dehnungen zum Zeitpunkt der Verstärkung auf Gebrauchstauglichkeitsniveau, analog Kapitel 3.2.2.3 mit den charakteristischen Lasten. Dabei wird der mittlere Hebelarm nach Anhang D berechnet. Um die erforderliche Lamellenfläche zu berechnen, wird die Iteration 2 (vgl. Konfigurationsschema) mit dem Solver durchgeführt, wie sie im Kapitel 2.7.4 in Abbildung 19 beschrieben ist. Analog zur vorherigen Iteration wird der Solver mit den Eingaben gemäß Tabelle 6 ausgeführt. Hier wird das Gleichge- 
wicht der inneren und äußeren Schnittgrößen als Ziel eingesetzt, da die erforderliche Lamellenfläche exakt für das einwirkende Moment bestimmt werden soll. Bei diesem Vorgang wird zuerst ein rechnerisches Lamellenversagen überprüft. Sollte sich dafür keine Lösung ergeben, wird Betonversagen unterstellt und die Lamellendehnung variiert. Wie aus den Nebenbedingungen ersichtlich, wird davon ausgegangen, dass im verstärkten Zustand die rechnerisch zulässige Grenzdehnung des Betonstahls stets unterschritten wird, wie es bereits unter 2.7.4 erörtert wurde.

Tab. 6 Solver-Iteration verstärkter Querschnitt

(http://doi.org/10.33968/9783966270021-03-T-02)

\begin{tabular}{lll} 
& Lamellenversagenversagen & Betonversagen \\
\hline Ziel & $\Sigma \mathrm{M}=0$ & $\Sigma \mathrm{M}=0$ \\
\hline variable Zellen & $\left|\varepsilon_{\mathrm{cr} 2}\right|$ & $\varepsilon_{\mathrm{L}}$ \\
\hline Nebenbedingungen & $\Sigma \mathrm{F}=0$ & $\Sigma \mathrm{F}=0$ \\
& $\left|\varepsilon_{\mathrm{cr} 2}\right| \geq 0$ & $\varepsilon_{\mathrm{L}} \geq 0$ \\
& $\left|\varepsilon_{\mathrm{cr} 2}\right| \leq\left|\varepsilon_{\mathrm{cu} 2}\right|$ & $\varepsilon_{\mathrm{L}} \leq \varepsilon_{\mathrm{Lud}}$ \\
\hline
\end{tabular}

Anschließend kann der Verbundnachweis mit der berechneten Lamellenfläche geführt werden. Dazu muss das einwirkende Moment in Abhängigkeit des Abstands zum Auflager an jedem Biegeriss nach Gleichung (3-55) berechnet werden ([Zilch et al. 2013] S. 500). Da es sich um einen Einfeldträger handelt, ist der Momentenverlauf bei konstanten Streckenlasten symmetrisch. Daher muss nur eine Hälfte des Systems berechnet werden, die gleichermaßen für beide Hälften gilt. Zur Unterscheidung zwischen der Höhe der Betondruckzone und dem Abstand zum Auflager wird hier der Index „A“ ergänzt.

$M_{E d}\left(x_{A}\right)=\frac{p_{d} \cdot l}{2} \cdot x_{A}-\frac{p_{d}}{2} \cdot x_{A}^{2}$

Mit:
$M_{E d}\left(x_{A}\right) \quad$ einwirkendes Bemessungsmoment im Abstand $\mathrm{x}_{\mathrm{A}}$ zum Auflager
$p_{d} \quad$ Bemessungseinwirkung
$l \quad$ effektive Stützweite
$x_{A} \quad$ Abstand zum Auflager

Unabhängig vom einwirkenden Moment kann zum Zeitpunkt der Verstärkung die Druckzonenhöhe mit Gl. (3-51) und der innere Hebelarm nach Anhang D, unter der Voraussetzung einer linear-elastischen Schnittgrößenermittlung berechnet werden, um die Dehnungen zum Zeitpunkt „,0“ zu ermitteln. Anschließend folgt die iterative Berechnung der Lamellenkraft, die eine Handrechnung dieses Nachweises in der Praxis nahezu unmöglich macht. An allen Rissen muss durch Iteration 
ein Dehnungszustand gefunden werden, für den die Gleichgewichtsbedingungen erfüllt sind. Als iterative Größen wurden in der Excel-Arbeitsmappe die Betonrandstauchung am oberen Querschnittsrand und die Dehnung der Biegezugbewehrung angesetzt. Da die Hypothese von Bernoulli gilt, kann ebenso jede andere Dehnung für diesen Vorgang gewählt werden. Die Berechnung der Kräfte, Hebelarme und Momente erfolgt nach Kapitel 2.7.4. Zur Lösung des Problems wird der Solver mit den Eingaben gemäß Tabelle 7 verwendet.

Tab. 7 Solver-Iteration Lamellenkraft (http://doi.org/10.33968/9783966270021-03-T-03)

\begin{tabular}{ll} 
Ziel & $\Sigma \mathrm{M}=0$ \\
\hline variable Zellen & $\left|\varepsilon_{\mathrm{cr} 2}\right|$ \\
& $\varepsilon_{\mathrm{s} 1}$ \\
\hline Nebenbedingungen & $\Sigma \mathrm{F}=0$ \\
& $\left|\varepsilon_{\mathrm{cr} 2}\right| \geq 0$ \\
& $\left|\varepsilon_{\mathrm{cr} 2}\right| \leq\left|\varepsilon_{\mathrm{cu} 2}\right|$ \\
& $\varepsilon_{\mathrm{s} 1} \geq 0$ \\
& $\varepsilon_{\mathrm{s} 1} \leq \varepsilon_{\mathrm{ud}}$
\end{tabular}

Eine Begrenzung der Lamellendehnung erübrigt sich an dieser Stelle, da die Abmessungen der Lamelle aus dem Biegenachweis abgeleitet wurden. Wird die Lamellenfläche vergrößert, kann in jedem Fall der reine Nachweis der Biegetragfähigkeit erfüllt werden. Anschließend folgt der eigentliche Nachweis der Lamellenkraftübertragung am ZRE (vgl. Abs. 2.7.5.2). Abbildung 49 stellt den vorab beschriebenen Vorgang dar. 


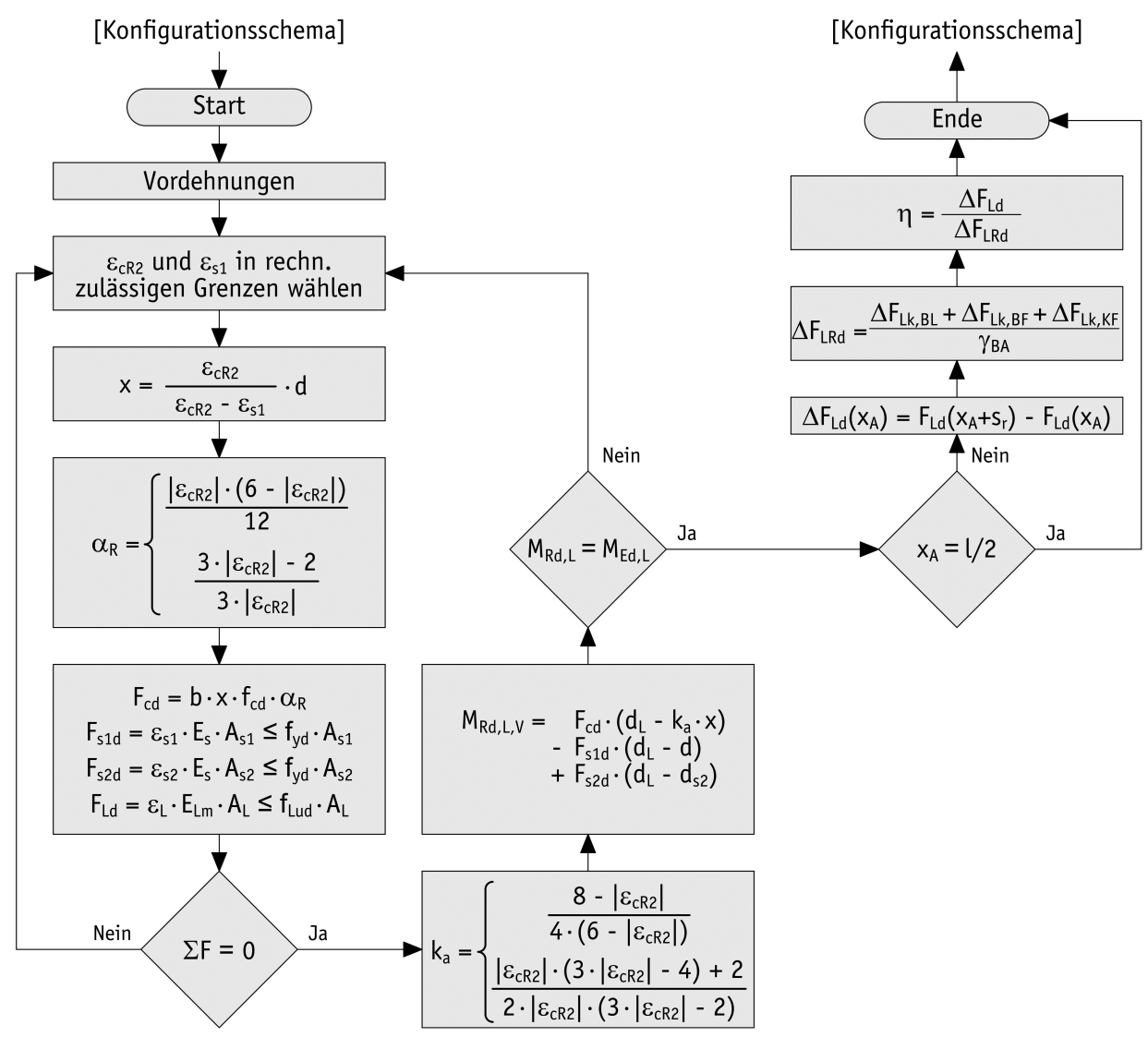

Abb. 49 Ablaufschema des Verbundnachweises am ZRE (Iteration 3) (http://doi.org/10.33968/9783966270021-03-A-22)

Dieser Vorgang erfolgt im Konfigurationsschema jeweils an der Stelle „Iteration 3“, wenn die Lamellenkraft an jedem Biegeriss iterativ berechnet werden muss, um damit den Verbundnachweis am ZRE zu führen.

Im Anhang $\mathrm{G}$ ist der gesamte Code aus dem VBA-Editor abgedruckt, der für die Übernahme der Eingabewerte und die Nachweisführung sowie die grundlegende Konfiguration der Excel-Arbeitsmappe „Verbundnachweis_aufgeklebte_CFK-Lamellen.xlsm" gemäß der vorangegangenen Beschreibung erforderlich ist. Teilweise treten bei den Berechnungen Fehlermeldungen auf, die abhängig von den Voreinstellungen der Excel-Version auf den unterschiedlichen Computern sind. Die Excel-Arbeitsmappe wurde mit Excel 2016 erstellt. Um eventuell auftretende Probleme zu beheben sind im Anhang $\mathrm{H}$ mögliche Ursachen und Lösungswege für die bekannten Fehlermeldungen beschrieben. 


\section{Beispiel}

\subsection{Ausgangssituation}

\subsubsection{Statisches System mit Einwirkungen}

Um einen Realitätsbezug herzustellen wurde zur Demonstration der Bemessungshilfsmittel und der Berechnungsvorgänge ein Beispiel aus dem Betonkalender 2013 gewählt ([Zilch et al. 2013] S. 494 ff.). Dabei werden die Nachweise mit den Bemessungshilfen in dem Umfang geführt, in dem sie in dieser Arbeit beschrieben sind. Das bedeutet im Folgenden wird einmal der vereinfachte Nachweis aus Kapitel 2.7.6 gemäß DAfStb-Richtlinie Abschnitt RV 6.1.1.2 und zum Vergleich der genauere Nachweis der Lamellenkraftänderung am ZRE (Kapitel 2.7.5.2 / DAfStbRichtlinie RV 6.1.1.3.6) geführt. Da aber eine andere Herangehensweise im Vergleich zum eigentlichen Beispiel gewählt wurde und abweichende Materialkennwerte (CFK-Lamellen) vorliegen, werden die Ergebnisse leicht voneinander abweichen.

Es handelt sich in diesem Beispiel um eine einachsig gespannte Stahlbetondecke, die infolge einer Nutzungsänderung mit aufgeklebten CFK-Lamellen verstärkt werden soll. Da die Decke auf den Wänden frei drehbar gelagert ist, handelt es sich bei dem statischen System um einen Einfeldträger (vgl. Abbildung 50). Außerdem wird angegeben, dass sich die Stahlbetondecke im Inneren eines Wohngebäudes befindet und dabei keine aussteifende Funktion übernimmt. Die Einwirkungen sind als vorwiegend ruhend deklariert und wie folgt angegeben:

Tab. 8 Einwirkungen (http://doi.org/10.33968/9783966270021-04-T-01)

\begin{tabular}{lll} 
Zeitpunkt & während der Verstärkung („,0“) & nach der Verstärkung (,,“) \\
\hline Eigengewicht $\mathbf{g}_{\mathbf{k}}$ & $4,0 \mathrm{kn} / \mathrm{m}$ & $4,0 \mathrm{kn} / \mathrm{m}$ \\
\hline Ausbaulast $\Delta \mathbf{g}_{\mathbf{k}}$ & $0 \mathrm{kn} / \mathrm{m}$ & $3,0 \mathrm{kn} / \mathrm{m}$ \\
\hline Verkehrslast $\mathbf{q}_{\mathbf{k}}$ & $0 \mathrm{kn} / \mathrm{m}$ & $5,0 \mathrm{kn} / \mathrm{m}$
\end{tabular}

Dabei bleibt in diesem Beispiel die Einwirkungskombination vor der Verstärkung unberücksichtigt, da diese keine Auswirkungen auf die weitere Berechnung dieses Beispiels hat. 


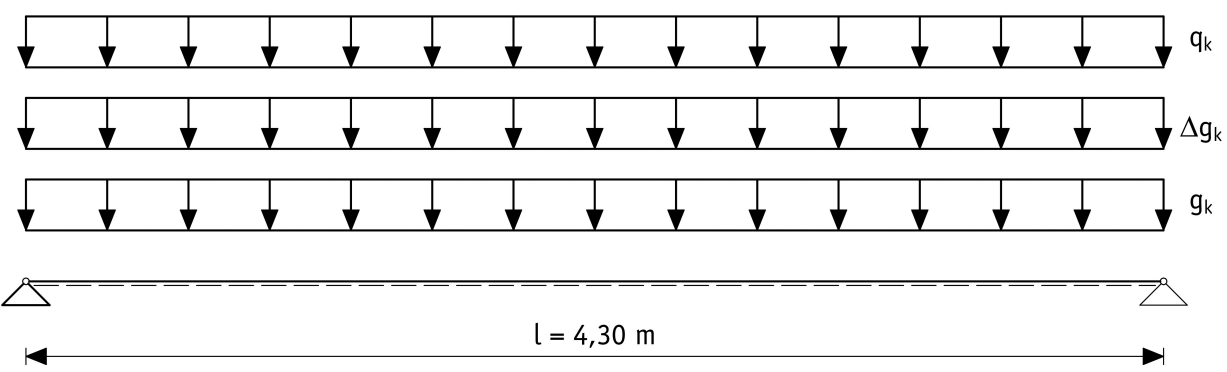

Abb. 50 statisches System mit Belastung (http://doi.org/10.33968/9783966270021-04-A-01)

Über die Abmessungen des Querschnitts kann die einwirkende Belastung aus dem Eigengewicht bestimmt werden. Die Bauteilgeometrie ist in der folgenden Abbildung dargestellt. Dabei werden einachsig gespannte Platten wie Biegebalken behandelt und pro 1 Meter Breite bemessen.

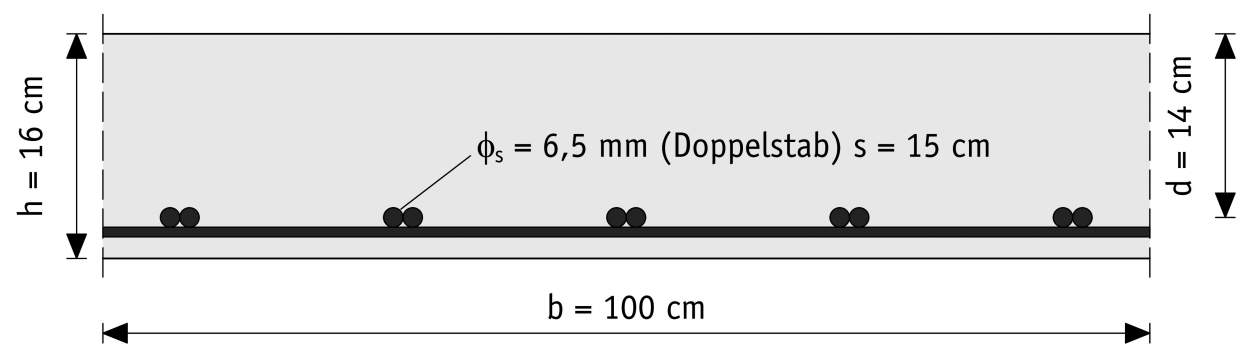

Abb. 51 Querschnittsabmessungen (http://doi.org/10.33968/9783966270021-04-A-02)

$g_{k}=b \cdot h \cdot \gamma_{S t b}=1,0 \cdot 0,16 \cdot 25=4,0 \mathrm{kN} / \mathrm{m}$

Die Bemessung der Verstärkung erfolgt für den Grenzzustand der Tragfähigkeit. Damit sind die Einwirkungen gemäß (2-3) zu kombinieren. Zum Zeitpunkt der Verstärkung wirkt nur das Eigengewicht auf das System, da alle weiteren ständigen Lasten zurückgebaut wurden. Zu diesem Zeitpunkt darf gemäß Kapitel 2.7.4 mit charakteristischen Lasten gerechnet werden.

Bemessungseinwirkung zum Zeitpunkt der Verstärkung:

$p_{d, 0}=g_{k}=4,0 \mathrm{kN} / \mathrm{m}$

Bemessungseinwirkung nach der Verstärkung:

$p_{d, V}=\left(g_{k}+\Delta g_{k}\right) \cdot \gamma_{G}+q_{k} \cdot \gamma_{Q}=(4+3) \cdot 1,35+5 \cdot 1,5=16,95 \mathrm{kN} / \mathrm{m}$ 


\subsubsection{Materialkennwerte}

\subsubsection{Beton}

Die Druckfestigkeitsklasse wurde anhand von Bestandsunterlagen und Prüfungen am Bauteil zu C20/25 bestimmt. Für die Bemessung resultieren daraus die Werte gemäß Tabelle 2 .

$f_{c k}=20 \mathrm{~N} / \mathrm{mm}^{2}$

$f_{c d}=\alpha_{c c} \cdot \frac{f_{c k}}{\gamma_{c}}=0,85 \cdot \frac{20}{1,5} \approx 11,33 \mathrm{~N} / \mathrm{mm}^{2}$

$f_{c m}=28 \mathrm{~N} / \mathrm{mm}^{2}$

$E_{c m} \approx 30.000 \mathrm{~N} / \mathrm{mm}^{2}$

$\varepsilon_{c u 2}=-3,5 \%$

Zur Bestimmung der Oberflächenzugfestigkeit wurden fünf Werte am Bauteil ermittelt, die nach Anhang A der DAfStb-Richtlinie Teil 4 ausgewertet wurden. Damit wird für die Oberflächenzugfestigkeit des Betons folgender Wert angegeben:

$f_{c t m, \text { surf }}=2,1 \mathrm{~N} / \mathrm{mm}^{2}$

\subsubsection{Bewehrung}

Bei der Bewehrung wird auf Bestandsunterlagen verwiesen. Demnach wurde eine Lagermatte des Typs R443 verwendet. Damit liegt ein Betonmattenstahl BSt 500 M vor, woraus sich folgende Kennwerte ableiten lassen ([Zilch et al. 2013] S. 495):

$f_{y k}=500 \mathrm{~N} / \mathrm{mm}^{2}$

$f_{y d}=\frac{f_{y k}}{\gamma_{S}}=\frac{500}{1,15} \approx 434,78 \mathrm{~N} / \mathrm{mm}^{2}$

$E_{S}=200.000 \mathrm{~N} / \mathrm{mm}^{2}$

$\varepsilon_{u d}=25 \%$

$\phi_{s}=6,5 \mathrm{~mm}$ (Doppelstab) 
$s=15 \mathrm{~cm}$

$a_{s l}=\frac{\pi}{4} \cdot{\phi_{s}}^{2} \cdot \frac{100}{s} \cdot 2=\frac{\pi}{4} \cdot 0,65^{2} \cdot \frac{100}{15} \cdot 2 \approx 4,42 \frac{\mathrm{cm}^{2}}{\mathrm{~m}}$

$a_{s q} \approx 0,95 \frac{\mathrm{cm}^{2}}{\mathrm{~m}}$

Bei Betonstahllagermatten werden die einzelnen Bewehrungen mit kleinen Buchstaben gekennzeichnet, wobei die Längsbewehrung der Biegebewehrung $\left(\mathrm{A}_{\text {s1 }}\right)$ entspricht. Die Querbewehrung wird in der folgenden Berechnung nicht benötigt. Aus Abbildung 51 kann die statische Höhe der Bewehrung entnommen werden. In dem vorliegenden Beispiel wurde bei der ursprünglichen Bemessung keine Druckbewehrung benötigt. Aus Abbildung 51 ist die statische Höhe ersichtlich.

$d=14 \mathrm{~cm}$

\subsubsection{Verstärkungssystem}

Aufgrund der erneuerten bauaufsichtlichen Zulassungen (jeweils gültig ab 2015), weichen die Materialkennwerte des gewählten Systems von denen des vorgegebenen Beispiels ab. Für die Berechnung werden die aufgeklebten CFK-Lamellen des Verstärkungssystems „Carboplus ${ }^{\circledR}$ 160/2400“ gewählt [Z-36.12-84]. Das System ist durch die folgenden Kennwerte charakterisiert:

$f_{\text {Luk }}=2.800 \mathrm{~N} / \mathrm{mm}^{2}$

$f_{\text {Lud }}=\alpha_{\text {Zeit }} \cdot \frac{f_{L u k}}{\gamma_{L L}}=0,85 \cdot \frac{2.800}{1,2} \approx 1.983,33 \mathrm{~N} / \mathrm{mm}^{2}$

$E_{L m}=162.000 \mathrm{~N} / \mathrm{mm}^{2}$

$\varepsilon_{\text {Luk }}=16 \%$

$\varepsilon_{\text {Lud }}=\frac{\varepsilon_{\text {Luk }}}{\gamma_{L L}}=\frac{16}{1,2} \approx 13,33 \% 0$

In den vorangegangenen Kapiteln wurde mehrfach erläutert, dass die statische Höhe der aufgeklebten CFK-Lamelle vereinfacht mit der Querschnittshöhe gleichgesetzt werden kann.

$d_{L} \approx h=16 \mathrm{~cm}$ 
In allen aktuell gültigen Zulassungen wird für die Verbundbeiwerte auf den Anhang RV K zur DAfStb-Richtlinie verwiesen. Diese ergeben sich nach Abschnitt 2.7.5.2 wie folgt:

$$
\begin{aligned}
& \tau_{L 1 k}=0,366 \cdot \sqrt{\alpha_{c c} \cdot f_{c m} \cdot \alpha_{c t} \cdot f_{c t m, s u r f}}=0,366 \cdot \sqrt{0,85 \cdot 28 \cdot 0,85 \cdot 2,1} \approx 2,39 \mathrm{~N} / \mathrm{mm}^{2} \\
& s_{L 0 k}=0,201 \mathrm{~mm} \\
& \tau_{L F k}=10,8 \cdot \alpha_{c c} \cdot f_{c m}^{-0,89}=10,8 \cdot 0,85 \cdot 28^{-0,89} \approx 0,47 \mathrm{~N} / \mathrm{mm}^{2}
\end{aligned}
$$

\subsubsection{Bemessungsschnittgrößen}

Wie in dem Beispiel des Betonkalenders 2013 ist der Momentenverlauf qualitativ für den Einfeldträger in Abbildung 52 dargestellt ([Zilch et al. 2013] S. 496). Da es sich in dieser Arbeit ausschließlich um die Biegeverstärkung handelt, wird nur der Momentenverlauf benötigt. Die Schnittgrößen werden bei Platten mit kleinen Buchstaben bezeichnet.
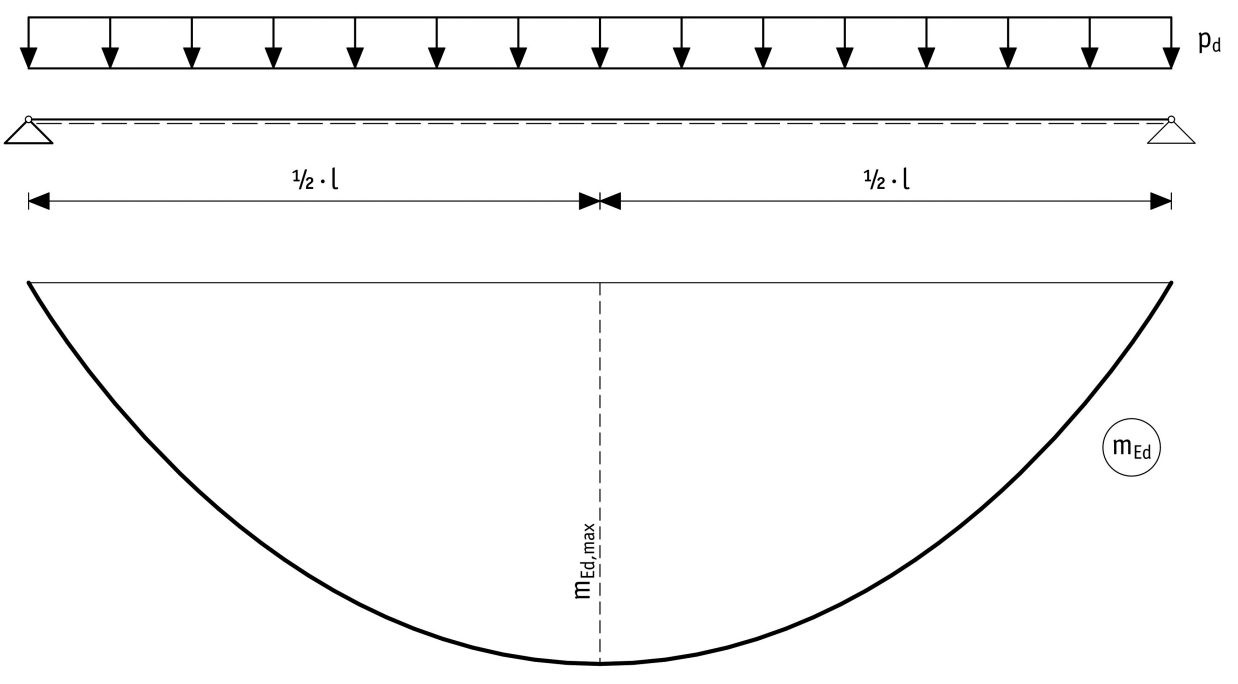

Abb. 52 qualitative Darstellung des Biegemoments (http://doi.org/10.33968/9783966270021-04-A-03)

Maximales einwirkendes Bemessungsmoment zum Zeitpunkt der Verstärkung: 


$$
m_{E d, 0}=\frac{p_{d, 0} \cdot l^{2}}{8}=\frac{4 \cdot 4,3^{2}}{8} \approx 9,25 \frac{\mathrm{kNm}}{\mathrm{m}}
$$

Maximales einwirkendes Bemessungsmoment nach der Verstärkung:

$$
m_{E d, V}=\frac{p_{d, V} \cdot l^{2}}{8}=\frac{16,95 \cdot 4,3^{2}}{8} \approx 39,18 \frac{\mathrm{kNm}}{\mathrm{m}}
$$

\subsection{Biegetragfähigkeit im Bestand}

Bevor die Verstärkungsmaßnahme bemessen wird, soll überprüft werden, ob die vorhandene Biegetragfähigkeit überhaupt überschritten wird. Um an dieser Stelle eine iterative Berechnung zu umgehen, wird mittels der Bemessungstafeln mit dimensionslosen Beiwerten (vgl. bspw. [Schneider et al. 2012]) über die vorhandene Bewehrungsfläche die Tragfähigkeit ermittelt. Im Prinzip stellt dies den umgekehrten Weg dar, für den die Bemessungstafeln eigentlich entwickelt wurden. Dabei soll für ein einwirkendes Moment die erforderliche Fläche bestimmt werden, wobei die Tragfähigkeit exakt der Einwirkung entsprechen soll. Genau diese Voraussetzung wird in diesem Beispiel verwendet, um darüber die Biegetragfähigkeit zu bestimmen. Für Stahlbetonrechteckquerschnitte ohne Druckbewehrung lässt sich diese Methode durch einfaches Umstellen der Formeln umsetzen.

$\omega=\frac{a_{s l} \cdot \sigma_{s}}{b \cdot d \cdot f_{c d}}=\frac{4,42 \cdot 10^{2} \cdot 434,78}{1.000 \cdot 140 \cdot 11,33} \approx 0,1212$

Das bezogene Bemessungsmoment kann somit aus den Bemessungstafeln interpoliert werden.

$\mu_{E d s}=(0,12-0,11) \cdot \frac{0,1212-0,1170}{0,1285-0,1170}+0,11 \approx 0,1137$

Es ergibt sich das einwirkende Bemessungsmoment für das der unverstärkte Querschnitt gemäß EC2 ursprünglich bemessen wäre. Da die Bemessung mit diesen Bemessungstafeln auf dem Gleichgewicht von einwirkenden Schnittgrößen und Widerstand des Bauteils beruht, lässt sich die vorhandene Biegetragfähigkeit durch Umstellen der Formel für das bezogene Bemessungsmoment bestimmen.

$m_{R d, s, 0}=\mu_{E d s} \cdot b \cdot d^{2} \cdot f_{c d}=0,1137 \cdot 1.000 \cdot 140^{2} \cdot 11,33 \cdot\left[10^{-6}\right] \approx 25,25 \frac{\mathrm{kNm}}{\mathrm{m}}$

Da die vorhandene Biegetragfähigkeit der Stahlbetondecke durch die neue Bemessungseinwirkung überschritten wird, ist in diesem Fall eine Verstärkungsmaßnahme erforderlich. 
$m_{R d, s, 0} \approx 25,25 \frac{k N m}{m}<m_{E d, V} \approx 39,18 \frac{k N m}{m}$

\subsection{Dehnungen zum Zeitpunkt der Verstärkung}

Bevor die Nachweisführung erfolgt, werden die Dehnungen zum Zeitpunkt der Verstärkung bestimmt, denn diese werden für die folgenden Nachweisformate benötigt. Da in diesem Beispiel keine Druckbewehrung vorhanden ist, werden zur vereinfachten Ermittlung der Dehnungen die Formeln aus Kapitel 3.2.1.3 verwendet.

$\alpha_{s}=\frac{E_{s}}{E_{c m}}=\frac{200.000}{30.000} \approx 6,67$

$\rho_{s 1}=\frac{a_{s l}}{b \cdot h}=\frac{4,42}{100 \cdot 16} \approx 2,765 \%$

$x_{0}=\left(-\alpha_{s} \cdot \rho_{s 1}+\sqrt{\left(\alpha_{s} \cdot \rho_{s 1}\right)^{2}+2 \cdot \alpha_{s} \cdot \rho_{s 1} \cdot \frac{d}{h}}\right) \cdot h$

$$
\begin{aligned}
& =\left(-6,67 \cdot 0,002765+\sqrt{(6,67 \cdot 0,002765)^{2}+2 \cdot 6,67 \cdot 0,002765 \cdot \frac{14}{16}}\right) \cdot 16 \\
& \approx 2,59 \mathrm{~cm}
\end{aligned}
$$

$z_{s 1,0}=d-\frac{1}{3} \cdot x_{0}=14-\frac{1}{3} \cdot 2,59 \approx 13,14 \mathrm{~cm}$

$F_{s 1,0}=\frac{m_{E d, 0}}{z_{s 1,0}}=\frac{9,25}{13,14 \cdot 10^{-2}} \approx 70,38 \frac{\mathrm{kNm}}{\mathrm{m}}$

$\varepsilon_{s 1,0}=\frac{F_{s 1,0}}{E_{s} \cdot \rho_{s 1} \cdot b \cdot h}=\frac{70,38 \cdot 10^{3}}{200.000 \cdot 0,002765 \cdot 1.000 \cdot 160} \approx 0,795 \%$

$\varepsilon_{L, 0}=\varepsilon_{s 1,0} \cdot \frac{d_{L}-x_{0}}{d-x_{0}}=0,795 \cdot \frac{16-2,59}{14-2,59} \approx 0,935 \% 0$

Es wird nochmals darauf hingewiesen, dass es sich um eine Vorbemessung handelt und daher die Belastungsgeschichte vernachlässigt wurde. In der Praxis sind Messwerte zu empfehlen. 


\subsection{Vereinfachter Nachweis ohne Verbundbetrachtung}

\subsubsection{Zulässige Grenzdehnung}

Zunächst muss überprüft werden, ob die Oberflächenzugfestigkeit die geforderte Bedingung erfüllt.

$f_{c t m, \text { surf }} \geq 0,26 \cdot f_{c m^{\frac{2}{3}}}=0,26 \cdot 28^{\frac{2}{3}} \approx 2,397 \mathrm{~N} / \mathrm{mm}^{2}$

Für die Ermittlung der zulässigen Grenzdehnung muss die mittlere Betondruckfestigkeit angepasst werden, da die Oberflächenzugfestigkeit geringer ausfällt, als es diese Bedingung fordert.

$f_{c m, \text { vorh }}=\left(\frac{f_{c t m, \text { surf }}}{0,26}\right)^{\frac{3}{2}}=\left(\frac{2,1}{0,26}\right)^{\frac{3}{2}} \approx 22,95 \mathrm{~N} / \mathrm{mm}^{2}$

Anschließend kann die maximal zulässige Grenzdehnung für die aufgeklebten CFK-Lamellen bestimmt werden. Diese ergibt sich für den vereinfachten Nachweis mit Gleichung (2-71) aus Kapitel 2.7.6.

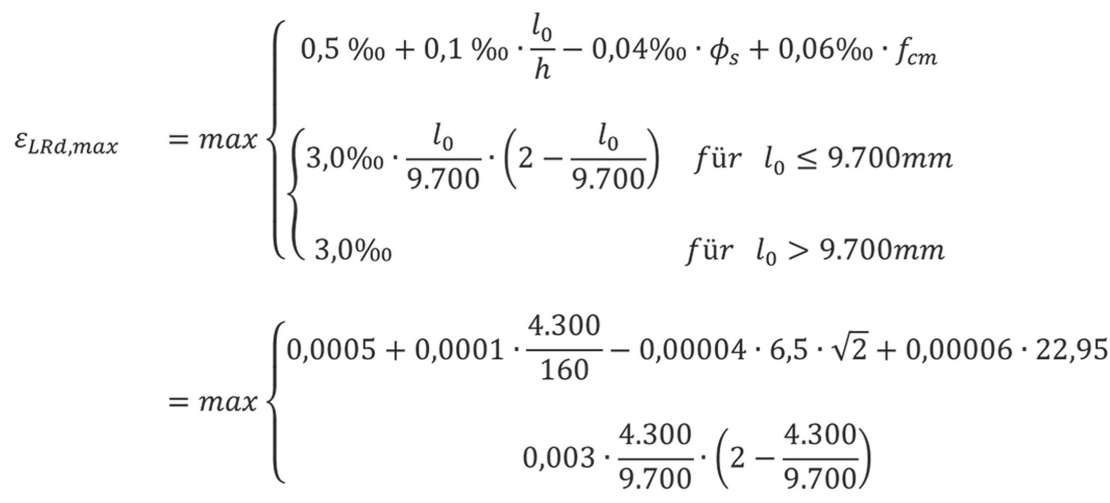

$$
\begin{aligned}
& \approx \max \left\{\begin{array}{l}
4,197 \% 0 \\
2,070 \% 0
\end{array}=4,197 \% 0\right.
\end{aligned}
$$

Dabei muss beachtet werden, dass bei Doppelstäben ein Ersatzstabdurchmesser gemäß Gleichung (2-68) anzusetzen ist. In der Richtlinie ist dieser rechnerische Ansatz an dieser Stelle nicht explizit enthalten. Diese Anpassung geht aber aus dem Beispiel des Betonkalenders 2013 hervor ([Zilch et al. 2013] S. 497). Damit ist zwar die zulässige Grenzdehnung für die Verstärkungsmaßnahme mit aufgekleb- 
ten CFK-Lamellen bestimmt, aber es ist noch zu überprüfen, ob alle Voraussetzungen zur Durchführung des vereinfachten Nachweises vorliegen:

$\checkmark$ positives Feldmoment

$\checkmark$ nicht vorgespanntes Bauteil

$\checkmark$ CFK-Lamelle bis $50 \mathrm{~mm}$ vor die Auflagerkante führen (bei Ausführung zu beachten!)

$\checkmark$ gerippter Betonstahl

$\checkmark$ Betonstahl ist nicht abgestuft

$\checkmark$ Lamellendicke $\leq 1,4 \mathrm{~mm}$ (kann bei der Wahl des Systems berücksichtigt werden)

Damit sind alle erforderlichen Bedingungen erfüllt bzw. können bei der Ausführung berücksichtigt werden. Damit kann die Ermittlung der erforderlichen Lamellenfläche mit den Bemessungstafeln erfolgen.

\subsubsection{Erforderliche Lamellenfläche}

Anhand der Grenzdehnung kann der zulässige Gesamtdehnungszustand auf Höhe der aufgeklebten CFK-Lamelle berechnet werden, um damit in die Bemessungstafeln einzusteigen.

$\varepsilon_{L, g e s, z u l}=\varepsilon_{L R d, \max }+\varepsilon_{L, 0}=4,197+0,935=5,132 \% 0$

Auf der sicheren Seite liegend könnte mit der Bemessungstafel mit der kleineren zulässigen Gesamtdehnung die Lamellenfläche bestimmt werden. Da aber die größtmögliche Wirtschaftlichkeit auch bei diesem Nachweis erzielt werden soll, wird zwischen den Bemessungstafeln mit den zulässigen Gesamtdehnungszuständen von 5,0 \%o und 5,5 \%o interpoliert. Zunächst muss der Eingangswert für die Bemessungstafeln bestimmt werden, wobei in diesem Beispiel keine Normalkraft auf den Querschnitt wirkt.

$$
\begin{aligned}
m_{E d, L}= & m_{E d, V} \approx 39,18 \frac{k N m}{m} \\
\mu_{E d, L} & =\frac{m_{E d, L}}{b \cdot h^{2} \cdot f_{c d}}+\frac{f_{y d}}{f_{c d}} \cdot \rho_{s 1} \cdot\left(1-\frac{d}{h}\right) \\
& =\frac{39,18 \cdot 10^{6}}{1.000 \cdot 160^{2} \cdot 11,33}+\frac{434,78}{11,33} \cdot 0,002765 \cdot\left(1-\frac{140}{160}\right) \approx 0,1483
\end{aligned}
$$

Es folgt eine Interpolation der Beiwerte zur Berechnung der Lamellenfläche. An dieser Stelle wird ebenfalls interpoliert, um in diesem Beispiel ein Höchstmaß an Genauigkeit zu erlangen. Zur Vermeidung der Interpolation kann in der Praxis der 
Eingangswert auf der sicheren Seite liegend aufgerundet werden. Dabei werden ausreichend genaue Ergebnisse für eine Vorbemessung erzielt.

$\omega_{L}(5,0 \%)=(0,1662-0,1543) \cdot \frac{0,1483-0,14}{0,15-0,14}+0,1543 \approx 0,1642$

$\omega_{L}(5,5 \%)=(0,1658-0,1539) \cdot \frac{0,1483-0,14}{0,15-0,14}+0,1539 \approx 0,1637$

$\omega_{L}(5,132 \% 0)=(0,1642-0,1637) \cdot \frac{5,132-5,0}{5,5-5,0}+0,1637 \approx 0,1638$

Damit kann die erforderliche Lamellenfläche mit Gleichung (3-17) berechnet werden, um den vereinfachten Nachweis zu erfüllen.

$$
\begin{aligned}
a_{L, \text { erf }} & =\frac{\left(\omega_{L} \cdot f_{c d}-f_{y d} \cdot \rho_{s 1}\right) \cdot b \cdot h+N_{E d}}{\varepsilon_{L} \cdot E_{L m}} \\
& =\frac{(0,1638 \cdot 11,33-434,78 \cdot 0,002765) \cdot 1.000 \cdot 160+0}{0,004197 \cdot 162.000} \cdot\left[10^{-2}\right] \approx 1,54 \frac{\mathrm{cm}^{2}}{\mathrm{~m}}
\end{aligned}
$$

Anschließend muss noch nachgewiesen werden, dass sich die Bewehrung im Fließen befindet.

$\varepsilon_{s 1}=\frac{d}{d_{L}} \cdot\left(\varepsilon_{L, g e s}+\varepsilon_{c R 2}\right)-\varepsilon_{c R 2}$

Da vorab sämtliche Werte interpoliert wurden, soll das an dieser Stelle auch für die Betonrandstauchung erfolgen, um ein einheitliches Genauigkeitsniveau beizubehalten. Dabei wird wieder darauf verwiesen, dass solche genauen Berechnungen nicht das Ziel einer Vorbemessung sind. In der Praxis werden jeweils auf der sicheren Seite liegende Werte empfohlen.

$$
\begin{aligned}
& \varepsilon_{c R 2}(5,0 \% 0)=(-1,80+1,70) \cdot \frac{0,1483-0,14}{0,15-0,14}-1,70 \approx-1,783 \% 0 \\
& \varepsilon_{c R 2}(5,5 \%)=(-1,89+1,79) \cdot \frac{0,1483-0,14}{0,15-0,14}-1,79 \approx-1,873 \% 0 \\
& \varepsilon_{c R 2}(5,132 \%)=(-1,873+1,783) \cdot \frac{5,132-5,0}{5,5-5,0}-1,783 \approx-1,807 \% 0
\end{aligned}
$$

Damit lässt sich jetzt endgültig die Dehnung der Biegezugbewehrung bestimmen und überprüfen, ob die Bemessungsstreckgrenze überschritten wird. 
$\varepsilon_{s 1}=\frac{14}{16} \cdot(5,132+1,807)-1,807 \approx 4,265 \% 0>\frac{f_{y d}}{E_{s}}=\frac{434,78}{200.000} \approx 2,174 \% 0$

Um den Nachweis abschließen zu können, muss nur noch nachgewiesen werden, dass die Bemessungsfestigkeit der aufgeklebten CFK-Lamelle nicht überschritten wird. Dazu kann die Spannung in der Lamelle über deren Elastizitätsmodul und die Lamellendehnung bestimmt werden.

$\sigma_{L}=\varepsilon_{L} \cdot E_{L m}=0,004197 \cdot 162.000 \approx 679,9 \frac{\mathrm{N}}{\mathrm{mm}^{2}}<f_{L u d}=1.983,33 \mathrm{~N} / \mathrm{mm}^{2}$

Damit ist der vereinfachte Nachweis für Biegung ohne Normalkraft im Grenzzustand der Tragfähigkeit erbracht. Anhand dieses ersten Teils des Beispiels kann somit verdeutlicht werden, dass eine Handrechnung zur Nachweisführung für aufgeklebte CFK-Lamellen mit den erstellten Bemessungstafeln mit moderatem Aufwand möglich ist. Da dieses Nachweisformat zu den ungenauesten und somit unwirtschaftlichsten Ergebnissen führt, ist davon auszugehen, dass mit der folgenden genaueren Nachweisführung ein wirtschaftlicheres Ergebnis zu erzielen ist ([Finckh 2012] S. 223). Damit sollte also letztlich eine geringere Lamellenfläche aus dem genaueren Nachweis der Lamellenkraftänderung am ZRE resultieren.

\subsection{Genauerer Nachweis}

\subsubsection{Nachweis der Biegetragfähigkeit}

Mit diesem Abschnitt soll der genauere Nachweis der Lamellenkraftänderung am ZRE beispielhaft erläutert werden, der in der Excel-Arbeitsmappe konfiguriert ist (vgl. Abs. 3.3.2.4). Es folgt als erstes der reine Nachweis der Biegetragfähigkeit. An dieser Stelle kann ohne Einschränkungen die Bemessungsbruchdehnung des gewählten Verstärkungssystems angesetzt werden. Die Dehnung der Lamelle wird sich schrittweise in Folge des iterativen Berechnungsvorgangs durch die Vergrößerung der Lamellenfläche reduzieren. Um einen Startwert der Lamellenfläche für den Verbundnachweis am ZRE zu erhalten, stellt dieses Vorgehen die wirtschaftlichste Variante dar. Prinzipiell könnten dafür die Bemessungstafeln analog zu Abs. 4.4.2 verwendet werden. Um aber das iterative Vorgehen in der Excel-Arbeitsmappe zu beschreiben, soll der in Kapitel 2.7.4 beschriebene Lösungsvorgang aufgezeigt werden. Am besten lässt sich dieses Vorgehen mit Abbildung 12 verdeutlichen. Dabei wird auf die Dehnungen zum Zeitpunkt der Verstärkung aus Abschnitt 4.3 zurückgegriffen, da unter der Annahme eines linear-elastischen SpannungsDehnungs-Verhaltens die Berechnung identisch ist.

$\varepsilon_{L, 0} \approx 0,935 \%$

vgl. Gleichung (4-40) 
Als nächstes muss eine Variable auf den maximal zulässigen Betrag festgelegt werden. Da sich aus der Iteration ergeben wird, dass in diesem Beispiel Betonversagen vorliegt, wird der Betrag der Betonrandstauchung auf den Maximalwert festgelegt. Somit gilt:

$\varepsilon_{c R 2}=\varepsilon_{c u 2}=-3,50 \%$

Damit beginnt die Suche nach dem variablen Wert der Lamellendehnung. Diese darf die Bemessungsbruchdehnung nicht überschreiten und muss dabei größer als 0 sein, was mit der folgenden Bedingung mathematisch ausgedrückt werden kann.

$0 \%<\varepsilon_{L} \leq \varepsilon_{\text {Lud }} \approx 13,33 \%$

Wie bereits erwähnt, sind die iterativen Werte bekannt und werden direkt für die folgenden Berechnungen verwendet. Für die Lamellendehnung ergibt sich über die Iteration ein Wert von:

$\varepsilon_{L} \approx 13,084 \%$

$\varepsilon_{L, g e s}=\varepsilon_{L}+\varepsilon_{L, 0}=13,084+0,935 \approx 14,019 \%$

Somit lässt sich die Höhe der Betondruckzone und die Dehnung der Biegezugbewehrung bestimmen. Druckbewehrung ist in diesem Beispiel nicht vorhanden, daher muss die auftretende Druckkraft allein vom Beton aufgenommen werden. Dazu werden der Völligkeitsbeiwert nach Gleichung (2-17) und der Beiwert des Randabstandes der resultierenden Betondruckkraft nach Gl. (2-18) benötigt. Es ist zu berücksichtigen, dass die Betonrandstauchung größer als 2,0 \%o ist.

$$
\begin{aligned}
& x=\frac{-\varepsilon_{c R 2}}{\varepsilon_{L, g e s}-\varepsilon_{c R 2}} \cdot d_{L}=\frac{3,5}{14,019+3,5} \cdot 16 \approx 3,20 \mathrm{~cm} \\
& \varepsilon_{s 1}=\frac{d-x}{d_{L}-x} \cdot \varepsilon_{L, g e s}=\frac{14-3,20}{16-3,20} \cdot 14,019 \approx 11,829 \% 0 \\
& \alpha_{R}\left(\left|\varepsilon_{c R 2}\right|>2 \% 0\right)=\frac{3 \cdot\left|\varepsilon_{c R 2}\right|-2}{3 \cdot\left|\varepsilon_{c R 2}\right|}=\frac{3 \cdot 3,5-2}{3 \cdot 3,5} \approx 0,8095 \\
& k_{a}\left(\left|\varepsilon_{c R 2}\right|>2 \% 0\right)=\frac{\left|\varepsilon_{c R 2}\right| \cdot\left(3 \cdot\left|\varepsilon_{c R 2}\right|-4\right)+2}{2 \cdot\left|\varepsilon_{c R 2}\right| \cdot\left(3 \cdot\left|\varepsilon_{c R 2}\right|-2\right)}=\frac{3,5 \cdot(3 \cdot 3,5-4)+2}{2 \cdot 3,5 \cdot(3 \cdot 3,5-2)} \approx 0,4160
\end{aligned}
$$

Somit liegen alle Voraussetzungen vor um die inneren Kräfte zu berechnen und das Gleichgewicht aufzustellen, indem die Lamellenkraft die Zugkräfte aufnimmt die nicht durch die Betonstahlbewehrung abgedeckt werden können. 


$$
\begin{aligned}
& F_{c d}=b \cdot x \cdot f_{c d} \cdot \alpha_{R}=1.000 \cdot 32 \cdot 11,33 \cdot 0,8095 \cdot 10^{-3} \approx 293,49 \frac{\mathrm{kN}}{\mathrm{m}} \\
& F_{s 1 d}=\min \left\{\begin{array}{c}
\varepsilon_{s 1} \cdot E_{s} \cdot a_{s l} \\
f_{y d} \cdot a_{s l}
\end{array}=\min \left\{\begin{array}{c}
0,011829 \cdot 200.000 \cdot 4,42 \cdot 10^{2} \\
434,78 \cdot 4,42 \cdot 10^{2}
\end{array} \cdot 10^{-3} \approx 192,17 \frac{\mathrm{kN}}{\mathrm{m}}\right.\right.
\end{aligned}
$$

$$
F_{L d}=F_{c d}-F_{s 1 d}=293,49-192,17 \approx 101,32 \frac{\mathrm{kN}}{\mathrm{m}}
$$

Aus den inneren Kräften resultierend, wird die Biegetragfähigkeit des Querschnitts bestimmt und geprüft, ob diese gleich der Bemessungseinwirkung ist.

$$
\begin{aligned}
m_{R d, L, V} & =F_{c d} \cdot\left(d_{L}-k_{a} \cdot x\right)-F_{s 1 d} \cdot\left(d_{L}-d\right) \\
& =293,49 \cdot(0,16-0,4160 \cdot 0,032)-192,17 \cdot(0,16-0,14) \approx 39,21 \frac{\mathrm{kNm}}{\mathrm{m}} \\
m_{R d, L, V}= & 39,21 \frac{\mathrm{kNm}}{\mathrm{m}} \approx m_{E d, L, V}=39,18 \frac{\mathrm{kNm}}{\mathrm{m}}
\end{aligned}
$$

Da die Bedingung mit ausreichender Genauigkeit erfüllt ist, kann somit die erforderliche Lamellenfläche berechnet werden und der Nachweis der Biegetragfähigkeit ist damit abgeschlossen. Sollte an dieser Stelle das Gleichgewicht der Momente nicht hergestellt sein, müssten die Dehnungen angepasst und der Vorgang gemäß Abbildung 19 so oft wiederholt werden, bis das Gleichgewicht der inneren und äußeren Schnittgrößen hergestellt ist.

$a_{L, e r f}=\frac{F_{L d}}{\varepsilon_{L} \cdot E_{L m}}=\frac{101,32 \cdot 10^{3}}{0,013084 \cdot 162.000} \cdot 10^{-2} \approx 0,48 \frac{\mathrm{cm}^{2}}{\mathrm{~m}}$

Damit wurde die erforderliche Lamellenfläche für die Biegetragfähigkeit bestimmt. Diese soll im Folgenden als Ausgangswert für die weitere Berechnung dienen.

\subsubsection{Rissabstand}

Da für den Nachweis der Lamellenkraftänderung am ZRE die einwirkende Lamellenkraft an jedem Biegeriss benötigt wird, muss zunächst der Rissabstand nach Abschnitt 2.7.5.3 bestimmt werden. Dabei erfolgt ausschließlich eine Berücksichtigung des Betonstahls, wodurch die Rissabstände größer werden als bei der Berücksichtigung der CFK-Lamellen und somit auf der sicheren Seite liegen. Da es sich bei den Betonstahllagermatten des Typs R443 um gerippten Betonstahl handelt, kann für die mittlere Verbundspannung nachfolgender rechnerischer Ansatz ange- 
nommen werden. Dabei ist der Verbundbeiwert aufgrund der Bauteilabmessungen für guten Verbund anzusetzen ( $\mathrm{h} \leq 250 \mathrm{~mm}$ vgl. [EC2-1-1 2011-01] Bild 8.2).

$f_{b s m}=\kappa_{v b 1} \cdot 0,43 \cdot f_{c m}{ }^{2 / 3}=1,0 \cdot 0,43 \cdot 28^{2 / 3} \approx 3,96 \mathrm{~N} / \mathrm{mm}^{2}$

Bei der Verbundkraft je Länge ist zu berücksichtigen, dass es sich bei diesem Lagermatten Typ um Doppelstäbe handelt, weshalb der Durchmesser dementsprechend anzupassen ist.

$F_{b s m}=\sum_{i=1}^{n} n_{s, i} \cdot \phi_{i} \cdot \pi \cdot f_{b s m}=\frac{100}{15} \cdot 6,5 \cdot \sqrt{2} \cdot \pi \cdot 3,96 \approx 763,36 \mathrm{~N} / \mathrm{mm}$

Das Widerstandsmoment eines ungerissenen Rechteckquerschnitts ergibt sich zu:

$W_{c, 0}=\frac{b \cdot h^{2}}{6}=\frac{1.000 \cdot 160^{2}}{6} \approx 4.266 .667 \mathrm{~mm}^{3}$

Damit lässt sich das Rissmoment des Querschnitts bestimmen. Da der Umrechnungsbeiwert zwischen Biegezugfestigkeit und zentrischer Zugfestigkeit größer als 1,0 ist, wird dieser direkt in der Berechnung des Rissmoments berücksichtigt.

$$
\begin{aligned}
m_{c r} & =\left(1,6-\frac{h}{1.000}\right) \cdot f_{c t m, \text { surf }} \cdot W_{c, 0}=\left(1,6-\frac{160}{1.000}\right) \cdot 2,1 \cdot 4.266 .667 \\
& \approx 12.902 .400 \frac{\mathrm{Nmm}}{\mathrm{m}}
\end{aligned}
$$

Da der Hebelarm der inneren Kräfte durch die Vereinfachung in der Richtlinie ([DAfStb 2012- 03] Teil 1 RV 6.1.1.3.3 (RV2)) insbesondere bei Platten zum Teil deutlich zu groß würde, wird auf die Biegebemessung des Bestands aus Abschnitt 4.2 zurückgegriffen. Weil für den Rissabstand nur der Betonstahl berücksichtigt werden soll, wird diese Annahme als gerechtfertigt erachtet. Die Biegetragfähigkeit wurde in diesem Beispiel über die Bemessungstafeln mit dimensionslosen Beiwerten berechnet. Daraus geht hervor, dass der Stahl die Bemessungsstreckgrenze überschritten hat und sich somit im Fließen befindet.

$z_{s 1}=\frac{m_{R d, s, 0}}{F_{s 1 d}}=\frac{m_{R d, s, 0}}{f_{y d} \cdot a_{s l}}=\frac{25,25 \cdot 10^{6}}{434,78 \cdot 4,42 \cdot 10^{2}} \approx 131,3 \mathrm{~mm}$

Mit den vorhandenen Werten lässt sich die Eintragungslänge des Betonstahls und abschließend der Rissabstand berechnen. 


$$
\begin{aligned}
& l_{e, 0}=\frac{m_{c r}}{z_{s 1} \cdot F_{b s m}}=\frac{12.902 .400}{131,3 \cdot 763,36} \approx 128,7 \mathrm{~mm} \\
& s_{r}=1,5 \cdot l_{e, 0}=1,5 \cdot 128,8 \approx 193,1 \mathrm{~mm}
\end{aligned}
$$

\subsubsection{Iterative Ermittlung der Lamellenkraft}

Mit dem bekannten Rissabstand können die Zwischenrisselemente angeordnet werden. Der erste Biegeriss soll am Momentenmaximum auftreten. Von dort aus werden die Risse jeweils um den Rissabstand versetzt angeordnet bis der Biegeriss erreicht ist, der dem Momentennullpunkt am nächsten ist. Exemplarisch soll die Berechnung der Lamellenkraft für einen Biegeriss veranschaulicht werden. Die restlichen Werte werden dann nur noch tabellarisch aufgeführt, da die Berechnung identisch ist. Für die folgende Verdeutlichung der iterativen Berechnung der Lamellenkraft wurde der Biegeriss mit dem Abstand zum Auflager $\mathrm{x}_{\mathrm{A}}=176,37 \mathrm{~cm}$ gewählt.

Zuerst werden wieder die Dehnungen zum Zeitpunkt der Verstärkung berechnet. Dazu wird das Moment an dieser Stelle zum Zeitpunkt „,0“ benötigt, woraus anschließend über den inneren Hebelarm die Stahlzugkraft und die Stahldehnung abgeleitet werden können. Um diesen bestimmen zu können, wird die Druckzonenhöhe gemäß Gl. (3-34) berechnet. Da die vereinfachte Ermittlung der Druckzonenhöhe bei linear-elastischen Spannungs-Dehnungslinien einwirkungsunabhängig ist, kann dieser Wert direkt dem Abschnitt 4.3, Gleichung (4-36), entnommen werden. Analog wird der Wert des inneren Hebelarms aus Gleichung (4-37) übernommen.

$$
\begin{aligned}
& m_{E d, 0}\left(x_{A}\right)=\frac{p_{d, 0} \cdot l}{2} \cdot x_{A}-\frac{p_{d, 0}}{2} \cdot x_{A}^{2}=\frac{4,0 \cdot 4,3}{2} \cdot 1,7637-\frac{4,0}{2} \cdot 1,7637^{2} \approx 8,95 \frac{\mathrm{kNm}}{\mathrm{m}} \\
& x_{0} \approx 2,59 \mathrm{~cm} \\
& z_{s 1,0} \approx 13,14 \mathrm{~cm} \\
& \text { vgl. Gleichung (4-36) } \\
& \text { vgl. Gleichung (4-37) } \\
& F_{S 1,0}\left(x_{A}\right)=\frac{m_{E d, 0}\left(x_{A}\right)}{z_{S 1,0}}=\frac{8,95}{0,1314} \approx 68,11 \frac{\mathrm{kN}}{\mathrm{m}} \\
& \varepsilon_{s 1,0}=\frac{F_{s 1,0}}{E_{s} \cdot \rho_{s 1} \cdot b \cdot h}=\frac{68,11 \cdot 10^{3}}{200.000 \cdot 0,002765 \cdot 1.000 \cdot 160} \approx 0,7697 \%
\end{aligned}
$$


$\varepsilon_{L, 0}=\varepsilon_{s 1,0} \cdot \frac{d_{L}-x_{0}}{d-x_{0}}=0,7697 \cdot \frac{16-2,59}{14-2,59} \approx 0,9047 \% 0$

Es folgt die iterative Ermittlung der Lamellenkraft an diesem Riss. Dabei wird nach dem Ablaufschema, das in Abbildung 19 dargestellt ist, vorgegangen, wobei diesmal die Lamellenfläche bereits vorgegeben ist und über die Iteration der Dehnungen das Kräftegleichgewicht hergestellt werden muss. Da auch dies ein äußerst aufwendiger iterativer Vorgang ist, wird wieder mit den bereits ermittelten iterativen Werten das Vorgehen verdeutlicht. Außerdem wird bei der automatisierten Berechnung mit der Excel-Arbeitsmappe die Lamellenfläche angepasst, um den Nachweis der Verbundkraftübertragung erfüllen zu können. Das entsprechende Vorgehen ist bereits im Abschnitt 3.3.2.4 beschrieben. Dabei wird die Lamellenbreite jeweils um $5 \mathrm{~mm}$ gesteigert bis der Nachweis erfüllt ist. Lässt sich die Breite nicht mehr erhöhen, wird versucht über eine Erhöhung der Lamellendicke das Ziel zu erreichen. An dieser Stelle wird direkt mit der endgültigen Lamellenfläche gerechnet, die aus dem Verbundnachweis resultiert. Dabei ergeben sich die Abmessungen der CFK-Lamelle für das Verstärkungssystem „Carboplus ${ }^{\circledR}$ 160/2400“ zu:

$t_{L}=1,2 \mathrm{~mm}$

$b_{L}=105 \mathrm{~mm}$

$a_{L}=t_{L} \cdot b_{L}=1,2 \cdot 105 \cdot 10^{-2}=1,26 \frac{\mathrm{cm}^{2}}{\mathrm{~m}}$

Dabei wird für die Berechnung die geringste lieferbare Dicke von 1,2 mm gewählt. Prinzipiell gilt die DAfStb-Richtlinie für aufgeklebte CFK-Lamellen ab 1,0 mm Dicke ([DAfStb 2012-03] Teil 2 Abs. 3.3). Da jedoch alle aktuell gültigen bauaufsichtlichen Zulassungen ausschließlich aufgeklebte CFK-Lamellen ab einer Lamellendicke von 1,2 mm regeln, wird dieser Wert als Ausgangswert für die Dicke. Da die Resultate durch Steigerung der Lamellenbreite deutlich effektiver sind, wird diese in der Excel-Arbeitsmappe in erster Instanz erhöht. Damit kann der Iterationsvorgang starten. Die Lamellenfläche wird bei Platten wieder je Meter ausgegeben.

Dazu ist das einwirkende Bemessungsmoment am entsprechenden Biegeriss $\left(x_{A}=176,37 \mathrm{~cm}\right) \mathrm{zu}$ bestimmen. Dieses lässt sich analog zu Gleichung (4-78) mit der Bemessungseinwirkung im verstärkten Zustand ermitteln.

$m_{E d, V}\left(x_{A}\right)=\frac{16,95 \cdot 4,3}{2} \cdot 1,7637-\frac{16,95}{2} \cdot 1,7637^{2} \approx 37,91 \frac{\mathrm{kNm}}{\mathrm{m}}$

Dann müssen zunächst Startwerte für die Variablen gewählt werden. Wie bereits im Kapitel 3.3.2.4 erörtert, tritt bei keiner Variable der rechnerische Versagenszustand ein, sondern beide Werte bewegen sich als iterative Größe in deren jeweiligen rechnerisch zulässigen Grenzen. Als Variablen wurden die Betonstauchung am 
druckbeanspruchten oberen Querschnittsrand sowie die Stahldehnung der Biegezugbewehrung gewählt. Da die Hypothese von Bernoulli gilt, kann hierfür sowohl die Stahldehnung als auch die Lamellendehnung gewählt werden. Für die Dehnungen ergeben sich anhand der Iteration folgende Werte:

$\varepsilon_{c R 2}=-1,8396 \%$

$\varepsilon_{s 1}=4,6370 \%$

Damit lässt sich die Druckzonenhöhe berechnen. Anschließend kann der Gesamtdehnungszustand am unteren Querschnittsrand sowie die reine Lamellendehnung berechnet werden.

$x=d \cdot \frac{-\varepsilon_{c R 2}}{\varepsilon_{s 1}-\varepsilon_{c R 2}}=14 \cdot \frac{1,8396}{4,6370+1,8396} \approx 3,98 \mathrm{~cm}$

$\varepsilon_{L, g e s}=\frac{d_{L}-x}{d-x} \cdot \varepsilon_{s 1}=\frac{16-3,98}{14-3,98} \cdot 4,6370 \approx 5,5623 \% 0$

$\varepsilon_{L}=\varepsilon_{L, g e s}-\varepsilon_{L, 0}=5,5623-0,9047=4,6576 \% 0$

Somit ergeben sich die Beiwerte der Betondruckkraft, wobei der gültige Bereich der Betonrandstauchung zu beachten ist.

$\alpha_{R}\left(\left|\varepsilon_{c R 2}\right|<2 \%\right)=\frac{\left|\varepsilon_{c R 2}\right| \cdot\left(6-\left|\varepsilon_{c R 2}\right|\right)}{12}=\frac{1,8396 \cdot(6-1,8396)}{12} \approx 0,6378$

$k_{a}\left(\left|\varepsilon_{c R 2}\right|<2 \% 0\right)=\frac{8-\left|\varepsilon_{c R 2}\right|}{4 \cdot\left(6-\left|\varepsilon_{c R 2}\right|\right)}=\frac{8-1,8396}{4 \cdot(6-1,8396)} \approx 0,3702$

Anschließend werden die inneren Kräfte berechnet.

$$
\begin{aligned}
& F_{c d}=b \cdot x \cdot f_{c d} \cdot \alpha_{R}=1.000 \cdot 39,8 \cdot 11,33 \cdot 0,6378 \cdot 10^{-3} \approx 287,44 \frac{\mathrm{kN}}{\mathrm{m}} \\
& F_{s 1 d}=\min \left\{\begin{array}{c}
\varepsilon_{s 1} \cdot E_{s} \cdot a_{s l}=0,004637 \cdot 200.000 \cdot 4,42 \cdot 10^{2} \\
f_{y d} \cdot a_{s l}=434,78 \cdot 4,42 \cdot 10^{2} \\
F_{L d}=\min \left\{\begin{array}{c}
\varepsilon_{L} \cdot E_{L m} \cdot a_{L}=0,0046576 \cdot 162.000 \cdot 1,26 \cdot 10^{2} \\
f_{L u d} \cdot a_{L}=1.983,33 \cdot 1,26 \cdot 10^{2}
\end{array}\right.
\end{array}\right.
\end{aligned}
$$

Damit muss das Gleichgewicht der inneren Kräfte aufgestellt werden. 
$\Sigma F=F_{c d}-F_{s 1 d}-F_{L d}=287,44-192,37-95,07=0$

Da diese erste Bedingung erfüllt ist, kann die Biegetragfähigkeit des Querschnitts bestimmt werden, um zu prüfen, ob diese mit der Bemessungseinwirkung im Gleichgewicht steht. Sollte diese Bedingung nicht erfüllt sein, muss der iterative Vorgang wiederholt werden.

$$
\begin{aligned}
m_{R d, L, V}\left(x_{A}\right) & =F_{c d} \cdot\left(d_{L}-k_{a} \cdot x\right)-F_{s 1 d} \cdot\left(d_{L}-d\right) \\
& =287,44 \cdot(0,16-0,3702 \cdot 0,0398)-192,37 \cdot(0,16-0,14) \\
& \approx 37,91 \frac{\mathrm{kNm}}{\mathrm{m}} \\
m_{R d, L, V}\left(x_{A}\right)= & 37,91 \frac{\mathrm{kNm}}{\mathrm{m}}=m_{E d, L, V}\left(x_{A}\right)=37,91 \frac{\mathrm{kNm}}{\mathrm{m}}
\end{aligned}
$$

Ist diese Bedingung erfüllt, ist somit der Dehnungszustand an diesem Biegeriss unter dem einwirkenden Bemessungsmoment bekannt und es kann mit dem nächsten Biegeriss fortgefahren werden. Sollte diese Bedingung jedoch nicht erfüllt sein, müsste der Iterationsvorgangerneut bei den Dehnungen begonnen werden. Mit dieser Vorgehensweise wurde die Lamellenkraft an jedem Biegeriss bestimmt (vgl. Tabelle 9). 
Tab. 9 Schnittgrößen und Dehnungen (http://doi.org/10.33968/9783966270021-04-T-02)

\begin{tabular}{|c|c|c|c|c|c|c|c|c|c|}
\hline $\begin{array}{c}\mathbf{x}_{\mathrm{A}} \\
{[\mathrm{cm}]}\end{array}$ & $\begin{array}{c}\mathrm{m}_{\mathrm{Ed}, 0} \\
{[\mathrm{kNm} / \mathrm{m}]}\end{array}$ & $\begin{array}{c}\mathrm{m}_{\mathrm{Ed}, \mathrm{V}} \\
{[\mathrm{kNm} / \mathrm{m}]}\end{array}$ & $\begin{array}{c}\varepsilon_{\mathrm{cR} 2} \\
{[\% \circ]}\end{array}$ & $\begin{array}{c}\varepsilon_{s 1} \\
{[\% o]}\end{array}$ & $\begin{array}{c}\varepsilon_{L, 0} \\
{[\% \circ]}\end{array}$ & $\begin{array}{c}\varepsilon_{\mathrm{L}} \\
{[\% \mathrm{o}]}\end{array}$ & $\begin{array}{c}\mathbf{F}_{\mathrm{cd}} \\
{[\mathrm{kN} / \mathrm{m}]}\end{array}$ & $\begin{array}{c}\mathbf{F}_{\mathrm{s} 1 \mathrm{~d}} \\
{[\mathrm{kN} / \mathrm{m}]}\end{array}$ & $\begin{array}{c}F_{L d} \\
{[k N / m]}\end{array}$ \\
\hline 215,00 & 9,25 & 39,18 & $-1,973$ & 5,024 & 0,935 & 5,089 & 296,24 & 192,37 & 103,88 \\
\hline 195,69 & 9,17 & 38,86 & $-1,939$ & 4,927 & 0,927 & 4,981 & 294,03 & 192,37 & 101,66 \\
\hline 176,37 & 8,95 & 37,91 & $-1,840$ & 4,637 & 0,905 & 4,658 & 287,44 & 192,37 & 95,07 \\
\hline 157,06 & 8,57 & 36,33 & $-1,683$ & 4,160 & 0,867 & 4,127 & 276,61 & 192,37 & 84,25 \\
\hline 137,75 & 8,05 & 34,12 & $-1,476$ & 3,503 & 0,814 & 3,400 & 261,77 & 192,37 & 69,40 \\
\hline 118,44 & 7,38 & 31,27 & $-1,227$ & 2,679 & 0,746 & 2,491 & 243,22 & 192,37 & 50,85 \\
\hline 99,12 & 6,56 & 27,80 & $-1,005$ & 2,048 & 0,663 & 1,821 & 218,40 & 181,23 & 37,17 \\
\hline 79,81 & 5,59 & 23,69 & $-0,837$ & 1,741 & 0,565 & 1,544 & 185,59 & 154,07 & 31,52 \\
\hline 60,50 & 4,47 & 18,95 & $-0,654$ & 1,389 & 0,452 & 1,229 & 148,02 & 122,93 & 25,09 \\
\hline 41,19 & 3,20 & 13,57 & $-0,457$ & 0,993 & 0,324 & 0,876 & 105,73 & 87,85 & 17,88 \\
\hline 21,87 & 1,79 & 7,57 & $-0,250$ & 0,552 & 0,181 & 0,486 & 58,78 & 48,86 & 9,92 \\
\hline 2,56 & 0,22 & 0,93 & $-0,030$ & 0,068 & 0,022 & 0,059 & 7,19 & 5,98 & 1,21 \\
\hline 0,00 & 0,00 & 0,00 & $-0,000$ & 0,000 & 0,000 & 0,000 & 0,00 & 0,00 & 0,00 \\
\hline
\end{tabular}

Mit den Werten aus Tabelle 9 lässt sich der Kraftverlauf der Lamelle grafisch darstellen (s. Abbildung 53). In der Grafik ist außerdem die Zugkraft des Betonstahls abgebildet, um die Aufteilung der Gesamtzugkraft auf die einbetonierte und die aufgeklebte Bewehrung darzustellen. 


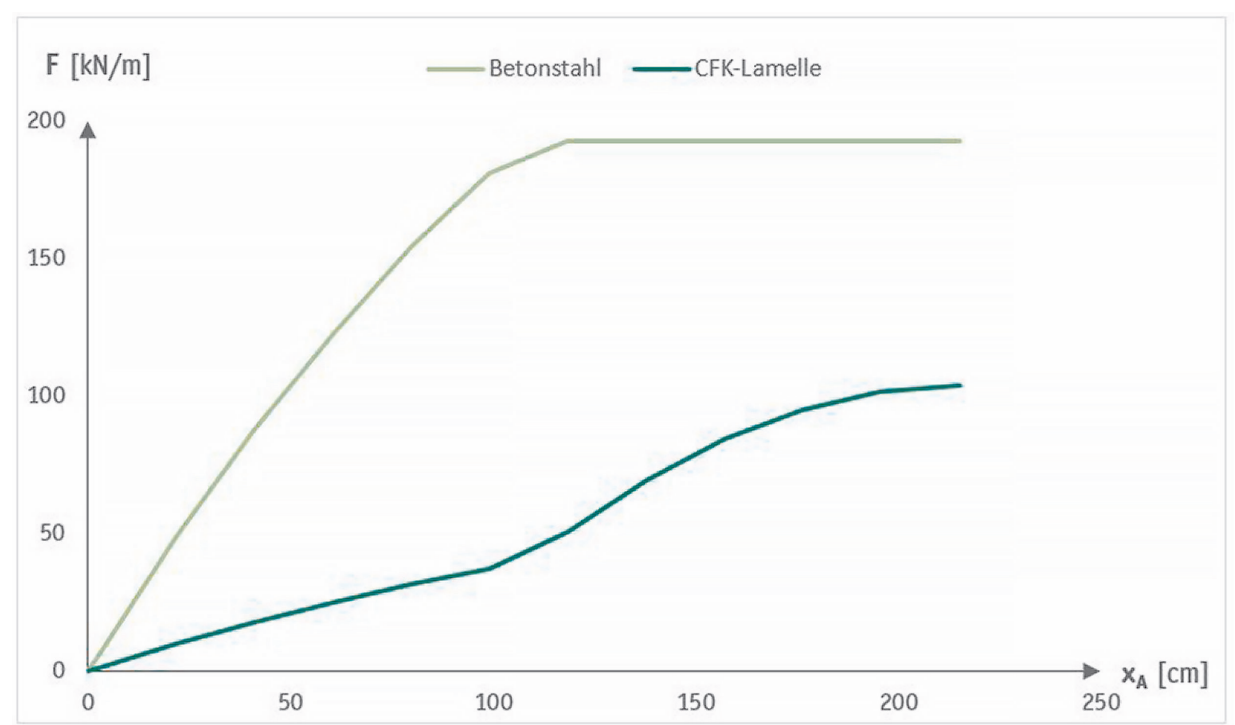

Abb. 53 Zugkraftverlauf der einbetonierten und aufgeklebten Bewehrung (http://doi.org/10.33968/9783966270021-04-A-04)

Daran lässt sich erkennen, weshalb eine Überschätzung des Rissabstandes zu auf der sicheren Seite liegenden Ergebnissen führt. Je größer der Rissabstand, umso größer ist die Lamellenkraftdifferenz eines jeden Zwischenrisselements an dem der Nachweis der Verbundkraftübertragung zu führen ist.

\subsubsection{Nachweis der Verbundkraftübertragung}

Mit den vorhandenen Werten kann der eigentliche Nachweis der Lamellenkraftänderung am ZRE geführt werden. Dazu werden die Zwischenrisselemente den Biegerissen folgend ab dem Momentenmaximum angeordnet. Die Lamellenkraftdifferenz an einem ZRE ergibt sich aus der Differenz der Lamellenkraft am höher beanspruchten Rissufer abzüglich der Lamellenkraft am geringer beanspruchten Rissufer. Die ermittelten Werte sind in Tabelle 10 aufgeführt. 
Tab. 10 Lamellenkraftdifferenz an den Zwischenrisselementen (http://doi.org/10.33968/9783966270021-04-T-03)

\begin{tabular}{|c|c|c|c|c|c|}
\hline $\begin{array}{l}\text { ZRE } \\
{[-]}\end{array}$ & $\begin{array}{c}\mathbf{X}_{\mathrm{A} 1} \\
{[\mathrm{~cm}]}\end{array}$ & $\begin{array}{c}\mathbf{X}_{\mathrm{A} 2} \\
{[\mathrm{~cm}]}\end{array}$ & $\begin{array}{c}F_{\mathrm{Ld}}\left(\mathbf{x}_{\mathrm{A} 1}\right) \\
{[\mathrm{kN} / \mathrm{m}]}\end{array}$ & $\begin{array}{c}\mathbf{F}_{\mathrm{Ld}}\left(\mathbf{x}_{\mathrm{A} 2}\right) \\
{[\mathrm{kN} / \mathrm{m}]}\end{array}$ & $\begin{array}{c}\Delta F_{L d} \\
{[k N / m]}\end{array}$ \\
\hline 1 & 215,00 & 195,69 & 103,88 & 101,66 & 2,22 \\
\hline 2 & 195,69 & 176,37 & 101,66 & 95,07 & 6,59 \\
\hline 3 & 176,37 & 157,06 & 95,07 & 84,25 & 10,82 \\
\hline 4 & 157,06 & 137,75 & 84,25 & 69,40 & 14,85 \\
\hline 5 & 137,75 & 118,44 & 69,40 & 50,85 & 18,55 \\
\hline 6 & 118,44 & 99,12 & 50,85 & 37,17 & 13,68 \\
\hline 7 & 99,12 & 79,81 & 37,17 & 31,52 & 5,65 \\
\hline 8 & 79,81 & 60,50 & 31,52 & 25,09 & 6,43 \\
\hline 9 & 60,50 & 41,19 & 25,09 & 17,88 & 7,20 \\
\hline 10 & 41,19 & 21,87 & 17,88 & 9,92 & 7,96 \\
\hline 11 & 21,87 & 2,56 & 9,92 & 1,21 & 8,71 \\
\hline 12 & 2,56 & 0,00 & 1,21 & 0,00 & 1,21 \\
\hline
\end{tabular}

Beim genaueren Verbundnachweis muss die aufnehmbare Lamellenkraftänderung für jedes ZRE einzeln berechnet und nachgewiesen werden, dass die einwirkende Lamellenkraftdifferenz kleiner ist. Beispielhaft wird der Nachweis für das ZRE 5 geführt. Die aufnehmbare Lamellenkraftdifferenz ergibt sich aus den Anteilen des bilinearen Verbundansatzes, der Reibung sowie der Bauteilkrümmung gemäß Abschnitt 2.7.5.2. Dazu wird zunächst die Verbundfestigkeit der Verstärkung benötigt, die von der effektiven Verbundlänge und somit vom Rissabstand abhängt.

$l_{b L, \max }=\frac{2}{k} \cdot \sqrt{\frac{E_{L} \cdot t_{L} \cdot s_{L 0 k}}{\tau_{L 1 k}}}$

Um die effektive Verbundlänge zu bestimmen, werden die Verbundbeiwerte des bilinearen Ansatzes aus dem Anhang RV K der DAfStb-Richtlinie gemäß bauaufsichtlicher Zulassung für die Carboplus ${ }^{\circledR}$-Lamellen sowie der empirische Faktor $k=$ 1,128 nach Niedermeier verwendet. 


$$
\begin{aligned}
\tau_{L 1 k} & =0,366 \cdot \sqrt{\alpha_{c c} \cdot f_{c m} \cdot \alpha_{c t} \cdot f_{c t m, \text { surf }}}=0,366 \cdot \sqrt{0,85 \cdot 28 \cdot 0,85 \cdot 2,1} \\
& \approx 2,39 \mathrm{~N} / \mathrm{mm}^{2} \\
s_{L 0 k}= & 0,201 \mathrm{~mm} \\
l_{b L, \max } & =\frac{2}{1,128} \cdot \sqrt{\frac{162.000 \cdot 1,2 \cdot 0,201}{2,39}} \approx 226,92 \mathrm{~mm}
\end{aligned}
$$

Die effektive Verbundlänge ist größer als der vorhandene Rissabstand. Daraus resultiert die Berechnung der charakteristischen Verbundfestigkeit, wofür die maximale Verbundfestigkeit der Verstärkung am Endverankerungspunkt benötigt wird.

$$
\begin{aligned}
& f_{b L k}\left(s_{r}\right)=f_{b L k, \text { max }} \cdot \frac{s_{r}}{l_{b L, \text { max }}} \cdot\left(2-\frac{s_{r}}{l_{b L, \text { max }}}\right) \\
& f_{b L k, \text { max }}=\sqrt{\frac{E_{L m} \cdot s_{L 0 k} \cdot \tau_{L 1 k}}{t_{L}}}=\sqrt{\frac{162.000 \cdot 0,201 \cdot 2,39}{1,2}} \approx 254,42 \mathrm{~N} / \mathrm{mm}^{2} \\
& f_{b L k}\left(s_{r}\right)=254,42 \cdot \frac{193,1}{226,92} \cdot\left(2-\frac{193,1}{226,92}\right) \approx 248,78 \mathrm{~N} / \mathrm{mm}^{2}
\end{aligned}
$$

Damit kann der Verbundwiderstand am Punkt G (vgl. Abbildung 23) berechnet werden.

$$
\Delta F_{L k, B L}^{G}=f_{b L k}\left(s_{r}\right) \cdot b_{L} \cdot t_{L}=248,78 \cdot 105 \cdot 1,2 \cdot 10^{-3} \approx 31,35 k N
$$

Es folgt die Berechnung der Lamellenkraft und der zugehörigen aufnehmbaren Lamellenkraftdifferenz am Punkt D, ab dem der Rissabstand keinen Einfluss mehr auf die aufnehmbare Lamellenkraftdifferenz ausübt. Dieser wird benötigt um die endgültig aufnehmbare Lamellenkraftdifferenz nach Gleichung (2-51) in Abhängigkeit zur einwirkenden Lamellenkraft am geringer beanspruchten Rissufer für den Bereich 1 zu bestimmen (vgl. Abbildung 23).

$$
\begin{aligned}
F_{L k, B L}^{D} & =\frac{E_{L m} \cdot s_{L 0 k} \cdot b_{L} \cdot t_{L}}{s_{r}}-\tau_{L 1 k} \cdot \frac{s_{r} \cdot b_{L}}{4} \\
& =\left(\frac{162.000 \cdot 0,201 \cdot 105 \cdot 1,2}{193,1}-2,39 \cdot \frac{193,1 \cdot 105}{4}\right) \cdot 10^{-3} \\
& \approx 9,15 \mathrm{kN}
\end{aligned}
$$




$$
\begin{aligned}
\Delta F_{L k, B L}^{D} & =\sqrt{b_{L}{ }^{2} \cdot \tau_{L 1 k} \cdot s_{L 0 k} \cdot E_{L m} \cdot t_{L}+{F_{L k, B L}^{D}}^{2}}-F_{L k, B L}^{D} \\
& =\sqrt{105^{2} \cdot 2,39 \cdot 0,201 \cdot 162.000 \cdot 1,2 \cdot 10^{-6}+9,15^{2}}-9,15 \\
& \approx 24,19 k N
\end{aligned}
$$

Aus Tabelle 10 geht hervor, dass die Lamellenkraft am geringer beanspruchten Rissufer $(50,85 \mathrm{kN})$ deutlich größer als die Lamellenkraft am Punkt D ist. Somit muss die aufnehmbare Lamellenkraftdifferenz wie folgt berechnen werden:

$$
\begin{aligned}
& \Delta F_{L k, B L}=\sqrt{b_{L}{ }^{2} \cdot \tau_{L 1 k} \cdot s_{L 0 k} \cdot E_{L m} \cdot t_{L}+F_{L E d}{ }^{2}}-F_{L E d} \\
& =\sqrt{105^{2} \cdot 2,39 \cdot 0,201 \cdot 162.000 \cdot 1,2 \cdot 10^{-6}+50,85^{2}}-50,85 \\
& \approx 9,26 k N
\end{aligned}
$$

Aus der vorab beschriebenen Überschreitung der Lamellenkraft am Punkt D durch die einwirkende Lamellenkraft ergibt sich ein weiterer Anteil aus Reibungseffekten, der zur aufnehmbaren Lamellenkraftdifferenz am ZRE beiträgt. Hierfür wird zunächst die Reibverbundspannung benötigt. Diese lässt sich aus dem Anhang RV K zur DAfStb-Richtlinie ermitteln.

$$
\begin{aligned}
& \tau_{L F k}=10,8 \cdot \alpha_{c c} \cdot f_{c m}{ }^{-0,89}=10,8 \cdot 0,85 \cdot 28^{-0,89} \approx 0,47 \mathrm{~N} / \mathrm{mm}^{2} \\
& \Delta F_{L k, B F}=\tau_{L F k} \cdot b_{L}\left(s_{r}-\frac{2 \cdot t_{L} \cdot E_{L m}}{\tau_{L 1 k}} \cdot\left[\sqrt{\frac{\tau_{L 1 k} \cdot s_{L 0 k}}{t_{L} \cdot E_{L m}}+\frac{F_{L E d}{ }^{2}}{b_{L}{ }^{2} \cdot t_{L}{ }^{2} \cdot E_{L m}{ }^{2}}}-\frac{F_{L E d}}{b_{L} \cdot t_{L} \cdot E_{L m}}\right]\right) \\
& =0,47 \cdot 105 \cdot\left(193,1-\frac{2 \cdot 1,2 \cdot 162.000}{2,39} \cdot\left[\sqrt{\frac{2,39 \cdot 0,201}{1,2 \cdot 162.000}+\frac{\left(50,85 \cdot 10^{3}\right)^{2}}{105^{2} \cdot 1,2^{2} \cdot 162.000^{2}}}-\frac{50,85 \cdot 10^{3}}{105 \cdot 1,2 \cdot 162.000}\right]\right) \\
& \approx 5.919 \mathrm{~N} \approx 5,20 \mathrm{kN}
\end{aligned}
$$

Anschließend wird mit den Dehnungen aus Tabelle 9 die Bauteilkrümmung berücksichtigt.

$$
\begin{aligned}
& \Delta F_{L k, K F}=s_{r} \cdot \kappa_{k} \cdot \frac{\varepsilon_{L r 1}-\varepsilon_{c r 1}}{h} \cdot b_{L} \\
& \varepsilon_{L r 1}=\varepsilon_{L, 0}+\varepsilon_{L}=0,746+2,491=3,237 \% 0
\end{aligned}
$$




$$
\Delta F_{L k, K F}=193,1 \cdot 24.300 \cdot \frac{0,003237-(-0,001227)}{160} \cdot 105 \cdot 10^{3} \approx 13,75 \mathrm{kN}
$$

Damit kann die aufnehmbare Lamellenkraftdifferenz am ZRE 5 aus den drei Anteilen zusammengesetzt werden:

$\Delta F_{L R d}=\frac{\Delta F_{L k, B L}+\Delta F_{L k, B F}+\Delta F_{L k, K F}}{\gamma_{B A}}=\frac{9,26+5,20+13,75}{1,5} \approx 18,81 \mathrm{kN}$

$\Delta F_{L d} \approx 18,55 k N<\Delta F_{L R d} \approx 18,81 k N$

Damit ist der Nachweis der Lamellenkraftänderung am ZRE für das Zwischenrisselement 5 erfüllt. Diese Berechnung wird an jedem Zwischenrisselement durchgeführt. Sobald für alle ZRE die Einwirkung geringer als der Widerstand ist, gilt der Nachweis für das gesamte Bauteil als erfüllt. In diesem Beispiel wurde das am stärksten ausgenutzte ZRE gewählt, um die Nachweisführung zu verdeutlichen. Für alle andere ZRE ist die Ausnutzung dieses Nachweisformats geringer und somit der Nachweis für dieses Bauteil mit einer Lamellenfläche von ca. 1,26 cm² erfüllt.

\subsection{Vergleich der Ergebnisse}

Wie zu erwarten, zeigt sich in diesem Beispiel, dass durch den genaueren Nachweis der Lamellenkraftänderung am ZRE eine geringere Lamellenfläche für die Erfüllung des Nachweises im Vergleich zum vereinfachten Nachweisverfahren genügt. 


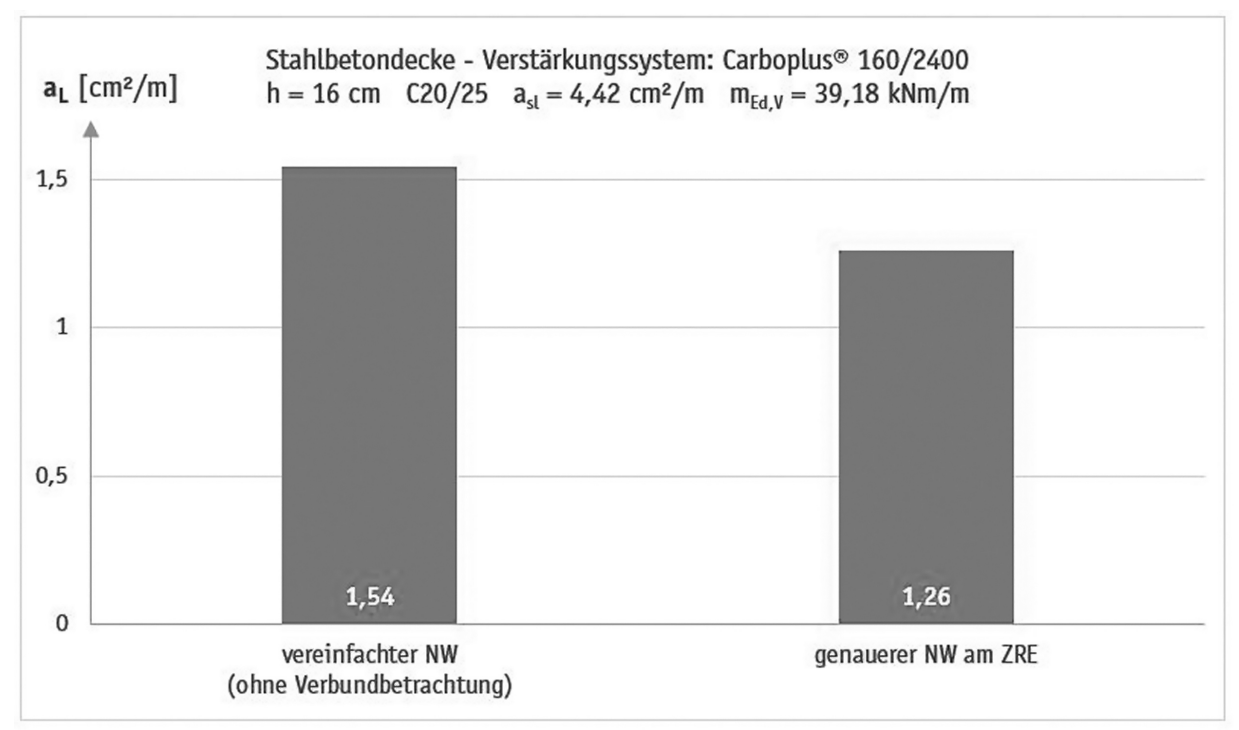

Abb. 54 erforderliche Lamellenfläche in Abhängigkeit des Nachweisformats (http://doi.org/10.33968/9783966270021-04-A-05)

Daher wird im Sinne einer möglichst wirtschaftlichen Bemessung empfohlen, mit der konfigurierten Excel-Tabelle den Nachweis der Biegetragfähigkeit für aufgeklebte CFK-Lamellen zu führen, wozu auch die Verbundbetrachtung zählt. 



\section{Zusammenfassung}

\subsection{Ergebnisse}

In der DAfStb-Richtlinie „Verstärken von Betonbauteilen mit geklebter Bewehrung“ werden unterschiedliche Möglichkeiten zum Nachweis der Biegeverstärkung von Stahlbetonbauteilen mit aufgeklebten CFK-Lamellen bereitgestellt, wie Abbildung 55 nochmals verdeutlichen soll. Durch den DAfStb wurde eine Methode zur Nachweisführung anhand von Versuchen und Forschungen hergeleitet, die modellhaft das reale Verbundverhalten darstellen soll. Dabei erscheint die Nachweisführung äußerst komplex. Anhand der Bemessungsgrundlagen wurde festgestellt, dass bei aufgeklebten CFK-Lamellen insbesondere das Verbundverhalten maßgebend wird. Durch die detaillierte Betrachtung der Bemessungsansätze der aufgeklebten CFK-Lamellen konnten Hilfsmittel entwickelt werden, die eine Vorbemessung mit unterschiedlichen Genauigkeitsstufen hinsichtlich der erforderlichen Lamellenfläche ermöglichen.

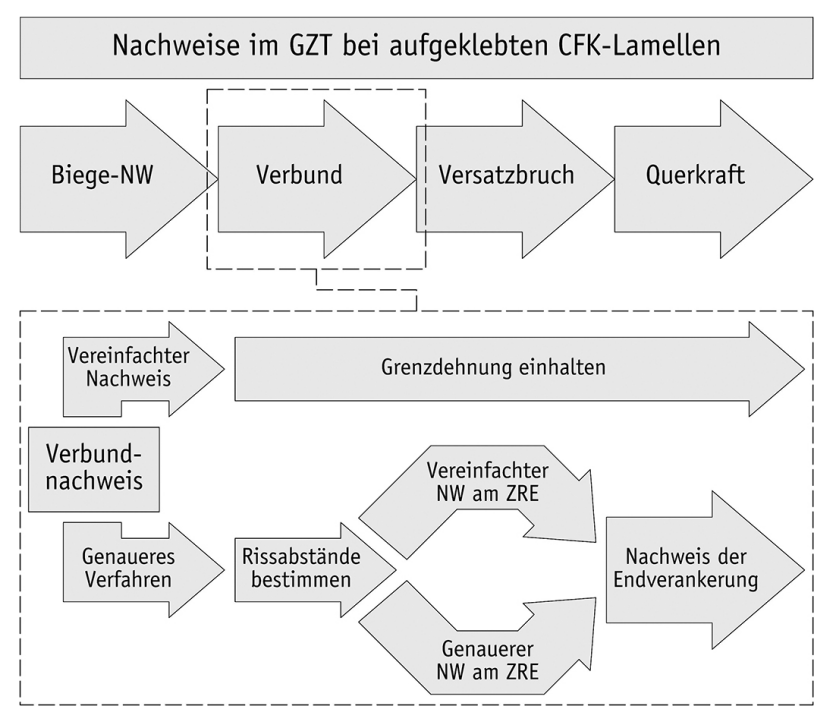

Abb. 55 Ablaufschema des Nachweisverfahrens bei aufgeklebten CFK-Lamellen (Quelle: Eigene Darstellung in Anlehnung an [DAfStb-Heft 595] Bild H.8, S. 17)

(http://doi.org/10.33968/9783966270021-05-A-01) 
Der größte rechnerische Aufwand besteht dabei in der iterativen Ermittlung der Lamellenkraft. Je nach Nachweisformat steigt oder sinkt der rechnerische Aufwand. Für die einfachste Art des Nachweises konnten Bemessungstafeln entwickelt werden, die auf der Erweiterung der Bemessungsansätze des reinen Stahlbetons um die aufgeklebten Lamellen beruhen. Mit diesen Bemessungstafeln lassen sich Biegeverstärkungen von Stahlbetonbauteilen mit Rechteckquerschnitt mittels aufgeklebten CFK-Lamellen anhand des vereinfachten Nachweises gemäß der DAfStb- Richtlinie bemessen, ohne dass weitere Verbundbetrachtungen erforderlich sind. Dabei gelten die Tafeln im Anhang C sowohl für Querschnitte mit, als auch ohne Druckbewehrung. Lediglich Berechnungen der einzelnen Werte erfolgt mit unterschiedlichen Ansätzen, die in den Anhängen A und B zu finden sind. Je nachdem ob es sich um Stahlbetonrechteckquerschnitte mit oder ohne Druckbewehrung handelt, decken die Bemessungstafeln unterschiedlich große Bereiche $\mathrm{ab}$, da sich der Stahl für die Anwendung der Bemessungstafeln im Fließen befinden muss.

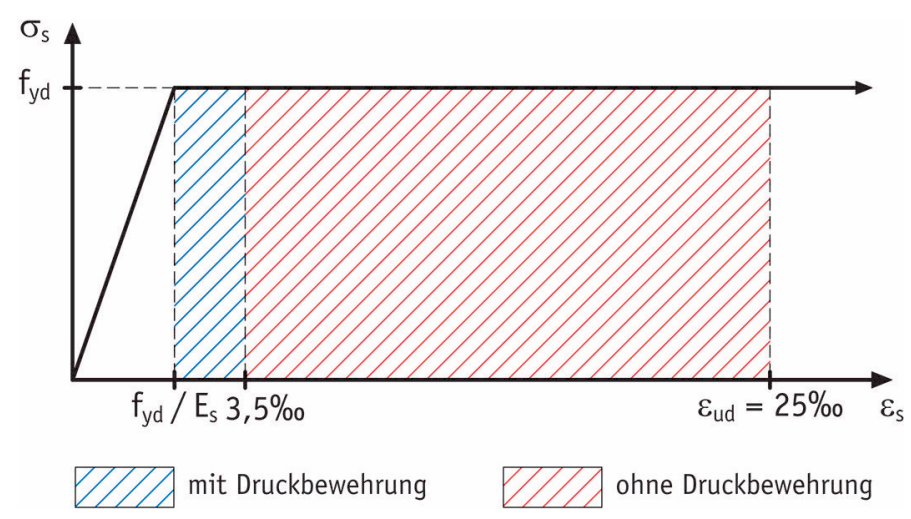

Abb. 56 zulässige Bereiche der Bemessungstafeln in Bezug zur Betonstahlspannung (http://doi.org/10.33968/9783966270021-05-A-02)

Diese Festlegung ist erforderlich, da sonst die Bemessung iterativ bleiben würde, denn die Stahlspannung geht in den Eingangswert der Bemessungstafeln ein. Bei der Anwendung der Bemessungstafeln ohne Druckbewehrung kann im Nachhinein überprüft werden, ob diese Bedingung erfüllt ist, da hierbei ein verhältnismäßig großer Bereich abgedeckt wird. Im Gegensatz dazu sollte bei Druckbewehrung als erstes überprüft werden, ob die erarbeiteten Tabellen anwendbar sind, da der gültige Bereich dafür deutlich kleiner ausfällt (vgl. Abbildung 56). Daher wurde ein Verhältniswert eingeführt der eine sofortige Aussage über die Anwendbarkeit der Bemessungstafeln bei Druckbewehrung zulässt. Sollten die Bemessungstafeln nicht angewendet werden können, kann die Bemessung nur iterativ erfolgen. Im Prinzip stellen die Bemessungstafeln die Lösung des iterativen Vorgangs für vorgegebene Werte dar. Soll damit der vereinfachte Nachweis der Biegetragfähigkeit ge- 
mäß DAfStb-Richtlinie ohne Verbundbetrachtung geführt werden, sind gewisse Randbedingungen einzuhalten. Außerdem gilt dieses Nachweisformat als unwirtschaftlichste Variante der Bemessung. Um genauere Ergebnisse in der Bemessung zu erzielen, wurde der genauere Nachweis der Lamellenkraftänderung in einer Excel-Arbeitsmappe konfiguriert. Dieser stellt derzeit die wirtschaftlichste Methode zur Bemessung einer Biegeverstärkung mit aufgeklebten CFK-Lamellen dar, da die Bemessungsansätze das reale Verbundverhalten am genauesten modellhaft abbilden. Außerdem sind in der Excel-Arbeitsmappe die erforderlichen Iterationen integriert, weshalb keine Einschränkungen hinsichtlich der Fließgrenze des Betonstahls resultieren. Auch die Randbedingungen die beim vereinfachten Nachweis eingehalten werden müssen, gelten für dieses Nachweisformat nicht. Jedoch ergaben sich Einschränkungen während der Erarbeitung der Excel-Arbeitsmappe, die aus der Begrenzung des Bearbeitungsumfangs dieser Arbeit resultieren. Im Bedarfsfall ist es möglich diese Arbeitsmappe entsprechend zu erweitern und anzupassen, sodass die vorgenommenen Einschränkungen aufgehoben werden können. Die Excel-Arbeitsmappe „Verbundnachweis_aufgeklebte_CFK-Lamellen. xlsm“ ist auf dem beiliegenden Datenträger zu finden. Damit wird jedem Bauingenieur ermöglicht, die Vorbemessung einer Verstärkungsmaßnahme mit geringem Aufwand durchzuführen.

\subsection{Fazit}

Mit den Bemessungstafeln wurde ein Instrument entwickelt, anhand derer der vereinfachte Nachweis der Biegeverstärkung von Stahlbetonbauteilen mit Rechteckquerschnitt mittels aufgeklebten CFK-Lamellen in kürzester Zeit durchzuführen ist. Damit kann bereits frühzeitig und ohne großen Aufwand die erforderliche Lamellenfläche bestimmt werden. Dabei werden auf der sicheren Seite liegende Ergebnisse erzielt. Somit sind die erarbeiteten Tabellen mit den Bemessungstafeln mit dimensionslosen Beiwerten des reinen Stahlbetonbaus vergleichbar. Zwar stellt der vereinfachte Nachweis die unwirtschaftlichste Form der Nachweisführung dar, aber die leichte Handhabung und der Vorteil der einfachen und schnellen Bemessung der Verstärkung ermöglicht eine frühzeitige Abschätzung einer solchen Verstärkungsmaßnahme im Hinblick auf die Kosten, den Zeitaufwand sowie die generelle Machbarkeit dieser Verstärkungsart. Die Bemessungstafeln sind also für eine Vorbemessung bestens geeignet. Damit ist jeder Bauingenieur in der Lage, die Biegeverstärkung mit aufgeklebten CFK-Lamellen überschlägig zu bewerten. Anhand von Abbildung 56 lässt sich feststellen, dass die Bemessungstafeln für Stahlbetonrechteckquerschnitte ohne Druckbewehrung deutlich besser geeignet sind, als für solche mit Druckbewehrung. Für den vereinfachten Nachweis der Biegetragfähigkeit der DAfStb-Richtlinie liefern die Bemessungstafeln nahezu exakte Ergebnisse. In Zusammenhang mit anderen Nachweisformaten wird die konfigurierte Excel-Arbeitsmappe empfohlen. Darin ist mit dem genaueren Nachweis der Lamellenkraftänderung am ZRE die genaueste und wirtschaftlichste Nachweismethode der aufgeklebten CFK-Lamellen enthalten. Sollten die zulässigen Grenzen 
der Bemessungstafeln verlassen werden, kann mit der Excel-Tabelle eine Lösung gefunden werden. Dabei muss angemerkt werden, dass der Umfang der Excel-Arbeitsmappe sich nicht auf den Endverankerungsnachweis erstreckt, doch für die Vorbemessung sind die Ergebnisse gegenüber den Bemessungstafeln bereits deutlich genauer.

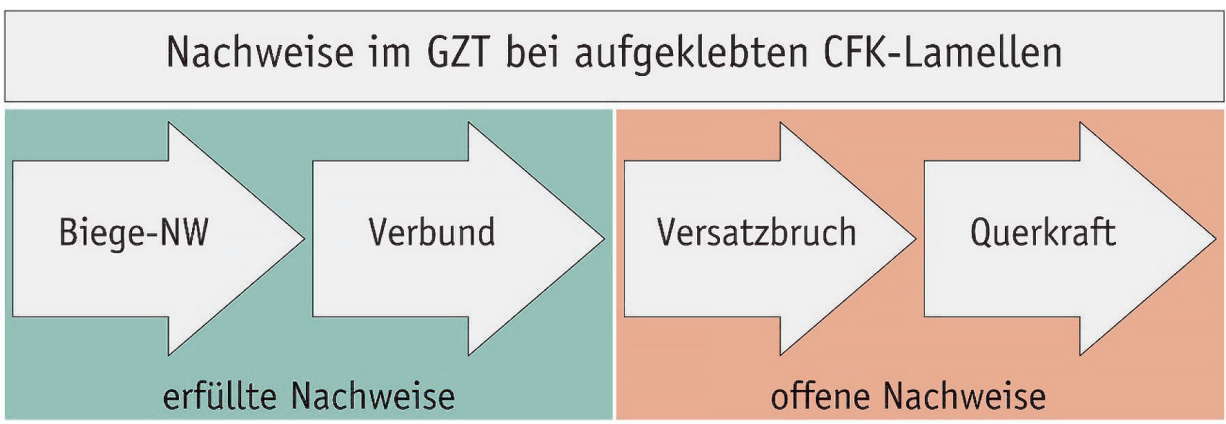

Abb. 57 Umfang der integrierten und der zu führenden Nachweise (http://doi.org/10.33968/9783966270021-05-A-03)

Der Endverankerungsnachweis ist für eine abgeschlossene Verbundbetrachtung in Ergänzung zu den erfolgten Nachweisen zu führen. Bei dem vereinfachten Nachweis und der Anwendung der Bemessungstafeln kann dieser unter bestimmten Randbedingungen gänzlich entfallen. Dagegen unterliegt die Excel-Arbeitsmappe mit dem genaueren Verbundnachweis am ZRE keinen Randbedingungen außer denen, die dem Bearbeitungsumfang geschuldet sind. Außerdem lässt sich die ExcelArbeitsmappe mit moderatem Aufwand um die nötigen Elemente und Nachweise erweitern. In Abhängigkeit der erforderlichen Genauigkeit und dem Zeitpunkt der Vorbemessung sind in jedem Fall beide entwickelten Hilfsmittel empfehlenswert, da sie die Bemessung und somit die Beurteilung eines Einsatzes von aufgeklebten CFK-Lamellen ungemein erleichtern. Insgesamt konnten die eingangs gesetzten Ziele der Arbeit erreicht werden. Es wurden aussagekräftige Bemessungshilfsmittel erstellt, wobei aber die Nachweisführung an dieser Stelle keineswegs beendet ist (vgl. Abbildung 57). Anschließend muss die Vermeidung des Versatzbruchs und die Querkrafttragfähigkeit nachgewiesen werden. Bei Stahlbetonbalken kann bei Überschreitung der vorhandenen Querkrafttragfähigkeit durch Stahllaschen o.ä. auch hier eine Verstärkung erfolgen. Sollte diese aber bei Platten überschritten werden, kann das ein generelles Ausschlusskriterium für eine Verstärkungsmaßnahme sein. 


\section{Ausblick}

Die aufgeklebten CFK-Lamellen sowie der Werkstoff CFK allgemein haben sich in verhältnismäßig kurzer Zeit im Bauwesen etabliert. Aufgrund der vielfältigen Anwendungsmöglichkeiten ist zu erwarten, dass der Einsatz in Zukunft weiter zunehmen wird. Bereits durch die DAfStb-Richtlinie wurde der Weg hin zu einer Erleichterung der Handhabung durch allgemeingültige Bemessungsansätze geebnet. Auch durch die entwickelten Bemessungshilfsmittel wird der Einsatz in Zukunft deutlich erleichtert und vermutlich zu einem weiteren Anstieg der Häufigkeit der Anwendung führen. In Fortführung dieser Arbeit können die Bemessungshilfen um die noch unberücksichtigten Nachweise ergänzt werden, um eine ganzheitliche Nachweisführung für aufgeklebte CFK-Lamellen zu ermöglichen. Der aktuelle Stand der Bemessungshilfen kann als ein erster Schritt in diese Richtung betrachtet werden. Weiterhin sollte in Zukunft eine Erweiterung im Hinblick auf die unterschiedlichen Verstärkungsmöglichkeiten mit geklebter Bewehrung, wie beispielsweise in Schlitze geklebte CFK-Lamellen oder aufgeklebte Stahllaschen in Betracht gezogen werden. Damit würden Beurteilungen über alternative Verstärkungen möglich, sofern die aufgeklebten CFK-Lamellen die Nachweise nicht erfüllen können. Zum Vergleich der unterschiedlichen Applikationsarten und den Rückschluss über die wirtschaftlichste Alternative mit möglichst geringem rechnerischem Aufwand sind solche Betrachtungen ebenfalls zu empfehlen. Auch eine Betrachtung hinsichtlich nicht rechteckiger Querschnitte, wie bspw. Plattenbalken ist als sinnvoll zu erachten. In Hinblick auf das statische System stellt die Excel-Arbeitsmappe nur eine Möglichkeit dar, wobei hier unzählige weitere statische Systeme und Einwirkungen betrachtet werden könnten.

Auch die HTWK forscht derzeit auf dem Gebiet der Faserverbundwerkstoffe. Hier wird seit 2009 am Institut für Betonbau die Verstärkung von Stahlbetonstützen mit Kreisquerschnitt durch Umschnürung mit CF-Gelegen untersucht und ausgewertet. Die Aktualität des Themas wird vermutlich langfristig aufgrund der Vielzahl an Bestandsbauwerken in Deutschland erhalten bleiben und weitere Forschungsvorhaben zur genauen Beschreibung des Material- und Verbundverhaltens sowie der Erweiterung der Anwendungsmöglichkeiten nach sich ziehen. 



\section{Literaturverzeichnis}

\section{Allgemeine Literatur}

[Baar u. Ebeling 2017] Baar, S.; Ebeling, K.: Lohmeyer Stahlbetonbau. Bemessung - Konstruktion Ausführung. 10. Auflage. Wiesbaden: Springer Vieweg (2017)

[Bindseil 2008] Bindseil, P.: Massivbau. Bemessung und Konstruktion im Stahlbetonbau mit Beispielen. 4. Auflage. Wiesbaden: Vieweg + Teubner (2008)

[BVPI 2016] BVPI, DBV, ISB, VBI (Hg.): Eurocode 2 für Deutschland. DIN EN 1992-1-1. Eurocode 2: Bemessung und Konstruktion von Stahlbeton- und Spannbetontragwerken - Teil 1-1: Allgemeine Regeln für den Hochbau. Kommentierte Fassung. 2. Auflage. Berlin: Ernst \& Sohn (2016)

[DAfStb-Heft 394] Deutscher Ausschuss für Stahlbeton (Hg.): Nachweisverfahren für Verankerung, Verformung, Zwangbeanspruchung und Rißbreite. Kontinuierliche Theorie der Mitwirkung des Betons auf Zug. Rechenhilfen für die Praxis. Heft 394. Berlin: Beuth (1988)

[DAfStb-Heft 591] Deutscher Ausschuss für Stahlbeton (Hg.): Sachstandbericht Verstärken von Betonbauteilen mit geklebter Bewehrung. Heft 591. Berlin: Beuth (2011)

[DAfStb-Heft 592] Deutscher Ausschuss für Stahlbeton (Hg.): Praxisgerechte Bemessungsansätze für das wirtschaftliche Verstärken von Betonbauteilen mit geklebter Bewehrung - Verbundtragfähigkeit unter statischer Belastung. Heft 592. Berlin: Beuth (2012)

[DAfStb-Heft 594] Deutscher Ausschuss für Stahlbeton (Hg.): Praxisgerechte Bemessungsansätze für das wirtschaftliche Verstärken von Betonbauteilen mit geklebter Bewehrung - Querkrafttragfähigkeit. Heft 594. Berlin: Beuth (2012)

[DAfStb-Heft 595] Deutscher Ausschuss für Stahlbeton (Hg.): Erläuterungen und Beispiele zur DAfStb-Richtlinie „Verstärken von Betonbauteilen mit geklebter Bewehrung“. Heft 595. Berlin: Beuth (2013)

[Dehn et al. 2005] Dehn, F.; Holschemacher, K.; Tue, N. (Hg.): Faserverbundwerkstoffe. Innovationen im Bauwesen. Beiträge aus Praxis und Wissenschaft. 1. Auflage. Berlin: Bauwerk (2005)

[FIB 2001] fédération internationale du béton (fib) (Hg.): Externally bonded FRP reinforcement for RC structures. Technical report on the design and use of externally bonded fibre reinforced polymer reinforcement (FRP EBR) for reinforced concrete structures. Lausanne: fib (2001)

[Finckh 2012] Finckh, W.: Einfluss bauteilspezifischer Effekte auf die Bemessung von mit CFK-Lamellen verstärkten Bauteilen. Dissertation. Technische Universität München, Lehrstuhl für Massivbau, München. (2012)

[Holschemacher et al. 2012] Holschemacher, K.; Müller, T.; Lobisch, F.: Bemessungshilfsmittel für Betonbauteile nach Eurocode 2. Berlin: Ernst \& Sohn (2012)

[Küchler 2013] Küchler, M.: Instandsetzung von Betontragwerken. Erschienen in: Betonkalender 2013. Lebensdauer und Instandsetzung - Brandschutz. Teil 1. S. 345-468. Berlin: Ernst \& Sohn (2013) 
[Leonhardt u. Mönnig 1984] Leonhardt, F.; Mönnig, E.: Vorlesungen über Massivbau. Teil 1: Grundlagen zur Bemessung im Stahlbetonbau. 3. Auflage. Heidelberg: Springer (1984)

[Mehlhorn et al. 2002] Mehlhorn, G.; Fehling, E.; Jahn, T.; Kleinheinz, A.: Bemessung von Betonbauten im Hoch- und Industriebau. Berlin: Ernst \& Sohn (2002)

[Onken u. Vom Berg 2001] Onken, P.; Vom Berg, W.: Biegezugverstärkung mit CFK-Lamellen. Erschienen in: Beton- und Stahlbetonbau 96. Heft 2. S. 61-70. Berlin: Ernst \& Sohn (2001)

[Otto 2017] Otto, S.: Nachträgliche Verstärkung von Betonbauwerken. CFK-Lamellen als Alternative zu Stahlträgern und Spritzbeton. Erschienen in: Der Bausachverständige 01/2017. S. 30-32. Köln: Bundesanzeiger Verlag (2017)

[Otto 2017] Otto, S.: Nachträgliche Verstärkung von Betonbauwerken. CFK-Lamellen als Alternative zu Stahlträgern und Spritzbeton. Erschienen in: Der Bausachverständige 01/2017. S. 30-32. Köln: Bundesanzeiger Verlag (2017)

[Papula 2014] Papula, L.: Mathematik für Ingenieure und Naturwissenschaftler. Band 1. Ein Lehrund Arbeitsbuch für das Grundstudium. 14. Auflage. Wiesbaden: Springer Vieweg (2014)

[Rostásy et al. 1996] Rostásy, F. S.; Holzenkämpfer, P.; Hankers, C.: Geklebte Bewehrung für die Verstärkung von Betonbauteilen. Erschienen in: Betonkalender 1996. Teil 2. S. 547-576. Berlin: Ernst \& Sohn (1996)

[Schneider et al. 2012] Schneider, K.-J.; Goris, A.; Albert, A.: Bautabellen für Ingenieure. Mit Berechnungshinweisen und Beispielen. 20. Auflage. Köln: Werner (2012)

[Schwarz u. Köckler 2006] Schwarz, H. R.; Köckler, N.: Numerische Mathematik. 6. Auflage. Wiesbaden: Teubner (2006)

[Stahr 2015] Stahr, M. (Hg.): Bausanierung. Erkennen und Beheben von Bauschäden. 6. Auflage. Wiesbaden: Springer Vieweg (2015)

[Stroppe 2012] Stroppe, H.: PHYSIK für Studierende der Natur- und Ingenieurwissenschaften. 15. Auflage. München: Fachbuchverlag Leipzig im Carl Hanser Verlag (2012)

[Ulaga 2003] Ulaga, T.: Betonbauteile mit Stab- und Lamellenbewehrung: Verbundund Zugtragfähigkeit. Dissertation. Eidgenössische Technische Hochschule Zürich, Institut für Baustatik und Konstruktion, Zürich. (2003)

[Wommelsdorff u. Albert 2011] Wommelsdorff, O.; Albert, A.: Stahlbetonbau. Bemessung und Konstruktion. Teil 1 Grundlagen Biegebeanspruchte Bauteile. 10. Auflage. Köln: Werner (2011)

[Zilch et al. 2013] Zilch, K.; Niedermeier, R.; Finckh, W.: Geklebte Verstärkung mit CFK-Lamellen und Stahllaschen. Erschienen in: Betonkalender 2013. Lebensdauer und Instandsetzung Brandschutz. Teil 1. S. 469-552. Berlin: Ernst \& Sohn (2013)

\section{Normen und Regelwerke}

[DAfStb 2012-03] Deutscher Ausschuss für Stahlbeton: DAfStb-Richtlinie Verstärken von Betonbauteilen mit geklebter Bewehrung. Berlin: Beuth (März 2012) 
[EC0 2010-12] Deutsches Institut für Normung: DIN EN 1990. Eurocode: Grundlagen der Tragwerksplanung; Deutsche Fassung EN 1990:2002 + A1:2005 + A1:2005/AC:2010. Berlin: Beuth (Dezember 2010)

[EC0 NA 2010-12] Deutsches Institut für Normung: DIN EN 1990/NA. Nationaler Anhang - National festgelegte Parameter - Eurocode: Grundlagen der Tragwerksplanung. Berlin: Beuth (Dezember 2010)

[EC2-1-1 2011-01] Deutsches Institut für Normung: DIN EN 1992-1-1. Eurocode 2: Bemessung und Konstruktion von Stahlbeton- und Spannbetontragwerken - Teil 1-1: Allgemeine Bemessungsregeln und Regeln für den Hochbau; Deutsche Fassung EN 1992-1-1:2004 + AC:2010. Berlin: Beuth (Januar 2011)

[EC2-1-1 NA 2013-04] Deutsches Institut für Normung: DIN EN 1992-1-1/NA. Nationaler Anhang National festgelegte Parameter - Eurocode 2: Bemessung und Konstruktion von Stahlbetonund Spannbetontragwerken - Teil 1-1: Allgemeine Bemessungsregeln und Regeln für den Hochbau. Berlin: Beuth (April 2013)

[Z-36.12-84] Deutsches Institut für Bautechnik: Allgemeine bauaufsichtliche Zulassung. Zulassungsnummer: Z-36.12-84. Antragsteller: Implenia Construction GmbH. Geltungsdauer: 01. August 2015 bis 01. Januar 2020. Zulassungsgegenstand: Schubfest aufgeklebte Kohlefaserlamellen „Carboplus ${ }^{\circledR}$ Lamellen“ nach der DAfStb-Verstärkungs-Richtlinie. DIBt (27. August 2015)

[Z-36.12-85] Deutsches Institut für Bautechnik: Allgemeine bauaufsichtliche Zulassung. Zulassungsnummer: Z-36.12-85. Antragsteller: MC-Bauchemie Müller GmbH \& Co. KG. Geltungsdauer: 01. Januar 2015 bis 01. Januar 2020. Zulassungsgegenstand: Verstärken von Stahlbetonbauteilen durch schubfest aufgeklebte Kohlefaserlamellen „MC-DUR“ nach der DAfStb-Verstärkungs-Richtlinie. DIBt (16. Dezember 2014)

[Z-36.12-86] Deutsches Institut für Bautechnik: Allgemeine bauaufsichtliche Zulassung. Zulassungsnummer: Z-36.12-86. Antragsteller: StoCretec GmbH. Geltungsdauer: 24. März 2015 bis 01. Januar 2020. Zulassungsgegenstand: Bausatz StoCretec zum Verstärken von Stahl- und Spannbetonbauteilen durch schubfest aufgeklebte CFK-Lamellen nach der DAfStb- Verstärkungs-Richtlinie. DIBt (26. März 2015)

\section{Internetquellen}

[bm engineering 2017] bm engineerung sa: statische Verstärkung. http://www.bm-eng.ch/de/ ausfuehrung/strukturverstaerkung; Zugriff: 18. Juli 2017

[CTQ GmbH 2017] CTQ - Center for Testing and Qualifications GmbH: Anwendungsgerechte Materialentwicklung und Materialoptimierung. http://www.ctq-gmbh.de/?page_id=75; Zugriff: 13. Februar 2017

[DIBt 2017] Deutsches Institut für Bautechnik: Verzeichnis der allgemeinen bauaufsichtlichen Zulassungen. Zulassungsbereich: Klebetechnik. https:/www.dibt.de/de/zv/NAT_n/zv_referat_I4/ SVA_36.htm; Zugriff: 09. Mai 2017

[Microsoft 2017] Microsoft: Microsoft by the numbers. https://news.microsoft.com/bythenumbers/ planet-office; Zugriff: 21. Juni 2017 
[S\&P 2017] S\&P Clever Reinforcement Company AG: Verstärkung Auto Ausstellungsraum Basel/BS. http://www.sp-reinforcement.ch/de-CH/projekte/biegezug/verstaerkung- auto-ausstellungsraum-baselbs; Zugriff: 18. Juli 2017

Titelbild Fritz Wiedemann \& Sohn GmbH: Kohlefaserkunststoffe (CFK) http://www.wiedemanngmbh.com/cfk_lamellen.html; Zugriff: 20. Juli 2017 (c) Fritz Wiedemann \& Sohn GmbH; Fotograf: Marc Ruske 
Anhang 



\section{Anhang A}

\section{Anwendung der Bemessungstafeln ohne Druckbewehrung}

\section{Dehnungen zum Zeitpunkt der Verstärkung}

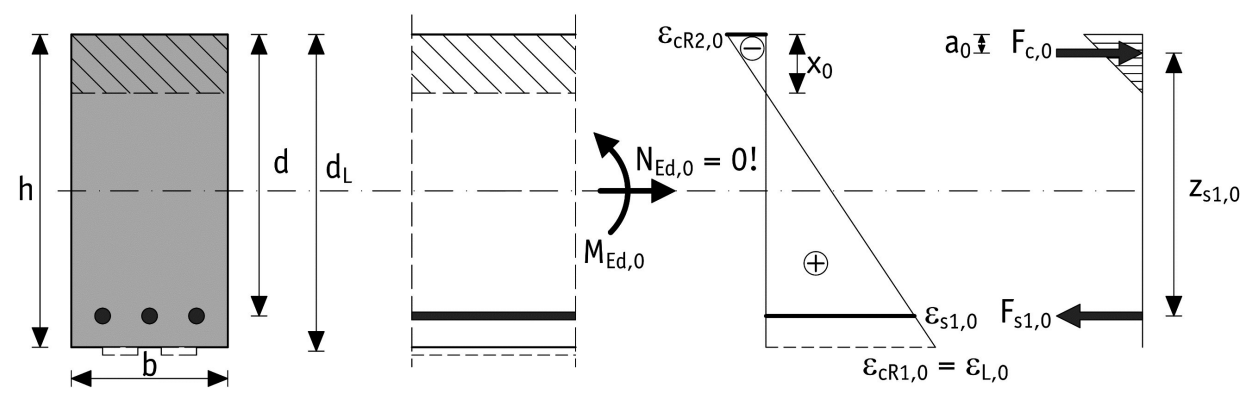

Abb. A.1 Dehnungs- und Spannungsverteilung am Stahlbetonquerschnitt bei linear-elastischem Materialverhalten ohne Druckbewehrung (http://doi.org/10.33968/9783966270021-07-A-01)

Die Dehnungen zum Zeitpunkt der Verstärkung können bei linear-elastischem Materialverhalten und reiner Biegebeanspruchung näherungsweise anhand des folgenden Formelapparats für Rechteckquerschnitte bestimmt werden. Die Einwirkungen sind realitätsnah oder vereinfachend auf Gebrauchstauglichkeitsniveau mit der quasi-ständigen Belastungskombination anzusetzen.

$x_{0}=\left(-\alpha_{s} \cdot \rho_{s 1}+\sqrt{\left(\alpha_{s} \cdot \rho_{s 1}\right)^{2}+2 \cdot \alpha_{s} \cdot \rho_{s 1} \cdot \frac{d}{h}}\right) \cdot h$

$\rho_{s 1}=\frac{A_{s 1}}{b \cdot h}$ 
$\alpha_{s}=\frac{E_{s}}{E_{c}}$

$z_{s 1,0}=d-\frac{1}{3} \cdot x_{0}$

$F_{S 1,0}=\frac{M_{E d, 0}}{z_{S 1,0}}$

$\varepsilon_{s 1,0}=\frac{F_{S 1,0}}{A_{s 1} \cdot E_{S}}$

$\varepsilon_{L, 0}=\varepsilon_{s 1,0} \cdot \frac{d_{L}-x_{0}}{d_{s 1}-x_{0}}$

\section{Bezogenes Bemessungsmoment}

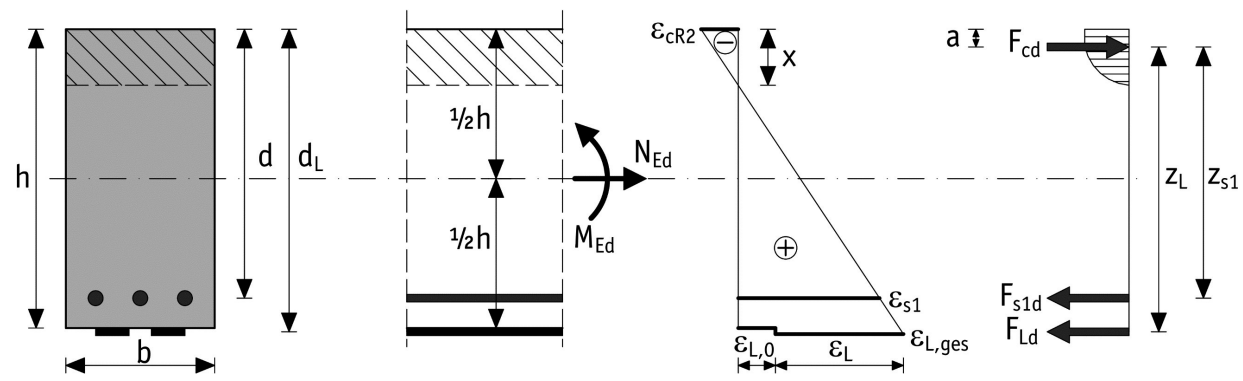

Abb. A.2 Dehnungs- und Spannungsverteilung am verstärkten Querschnitt ohne Druckbewehrung (http://doi.org/10.33968/9783966270021-07-A-02)

$$
\begin{aligned}
& \boldsymbol{\mu}_{E d, L}=\frac{\boldsymbol{M}_{E d, L}}{\boldsymbol{b} \cdot \boldsymbol{h}^{2} \cdot \boldsymbol{f}_{\boldsymbol{c d}}}+\frac{\boldsymbol{f}_{\boldsymbol{y d}}}{\boldsymbol{f}_{\boldsymbol{c d}}} \cdot \rho_{\boldsymbol{s} \mathbf{1}} \cdot\left(\mathbf{1}-\frac{\boldsymbol{d}}{\boldsymbol{h}}\right) \\
& M_{E d, L}=M_{E d}-N_{E d} \cdot \frac{h}{2}
\end{aligned}
$$




\section{Erforderliche Lamellenfläche}

$$
\begin{aligned}
& A_{L}=\frac{\left(\omega_{L} \cdot f_{c \boldsymbol{d}}-\boldsymbol{f}_{\boldsymbol{y d}} \cdot \boldsymbol{\rho}_{\boldsymbol{s}}\right) \cdot \boldsymbol{b} \cdot \boldsymbol{h}+\boldsymbol{N}_{\boldsymbol{E} \boldsymbol{d}}}{\varepsilon_{\boldsymbol{L}} \cdot \boldsymbol{E}_{\boldsymbol{L} \boldsymbol{m}}} \\
& \varepsilon_{L}=\varepsilon_{L, g e s}-\varepsilon_{L, 0}
\end{aligned}
$$

\section{Betonstahlspannung}

Die Bemessungstafeln sind für den horizontalen Ast der rechnerischen Spannungs-Dehnungs- Linie des Betonstahls ausgelegt. Hierbei wird unterstellt, dass sich der Stahl im Fließen befindet. Aus diesem Grund ist über die Dehnungen stets zu prüfen, ob die Stahlspannung den Bemessungswert der Streckgrenze tatsächlich übersteigt.

$$
\begin{aligned}
& \varepsilon_{S 1}=\frac{d}{d_{L}} \cdot\left(\varepsilon_{L, g e s}-\varepsilon_{c R 2}\right)+\varepsilon_{c R 2} \quad\left(d_{L} \approx h\right) \\
& \varepsilon_{S 1} \geq \frac{f_{y d}}{E_{S}} !
\end{aligned}
$$

Sofern die Betonstahldehnung diesen Wert unterschreitet sind die Dehnungen iterativ zu ermitteln und die Bemessungstafeln sind somit ungültig! 



\section{Anhang B}

\section{Anwendung der Bemessungstafeln mit Druckbewehrung}

\section{Dehnungen zum Zeitpunkt der Verstärkung}

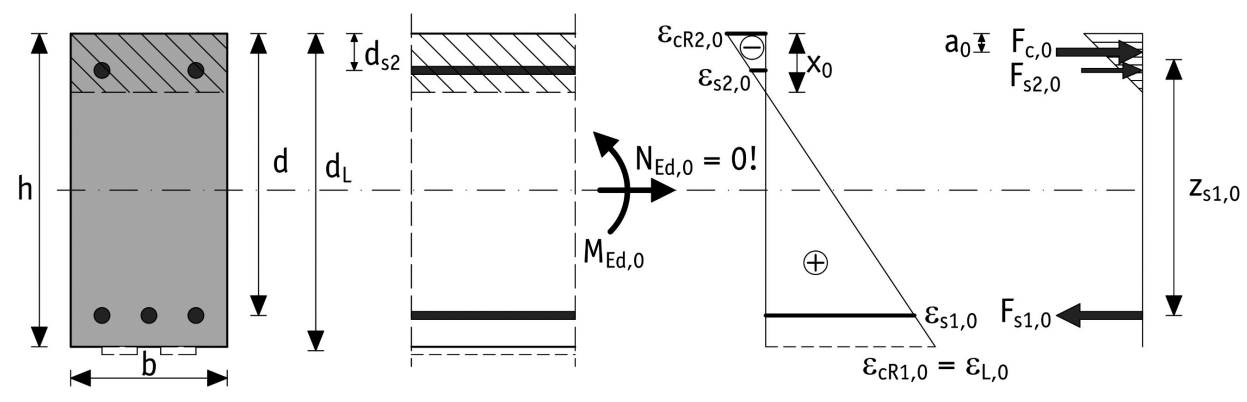

Abb. B.1 Dehnungs- und Spannungsverteilung am Stahlbetonquerschnitt bei linear-elastischem Materialverhalten mit Druckbewehrung (http://doi.org/10.33968/9783966270021-08-A-01)

Die Dehnungen zum Zeitpunkt der Verstärkung können bei linear-elastischem Materialverhalten und reiner Biegebeanspruchung näherungsweise anhand des folgenden Formelapparats für Rechteckquerschnitte bestimmt werden. Die Einwirkungen sind realitätsnah oder vereinfachend auf Gebrauchstauglichkeitsniveau mit der quasi-ständigen Belastungskombination anzusetzen.

$$
\begin{aligned}
& x_{0}=\left(-\alpha_{s} \cdot\left(\rho_{s 1}+\rho_{s 2}\right)+\sqrt{\left(\alpha_{s} \cdot\left(\rho_{s 1}+\rho_{s 2}\right)\right)^{2}+2 \cdot \alpha_{s} \cdot\left(\rho_{s 1} \cdot \frac{d}{h}+\rho_{s 2} \cdot \frac{d_{s 2}}{h}\right)}\right) \cdot h \\
& \rho_{s 1}=\frac{A_{s 1}}{b \cdot h} \quad \rho_{s 2}=\frac{A_{s 2}}{b \cdot h}
\end{aligned}
$$


$\alpha_{s}=\frac{E_{s}}{E_{C}}$

$z_{s 1,0} \approx d-0,4 \cdot x_{0}$

$F_{S 1,0}=\frac{M_{E d, 0}}{z_{S 1,0}}$

$\varepsilon_{s 1,0}=\frac{F_{s 1,0}}{A_{s 1} \cdot E_{S}}$

$\varepsilon_{L, 0}=\varepsilon_{S 1,0} \cdot \frac{d_{L}-x_{0}}{d-x_{0}}$

\section{Bezogenes Bemessungsmoment}

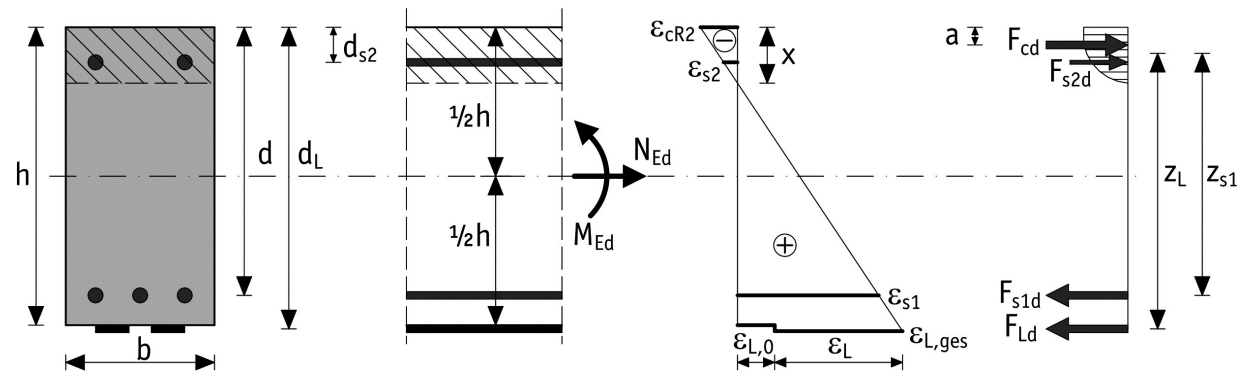

Abb. B.2 Dehnungs- und Spannungsverteilung am verstärkten Querschnitt mit Druckbewehrung (http://doi.org/10.33968/9783966270021-08-A-02)

$\mu_{E d, L}=\frac{M_{E d, L}}{b \cdot h^{2} \cdot f_{c d}}+\frac{f_{y d}}{f_{c d}} \cdot\left(\rho_{s 1} \cdot\left(1-\frac{d}{h}\right)-\rho_{s 2} \cdot\left(1-\frac{d_{s 2}}{h}\right)\right)$

$M_{E d, L}=M_{E d}-N_{E d} \cdot \frac{h}{2}$ 


\section{Erforderliche Lamellenfläche}

$$
\begin{aligned}
& A_{L}=\frac{\left(\omega_{L} \cdot \boldsymbol{f}_{\boldsymbol{c d}}-\boldsymbol{f}_{\boldsymbol{y d}} \cdot\left(\boldsymbol{\rho}_{\boldsymbol{s} 1}-\boldsymbol{\rho}_{\boldsymbol{s} 2}\right)\right) \cdot \boldsymbol{b} \cdot \boldsymbol{h}+\boldsymbol{N}_{\boldsymbol{E d}}}{\varepsilon_{\boldsymbol{L}} \cdot \boldsymbol{E}_{\boldsymbol{L} \boldsymbol{m}}} \\
& \varepsilon_{L}=\varepsilon_{L, g e s}-\varepsilon_{L, 0}
\end{aligned}
$$

\section{Betonstahlspannung}

Die Bemessungstafeln sind für den horizontalen Ast der rechnerischen Spannungs-Dehnungs- Linie des Betonstahls ausgelegt. Hierbei wird unterstellt, dass sich der Stahl im Fließen befindet. Aus diesem Grund ist über die Dehnungen stets zu prüfen, ob die Stahlspannung den Bemessungswert der Streckgrenze tatsächlich übersteigt.

$$
\begin{aligned}
& \varepsilon_{s 1}=\frac{d}{d_{L}} \cdot\left(\varepsilon_{L, g e s}-\varepsilon_{c R 2}\right)+\varepsilon_{c R 2} \quad\left(d_{L} \approx h\right) \\
& \varepsilon_{S 1} \geq \frac{f_{y d}}{E_{s}} !
\end{aligned}
$$

Für die Druckbewehrung wird in diesen Bemessungstafeln ebenfalls unterstellt, dass die Bemessungsstreckgrenze überschritten wird. Daher sind die Grenzwerte (Maximalwerte!) für $\mathbf{d}_{\mathbf{s} 2} / \mathbf{h}$ zwingend einzuhalten.

Sofern die Betonstahldehnungen den Wert unterschreiten sind die Dehnungen iterativ zu ermitteln und die Bemessungstafeln sind somit ungültig! 



\section{Anhang C \\ Bemessungstafeln}


Tab. C.1 Bemessungstafel für Rechteckquerschnitte mit und ohne Druckbewehrung (Normalbeton C12/16 - C50/60 | Betonstahl B500 | $\varepsilon_{\mathrm{L}, \text { ges,zul }}=2,5 \%$ \%)

(http://doi.org/10.33968/9783966270021-09-T-01)

\begin{tabular}{|c|c|c|c|c|c|}
\hline$\mu_{\mathrm{Ed}, \mathrm{L}}$ & $\omega_{\mathrm{L}}$ & $\varepsilon_{C R 2}$ & $\varepsilon_{\mathrm{L}, \mathrm{ges}}$ & $\xi_{L}$ & $\max . \mathrm{d}_{\mathrm{s} 2} / \mathrm{h}$ \\
\hline 0,01 & 0,0103 & $-0,24$ & 2,50 & 0,0885 & \multirow{26}{*}{ 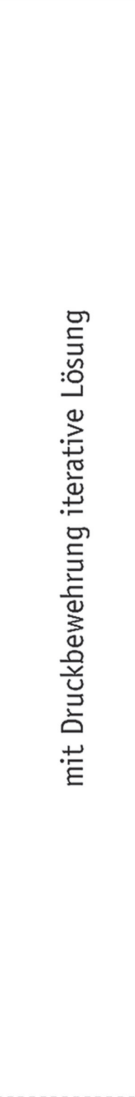 } \\
\hline 0,02 & 0,0209 & $-0,36$ & 2,50 & 0,1247 & \\
\hline 0,03 & 0,0316 & $-0,45$ & 2,50 & 0,1523 & \\
\hline 0,04 & 0,0425 & $-0,53$ & 2,50 & 0,1755 & \\
\hline 0,05 & 0,0536 & $-0,61$ & 2,50 & 0,1959 & \\
\hline 0,06 & 0,0648 & $-0,68$ & 2,50 & 0,2143 & \\
\hline 0,07 & 0,0761 & $-0,75$ & 2,50 & 0,2313 & \\
\hline 0,08 & 0,0875 & $-0,82$ & 2,50 & 0,2471 & \\
\hline 0,09 & 0,0990 & $-0,89$ & 2,50 & 0,2619 & \\
\hline 0,10 & 0,1107 & $-0,95$ & 2,50 & 0,2760 & \\
\hline 0,11 & 0,1224 & $-1,02$ & 2,50 & 0,2895 & \\
\hline 0,12 & 0,1343 & $-1,08$ & 2,50 & 0,3024 & \\
\hline 0,13 & 0,1463 & $-1,15$ & 2,50 & 0,3149 & \\
\hline 0,14 & 0,1584 & $-1,21$ & 2,50 & 0,3270 & \\
\hline 0,15 & 0,1706 & $-1,28$ & 2,50 & 0,3387 & \\
\hline 0,16 & 0,1829 & $-1,35$ & 2,50 & 0,3502 & \\
\hline 0,17 & 0,1953 & $-1,41$ & 2,50 & 0,3614 & \\
\hline 0,18 & 0,2079 & $-1,48$ & 2,50 & 0,3724 & \\
\hline 0,19 & 0,2207 & $-1,55$ & 2,50 & 0,3833 & \\
\hline 0,20 & 0,2335 & $-1,63$ & 2,50 & 0,3941 & \\
\hline 0,21 & 0,2466 & $-1,70$ & 2,50 & 0,4047 & \\
\hline 0,22 & 0,2598 & $-1,78$ & 2,50 & 0,4154 & \\
\hline 0,23 & 0,2731 & $-1,86$ & 2,50 & 0,4261 & \\
\hline 0,24 & 0,2867 & $-1,94$ & 2,50 & 0,4369 & \\
\hline 0,25 & 0,3006 & $-2,03$ & 2,50 & 0,4478 & \\
\hline 0,26 & 0,3147 & $-2,12$ & 2,50 & 0,4590 & \\
\hline 0,27 & 0,3292 & $-2,22$ & 2,50 & 0,4704 & 0,0099 \\
\hline 0,28 & 0,3439 & $-2,33$ & 2,50 & 0,4820 & 0,0316 \\
\hline 0,29 & 0,3590 & $-2,44$ & 2,50 & 0,4939 & 0,0539 \\
\hline 0,30 & 0,3744 & $-2,56$ & 2,50 & 0,5061 & 0,0767 \\
\hline 0,31 & 0,3903 & $-2,69$ & 2,50 & 0,5186 & 0,1001 \\
\hline 0,32 & 0,4065 & $-2,84$ & 2,50 & 0,5315 & 0,1241 \\
\hline 0,33 & 0,4233 & $-2,99$ & 2,50 & 0,5447 & 0,1487 \\
\hline 0,34 & 0,4405 & $-3,16$ & 2,50 & 0,5583 & 0,1742 \\
\hline 0,35 & 0,4582 & $-3,35$ & 2,50 & 0,5723 & 0,2004 \\
\hline 0,36 & 0,4768 & $-3,50$ & 2,44 & 0,5890 & 0,2232 \\
\hline 0,37 & 0,4968 & $-3,50$ & 2,20 & 0,6137 & 0,2325 \\
\hline
\end{tabular}


Tab. C.2 Bemessungstafel für Rechteckquerschnitte mit und ohne Druckbewehrung (Normalbeton C12/16 - C50/60 | Betonstahl B500 | $\varepsilon_{\mathrm{L}, \mathrm{ges}, \mathrm{zul}}=3 \%$ )

(http://doi.org/10.33968/9783966270021-09-T-02)

\begin{tabular}{|c|c|c|c|c|c|}
\hline$\mu_{\mathrm{Ed}, \mathrm{L}}$ & $\omega_{\mathrm{L}}$ & $\varepsilon_{c R 2}$ & $\varepsilon_{\mathrm{L}, \mathrm{ges}}$ & $\xi_{\mathrm{L}}$ & $\max . \mathrm{d}_{\mathrm{s} 2} / \mathrm{h}$ \\
\hline 0,01 & 0,0103 & $-0,27$ & 3,00 & 0,0812 & \multirow{24}{*}{ 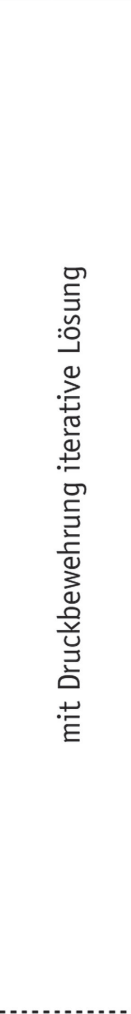 } \\
\hline 0,02 & 0,0208 & $-0,39$ & 3,00 & 0,1146 & \\
\hline 0,03 & 0,0315 & $-0,49$ & 3,00 & 0,1402 & \\
\hline 0,04 & 0,0423 & $-0,58$ & 3,00 & 0,1618 & \\
\hline 0,05 & 0,0533 & $-0,66$ & 3,00 & 0,1809 & \\
\hline 0,06 & 0,0644 & $-0,74$ & 3,00 & 0,1982 & \\
\hline 0,07 & 0,0756 & $-0,82$ & 3,00 & 0,2142 & \\
\hline 0,08 & 0,0869 & $-0,89$ & 3,00 & 0,2291 & \\
\hline 0,09 & 0,0984 & $-0,96$ & 3,00 & 0,2432 & \\
\hline 0,10 & 0,1099 & $-1,04$ & 3,00 & 0,2566 & \\
\hline 0,11 & 0,1215 & $-1,11$ & 3,00 & 0,2694 & \\
\hline 0,12 & 0,1333 & $-1,18$ & 3,00 & 0,2818 & \\
\hline 0,13 & 0,1451 & $-1,25$ & 3,00 & 0,2937 & \\
\hline 0,14 & 0,1571 & $-1,32$ & 3,00 & 0,3054 & \\
\hline 0,15 & 0,1692 & $-1,39$ & 3,00 & 0,3168 & \\
\hline 0,16 & 0,1814 & $-1,46$ & 3,00 & 0,3279 & \\
\hline 0,17 & 0,1938 & $-1,54$ & 3,00 & 0,3389 & \\
\hline 0,18 & 0,2063 & $-1,61$ & 3,00 & 0,3497 & \\
\hline 0,19 & 0,2189 & $-1,69$ & 3,00 & 0,3605 & \\
\hline 0,20 & 0,2317 & $-1,77$ & 3,00 & 0,3712 & \\
\hline 0,21 & 0,2446 & $-1,85$ & 3,00 & 0,3819 & \\
\hline 0,22 & 0,2578 & $-1,94$ & 3,00 & 0,3927 & \\
\hline 0,23 & 0,2712 & $-2,03$ & 3,00 & 0,4037 & \\
\hline 0,24 & 0,2848 & $-2,13$ & 3,00 & 0,4148 & \\
\hline 0,25 & 0,2987 & $-2,23$ & 3,00 & 0,4262 & 0,0104 \\
\hline 0,26 & 0,3128 & $-2,34$ & 3,00 & 0,4378 & 0,0304 \\
\hline 0,27 & 0,3273 & $-2,45$ & 3,00 & 0,4496 & 0,0508 \\
\hline 0,28 & 0,3421 & $-2,57$ & 3,00 & 0,4617 & 0,0716 \\
\hline 0,29 & 0,3572 & $-2,70$ & 3,00 & 0,4741 & 0,0930 \\
\hline 0,30 & 0,3727 & $-2,85$ & 3,00 & 0,4868 & 0,1148 \\
\hline 0,31 & 0,3886 & $-3,00$ & 3,00 & 0,4998 & 0,1373 \\
\hline 0,32 & 0,4049 & $-3,16$ & 3,00 & 0,5131 & 0,1603 \\
\hline 0,33 & 0,4217 & $-3,34$ & 3,00 & 0,5268 & 0,1839 \\
\hline 0,34 & 0,4391 & $-3,50$ & 2,95 & 0,5424 & 0,2055 \\
\hline 0,35 & 0,4768 & $-3,50$ & 2,44 & 0,5890 & 0,2232 \\
\hline 0,36 & 0,4968 & $-3,50$ & 2,20 & 0,6137 & 0,2325 \\
\hline 0,37 & 0,5177 & $-3,50$ & 1,97 & 0,6396 & 0,2423 \\
\hline
\end{tabular}


Tab. C.3 Bemessungstafel für Rechteckquerschnitte mit und ohne Druckbewehrung (Normalbeton C12/16 - C50/60 | Betonstahl B500 | $\varepsilon_{\mathrm{L}, \text { ges,zul }}=3,5 \%$ \%)

(http://doi.org/10.33968/9783966270021-09-T-03)

\begin{tabular}{|c|c|c|c|c|c|}
\hline$\mu_{\mathrm{Ed}, \mathrm{L}}$ & $\omega_{\llcorner}$ & $\varepsilon_{C R 2}$ & $\varepsilon_{\mathrm{L}, \mathrm{ges}}$ & $\xi_{L}$ & $\max . d_{s 2} / h$ \\
\hline 0,01 & 0,0103 & $-0,29$ & 3,50 & 0,0754 & \multirow{22}{*}{ 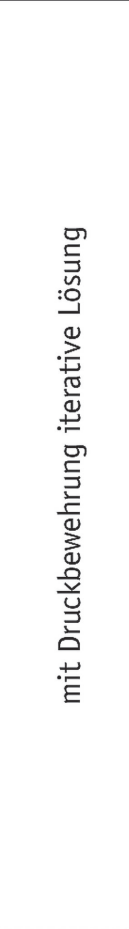 } \\
\hline 0,02 & 0,0208 & $-0,42$ & 3,50 & 0,1067 & \\
\hline 0,03 & 0,0314 & $-0,53$ & 3,50 & 0,1308 & \\
\hline 0,04 & 0,0422 & $-0,62$ & 3,50 & 0,1511 & \\
\hline 0,05 & 0,0531 & $-0,71$ & 3,50 & 0,1691 & \\
\hline 0,06 & 0,0641 & $-0,80$ & 3,50 & 0,1855 & \\
\hline 0,07 & 0,0752 & $-0,88$ & 3,50 & 0,2007 & \\
\hline 0,08 & 0,0865 & $-0,96$ & 3,50 & 0,2149 & \\
\hline 0,09 & 0,0978 & $-1,04$ & 3,50 & 0,2283 & \\
\hline 0,10 & 0,1093 & $-1,11$ & 3,50 & 0,2412 & \\
\hline 0,11 & 0,1208 & $-1,19$ & 3,50 & 0,2535 & \\
\hline 0,12 & 0,1325 & $-1,26$ & 3,50 & 0,2655 & \\
\hline 0,13 & 0,1443 & $-1,34$ & 3,50 & 0,2771 & \\
\hline 0,14 & 0,1562 & $-1,42$ & 3,50 & 0,2884 & \\
\hline 0,15 & 0,1682 & $-1,50$ & 3,50 & 0,2995 & \\
\hline 0,16 & 0,1803 & $-1,58$ & 3,50 & 0,3104 & \\
\hline 0,17 & 0,1926 & $-1,66$ & 3,50 & 0,3212 & \\
\hline 0,18 & 0,2050 & $-1,74$ & 3,50 & 0,3320 & \\
\hline 0,19 & 0,2176 & $-1,82$ & 3,50 & 0,3427 & \\
\hline 0,20 & 0,2303 & $-1,91$ & 3,50 & 0,3535 & \\
\hline 0,21 & 0,2433 & $-2,01$ & 3,50 & 0,3643 & \\
\hline 0,22 & 0,2564 & $-2,10$ & 3,50 & 0,3754 & \\
\hline 0,23 & 0,2698 & $-2,21$ & 3,50 & 0,3866 & 0,0057 \\
\hline 0,24 & 0,2835 & $-2,31$ & 3,50 & 0,3981 & 0,0243 \\
\hline 0,25 & 0,2974 & $-2,43$ & 3,50 & 0,4098 & 0,0432 \\
\hline 0,26 & 0,3116 & $-2,55$ & 3,50 & 0,4217 & 0,0625 \\
\hline 0,27 & 0,3261 & $-2,68$ & 3,50 & 0,4339 & 0,0823 \\
\hline 0,28 & 0,3409 & $-2,82$ & 3,50 & 0,4463 & 0,1025 \\
\hline 0,29 & 0,3560 & $-2,97$ & 3,50 & 0,4591 & 0,1231 \\
\hline 0,30 & 0,3716 & $-3,13$ & 3,50 & 0,4721 & 0,1442 \\
\hline 0,31 & 0,3875 & $-3,30$ & 3,50 & 0,4855 & 0,1659 \\
\hline 0,32 & 0,4038 & $-3,49$ & 3,50 & 0,4992 & 0,1881 \\
\hline 0,33 & 0,4211 & $-3,50$ & 3,23 & 0,5202 & 0,1971 \\
\hline 0,34 & 0,4391 & $-3,50$ & 2,95 & 0,5424 & 0,2055 \\
\hline 0,35 & 0,4576 & $-3,50$ & 2,69 & 0,5653 & 0,2142 \\
\hline 0,36 & 0,4768 & $-3,50$ & 2,44 & 0,5890 & 0,2232 \\
\hline 0,37 & 0,4968 & $-3,50$ & 2,20 & 0,6137 & 0,2325 \\
\hline
\end{tabular}


Tab. C.4 Bemessungstafel für Rechteckquerschnitte mit und ohne Druckbewehrung (Normalbeton C12/16 - C50/60 | Betonstahl B500 | $\varepsilon_{\mathrm{L}, \mathrm{ges}, \mathrm{zul}}=4 \%$ )

(http://doi.org/10.33968/9783966270021-09-T-04)

\begin{tabular}{|c|c|c|c|c|c|}
\hline$\mu_{\mathrm{Ed}, \mathrm{L}}$ & $\omega_{\mathrm{L}}$ & $\varepsilon_{C R 2}$ & $\varepsilon_{\text {L,ges }}$ & $\xi_{\mathrm{L}}$ & $\max . \mathrm{d}_{\mathrm{s} 2} / \mathrm{h}$ \\
\hline 0,01 & 0,0102 & $-0,30$ & 4,00 & 0,0708 & \multirow{21}{*}{ 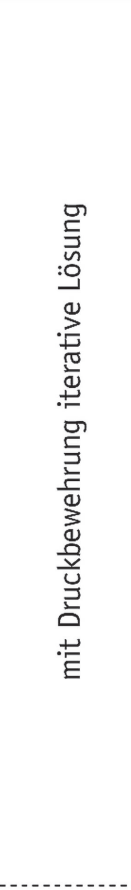 } \\
\hline 0,02 & 0,0207 & $-0,45$ & 4,00 & 0,1003 & \\
\hline 0,03 & 0,0313 & $-0,56$ & 4,00 & 0,1231 & \\
\hline 0,04 & 0,0421 & $-0,66$ & 4,00 & 0,1424 & \\
\hline 0,05 & 0,0529 & $-0,76$ & 4,00 & 0,1596 & \\
\hline 0,06 & 0,0639 & $-0,85$ & 4,00 & 0,1752 & \\
\hline 0,07 & 0,0750 & $-0,94$ & 4,00 & 0,1897 & \\
\hline 0,08 & 0,0861 & $-1,02$ & 4,00 & 0,2033 & \\
\hline 0,09 & 0,0974 & $-1,10$ & 4,00 & 0,2163 & \\
\hline 0,10 & 0,1088 & $-1,19$ & 4,00 & 0,2287 & \\
\hline 0,11 & 0,1203 & $-1,27$ & 4,00 & 0,2406 & \\
\hline 0,12 & 0,1319 & $-1,35$ & 4,00 & 0,2522 & \\
\hline 0,13 & 0,1436 & $-1,43$ & 4,00 & 0,2635 & \\
\hline 0,14 & 0,1554 & $-1,51$ & 4,00 & 0,2746 & \\
\hline 0,15 & 0,1674 & $-1,60$ & 4,00 & 0,2855 & \\
\hline 0,16 & 0,1795 & $-1,68$ & 4,00 & 0,2963 & \\
\hline 0,17 & 0,1917 & $-1,77$ & 4,00 & 0,3070 & \\
\hline 0,18 & 0,2040 & $-1,86$ & 4,00 & 0,3177 & \\
\hline 0,19 & 0,2166 & $-1,96$ & 4,00 & 0,3285 & \\
\hline 0,20 & 0,2293 & $-2,06$ & 4,00 & 0,3394 & \\
\hline 0,21 & 0,2423 & $-2,16$ & 4,00 & 0,3505 & \\
\hline 0,22 & 0,2555 & $-2,27$ & 4,00 & 0,3618 & 0,0150 \\
\hline 0,23 & 0,2689 & $-2,38$ & 4,00 & 0,3733 & 0,0327 \\
\hline 0,24 & 0,2825 & $-2,50$ & 4,00 & 0,3850 & 0,0508 \\
\hline 0,25 & 0,2965 & $-2,63$ & 4,00 & 0,3970 & 0,0692 \\
\hline 0,26 & 0,3107 & $-2,77$ & 4,00 & 0,4092 & 0,0881 \\
\hline 0,27 & 0,3252 & $-2,92$ & 4,00 & 0,4216 & 0,1073 \\
\hline 0,28 & 0,3400 & $-3,07$ & 4,00 & 0,4343 & 0,1269 \\
\hline 0,29 & 0,3552 & $-3,24$ & 4,00 & 0,4473 & 0,1470 \\
\hline 0,30 & 0,3707 & $-3,42$ & 4,00 & 0,4606 & 0,1675 \\
\hline 0,31 & 0,3869 & $-3,50$ & 3,82 & 0,4780 & 0,1811 \\
\hline 0,32 & 0,4038 & $-3,50$ & 3,52 & 0,4988 & 0,1890 \\
\hline 0,33 & 0,4211 & $-3,50$ & 3,23 & 0,5202 & 0,1971 \\
\hline 0,34 & 0,4391 & $-3,50$ & 2,95 & 0,5424 & 0,2055 \\
\hline 0,35 & 0,4576 & $-3,50$ & 2,69 & 0,5653 & 0,2142 \\
\hline 0,36 & 0,4768 & $-3,50$ & 2,44 & 0,5890 & 0,2232 \\
\hline 0,37 & 0,4968 & $-3,50$ & 2,20 & 0,6137 & 0,2325 \\
\hline
\end{tabular}


Tab. C.5 Bemessungstafel für Rechteckquerschnitte mit und ohne Druckbewehrung (Normalbeton C12/16 - C50/60 | Betonstahl B500 | $\varepsilon_{\mathrm{L}, \text { ges,zul }}=4,5 \%$ )

(http://doi.org/10.33968/9783966270021-09-T-05)

\begin{tabular}{|c|c|c|c|c|c|}
\hline$\mu_{\mathrm{Ed}, \mathrm{L}}$ & $\omega_{\llcorner}$ & $\varepsilon_{C R 2}$ & $\varepsilon_{\mathrm{L}, \mathrm{ges}}$ & $\xi_{\mathrm{L}}$ & $\max . \mathrm{d}_{\mathrm{s} 2} / \mathrm{h}$ \\
\hline 0,01 & 0,0102 & $-0,32$ & 4,50 & 0,0670 & \multirow{19}{*}{ 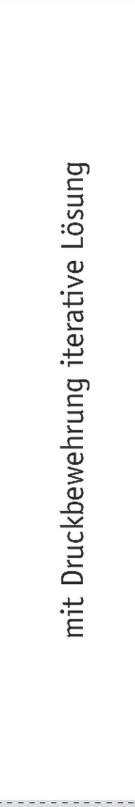 } \\
\hline 0,02 & 0,0207 & $-0,47$ & 4,50 & 0,0950 & \\
\hline 0,03 & 0,0312 & $-0,59$ & 4,50 & 0,1167 & \\
\hline 0,04 & 0,0420 & $-0,70$ & 4,50 & 0,1352 & \\
\hline 0,05 & 0,0528 & $-0,80$ & 4,50 & 0,1516 & \\
\hline 0,06 & 0,0637 & $-0,90$ & 4,50 & 0,1666 & \\
\hline 0,07 & 0,0747 & $-0,99$ & 4,50 & 0,1806 & \\
\hline 0,08 & 0,0858 & $-1,08$ & 4,50 & 0,1937 & \\
\hline 0,09 & 0,0971 & $-1,17$ & 4,50 & 0,2062 & \\
\hline 0,10 & 0,1084 & $-1,26$ & 4,50 & 0,2183 & \\
\hline 0,11 & 0,1198 & $-1,34$ & 4,50 & 0,2299 & \\
\hline 0,12 & 0,1314 & $-1,43$ & 4,50 & 0,2412 & \\
\hline 0,13 & 0,1430 & $-1,52$ & 4,50 & 0,2523 & \\
\hline 0,14 & 0,1548 & $-1,61$ & 4,50 & 0,2632 & \\
\hline 0,15 & 0,1667 & $-1,70$ & 4,50 & 0,2739 & \\
\hline 0,16 & 0,1788 & $-1,79$ & 4,50 & 0,2846 & \\
\hline 0,17 & 0,1910 & $-1,89$ & 4,50 & 0,2953 & \\
\hline 0,18 & 0,2033 & $-1,99$ & 4,50 & 0,3061 & \\
\hline 0,19 & 0,2159 & $-2,09$ & 4,50 & 0,3170 & \\
\hline 0,20 & 0,2286 & $-2,20$ & 4,50 & 0,3281 & 0,0036 \\
\hline 0,21 & 0,2416 & $-2,31$ & 4,50 & 0,3394 & 0,0203 \\
\hline 0,22 & 0,2548 & $-2,43$ & 4,50 & 0,3509 & 0,0374 \\
\hline 0,23 & 0,2682 & $-2,56$ & 4,50 & 0,3626 & 0,0547 \\
\hline 0,24 & 0,2819 & $-2,69$ & 4,50 & 0,3745 & 0,0724 \\
\hline 0,25 & 0,2958 & $-2,84$ & 4,50 & 0,3867 & 0,0904 \\
\hline 0,26 & 0,3100 & $-2,99$ & 4,50 & 0,3991 & 0,1088 \\
\hline 0,27 & 0,3246 & $-3,15$ & 4,50 & 0,4117 & 0,1275 \\
\hline 0,28 & 0,3394 & $-3,32$ & 4,50 & 0,4247 & 0,1467 \\
\hline 0,29 & 0,3546 & $-3,50$ & 4,49 & 0,4381 & 0,1660 \\
\hline 0,30 & 0,3706 & $-3,50$ & 4,15 & 0,4577 & 0,1734 \\
\hline 0,31 & 0,3869 & $-3,50$ & 3,82 & 0,4780 & 0,1811 \\
\hline 0,32 & 0,4038 & $-3,50$ & 3,52 & 0,4988 & 0,1890 \\
\hline 0,33 & 0,4211 & $-3,50$ & 3,23 & 0,5202 & 0,1971 \\
\hline 0,34 & 0,4391 & $-3,50$ & 2,95 & 0,5424 & 0,2055 \\
\hline 0,35 & 0,4576 & $-3,50$ & 2,69 & 0,5653 & 0,2142 \\
\hline 0,36 & 0,4768 & $-3,50$ & 2,44 & 0,5890 & 0,2232 \\
\hline 0,37 & 0,4968 & $-3,50$ & 2,20 & 0,6137 & 0,2325 \\
\hline
\end{tabular}


Tab. C.6 Bemessungstafel für Rechteckquerschnitte mit und ohne Druckbewehrung (Normalbeton C12/16 - C50/60 | Betonstahl B500 | $\varepsilon_{\mathrm{L}, \mathrm{ges}, \mathrm{zul}}=5 \%$ \%)

(http://doi.org/10.33968/9783966270021-09-T-06)

\begin{tabular}{|c|c|c|c|c|c|}
\hline$\mu_{\mathrm{Ed}, \mathrm{L}}$ & $\omega_{\mathrm{L}}$ & $\varepsilon_{c R 2}$ & $\varepsilon_{\text {L,ges }}$ & $\xi_{L}$ & $\max . \mathrm{d}_{\mathrm{s} 2} / \mathrm{h}$ \\
\hline 0,01 & 0,0102 & $-0,34$ & 5,00 & 0,0637 & \multirow{18}{*}{ 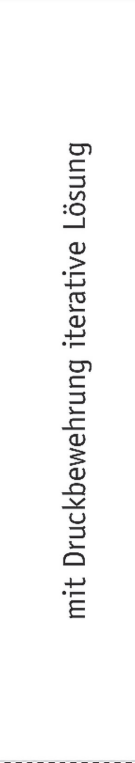 } \\
\hline 0,02 & 0,0206 & $-0,50$ & 5,00 & 0,0905 & \\
\hline 0,03 & 0,0312 & $-0,63$ & 5,00 & 0,1113 & \\
\hline 0,04 & 0,0419 & $-0,74$ & 5,00 & 0,1290 & \\
\hline 0,05 & 0,0526 & $-0,85$ & 5,00 & 0,1448 & \\
\hline 0,06 & 0,0635 & $-0,95$ & 5,00 & 0,1593 & \\
\hline 0,07 & 0,0745 & $-1,04$ & 5,00 & 0,1728 & \\
\hline 0,08 & 0,0856 & $-1,14$ & 5,00 & 0,1855 & \\
\hline 0,09 & 0,0968 & $-1,23$ & 5,00 & 0,1977 & \\
\hline 0,10 & 0,1081 & $-1,32$ & 5,00 & 0,2094 & \\
\hline 0,11 & 0,1195 & $-1,42$ & 5,00 & 0,2208 & \\
\hline 0,12 & 0,1310 & $-1,51$ & 5,00 & 0,2319 & \\
\hline 0,13 & 0,1426 & $-1,60$ & 5,00 & 0,2428 & \\
\hline 0,14 & 0,1543 & $-1,70$ & 5,00 & 0,2535 & \\
\hline 0,15 & 0,1662 & $-1,80$ & 5,00 & 0,2642 & \\
\hline 0,16 & 0,1782 & $-1,90$ & 5,00 & 0,2749 & \\
\hline 0,17 & 0,1904 & $-2,00$ & 5,00 & 0,2856 & \\
\hline 0,18 & 0,2028 & $-2,11$ & 5,00 & 0,2965 & \\
\hline 0,19 & 0,2153 & $-2,22$ & 5,00 & 0,3076 & 0,0066 \\
\hline 0,20 & 0,2281 & $-2,34$ & 5,00 & 0,3189 & 0,0227 \\
\hline 0,21 & 0,2410 & $-2,47$ & 5,00 & 0,3303 & 0,0392 \\
\hline 0,22 & 0,2542 & $-2,60$ & 5,00 & 0,3420 & 0,0559 \\
\hline 0,23 & 0,2677 & $-2,74$ & 5,00 & 0,3538 & 0,0729 \\
\hline 0,24 & 0,2814 & $-2,89$ & 5,00 & 0,3659 & 0,0902 \\
\hline 0,25 & 0,2953 & $-3,04$ & 5,00 & 0,3782 & 0,1079 \\
\hline 0,26 & 0,3096 & $-3,21$ & 5,00 & 0,3908 & 0,1259 \\
\hline 0,27 & 0,3241 & $-3,38$ & 5,00 & 0,4036 & 0,1443 \\
\hline 0,28 & 0,3391 & $-3,50$ & 4,86 & 0,4189 & 0,1587 \\
\hline 0,29 & 0,3546 & $-3,50$ & 4,49 & 0,4381 & 0,1660 \\
\hline 0,30 & 0,3706 & $-3,50$ & 4,15 & 0,4577 & 0,1734 \\
\hline 0,31 & 0,3869 & $-3,50$ & 3,82 & 0,4780 & 0,1811 \\
\hline 0,32 & 0,4038 & $-3,50$ & 3,52 & 0,4988 & 0,1890 \\
\hline 0,33 & 0,4211 & $-3,50$ & 3,23 & 0,5202 & 0,1971 \\
\hline 0,34 & 0,4391 & $-3,50$ & 2,95 & 0,5424 & 0,2055 \\
\hline 0,35 & 0,4576 & $-3,50$ & 2,69 & 0,5653 & 0,2142 \\
\hline 0,36 & 0,4768 & $-3,50$ & 2,44 & 0,5890 & 0,2232 \\
\hline 0,37 & 0,4968 & $-3,50$ & 2,20 & 0,6137 & 0,2325 \\
\hline
\end{tabular}


Tab. C.7 Bemessungstafel für Rechteckquerschnitte mit und ohne Druckbewehrung (Normalbeton C12/16 - C50/60 | Betonstahl B500 | $\varepsilon_{\mathrm{L}, \text { ges,zul }}=5,5 \%$ ) (http://doi.org/10.33968/9783966270021-09-T-07)

\begin{tabular}{|c|c|c|c|c|c|}
\hline$\mu_{\mathrm{Ed}, \mathrm{L}}$ & $\omega_{\llcorner}$ & $\varepsilon_{C R 2}$ & $\varepsilon_{\mathrm{L}, \mathrm{ges}}$ & $\xi_{\mathrm{L}}$ & $\max . \mathrm{d}_{\mathrm{s} 2} / \mathrm{h}$ \\
\hline 0,01 & 0,0102 & $-0,36$ & 5,50 & 0,0609 & \multirow{17}{*}{ 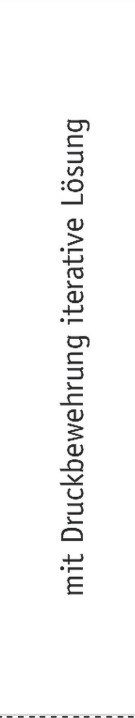 } \\
\hline 0,02 & 0,0206 & $-0,52$ & 5,50 & 0,0866 & \\
\hline 0,03 & 0,0311 & $-0,66$ & 5,50 & 0,1066 & \\
\hline 0,04 & 0,0418 & $-0,78$ & 5,50 & 0,1237 & \\
\hline 0,05 & 0,0525 & $-0,89$ & 5,50 & 0,1389 & \\
\hline 0,06 & 0,0634 & $-0,99$ & 5,50 & 0,1530 & \\
\hline 0,07 & 0,0743 & $-1,10$ & 5,50 & 0,1661 & \\
\hline 0,08 & 0,0854 & $-1,19$ & 5,50 & 0,1785 & \\
\hline 0,09 & 0,0965 & $-1,29$ & 5,50 & 0,1904 & \\
\hline 0,10 & 0,1078 & $-1,39$ & 5,50 & 0,2018 & \\
\hline 0,11 & 0,1192 & $-1,49$ & 5,50 & 0,2130 & \\
\hline 0,12 & 0,1306 & $-1,59$ & 5,50 & 0,2239 & \\
\hline 0,13 & 0,1422 & $-1,69$ & 5,50 & 0,2346 & \\
\hline 0,14 & 0,1539 & $-1,79$ & 5,50 & 0,2453 & \\
\hline 0,15 & 0,1658 & $-1,89$ & 5,50 & 0,2559 & \\
\hline 0,16 & 0,1778 & $-2,00$ & 5,50 & 0,2667 & \\
\hline 0,17 & 0,1900 & $-2,11$ & 5,50 & 0,2775 & \\
\hline 0,18 & 0,2023 & $-2,23$ & 5,50 & 0,2886 & 0,0074 \\
\hline 0,19 & 0,2149 & $-2,35$ & 5,50 & 0,2998 & 0,0230 \\
\hline 0,20 & 0,2277 & $-2,48$ & 5,50 & 0,3112 & 0,0389 \\
\hline 0,21 & 0,2406 & $-2,62$ & 5,50 & 0,3227 & 0,0550 \\
\hline 0,22 & 0,2538 & $-2,76$ & 5,50 & 0,3345 & 0,0715 \\
\hline 0,23 & 0,2673 & $-2,92$ & 5,50 & 0,3465 & 0,0882 \\
\hline 0,24 & 0,2810 & $-3,08$ & 5,50 & 0,3587 & 0,1052 \\
\hline 0,25 & 0,2950 & $-3,25$ & 5,50 & 0,3712 & 0,1226 \\
\hline 0,26 & 0,3092 & $-3,43$ & 5,50 & 0,3839 & 0,1403 \\
\hline 0,27 & 0,3239 & $-3,50$ & 5,25 & 0,4001 & 0,1516 \\
\hline 0,28 & 0,3391 & $-3,50$ & 4,86 & 0,4189 & 0,1587 \\
\hline 0,29 & 0,3546 & $-3,50$ & 4,49 & 0,4381 & 0,1660 \\
\hline 0,30 & 0,3706 & $-3,50$ & 4,15 & 0,4577 & 0,1734 \\
\hline 0,31 & 0,3869 & $-3,50$ & 3,82 & 0,4780 & 0,1811 \\
\hline 0,32 & 0,4038 & $-3,50$ & 3,52 & 0,4988 & 0,1890 \\
\hline 0,33 & 0,4211 & $-3,50$ & 3,23 & 0,5202 & 0,1971 \\
\hline 0,34 & 0,4391 & $-3,50$ & 2,95 & 0,5424 & 0,2055 \\
\hline 0,35 & 0,4576 & $-3,50$ & 2,69 & 0,5653 & 0,2142 \\
\hline 0,36 & 0,4768 & $-3,50$ & 2,44 & 0,5890 & 0,2232 \\
\hline 0,37 & 0,4968 & $-3,50$ & 2,20 & 0,6137 & 0,2325 \\
\hline
\end{tabular}


Tab. C.8 Bemessungstafel für Rechteckquerschnitte mit und ohne Druckbewehrung (Normalbeton C12/16 - C50/60 | Betonstahl B500 | $\varepsilon_{\text {L,ges,zul }}=6 \%$ ) (http://doi.org/10.33968/9783966270021-09-T-08)

\begin{tabular}{|c|c|c|c|c|c|}
\hline$\mu_{\mathrm{Ed}, \mathrm{L}}$ & $\omega_{\mathrm{L}}$ & $\varepsilon_{C R 2}$ & $\varepsilon_{\text {L,ges }}$ & $\xi_{L}$ & $\max . \mathrm{d}_{\mathrm{s} 2} / \mathrm{h}$ \\
\hline 0,01 & 0,0102 & $-0,37$ & 6,00 & 0,0584 & \multirow{16}{*}{ 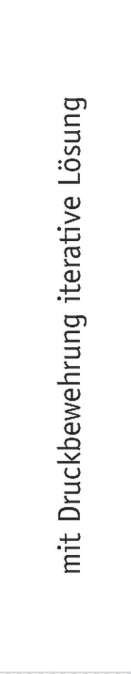 } \\
\hline 0,02 & 0,0206 & $-0,54$ & 6,00 & 0,0832 & \\
\hline 0,03 & 0,0311 & $-0,69$ & 6,00 & 0,1025 & \\
\hline 0,04 & 0,0417 & $-0,81$ & 6,00 & 0,1190 & \\
\hline 0,05 & 0,0524 & $-0,93$ & 6,00 & 0,1338 & \\
\hline 0,06 & 0,0633 & $-1,04$ & 6,00 & 0,1474 & \\
\hline 0,07 & 0,0742 & $-1,14$ & 6,00 & 0,1602 & \\
\hline 0,08 & 0,0852 & $-1,25$ & 6,00 & 0,1723 & \\
\hline 0,09 & 0,0963 & $-1,35$ & 6,00 & 0,1839 & \\
\hline 0,10 & 0,1076 & $-1,46$ & 6,00 & 0,1952 & \\
\hline 0,11 & 0,1189 & $-1,56$ & 6,00 & 0,2061 & \\
\hline 0,12 & 0,1303 & $-1,66$ & 6,00 & 0,2169 & \\
\hline 0,13 & 0,1419 & $-1,77$ & 6,00 & 0,2276 & \\
\hline 0,14 & 0,1536 & $-1,88$ & 6,00 & 0,2382 & \\
\hline 0,15 & 0,1654 & $-1,99$ & 6,00 & 0,2489 & \\
\hline 0,16 & 0,1774 & $-2,10$ & 6,00 & 0,2597 & \\
\hline 0,17 & 0,1896 & $-2,23$ & 6,00 & 0,2707 & 0,0064 \\
\hline 0,18 & 0,2020 & $-2,35$ & 6,00 & 0,2818 & 0,0216 \\
\hline 0,19 & 0,2146 & $-2,49$ & 6,00 & 0,2931 & 0,0370 \\
\hline 0,20 & 0,2273 & $-2,63$ & 6,00 & 0,3046 & 0,0526 \\
\hline 0,21 & 0,2403 & $-2,78$ & 6,00 & 0,3163 & 0,0686 \\
\hline 0,22 & 0,2535 & $-2,93$ & 6,00 & 0,3282 & 0,0848 \\
\hline 0,23 & 0,2670 & $-3,09$ & 6,00 & 0,3403 & 0,1013 \\
\hline 0,24 & 0,2807 & $-3,27$ & 6,00 & 0,3526 & 0,1181 \\
\hline 0,25 & 0,2947 & $-3,45$ & 6,00 & 0,3652 & 0,1352 \\
\hline 0,26 & 0,3091 & $-3,50$ & 5,67 & 0,3818 & 0,1447 \\
\hline 0,27 & 0,3239 & $-3,50$ & 5,25 & 0,4001 & 0,1516 \\
\hline 0,28 & 0,3391 & $-3,50$ & 4,86 & 0,4189 & 0,1587 \\
\hline 0,29 & 0,3546 & $-3,50$ & 4,49 & 0,4381 & 0,1660 \\
\hline 0,30 & 0,3706 & $-3,50$ & 4,15 & 0,4577 & 0,1734 \\
\hline 0,31 & 0,3869 & $-3,50$ & 3,82 & 0,4780 & 0,1811 \\
\hline 0,32 & 0,4038 & $-3,50$ & 3,52 & 0,4988 & 0,1890 \\
\hline 0,33 & 0,4211 & $-3,50$ & 3,23 & 0,5202 & 0,1971 \\
\hline 0,34 & 0,4391 & $-3,50$ & 2,95 & 0,5424 & 0,2055 \\
\hline 0,35 & 0,4576 & $-3,50$ & 2,69 & 0,5653 & 0,2142 \\
\hline 0,36 & 0,4768 & $-3,50$ & 2,44 & 0,5890 & 0,2232 \\
\hline 0,37 & 0,4968 & $-3,50$ & 2,20 & 0,6137 & 0,2325 \\
\hline
\end{tabular}


Tab. C.9 Bemessungstafel für Rechteckquerschnitte mit und ohne Druckbewehrung (Normalbeton C12/16 - C50/60 | Betonstahl B500 | $\varepsilon_{\mathrm{L}, \text { ges,zul }}=6,5 \%$ \%)

(http://doi.org/10.33968/9783966270021-09-T-09)

\begin{tabular}{|c|c|c|c|c|c|}
\hline$\mu_{\mathrm{Ed}, \mathrm{L}}$ & $\omega_{\llcorner}$ & $\varepsilon_{C R 2}$ & $\varepsilon_{\mathrm{L}, \mathrm{ges}}$ & $\xi_{\mathrm{L}}$ & $\max . \mathrm{d}_{\mathrm{s} 2} / \mathrm{h}$ \\
\hline 0,01 & 0,0102 & $-0,39$ & 6,50 & 0,0563 & \multirow{15}{*}{ 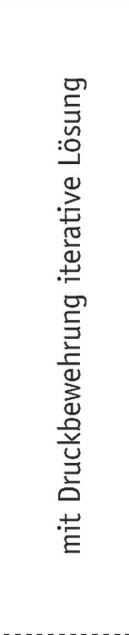 } \\
\hline 0,02 & 0,0206 & $-0,57$ & 6,50 & 0,0802 & \\
\hline 0,03 & 0,0311 & $-0,71$ & 6,50 & 0,0989 & \\
\hline 0,04 & 0,0417 & $-0,84$ & 6,50 & 0,1149 & \\
\hline 0,05 & 0,0524 & $-0,97$ & 6,50 & 0,1293 & \\
\hline 0,06 & 0,0632 & $-1,08$ & 6,50 & 0,1426 & \\
\hline 0,07 & 0,0741 & $-1,19$ & 6,50 & 0,1550 & \\
\hline 0,08 & 0,0851 & $-1,30$ & 6,50 & 0,1669 & \\
\hline 0,09 & 0,0962 & $-1,41$ & 6,50 & 0,1783 & \\
\hline 0,10 & 0,1073 & $-1,52$ & 6,50 & 0,1893 & \\
\hline 0,11 & 0,1187 & $-1,63$ & 6,50 & 0,2002 & \\
\hline 0,12 & 0,1301 & $-1,74$ & 6,50 & 0,2108 & \\
\hline 0,13 & 0,1416 & $-1,85$ & 6,50 & 0,2214 & \\
\hline 0,14 & 0,1533 & $-1,96$ & 6,50 & 0,2321 & \\
\hline 0,15 & 0,1651 & $-2,08$ & 6,50 & 0,2428 & \\
\hline 0,16 & 0,1772 & $-2,21$ & 6,50 & 0,2537 & 0,0041 \\
\hline 0,17 & 0,1893 & $-2,34$ & 6,50 & 0,2648 & 0,0189 \\
\hline 0,18 & 0,2017 & $-2,48$ & 6,50 & 0,2760 & 0,0338 \\
\hline 0,19 & 0,2143 & $-2,62$ & 6,50 & 0,2874 & 0,0491 \\
\hline 0,20 & 0,2271 & $-2,77$ & 6,50 & 0,2990 & 0,0645 \\
\hline 0,21 & 0,2401 & $-2,93$ & 6,50 & 0,3108 & 0,0802 \\
\hline 0,22 & 0,2533 & $-3,10$ & 6,50 & 0,3227 & 0,0962 \\
\hline 0,23 & 0,2667 & $-3,27$ & 6,50 & 0,3349 & 0,1125 \\
\hline 0,24 & 0,2804 & $-3,46$ & 6,50 & 0,3474 & 0,1291 \\
\hline 0,25 & 0,2946 & $-3,50$ & 6,12 & 0,3639 & 0,1379 \\
\hline 0,26 & 0,3091 & $-3,50$ & 5,67 & 0,3818 & 0,1447 \\
\hline 0,27 & 0,3239 & $-3,50$ & 5,25 & 0,4001 & 0,1516 \\
\hline 0,28 & 0,3391 & $-3,50$ & 4,86 & 0,4189 & 0,1587 \\
\hline 0,29 & 0,3546 & $-3,50$ & 4,49 & 0,4381 & 0,1660 \\
\hline 0,30 & 0,3706 & $-3,50$ & 4,15 & 0,4577 & 0,1734 \\
\hline 0,31 & 0,3869 & $-3,50$ & 3,82 & 0,4780 & 0,1811 \\
\hline 0,32 & 0,4038 & $-3,50$ & 3,52 & 0,4988 & 0,1890 \\
\hline 0,33 & 0,4211 & $-3,50$ & 3,23 & 0,5202 & 0,1971 \\
\hline 0,34 & 0,4391 & $-3,50$ & 2,95 & 0,5424 & 0,2055 \\
\hline 0,35 & 0,4576 & $-3,50$ & 2,69 & 0,5653 & 0,2142 \\
\hline 0,36 & 0,4768 & $-3,50$ & 2,44 & 0,5890 & 0,2232 \\
\hline 0,37 & 0,4968 & $-3,50$ & 2,20 & 0,6137 & 0,2325 \\
\hline
\end{tabular}


Tab. C.10 Bemessungstafel für Rechteckquerschnitte mit und ohne Druckbewehrung (Normalbeton C12/16 - C50/60 | Betonstahl B500 | $\varepsilon_{\mathrm{L}, \mathrm{ges}, \mathrm{zul}}=7 \%$ ) (http://doi.org/10.33968/9783966270021-09-T-10)

\begin{tabular}{|c|c|c|c|c|c|}
\hline$\mu_{\mathrm{Ed}, \mathrm{L}}$ & $\omega_{\llcorner}$ & $\varepsilon_{c R 2}$ & $\varepsilon_{\text {L,ges }}$ & $\xi_{L}$ & $\max . \mathrm{d}_{\mathrm{s} 2} / \mathrm{h}$ \\
\hline 0,01 & 0,0102 & $-0,40$ & 7,00 & 0,0543 & \multirow{14}{*}{ 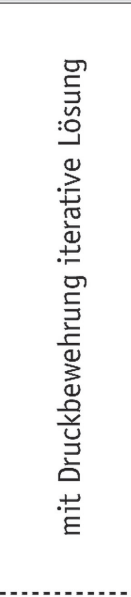 } \\
\hline 0,02 & 0,0205 & $-0,59$ & 7,00 & 0,0775 & \\
\hline 0,03 & 0,0310 & $-0,74$ & 7,00 & 0,0956 & \\
\hline 0,04 & 0,0416 & $-0,88$ & 7,00 & 0,1112 & \\
\hline 0,05 & 0,0523 & $-1,00$ & 7,00 & 0,1253 & \\
\hline 0,06 & 0,0631 & $-1,12$ & 7,00 & 0,1382 & \\
\hline 0,07 & 0,0739 & $-1,24$ & 7,00 & 0,1504 & \\
\hline 0,08 & 0,0849 & $-1,35$ & 7,00 & 0,1620 & \\
\hline 0,09 & 0,0960 & $-1,47$ & 7,00 & 0,1732 & \\
\hline 0,10 & 0,1072 & $-1,58$ & 7,00 & 0,1841 & \\
\hline 0,11 & 0,1185 & $-1,69$ & 7,00 & 0,1949 & \\
\hline 0,12 & 0,1299 & $-1,81$ & 7,00 & 0,2055 & \\
\hline 0,13 & 0,1414 & $-1,93$ & 7,00 & 0,2160 & \\
\hline 0,14 & 0,1531 & $-2,05$ & 7,00 & 0,2267 & \\
\hline 0,15 & 0,1649 & $-2,18$ & 7,00 & 0,2375 & 0,0007 \\
\hline 0,16 & 0,1769 & $-2,31$ & 7,00 & 0,2485 & 0,0151 \\
\hline 0,17 & 0,1891 & $-2,45$ & 7,00 & 0,2596 & 0,0297 \\
\hline 0,18 & 0,2015 & $-2,60$ & 7,00 & 0,2709 & 0,0445 \\
\hline 0,19 & 0,2141 & $-2,76$ & 7,00 & 0,2824 & 0,0596 \\
\hline 0,20 & 0,2269 & $-2,92$ & 7,00 & 0,2941 & 0,0749 \\
\hline 0,21 & 0,2399 & $-3,09$ & 7,00 & 0,3060 & 0,0904 \\
\hline 0,22 & 0,2531 & $-3,26$ & 7,00 & 0,3180 & 0,1062 \\
\hline 0,23 & 0,2665 & $-3,45$ & 7,00 & 0,3303 & 0,1223 \\
\hline 0,24 & 0,2804 & $-3,50$ & 6,60 & 0,3464 & 0,1312 \\
\hline 0,25 & 0,2946 & $-3,50$ & 6,12 & 0,3639 & 0,1379 \\
\hline 0,26 & 0,3091 & $-3,50$ & 5,67 & 0,3818 & 0,1447 \\
\hline 0,27 & 0,3239 & $-3,50$ & 5,25 & 0,4001 & 0,1516 \\
\hline 0,28 & 0,3391 & $-3,50$ & 4,86 & 0,4189 & 0,1587 \\
\hline 0,29 & 0,3546 & $-3,50$ & 4,49 & 0,4381 & 0,1660 \\
\hline 0,30 & 0,3706 & $-3,50$ & 4,15 & 0,4577 & 0,1734 \\
\hline 0,31 & 0,3869 & $-3,50$ & 3,82 & 0,4780 & 0,1811 \\
\hline 0,32 & 0,4038 & $-3,50$ & 3,52 & 0,4988 & 0,1890 \\
\hline 0,33 & 0,4211 & $-3,50$ & 3,23 & 0,5202 & 0,1971 \\
\hline 0,34 & 0,4391 & $-3,50$ & 2,95 & 0,5424 & 0,2055 \\
\hline 0,35 & 0,4576 & $-3,50$ & 2,69 & 0,5653 & 0,2142 \\
\hline 0,36 & 0,4768 & $-3,50$ & 2,44 & 0,5890 & 0,2232 \\
\hline 0,37 & 0,4968 & $-3,50$ & 2,20 & 0,6137 & 0,2325 \\
\hline
\end{tabular}


Tab. C.11 Bemessungstafel für Rechteckquerschnitte mit und ohne Druckbewehrung (Normalbeton C12/16 - C50/60 | Betonstahl B500 | $\varepsilon_{\mathrm{L}, \text { ges,zul }}=7,5 \%$ )

(http://doi.org/10.33968/9783966270021-09-T-11)

\begin{tabular}{|c|c|c|c|c|c|}
\hline$\mu_{\mathrm{Ed}, \mathrm{L}}$ & $\omega_{\llcorner}$ & $\varepsilon_{C R 2}$ & $\varepsilon_{\mathrm{L}, \mathrm{ges}}$ & $\xi_{\mathrm{L}}$ & $\max . \mathrm{d}_{\mathrm{s} 2} / \mathrm{h}$ \\
\hline 0,01 & 0,0102 & $-0,42$ & 7,50 & 0,0526 & \multirow{14}{*}{ 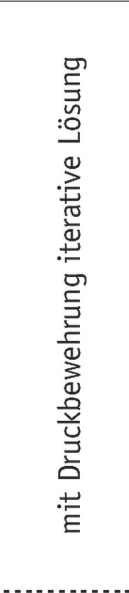 } \\
\hline 0,02 & 0,0205 & $-0,61$ & 7,50 & 0,0751 & \\
\hline 0,03 & 0,0310 & $-0,77$ & 7,50 & 0,0927 & \\
\hline 0,04 & 0,0416 & $-0,91$ & 7,50 & 0,1079 & \\
\hline 0,05 & 0,0522 & $-1,04$ & 7,50 & 0,1216 & \\
\hline 0,06 & 0,0630 & $-1,16$ & 7,50 & 0,1343 & \\
\hline 0,07 & 0,0738 & $-1,28$ & 7,50 & 0,1463 & \\
\hline 0,08 & 0,0848 & $-1,40$ & 7,50 & 0,1577 & \\
\hline 0,09 & 0,0958 & $-1,52$ & 7,50 & 0,1687 & \\
\hline 0,10 & 0,1070 & $-1,64$ & 7,50 & 0,1795 & \\
\hline 0,11 & 0,1183 & $-1,76$ & 7,50 & 0,1901 & \\
\hline 0,12 & 0,1297 & $-1,88$ & 7,50 & 0,2007 & \\
\hline 0,13 & 0,1412 & $-2,01$ & 7,50 & 0,2113 & \\
\hline 0,14 & 0,1529 & $-2,14$ & 7,50 & 0,2220 & \\
\hline 0,15 & 0,1647 & $-2,28$ & 7,50 & 0,2329 & 0,0106 \\
\hline 0,16 & 0,1767 & $-2,42$ & 7,50 & 0,2440 & 0,0248 \\
\hline 0,17 & 0,1889 & $-2,57$ & 7,50 & 0,2552 & 0,0393 \\
\hline 0,18 & 0,2013 & $-2,73$ & 7,50 & 0,2665 & 0,0539 \\
\hline 0,19 & 0,2139 & $-2,89$ & 7,50 & 0,2781 & 0,0688 \\
\hline 0,20 & 0,2267 & $-3,06$ & 7,50 & 0,2898 & 0,0840 \\
\hline 0,21 & 0,2397 & $-3,24$ & 7,50 & 0,3018 & 0,0994 \\
\hline 0,22 & 0,2529 & $-3,43$ & 7,50 & 0,3139 & 0,1150 \\
\hline 0,23 & 0,2665 & $-3,50$ & 7,13 & 0,3292 & 0,1247 \\
\hline 0,24 & 0,2804 & $-3,50$ & 6,60 & 0,3464 & 0,1312 \\
\hline 0,25 & 0,2946 & $-3,50$ & 6,12 & 0,3639 & 0,1379 \\
\hline 0,26 & 0,3091 & $-3,50$ & 5,67 & 0,3818 & 0,1447 \\
\hline 0,27 & 0,3239 & $-3,50$ & 5,25 & 0,4001 & 0,1516 \\
\hline 0,28 & 0,3391 & $-3,50$ & 4,86 & 0,4189 & 0,1587 \\
\hline 0,29 & 0,3546 & $-3,50$ & 4,49 & 0,4381 & 0,1660 \\
\hline 0,30 & 0,3706 & $-3,50$ & 4,15 & 0,4577 & 0,1734 \\
\hline 0,31 & 0,3869 & $-3,50$ & 3,82 & 0,4780 & 0,1811 \\
\hline 0,32 & 0,4038 & $-3,50$ & 3,52 & 0,4988 & 0,1890 \\
\hline 0,33 & 0,4211 & $-3,50$ & 3,23 & 0,5202 & 0,1971 \\
\hline 0,34 & 0,4391 & $-3,50$ & 2,95 & 0,5424 & 0,2055 \\
\hline 0,35 & 0,4576 & $-3,50$ & 2,69 & 0,5653 & 0,2142 \\
\hline 0,36 & 0,4768 & $-3,50$ & 2,44 & 0,5890 & 0,2232 \\
\hline 0,37 & 0,4968 & $-3,50$ & 2,20 & 0,6137 & 0,2325 \\
\hline
\end{tabular}


Tab. C.12 Bemessungstafel für Rechteckquerschnitte mit und ohne Druckbewehrung (Normalbeton C12/16 - C50/60 | Betonstahl B500 | $\varepsilon_{\mathrm{L}, \mathrm{ges}, \mathrm{zul}}=8 \%$ \%)

(http://doi.org/10.33968/9783966270021-09-T-12)

\begin{tabular}{|c|c|c|c|c|c|}
\hline$\mu_{\mathrm{Ed}, \mathrm{L}}$ & $\omega_{\mathrm{L}}$ & $\varepsilon_{C R 2}$ & $\varepsilon_{\text {L,ges }}$ & $\xi_{L}$ & $\max . \mathrm{d}_{\mathrm{s} 2} / \mathrm{h}$ \\
\hline 0,01 & 0,0102 & $-0,43$ & 8,00 & 0,0510 & \multirow{13}{*}{ 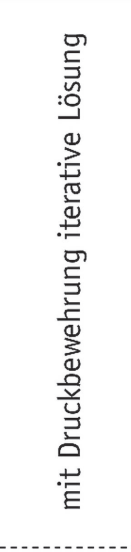 } \\
\hline 0,02 & 0,0205 & $-0,63$ & 8,00 & 0,0729 & \\
\hline 0,03 & 0,0310 & $-0,79$ & 8,00 & 0,0901 & \\
\hline 0,04 & 0,0415 & $-0,94$ & 8,00 & 0,1049 & \\
\hline 0,05 & 0,0522 & $-1,07$ & 8,00 & 0,1183 & \\
\hline 0,06 & 0,0629 & $-1,20$ & 8,00 & 0,1308 & \\
\hline 0,07 & 0,0738 & $-1,33$ & 8,00 & 0,1425 & \\
\hline 0,08 & 0,0847 & $-1,45$ & 8,00 & 0,1538 & \\
\hline 0,09 & 0,0957 & $-1,58$ & 8,00 & 0,1647 & \\
\hline 0,10 & 0,1069 & $-1,70$ & 8,00 & 0,1754 & \\
\hline 0,11 & 0,1181 & $-1,83$ & 8,00 & 0,1859 & \\
\hline 0,12 & 0,1295 & $-1,96$ & 8,00 & 0,1965 & \\
\hline 0,13 & 0,1410 & $-2,09$ & 8,00 & 0,2071 & \\
\hline 0,14 & 0,1527 & $-2,23$ & 8,00 & 0,2179 & 0,0054 \\
\hline 0,15 & 0,1646 & $-2,37$ & 8,00 & 0,2288 & 0,0193 \\
\hline 0,16 & 0,1766 & $-2,53$ & 8,00 & 0,2399 & 0,0334 \\
\hline 0,17 & 0,1888 & $-2,68$ & 8,00 & 0,2512 & 0,0477 \\
\hline 0,18 & 0,2012 & $-2,85$ & 8,00 & 0,2626 & 0,0623 \\
\hline 0,19 & 0,2138 & $-3,02$ & 8,00 & 0,2742 & 0,0770 \\
\hline 0,20 & 0,2265 & $-3,21$ & 8,00 & 0,2860 & 0,0920 \\
\hline 0,21 & 0,2395 & $-3,40$ & 8,00 & 0,2980 & 0,1073 \\
\hline 0,22 & 0,2529 & $-3,50$ & 7,71 & 0,3123 & 0,1183 \\
\hline 0,23 & 0,2665 & $-3,50$ & 7,13 & 0,3292 & 0,1247 \\
\hline 0,24 & 0,2804 & $-3,50$ & 6,60 & 0,3464 & 0,1312 \\
\hline 0,25 & 0,2946 & $-3,50$ & 6,12 & 0,3639 & 0,1379 \\
\hline 0,26 & 0,3091 & $-3,50$ & 5,67 & 0,3818 & 0,1447 \\
\hline 0,27 & 0,3239 & $-3,50$ & 5,25 & 0,4001 & 0,1516 \\
\hline 0,28 & 0,3391 & $-3,50$ & 4,86 & 0,4189 & 0,1587 \\
\hline 0,29 & 0,3546 & $-3,50$ & 4,49 & 0,4381 & 0,1660 \\
\hline 0,30 & 0,3706 & $-3,50$ & 4,15 & 0,4577 & 0,1734 \\
\hline 0,31 & 0,3869 & $-3,50$ & 3,82 & 0,4780 & 0,1811 \\
\hline 0,32 & 0,4038 & $-3,50$ & 3,52 & 0,4988 & 0,1890 \\
\hline 0,33 & 0,4211 & $-3,50$ & 3,23 & 0,5202 & 0,1971 \\
\hline 0,34 & 0,4391 & $-3,50$ & 2,95 & 0,5424 & 0,2055 \\
\hline 0,35 & 0,4576 & $-3,50$ & 2,69 & 0,5653 & 0,2142 \\
\hline 0,36 & 0,4768 & $-3,50$ & 2,44 & 0,5890 & 0,2232 \\
\hline 0,37 & 0,4968 & $-3,50$ & 2,20 & 0,6137 & 0,2325 \\
\hline
\end{tabular}


Tab. C.13 Bemessungstafel für Rechteckquerschnitte mit und ohne Druckbewehrung (Normalbeton C12/16 - C50/60 | Betonstahl B500 | $\varepsilon_{\mathrm{L}, \text { ges,zul }}=8,5 \%$ \%)

(http://doi.org/10.33968/9783966270021-09-T-13)

\begin{tabular}{|c|c|c|c|c|c|}
\hline$\mu_{\mathrm{Ed}, \mathrm{L}}$ & $\omega_{\llcorner}$ & $\varepsilon_{C R 2}$ & $\varepsilon_{\mathrm{L}, \mathrm{ges}}$ & $\xi_{\mathrm{L}}$ & $\max . \mathrm{d}_{\mathrm{s} 2} / \mathrm{h}$ \\
\hline 0,01 & 0,0102 & $-0,44$ & 8,50 & 0,0496 & \multirow{13}{*}{ 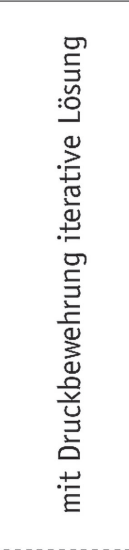 } \\
\hline 0,02 & 0,0205 & $-0,65$ & 8,50 & 0,0709 & \\
\hline 0,03 & 0,0309 & $-0,82$ & 8,50 & 0,0877 & \\
\hline 0,04 & 0,0415 & $-0,97$ & 8,50 & 0,1022 & \\
\hline 0,05 & 0,0521 & $-1,11$ & 8,50 & 0,1154 & \\
\hline 0,06 & 0,0628 & $-1,24$ & 8,50 & 0,1276 & \\
\hline 0,07 & 0,0737 & $-1,37$ & 8,50 & 0,1391 & \\
\hline 0,08 & 0,0846 & $-1,50$ & 8,50 & 0,1502 & \\
\hline 0,09 & 0,0956 & $-1,63$ & 8,50 & 0,1610 & \\
\hline 0,10 & 0,1067 & $-1,76$ & 8,50 & 0,1716 & \\
\hline 0,11 & 0,1180 & $-1,89$ & 8,50 & 0,1821 & \\
\hline 0,12 & 0,1294 & $-2,03$ & 8,50 & 0,1927 & \\
\hline 0,13 & 0,1409 & $-2,17$ & 8,50 & 0,2034 & \\
\hline 0,14 & 0,1526 & $-2,32$ & 8,50 & 0,2142 & 0,0133 \\
\hline 0,15 & 0,1644 & $-2,47$ & 8,50 & 0,2252 & 0,0271 \\
\hline 0,16 & 0,1765 & $-2,63$ & 8,50 & 0,2364 & 0,0411 \\
\hline 0,17 & 0,1887 & $-2,80$ & 8,50 & 0,2477 & 0,0553 \\
\hline 0,18 & 0,2011 & $-2,97$ & 8,50 & 0,2592 & 0,0697 \\
\hline 0,19 & 0,2136 & $-3,16$ & 8,50 & 0,2708 & 0,0843 \\
\hline 0,20 & 0,2264 & $-3,35$ & 8,50 & 0,2827 & 0,0992 \\
\hline 0,21 & 0,2395 & $-3,50$ & 8,33 & 0,2958 & 0,1121 \\
\hline 0,22 & 0,2529 & $-3,50$ & 7,71 & 0,3123 & 0,1183 \\
\hline 0,23 & 0,2665 & $-3,50$ & 7,13 & 0,3292 & 0,1247 \\
\hline 0,24 & 0,2804 & $-3,50$ & 6,60 & 0,3464 & 0,1312 \\
\hline 0,25 & 0,2946 & $-3,50$ & 6,12 & 0,3639 & 0,1379 \\
\hline 0,26 & 0,3091 & $-3,50$ & 5,67 & 0,3818 & 0,1447 \\
\hline 0,27 & 0,3239 & $-3,50$ & 5,25 & 0,4001 & 0,1516 \\
\hline 0,28 & 0,3391 & $-3,50$ & 4,86 & 0,4189 & 0,1587 \\
\hline 0,29 & 0,3546 & $-3,50$ & 4,49 & 0,4381 & 0,1660 \\
\hline 0,30 & 0,3706 & $-3,50$ & 4,15 & 0,4577 & 0,1734 \\
\hline 0,31 & 0,3869 & $-3,50$ & 3,82 & 0,4780 & 0,1811 \\
\hline 0,32 & 0,4038 & $-3,50$ & 3,52 & 0,4988 & 0,1890 \\
\hline 0,33 & 0,4211 & $-3,50$ & 3,23 & 0,5202 & 0,1971 \\
\hline 0,34 & 0,4391 & $-3,50$ & 2,95 & 0,5424 & 0,2055 \\
\hline 0,35 & 0,4576 & $-3,50$ & 2,69 & 0,5653 & 0,2142 \\
\hline 0,36 & 0,4768 & $-3,50$ & 2,44 & 0,5890 & 0,2232 \\
\hline 0,37 & 0,4968 & $-3,50$ & 2,20 & 0,6137 & 0,2325 \\
\hline
\end{tabular}


Tab. C.14 Bemessungstafel für Rechteckquerschnitte mit und ohne Druckbewehrung (Normalbeton C12/16 - C50/60 | Betonstahl B500 | $\varepsilon_{\mathrm{L}, \mathrm{ges}, \mathrm{zul}}=9 \%$ ) (http://doi.org/10.33968/9783966270021-09-T-14)

\begin{tabular}{|c|c|c|c|c|c|}
\hline$\mu_{\mathrm{Ed}, \mathrm{L}}$ & $\omega_{\mathrm{L}}$ & $\varepsilon_{c R 2}$ & $\varepsilon_{\text {L,ges }}$ & $\xi_{\mathrm{L}}$ & $\max . \mathrm{d}_{\mathrm{s} 2} / \mathrm{h}$ \\
\hline 0,01 & 0,0102 & $-0,46$ & 9,00 & 0,0482 & \multirow{12}{*}{ 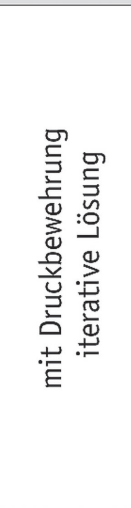 } \\
\hline 0,02 & 0,0205 & $-0,67$ & 9,00 & 0,0691 & \\
\hline 0,03 & 0,0309 & $-0,84$ & 9,00 & 0,0855 & \\
\hline 0,04 & 0,0414 & $-1,00$ & 9,00 & 0,0997 & \\
\hline 0,05 & 0,0521 & $-1,14$ & 9,00 & 0,1126 & \\
\hline 0,06 & 0,0628 & $-1,28$ & 9,00 & 0,1246 & \\
\hline 0,07 & 0,0736 & $-1,42$ & 9,00 & 0,1360 & \\
\hline 0,08 & 0,0845 & $-1,55$ & 9,00 & 0,1470 & \\
\hline 0,09 & 0,0955 & $-1,68$ & 9,00 & 0,1577 & \\
\hline 0,10 & 0,1066 & $-1,82$ & 9,00 & 0,1682 & \\
\hline 0,11 & 0,1179 & $-1,96$ & 9,00 & 0,1787 & \\
\hline 0,12 & 0,1293 & $-2,10$ & 9,00 & 0,1893 & \\
\hline 0,13 & 0,1408 & $-2,25$ & 9,00 & 0,2000 & 0,0068 \\
\hline 0,14 & 0,1525 & $-2,41$ & 9,00 & 0,2109 & 0,0203 \\
\hline 0,15 & 0,1643 & $-2,57$ & 9,00 & 0,2220 & 0,0340 \\
\hline 0,16 & 0,1764 & $-2,74$ & 9,00 & 0,2332 & 0,0479 \\
\hline 0,17 & 0,1886 & $-2,91$ & 9,00 & 0,2445 & 0,0620 \\
\hline 0,18 & 0,2009 & $-3,10$ & 9,00 & 0,2561 & 0,0764 \\
\hline 0,19 & 0,2135 & $-3,29$ & 9,00 & 0,2678 & 0,0909 \\
\hline 0,20 & 0,2263 & $-3,49$ & 9,00 & 0,2797 & 0,1057 \\
\hline 0,21 & 0,2395 & $-3,50$ & 8,33 & 0,2958 & 0,1121 \\
\hline 0,22 & 0,2529 & $-3,50$ & 7,71 & 0,3123 & 0,1183 \\
\hline 0,23 & 0,2665 & $-3,50$ & 7,13 & 0,3292 & 0,1247 \\
\hline 0,24 & 0,2804 & $-3,50$ & 6,60 & 0,3464 & 0,1312 \\
\hline 0,25 & 0,2946 & $-3,50$ & 6,12 & 0,3639 & 0,1379 \\
\hline 0,26 & 0,3091 & $-3,50$ & 5,67 & 0,3818 & 0,1447 \\
\hline 0,27 & 0,3239 & $-3,50$ & 5,25 & 0,4001 & 0,1516 \\
\hline 0,28 & 0,3391 & $-3,50$ & 4,86 & 0,4189 & 0,1587 \\
\hline 0,29 & 0,3546 & $-3,50$ & 4,49 & 0,4381 & 0,1660 \\
\hline 0,30 & 0,3706 & $-3,50$ & 4,15 & 0,4577 & 0,1734 \\
\hline 0,31 & 0,3869 & $-3,50$ & 3,82 & 0,4780 & 0,1811 \\
\hline 0,32 & 0,4038 & $-3,50$ & 3,52 & 0,4988 & 0,1890 \\
\hline 0,33 & 0,4211 & $-3,50$ & 3,23 & 0,5202 & 0,1971 \\
\hline 0,34 & 0,4391 & $-3,50$ & 2,95 & 0,5424 & 0,2055 \\
\hline 0,35 & 0,4576 & $-3,50$ & 2,69 & 0,5653 & 0,2142 \\
\hline 0,36 & 0,4768 & $-3,50$ & 2,44 & 0,5890 & 0,2232 \\
\hline 0,37 & 0,4968 & $-3,50$ & 2,20 & 0,6137 & 0,2325 \\
\hline
\end{tabular}


Tab. C.15 Bemessungstafel für Rechteckquerschnitte mit und ohne Druckbewehrung (Normalbeton C12/16 - C50/60 | Betonstahl B500 | $\varepsilon_{\mathrm{L}, \mathrm{ges}, \mathrm{zul}}=9,5 \%$ )

(http://doi.org/10.33968/9783966270021-09-T-15)

\begin{tabular}{|c|c|c|c|c|c|}
\hline$\mu_{\mathrm{Ed}, \mathrm{L}}$ & $\omega_{\mathrm{L}}$ & $\varepsilon_{C R 2}$ & $\varepsilon_{\mathrm{L}, \mathrm{ges}}$ & $\xi_{L}$ & $\max . \mathrm{d}_{\mathrm{s} 2} / \mathrm{h}$ \\
\hline 0,01 & 0,0102 & $-0,47$ & 9,50 & 0,0470 & \multirow{12}{*}{ 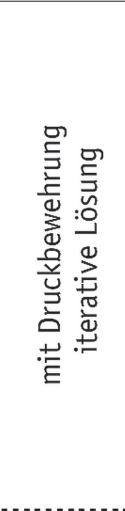 } \\
\hline 0,02 & 0,0205 & $-0,69$ & 9,50 & 0,0674 & \\
\hline 0,03 & 0,0309 & $-0,87$ & 9,50 & 0,0835 & \\
\hline 0,04 & 0,0414 & $-1,03$ & 9,50 & 0,0974 & \\
\hline 0,05 & 0,0520 & $-1,18$ & 9,50 & 0,1101 & \\
\hline 0,06 & 0,0627 & $-1,32$ & 9,50 & 0,1219 & \\
\hline 0,07 & 0,0735 & $-1,46$ & 9,50 & 0,1332 & \\
\hline 0,08 & 0,0844 & $-1,60$ & 9,50 & 0,1440 & \\
\hline 0,09 & 0,0954 & $-1,74$ & 9,50 & 0,1546 & \\
\hline 0,10 & 0,1065 & $-1,88$ & 9,50 & 0,1651 & \\
\hline 0,11 & 0,1178 & $-2,02$ & 9,50 & 0,1756 & \\
\hline 0,12 & 0,1292 & $-2,17$ & 9,50 & 0,1863 & \\
\hline 0,13 & 0,1407 & $-2,33$ & 9,50 & 0,1970 & 0,0133 \\
\hline 0,14 & 0,1524 & $-2,49$ & 9,50 & 0,2080 & 0,0267 \\
\hline 0,15 & 0,1642 & $-2,66$ & 9,50 & 0,2190 & 0,0403 \\
\hline 0,16 & 0,1763 & $-2,84$ & 9,50 & 0,2303 & 0,0541 \\
\hline 0,17 & 0,1885 & $-3,03$ & 9,50 & 0,2417 & 0,0682 \\
\hline 0,18 & 0,2009 & $-3,22$ & 9,50 & 0,2533 & 0,0824 \\
\hline 0,19 & 0,2134 & $-3,43$ & 9,50 & 0,2650 & 0,0968 \\
\hline 0,20 & 0,2263 & $-3,50$ & 9,02 & 0,2796 & 0,1059 \\
\hline 0,21 & 0,2395 & $-3,50$ & 8,33 & 0,2958 & 0,1121 \\
\hline 0,22 & 0,2529 & $-3,50$ & 7,71 & 0,3123 & 0,1183 \\
\hline 0,23 & 0,2665 & $-3,50$ & 7,13 & 0,3292 & 0,1247 \\
\hline 0,24 & 0,2804 & $-3,50$ & 6,60 & 0,3464 & 0,1312 \\
\hline 0,25 & 0,2946 & $-3,50$ & 6,12 & 0,3639 & 0,1379 \\
\hline 0,26 & 0,3091 & $-3,50$ & 5,67 & 0,3818 & 0,1447 \\
\hline 0,27 & 0,3239 & $-3,50$ & 5,25 & 0,4001 & 0,1516 \\
\hline 0,28 & 0,3391 & $-3,50$ & 4,86 & 0,4189 & 0,1587 \\
\hline 0,29 & 0,3546 & $-3,50$ & 4,49 & 0,4381 & 0,1660 \\
\hline 0,30 & 0,3706 & $-3,50$ & 4,15 & 0,4577 & 0,1734 \\
\hline 0,31 & 0,3869 & $-3,50$ & 3,82 & 0,4780 & 0,1811 \\
\hline 0,32 & 0,4038 & $-3,50$ & 3,52 & 0,4988 & 0,1890 \\
\hline 0,33 & 0,4211 & $-3,50$ & 3,23 & 0,5202 & 0,1971 \\
\hline 0,34 & 0,4391 & $-3,50$ & 2,95 & 0,5424 & 0,2055 \\
\hline 0,35 & 0,4576 & $-3,50$ & 2,69 & 0,5653 & 0,2142 \\
\hline 0,36 & 0,4768 & $-3,50$ & 2,44 & 0,5890 & 0,2232 \\
\hline 0,37 & 0,4968 & $-3,50$ & 2,20 & 0,6137 & 0,2325 \\
\hline
\end{tabular}


Tab. C.16 Bemessungstafel für Rechteckquerschnitte mit und ohne Druckbewehrung (Normalbeton C12/16 - C50/60 | Betonstahl B500 $\mid \varepsilon_{\mathrm{L}, \text { ges,zul }}=10 \%$ ) (http://doi.org/10.33968/9783966270021-09-T-16)

\begin{tabular}{|c|c|c|c|c|c|}
\hline$\mu_{\mathrm{Ed}, \mathrm{L}}$ & $\omega_{\llcorner}$ & $\varepsilon_{C R 2}$ & $\varepsilon_{\text {L,ges }}$ & $\xi_{L}$ & $\max . \mathrm{d}_{\mathrm{s} 2} / \mathrm{h}$ \\
\hline 0,01 & 0,0102 & $-0,48$ & 10,00 & 0,0459 & \multirow{11}{*}{ 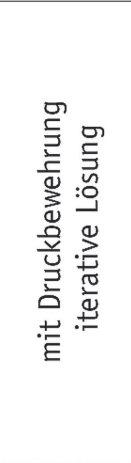 } \\
\hline 0,02 & 0,0205 & $-0,70$ & 10,00 & 0,0658 & \\
\hline 0,03 & 0,0309 & $-0,89$ & 10,00 & 0,0816 & \\
\hline 0,04 & 0,0414 & $-1,05$ & 10,00 & 0,0953 & \\
\hline 0,05 & 0,0520 & $-1,21$ & 10,00 & 0,1078 & \\
\hline 0,06 & 0,0627 & $-1,36$ & 10,00 & 0,1194 & \\
\hline 0,07 & 0,0735 & $-1,50$ & 10,00 & 0,1305 & \\
\hline 0,08 & 0,0843 & $-1,65$ & 10,00 & 0,1413 & \\
\hline 0,09 & 0,0953 & $-1,79$ & 10,00 & 0,1518 & \\
\hline 0,10 & 0,1064 & $-1,94$ & 10,00 & 0,1623 & \\
\hline 0,11 & 0,1177 & $-2,09$ & 10,00 & 0,1728 & \\
\hline 0,12 & 0,1291 & $-2,25$ & 10,00 & 0,1835 & 0,0060 \\
\hline 0,13 & 0,1406 & $-2,41$ & 10,00 & 0,1943 & 0,0192 \\
\hline 0,14 & 0,1523 & $-2,58$ & 10,00 & 0,2053 & 0,0325 \\
\hline 0,15 & 0,1642 & $-2,76$ & 10,00 & 0,2164 & 0,0460 \\
\hline 0,16 & 0,1762 & $-2,95$ & 10,00 & 0,2277 & 0,0598 \\
\hline 0,17 & 0,1884 & $-3,14$ & 10,00 & 0,2391 & 0,0737 \\
\hline 0,18 & 0,2008 & $-3,35$ & 10,00 & 0,2507 & 0,0878 \\
\hline 0,19 & 0,2134 & $-3,50$ & 9,78 & 0,2636 & 0,0999 \\
\hline 0,20 & 0,2263 & $-3,50$ & 9,02 & 0,2796 & 0,1059 \\
\hline 0,21 & 0,2395 & $-3,50$ & 8,33 & 0,2958 & 0,1121 \\
\hline 0,22 & 0,2529 & $-3,50$ & 7,71 & 0,3123 & 0,1183 \\
\hline 0,23 & 0,2665 & $-3,50$ & 7,13 & 0,3292 & 0,1247 \\
\hline 0,24 & 0,2804 & $-3,50$ & 6,60 & 0,3464 & 0,1312 \\
\hline 0,25 & 0,2946 & $-3,50$ & 6,12 & 0,3639 & 0,1379 \\
\hline 0,26 & 0,3091 & $-3,50$ & 5,67 & 0,3818 & 0,1447 \\
\hline 0,27 & 0,3239 & $-3,50$ & 5,25 & 0,4001 & 0,1516 \\
\hline 0,28 & 0,3391 & $-3,50$ & 4,86 & 0,4189 & 0,1587 \\
\hline 0,29 & 0,3546 & $-3,50$ & 4,49 & 0,4381 & 0,1660 \\
\hline 0,30 & 0,3706 & $-3,50$ & 4,15 & 0,4577 & 0,1734 \\
\hline 0,31 & 0,3869 & $-3,50$ & 3,82 & 0,4780 & 0,1811 \\
\hline 0,32 & 0,4038 & $-3,50$ & 3,52 & 0,4988 & 0,1890 \\
\hline 0,33 & 0,4211 & $-3,50$ & 3,23 & 0,5202 & 0,1971 \\
\hline 0,34 & 0,4391 & $-3,50$ & 2,95 & 0,5424 & 0,2055 \\
\hline 0,35 & 0,4576 & $-3,50$ & 2,69 & 0,5653 & 0,2142 \\
\hline 0,36 & 0,4768 & $-3,50$ & 2,44 & 0,5890 & 0,2232 \\
\hline 0,37 & 0,4968 & $-3,50$ & 2,20 & 0,6137 & 0,2325 \\
\hline
\end{tabular}


Tab. C.17 Bemessungstafel für Rechteckquerschnitte mit und ohne Druckbewehrung (Normalbeton C12/16 - C50/60 | Betonstahl B500 $\mid \varepsilon_{\mathrm{L}, \text { ges, zul }}=10,5 \%$ ) (http://doi.org/10.33968/9783966270021-09-T-17)

\begin{tabular}{|c|c|c|c|c|c|}
\hline$\mu_{\mathrm{Ed}, \mathrm{L}}$ & $\omega_{\mathrm{L}}$ & $\varepsilon_{C R 2}$ & $\varepsilon_{\mathrm{L}, \mathrm{ges}}$ & $\xi_{L}$ & $\max . \mathrm{d}_{\mathrm{s} 2} / \mathrm{h}$ \\
\hline 0,01 & 0,0102 & $-0,49$ & 10,50 & 0,0449 & \multirow{11}{*}{ 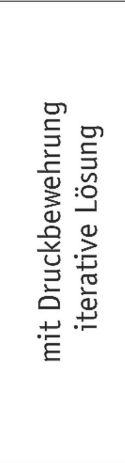 } \\
\hline 0,02 & 0,0205 & $-0,72$ & 10,50 & 0,0644 & \\
\hline 0,03 & 0,0309 & $-0,91$ & 10,50 & 0,0799 & \\
\hline 0,04 & 0,0414 & $-1,08$ & 10,50 & 0,0933 & \\
\hline 0,05 & 0,0519 & $-1,24$ & 10,50 & 0,1056 & \\
\hline 0,06 & 0,0626 & $-1,39$ & 10,50 & 0,1171 & \\
\hline 0,07 & 0,0734 & $-1,54$ & 10,50 & 0,1281 & \\
\hline 0,08 & 0,0843 & $-1,69$ & 10,50 & 0,1388 & \\
\hline 0,09 & 0,0953 & $-1,84$ & 10,50 & 0,1493 & \\
\hline 0,10 & 0,1064 & $-2,00$ & 10,50 & 0,1597 & \\
\hline 0,11 & 0,1176 & $-2,16$ & 10,50 & 0,1703 & \\
\hline 0,12 & 0,1290 & $-2,32$ & 10,50 & 0,1810 & 0,0114 \\
\hline 0,13 & 0,1405 & $-2,49$ & 10,50 & 0,1918 & 0,0245 \\
\hline 0,14 & 0,1522 & $-2,67$ & 10,50 & 0,2028 & 0,0378 \\
\hline 0,15 & 0,1641 & $-2,86$ & 10,50 & 0,2140 & 0,0513 \\
\hline 0,16 & 0,1761 & $-3,05$ & 10,50 & 0,2253 & 0,0649 \\
\hline 0,17 & 0,1883 & $-3,26$ & 10,50 & 0,2368 & 0,0788 \\
\hline 0,18 & 0,2007 & $-3,47$ & 10,50 & 0,2484 & 0,0928 \\
\hline 0,19 & 0,2134 & $-3,50$ & 9,78 & 0,2636 & 0,0999 \\
\hline 0,20 & 0,2263 & $-3,50$ & 9,02 & 0,2796 & 0,1059 \\
\hline 0,21 & 0,2395 & $-3,50$ & 8,33 & 0,2958 & 0,1121 \\
\hline 0,22 & 0,2529 & $-3,50$ & 7,71 & 0,3123 & 0,1183 \\
\hline 0,23 & 0,2665 & $-3,50$ & 7,13 & 0,3292 & 0,1247 \\
\hline 0,24 & 0,2804 & $-3,50$ & 6,60 & 0,3464 & 0,1312 \\
\hline 0,25 & 0,2946 & $-3,50$ & 6,12 & 0,3639 & 0,1379 \\
\hline 0,26 & 0,3091 & $-3,50$ & 5,67 & 0,3818 & 0,1447 \\
\hline 0,27 & 0,3239 & $-3,50$ & 5,25 & 0,4001 & 0,1516 \\
\hline 0,28 & 0,3391 & $-3,50$ & 4,86 & 0,4189 & 0,1587 \\
\hline 0,29 & 0,3546 & $-3,50$ & 4,49 & 0,4381 & 0,1660 \\
\hline 0,30 & 0,3706 & $-3,50$ & 4,15 & 0,4577 & 0,1734 \\
\hline 0,31 & 0,3869 & $-3,50$ & 3,82 & 0,4780 & 0,1811 \\
\hline 0,32 & 0,4038 & $-3,50$ & 3,52 & 0,4988 & 0,1890 \\
\hline 0,33 & 0,4211 & $-3,50$ & 3,23 & 0,5202 & 0,1971 \\
\hline 0,34 & 0,4391 & $-3,50$ & 2,95 & 0,5424 & 0,2055 \\
\hline 0,35 & 0,4576 & $-3,50$ & 2,69 & 0,5653 & 0,2142 \\
\hline 0,36 & 0,4768 & $-3,50$ & 2,44 & 0,5890 & 0,2232 \\
\hline 0,37 & 0,4968 & $-3,50$ & 2,20 & 0,6137 & 0,2325 \\
\hline
\end{tabular}


Tab. C.18 Bemessungstafel für Rechteckquerschnitte mit und ohne Druckbewehrung (Normalbeton C12/16 - C50/60 | Betonstahl B500 $\mid \varepsilon_{\mathrm{L}, \text { ges,zul }}=11 \%$ )

(http://doi.org/10.33968/9783966270021-09-T-18)

\begin{tabular}{|c|c|c|c|c|c|}
\hline$\mu_{\mathrm{Ed}, \mathrm{L}}$ & $\omega_{\mathrm{L}}$ & $\varepsilon_{C R 2}$ & $\varepsilon_{\text {L,ges }}$ & $\xi_{L}$ & $\max . \mathrm{d}_{\mathrm{s} 2} / \mathrm{h}$ \\
\hline 0,01 & 0,0102 & $-0,51$ & 11,00 & 0,0439 & \multirow{10}{*}{ 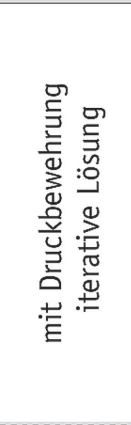 } \\
\hline 0,02 & 0,0204 & $-0,74$ & 11,00 & 0,0630 & \\
\hline 0,03 & 0,0308 & $-0,93$ & 11,00 & 0,0782 & \\
\hline 0,04 & 0,0413 & $-1,11$ & 11,00 & 0,0915 & \\
\hline 0,05 & 0,0519 & $-1,27$ & 11,00 & 0,1036 & \\
\hline 0,06 & 0,0626 & $-1,43$ & 11,00 & 0,1150 & \\
\hline 0,07 & 0,0734 & $-1,58$ & 11,00 & 0,1259 & \\
\hline 0,08 & 0,0842 & $-1,74$ & 11,00 & 0,1364 & \\
\hline 0,09 & 0,0952 & $-1,89$ & 11,00 & 0,1469 & \\
\hline 0,10 & 0,1063 & $-2,05$ & 11,00 & 0,1574 & \\
\hline 0,11 & 0,1175 & $-2,22$ & 11,00 & 0,1680 & 0,0035 \\
\hline 0,12 & 0,1289 & $-2,39$ & 11,00 & 0,1787 & 0,0164 \\
\hline 0,13 & 0,1405 & $-2,57$ & 11,00 & 0,1896 & 0,0294 \\
\hline 0,14 & 0,1522 & $-2,76$ & 11,00 & 0,2006 & 0,0426 \\
\hline 0,15 & 0,1640 & $-2,96$ & 11,00 & 0,2118 & 0,0560 \\
\hline 0,16 & 0,1761 & $-3,16$ & 11,00 & 0,2231 & 0,0696 \\
\hline 0,17 & 0,1883 & $-3,37$ & 11,00 & 0,2346 & 0,0834 \\
\hline 0,18 & 0,2007 & $-3,50$ & 10,62 & 0,2479 & 0,0939 \\
\hline 0,19 & 0,2134 & $-3,50$ & 9,78 & 0,2636 & 0,0999 \\
\hline 0,20 & 0,2263 & $-3,50$ & 9,02 & 0,2796 & 0,1059 \\
\hline 0,21 & 0,2395 & $-3,50$ & 8,33 & 0,2958 & 0,1121 \\
\hline 0,22 & 0,2529 & $-3,50$ & 7,71 & 0,3123 & 0,1183 \\
\hline 0,23 & 0,2665 & $-3,50$ & 7,13 & 0,3292 & 0,1247 \\
\hline 0,24 & 0,2804 & $-3,50$ & 6,60 & 0,3464 & 0,1312 \\
\hline 0,25 & 0,2946 & $-3,50$ & 6,12 & 0,3639 & 0,1379 \\
\hline 0,26 & 0,3091 & $-3,50$ & 5,67 & 0,3818 & 0,1447 \\
\hline 0,27 & 0,3239 & $-3,50$ & 5,25 & 0,4001 & 0,1516 \\
\hline 0,28 & 0,3391 & $-3,50$ & 4,86 & 0,4189 & 0,1587 \\
\hline 0,29 & 0,3546 & $-3,50$ & 4,49 & 0,4381 & 0,1660 \\
\hline 0,30 & 0,3706 & $-3,50$ & 4,15 & 0,4577 & 0,1734 \\
\hline 0,31 & 0,3869 & $-3,50$ & 3,82 & 0,4780 & 0,1811 \\
\hline 0,32 & 0,4038 & $-3,50$ & 3,52 & 0,4988 & 0,1890 \\
\hline 0,33 & 0,4211 & $-3,50$ & 3,23 & 0,5202 & 0,1971 \\
\hline 0,34 & 0,4391 & $-3,50$ & 2,95 & 0,5424 & 0,2055 \\
\hline 0,35 & 0,4576 & $-3,50$ & 2,69 & 0,5653 & 0,2142 \\
\hline 0,36 & 0,4768 & $-3,50$ & 2,44 & 0,5890 & 0,2232 \\
\hline 0,37 & 0,4968 & $-3,50$ & 2,20 & 0,6137 & 0,2325 \\
\hline
\end{tabular}


Tab. C.19 Bemessungstafel für Rechteckquerschnitte mit und ohne Druckbewehrung (Normalbeton C12/16 - C50/60 | Betonstahl B500 | $\varepsilon_{\mathrm{L}, \mathrm{ges}, \mathrm{zul}}=11,5 \%$ \%) (http://doi.org/10.33968/9783966270021-09-T-19)

\begin{tabular}{|c|c|c|c|c|c|}
\hline$\mu_{\mathrm{Ed}, \mathrm{L}}$ & $\omega_{\mathrm{L}}$ & $\varepsilon_{c R 2}$ & $\varepsilon_{\mathrm{L} \text {,ges }}$ & $\xi_{L}$ & $\max . d_{s 2} / h$ \\
\hline 0,01 & 0,0101 & $-0,52$ & 11,50 & 0,0430 & \multirow{10}{*}{ 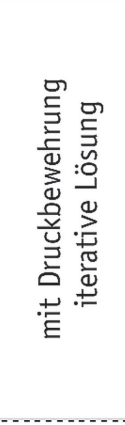 } \\
\hline 0,02 & 0,0204 & $-0,76$ & 11,50 & 0,0618 & \\
\hline 0,03 & 0,0308 & $-0,96$ & 11,50 & 0,0767 & \\
\hline 0,04 & 0,0413 & $-1,13$ & 11,50 & 0,0898 & \\
\hline 0,05 & 0,0519 & $-1,30$ & 11,50 & 0,1017 & \\
\hline 0,06 & 0,0625 & $-1,46$ & 11,50 & 0,1130 & \\
\hline 0,07 & 0,0733 & $-1,62$ & 11,50 & 0,1238 & \\
\hline 0,08 & 0,0842 & $-1,78$ & 11,50 & 0,1343 & \\
\hline 0,09 & 0,0951 & $-1,95$ & 11,50 & 0,1447 & \\
\hline 0,10 & 0,1062 & $-2,11$ & 11,50 & 0,1552 & \\
\hline 0,11 & 0,1175 & $-2,29$ & 11,50 & 0,1658 & 0,0082 \\
\hline 0,12 & 0,1289 & $-2,47$ & 11,50 & 0,1766 & 0,0210 \\
\hline 0,13 & 0,1404 & $-2,65$ & 11,50 & 0,1875 & 0,0339 \\
\hline 0,14 & 0,1521 & $-2,85$ & 11,50 & 0,1986 & 0,0471 \\
\hline 0,15 & 0,1640 & $-3,05$ & 11,50 & 0,2098 & 0,0604 \\
\hline 0,16 & 0,1760 & $-3,27$ & 11,50 & 0,2211 & 0,0739 \\
\hline 0,17 & 0,1882 & $-3,49$ & 11,50 & 0,2327 & 0,0876 \\
\hline 0,18 & 0,2007 & $-3,50$ & 10,62 & 0,2479 & 0,0939 \\
\hline 0,19 & 0,2134 & $-3,50$ & 9,78 & 0,2636 & 0,0999 \\
\hline 0,20 & 0,2263 & $-3,50$ & 9,02 & 0,2796 & 0,1059 \\
\hline 0,21 & 0,2395 & $-3,50$ & 8,33 & 0,2958 & 0,1121 \\
\hline 0,22 & 0,2529 & $-3,50$ & 7,71 & 0,3123 & 0,1183 \\
\hline 0,23 & 0,2665 & $-3,50$ & 7,13 & 0,3292 & 0,1247 \\
\hline 0,24 & 0,2804 & $-3,50$ & 6,60 & 0,3464 & 0,1312 \\
\hline 0,25 & 0,2946 & $-3,50$ & 6,12 & 0,3639 & 0,1379 \\
\hline 0,26 & 0,3091 & $-3,50$ & 5,67 & 0,3818 & 0,1447 \\
\hline 0,27 & 0,3239 & $-3,50$ & 5,25 & 0,4001 & 0,1516 \\
\hline 0,28 & 0,3391 & $-3,50$ & 4,86 & 0,4189 & 0,1587 \\
\hline 0,29 & 0,3546 & $-3,50$ & 4,49 & 0,4381 & 0,1660 \\
\hline 0,30 & 0,3706 & $-3,50$ & 4,15 & 0,4577 & 0,1734 \\
\hline 0,31 & 0,3869 & $-3,50$ & 3,82 & 0,4780 & 0,1811 \\
\hline 0,32 & 0,4038 & $-3,50$ & 3,52 & 0,4988 & 0,1890 \\
\hline 0,33 & 0,4211 & $-3,50$ & 3,23 & 0,5202 & 0,1971 \\
\hline 0,34 & 0,4391 & $-3,50$ & 2,95 & 0,5424 & 0,2055 \\
\hline 0,35 & 0,4576 & $-3,50$ & 2,69 & 0,5653 & 0,2142 \\
\hline 0,36 & 0,4768 & $-3,50$ & 2,44 & 0,5890 & 0,2232 \\
\hline 0,37 & 0,4968 & $-3,50$ & 2,20 & 0,6137 & 0,2325 \\
\hline
\end{tabular}


Tab. C.20 Bemessungstafel für Rechteckquerschnitte mit und ohne Druckbewehrung (Normalbeton C12/16 - C50/60 | Betonstahl B500 | $\varepsilon_{\mathrm{L}, \text { ges,zul }}=12 \%$ ) (http://doi.org/10.33968/9783966270021-09-T-20)

\begin{tabular}{|c|c|c|c|c|c|}
\hline$\mu_{\mathrm{Ed}, \mathrm{L}}$ & $\omega\llcorner$ & $\varepsilon_{C R 2}$ & $\varepsilon$ L,ges & $\xi_{L}$ & $\max . \mathrm{d}_{\mathrm{s} 2} / \mathrm{h}$ \\
\hline 0,01 & 0,0101 & $-0,53$ & 12,00 & 0,0421 & \multirow{10}{*}{ 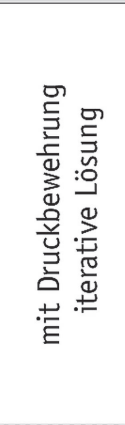 } \\
\hline 0,02 & 0,0204 & $-0,77$ & 12,00 & 0,0606 & \\
\hline 0,03 & 0,0308 & $-0,98$ & 12,00 & 0,0753 & \\
\hline 0,04 & 0,0413 & $-1,16$ & 12,00 & 0,0882 & \\
\hline 0,05 & 0,0519 & $-1,33$ & 12,00 & 0,1000 & \\
\hline 0,06 & 0,0625 & $-1,50$ & 12,00 & 0,1111 & \\
\hline 0,07 & 0,0733 & $-1,66$ & 12,00 & 0,1218 & \\
\hline 0,08 & 0,0841 & $-1,83$ & 12,00 & 0,1323 & \\
\hline 0,09 & 0,0951 & $-2,00$ & 12,00 & 0,1427 & \\
\hline 0,10 & 0,1062 & $-2,17$ & 12,00 & 0,1532 & \\
\hline 0,11 & 0,1174 & $-2,35$ & 12,00 & 0,1639 & 0,0124 \\
\hline 0,12 & 0,1288 & $-2,54$ & 12,00 & 0,1747 & 0,0252 \\
\hline 0,13 & 0,1404 & $-2,73$ & 12,00 & 0,1856 & 0,0381 \\
\hline 0,14 & 0,1521 & $-2,94$ & 12,00 & 0,1967 & 0,0512 \\
\hline 0,15 & 0,1639 & $-3,15$ & 12,00 & 0,2079 & 0,0644 \\
\hline 0,16 & 0,1759 & $-3,37$ & 12,00 & 0,2193 & 0,0779 \\
\hline 0,17 & 0,1882 & $-3,50$ & 11,55 & 0,2325 & 0,0881 \\
\hline 0,18 & 0,2007 & $-3,50$ & 10,62 & 0,2479 & 0,0939 \\
\hline 0,19 & 0,2134 & $-3,50$ & 9,78 & 0,2636 & 0,0999 \\
\hline 0,20 & 0,2263 & $-3,50$ & 9,02 & 0,2796 & 0,1059 \\
\hline 0,21 & 0,2395 & $-3,50$ & 8,33 & 0,2958 & 0,1121 \\
\hline 0,22 & 0,2529 & $-3,50$ & 7,71 & 0,3123 & 0,1183 \\
\hline 0,23 & 0,2665 & $-3,50$ & 7,13 & 0,3292 & 0,1247 \\
\hline 0,24 & 0,2804 & $-3,50$ & 6,60 & 0,3464 & 0,1312 \\
\hline 0,25 & 0,2946 & $-3,50$ & 6,12 & 0,3639 & 0,1379 \\
\hline 0,26 & 0,3091 & $-3,50$ & 5,67 & 0,3818 & 0,1447 \\
\hline 0,27 & 0,3239 & $-3,50$ & 5,25 & 0,4001 & 0,1516 \\
\hline 0,28 & 0,3391 & $-3,50$ & 4,86 & 0,4189 & 0,1587 \\
\hline 0,29 & 0,3546 & $-3,50$ & 4,49 & 0,4381 & 0,1660 \\
\hline 0,30 & 0,3706 & $-3,50$ & 4,15 & 0,4577 & 0,1734 \\
\hline 0,31 & 0,3869 & $-3,50$ & 3,82 & 0,4780 & 0,1811 \\
\hline 0,32 & 0,4038 & $-3,50$ & 3,52 & 0,4988 & 0,1890 \\
\hline 0,33 & 0,4211 & $-3,50$ & 3,23 & 0,5202 & 0,1971 \\
\hline 0,34 & 0,4391 & $-3,50$ & 2,95 & 0,5424 & 0,2055 \\
\hline 0,35 & 0,4576 & $-3,50$ & 2,69 & 0,5653 & 0,2142 \\
\hline 0,36 & 0,4768 & $-3,50$ & 2,44 & 0,5890 & 0,2232 \\
\hline 0,37 & 0,4968 & $-3,50$ & 2,20 & 0,6137 & 0,2325 \\
\hline
\end{tabular}


Tab. C.21 Bemessungstafel für Rechteckquerschnitte mit und ohne Druckbewehrung (Normalbeton C12/16 - C50/60 | Betonstahl B500 $\mid \varepsilon_{\mathrm{L}, \text { ges,zul }}=12,5 \%$ ) (http://doi.org/10.33968/9783966270021-09-T-21)

\begin{tabular}{|c|c|c|c|c|c|}
\hline$\mu_{\mathrm{Ed}, \mathrm{L}}$ & $\omega_{\llcorner}$ & $\varepsilon_{C R 2}$ & $\varepsilon_{\text {L,ges }}$ & $\xi_{\mathrm{L}}$ & $\max . d_{s 2} / h$ \\
\hline 0,01 & 0,0101 & $-0,54$ & 12,50 & 0,0413 & \multirow{9}{*}{ 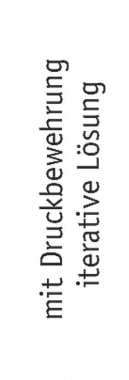 } \\
\hline 0,02 & 0,0204 & $-0,79$ & 12,50 & 0,0595 & \\
\hline 0,03 & 0,0308 & $-1,00$ & 12,50 & 0,0740 & \\
\hline 0,04 & 0,0413 & $-1,19$ & 12,50 & 0,0867 & \\
\hline 0,05 & 0,0518 & $-1,36$ & 12,50 & 0,0984 & \\
\hline 0,06 & 0,0625 & $-1,54$ & 12,50 & 0,1094 & \\
\hline 0,07 & 0,0732 & $-1,70$ & 12,50 & 0,1200 & \\
\hline 0,08 & 0,0841 & $-1,88$ & 12,50 & 0,1304 & \\
\hline 0,09 & 0,0950 & $-2,05$ & 12,50 & 0,1409 & \\
\hline 0,10 & 0,1061 & $-2,23$ & 12,50 & 0,1514 & 0,0038 \\
\hline 0,11 & 0,1174 & $-2,42$ & 12,50 & 0,1621 & 0,0164 \\
\hline 0,12 & 0,1288 & $-2,61$ & 12,50 & 0,1729 & 0,0290 \\
\hline 0,13 & 0,1403 & $-2,82$ & 12,50 & 0,1838 & 0,0419 \\
\hline 0,14 & 0,1520 & $-3,03$ & 12,50 & 0,1950 & 0,0549 \\
\hline 0,15 & 0,1639 & $-3,25$ & 12,50 & 0,2062 & 0,0682 \\
\hline 0,16 & 0,1759 & $-3,48$ & 12,50 & 0,2176 & 0,0816 \\
\hline 0,17 & 0,1882 & $-3,50$ & 11,55 & 0,2325 & 0,0881 \\
\hline 0,18 & 0,2007 & $-3,50$ & 10,62 & 0,2479 & 0,0939 \\
\hline 0,19 & 0,2134 & $-3,50$ & 9,78 & 0,2636 & 0,0999 \\
\hline 0,20 & 0,2263 & $-3,50$ & 9,02 & 0,2796 & 0,1059 \\
\hline 0,21 & 0,2395 & $-3,50$ & 8,33 & 0,2958 & 0,1121 \\
\hline 0,22 & 0,2529 & $-3,50$ & 7,71 & 0,3123 & 0,1183 \\
\hline 0,23 & 0,2665 & $-3,50$ & 7,13 & 0,3292 & 0,1247 \\
\hline 0,24 & 0,2804 & $-3,50$ & 6,60 & 0,3464 & 0,1312 \\
\hline 0,25 & 0,2946 & $-3,50$ & 6,12 & 0,3639 & 0,1379 \\
\hline 0,26 & 0,3091 & $-3,50$ & 5,67 & 0,3818 & 0,1447 \\
\hline 0,27 & 0,3239 & $-3,50$ & 5,25 & 0,4001 & 0,1516 \\
\hline 0,28 & 0,3391 & $-3,50$ & 4,86 & 0,4189 & 0,1587 \\
\hline 0,29 & 0,3546 & $-3,50$ & 4,49 & 0,4381 & 0,1660 \\
\hline 0,30 & 0,3706 & $-3,50$ & 4,15 & 0,4577 & 0,1734 \\
\hline 0,31 & 0,3869 & $-3,50$ & 3,82 & 0,4780 & 0,1811 \\
\hline 0,32 & 0,4038 & $-3,50$ & 3,52 & 0,4988 & 0,1890 \\
\hline 0,33 & 0,4211 & $-3,50$ & 3,23 & 0,5202 & 0,1971 \\
\hline 0,34 & 0,4391 & $-3,50$ & 2,95 & 0,5424 & 0,2055 \\
\hline 0,35 & 0,4576 & $-3,50$ & 2,69 & 0,5653 & 0,2142 \\
\hline 0,36 & 0,4768 & $-3,50$ & 2,44 & 0,5890 & 0,2232 \\
\hline 0,37 & 0,4968 & $-3,50$ & 2,20 & 0,6137 & 0,2325 \\
\hline
\end{tabular}


Tab. C.22 Bemessungstafel für Rechteckquerschnitte mit und ohne Druckbewehrung (Normalbeton C12/16 - C50/60 | Betonstahl B500 $\mid \varepsilon_{\mathrm{L}, \text { ges,zul }}=13 \%$ ) (http://doi.org/10.33968/9783966270021-09-T-22)

\begin{tabular}{|c|c|c|c|c|c|}
\hline$\mu_{\mathrm{Ed}, \mathrm{L}}$ & $\omega_{\mathrm{L}}$ & $\varepsilon_{c R 2}$ & $\varepsilon_{\text {L,ges }}$ & $\xi_{L}$ & $\max . \mathrm{d}_{\mathrm{s} 2} / \mathrm{h}$ \\
\hline 0,01 & 0,0101 & $-0,55$ & 13,00 & 0,0406 & \multirow{9}{*}{ 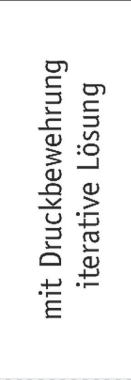 } \\
\hline 0,02 & 0,0204 & $-0,81$ & 13,00 & 0,0585 & \\
\hline 0,03 & 0,0308 & $-1,02$ & 13,00 & 0,0727 & \\
\hline 0,04 & 0,0412 & $-1,21$ & 13,00 & 0,0853 & \\
\hline 0,05 & 0,0518 & $-1,39$ & 13,00 & 0,0968 & \\
\hline 0,06 & 0,0624 & $-1,57$ & 13,00 & 0,1077 & \\
\hline 0,07 & 0,0732 & $-1,74$ & 13,00 & 0,1183 & \\
\hline 0,08 & 0,0840 & $-1,92$ & 13,00 & 0,1287 & \\
\hline 0,09 & 0,0950 & $-2,10$ & 13,00 & 0,1391 & \\
\hline 0,10 & 0,1061 & $-2,29$ & 13,00 & 0,1497 & 0,0075 \\
\hline 0,11 & 0,1173 & $-2,48$ & 13,00 & 0,1604 & 0,0200 \\
\hline 0,12 & 0,1287 & $-2,69$ & 13,00 & 0,1712 & 0,0327 \\
\hline 0,13 & 0,1403 & $-2,90$ & 13,00 & 0,1822 & 0,0455 \\
\hline 0,14 & 0,1520 & $-3,12$ & 13,00 & 0,1933 & 0,0585 \\
\hline 0,15 & 0,1638 & $-3,34$ & 13,00 & 0,2046 & 0,0716 \\
\hline 0,16 & 0,1759 & $-3,50$ & 12,61 & 0,2173 & 0,0823 \\
\hline 0,17 & 0,1882 & $-3,50$ & 11,55 & 0,2325 & 0,0881 \\
\hline 0,18 & 0,2007 & $-3,50$ & 10,62 & 0,2479 & 0,0939 \\
\hline 0,19 & 0,2134 & $-3,50$ & 9,78 & 0,2636 & 0,0999 \\
\hline 0,20 & 0,2263 & $-3,50$ & 9,02 & 0,2796 & 0,1059 \\
\hline 0,21 & 0,2395 & $-3,50$ & 8,33 & 0,2958 & 0,1121 \\
\hline 0,22 & 0,2529 & $-3,50$ & 7,71 & 0,3123 & 0,1183 \\
\hline 0,23 & 0,2665 & $-3,50$ & 7,13 & 0,3292 & 0,1247 \\
\hline 0,24 & 0,2804 & $-3,50$ & 6,60 & 0,3464 & 0,1312 \\
\hline 0,25 & 0,2946 & $-3,50$ & 6,12 & 0,3639 & 0,1379 \\
\hline 0,26 & 0,3091 & $-3,50$ & 5,67 & 0,3818 & 0,1447 \\
\hline 0,27 & 0,3239 & $-3,50$ & 5,25 & 0,4001 & 0,1516 \\
\hline 0,28 & 0,3391 & $-3,50$ & 4,86 & 0,4189 & 0,1587 \\
\hline 0,29 & 0,3546 & $-3,50$ & 4,49 & 0,4381 & 0,1660 \\
\hline 0,30 & 0,3706 & $-3,50$ & 4,15 & 0,4577 & 0,1734 \\
\hline 0,31 & 0,3869 & $-3,50$ & 3,82 & 0,4780 & 0,1811 \\
\hline 0,32 & 0,4038 & $-3,50$ & 3,52 & 0,4988 & 0,1890 \\
\hline 0,33 & 0,4211 & $-3,50$ & 3,23 & 0,5202 & 0,1971 \\
\hline 0,34 & 0,4391 & $-3,50$ & 2,95 & 0,5424 & 0,2055 \\
\hline 0,35 & 0,4576 & $-3,50$ & 2,69 & 0,5653 & 0,2142 \\
\hline 0,36 & 0,4768 & $-3,50$ & 2,44 & 0,5890 & 0,2232 \\
\hline 0,37 & 0,4968 & $-3,50$ & 2,20 & 0,6137 & 0,2325 \\
\hline
\end{tabular}


Tab. C.23 Bemessungstafel für Rechteckquerschnitte mit und ohne Druckbewehrung (Normalbeton C12/16 - C50/60 | Betonstahl B500 $\mid \varepsilon_{\mathrm{L}, \text { ges, zul }}=13,5 \%$ ) (http://doi.org/10.33968/9783966270021-09-T-23)

\begin{tabular}{|c|c|c|c|c|c|}
\hline$\mu_{\mathrm{Ed}, \mathrm{L}}$ & $\omega_{\mathrm{L}}$ & $\varepsilon_{C R 2}$ & $\varepsilon_{\mathrm{L}, \mathrm{ges}}$ & $\xi_{\mathrm{L}}$ & $\max . d_{s 2} / h$ \\
\hline 0,01 & 0,0101 & $-0,56$ & 13,50 & 0,0399 & \multirow{9}{*}{ 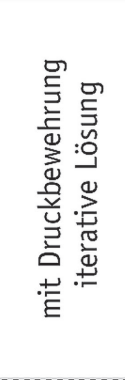 } \\
\hline 0,02 & 0,0204 & $-0,82$ & 13,50 & 0,0575 & \\
\hline 0,03 & 0,0308 & $-1,04$ & 13,50 & 0,0716 & \\
\hline 0,04 & 0,0412 & $-1,24$ & 13,50 & 0,0840 & \\
\hline 0,05 & 0,0518 & $-1,42$ & 13,50 & 0,0954 & \\
\hline 0,06 & 0,0624 & $-1,60$ & 13,50 & 0,1062 & \\
\hline 0,07 & 0,0731 & $-1,78$ & 13,50 & 0,1167 & \\
\hline 0,08 & 0,0840 & $-1,97$ & 13,50 & 0,1271 & \\
\hline 0,09 & 0,0950 & $-2,15$ & 13,50 & 0,1376 & \\
\hline 0,10 & 0,1061 & $-2,35$ & 13,50 & 0,1481 & 0,0110 \\
\hline 0,11 & 0,1173 & $-2,55$ & 13,50 & 0,1589 & 0,0234 \\
\hline 0,12 & 0,1287 & $-2,76$ & 13,50 & 0,1697 & 0,0360 \\
\hline 0,13 & 0,1402 & $-2,98$ & 13,50 & 0,1807 & 0,0488 \\
\hline 0,14 & 0,1519 & $-3,20$ & 13,50 & 0,1918 & 0,0617 \\
\hline 0,15 & 0,1638 & $-3,44$ & 13,50 & 0,2032 & 0,0748 \\
\hline 0,16 & 0,1759 & $-3,50$ & 12,61 & 0,2173 & 0,0823 \\
\hline 0,17 & 0,1882 & $-3,50$ & 11,55 & 0,2325 & 0,0881 \\
\hline 0,18 & 0,2007 & $-3,50$ & 10,62 & 0,2479 & 0,0939 \\
\hline 0,19 & 0,2134 & $-3,50$ & 9,78 & 0,2636 & 0,0999 \\
\hline 0,20 & 0,2263 & $-3,50$ & 9,02 & 0,2796 & 0,1059 \\
\hline 0,21 & 0,2395 & $-3,50$ & 8,33 & 0,2958 & 0,1121 \\
\hline 0,22 & 0,2529 & $-3,50$ & 7,71 & 0,3123 & 0,1183 \\
\hline 0,23 & 0,2665 & $-3,50$ & 7,13 & 0,3292 & 0,1247 \\
\hline 0,24 & 0,2804 & $-3,50$ & 6,60 & 0,3464 & 0,1312 \\
\hline 0,25 & 0,2946 & $-3,50$ & 6,12 & 0,3639 & 0,1379 \\
\hline 0,26 & 0,3091 & $-3,50$ & 5,67 & 0,3818 & 0,1447 \\
\hline 0,27 & 0,3239 & $-3,50$ & 5,25 & 0,4001 & 0,1516 \\
\hline 0,28 & 0,3391 & $-3,50$ & 4,86 & 0,4189 & 0,1587 \\
\hline 0,29 & 0,3546 & $-3,50$ & 4,49 & 0,4381 & 0,1660 \\
\hline 0,30 & 0,3706 & $-3,50$ & 4,15 & 0,4577 & 0,1734 \\
\hline 0,31 & 0,3869 & $-3,50$ & 3,82 & 0,4780 & 0,1811 \\
\hline 0,32 & 0,4038 & $-3,50$ & 3,52 & 0,4988 & 0,1890 \\
\hline 0,33 & 0,4211 & $-3,50$ & 3,23 & 0,5202 & 0,1971 \\
\hline 0,34 & 0,4391 & $-3,50$ & 2,95 & 0,5424 & 0,2055 \\
\hline 0,35 & 0,4576 & $-3,50$ & 2,69 & 0,5653 & 0,2142 \\
\hline 0,36 & 0,4768 & $-3,50$ & 2,44 & 0,5890 & 0,2232 \\
\hline 0,37 & 0,4968 & $-3,50$ & 2,20 & 0,6137 & 0,2325 \\
\hline
\end{tabular}


Tab. C.24 Bemessungstafel für Rechteckquerschnitte mit und ohne Druckbewehrung (Normalbeton C12/16 - C50/60 | Betonstahl B500 $\mid \varepsilon_{\mathrm{L}, \text { ges,zul }}=14 \%$ ) (http://doi.org/10.33968/9783966270021-09-T-24)

\begin{tabular}{|c|c|c|c|c|c|}
\hline$\mu_{\mathrm{Ed}, \mathrm{L}}$ & $\omega_{L}$ & $\varepsilon_{C R 2}$ & $\varepsilon_{\mathrm{L}, \mathrm{ges}}$ & $\xi_{\mathrm{L}}$ & $\max . \mathrm{d}_{\mathrm{s} 2} / \mathrm{h}$ \\
\hline 0,01 & 0,0101 & $-0,57$ & 14,00 & 0,0392 & \multirow{8}{*}{ 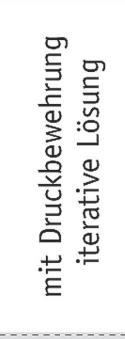 } \\
\hline 0,02 & 0,0204 & $-0,84$ & 14,00 & 0,0565 & \\
\hline 0,03 & 0,0308 & $-1,06$ & 14,00 & 0,0704 & \\
\hline 0,04 & 0,0412 & $-1,26$ & 14,00 & 0,0827 & \\
\hline 0,05 & 0,0518 & $-1,45$ & 14,00 & 0,0940 & \\
\hline 0,06 & 0,0624 & $-1,64$ & 14,00 & 0,1048 & \\
\hline 0,07 & 0,0731 & $-1,82$ & 14,00 & 0,1152 & \\
\hline 0,08 & 0,0840 & $-2,01$ & 14,00 & 0,1256 & \\
\hline 0,09 & 0,0949 & $-2,20$ & 14,00 & 0,1361 & 0,0019 \\
\hline 0,10 & 0,1060 & $-2,41$ & 14,00 & 0,1467 & 0,0142 \\
\hline 0,11 & 0,1173 & $-2,62$ & 14,00 & 0,1574 & 0,0266 \\
\hline 0,12 & 0,1287 & $-2,83$ & 14,00 & 0,1683 & 0,0391 \\
\hline 0,13 & 0,1402 & $-3,06$ & 14,00 & 0,1793 & 0,0519 \\
\hline 0,14 & 0,1519 & $-3,29$ & 14,00 & 0,1905 & 0,0648 \\
\hline 0,15 & 0,1638 & $-3,50$ & 13,80 & 0,2023 & 0,0767 \\
\hline 0,16 & 0,1759 & $-3,50$ & 12,61 & 0,2173 & 0,0823 \\
\hline 0,17 & 0,1882 & $-3,50$ & 11,55 & 0,2325 & 0,0881 \\
\hline 0,18 & 0,2007 & $-3,50$ & 10,62 & 0,2479 & 0,0939 \\
\hline 0,19 & 0,2134 & $-3,50$ & 9,78 & 0,2636 & 0,0999 \\
\hline 0,20 & 0,2263 & $-3,50$ & 9,02 & 0,2796 & 0,1059 \\
\hline 0,21 & 0,2395 & $-3,50$ & 8,33 & 0,2958 & 0,1121 \\
\hline 0,22 & 0,2529 & $-3,50$ & 7,71 & 0,3123 & 0,1183 \\
\hline 0,23 & 0,2665 & $-3,50$ & 7,13 & 0,3292 & 0,1247 \\
\hline 0,24 & 0,2804 & $-3,50$ & 6,60 & 0,3464 & 0,1312 \\
\hline 0,25 & 0,2946 & $-3,50$ & 6,12 & 0,3639 & 0,1379 \\
\hline 0,26 & 0,3091 & $-3,50$ & 5,67 & 0,3818 & 0,1447 \\
\hline 0,27 & 0,3239 & $-3,50$ & 5,25 & 0,4001 & 0,1516 \\
\hline 0,28 & 0,3391 & $-3,50$ & 4,86 & 0,4189 & 0,1587 \\
\hline 0,29 & 0,3546 & $-3,50$ & 4,49 & 0,4381 & 0,1660 \\
\hline 0,30 & 0,3706 & $-3,50$ & 4,15 & 0,4577 & 0,1734 \\
\hline 0,31 & 0,3869 & $-3,50$ & 3,82 & 0,4780 & 0,1811 \\
\hline 0,32 & 0,4038 & $-3,50$ & 3,52 & 0,4988 & 0,1890 \\
\hline 0,33 & 0,4211 & $-3,50$ & 3,23 & 0,5202 & 0,1971 \\
\hline 0,34 & 0,4391 & $-3,50$ & 2,95 & 0,5424 & 0,2055 \\
\hline 0,35 & 0,4576 & $-3,50$ & 2,69 & 0,5653 & 0,2142 \\
\hline 0,36 & 0,4768 & $-3,50$ & 2,44 & 0,5890 & 0,2232 \\
\hline 0,37 & 0,4968 & $-3,50$ & 2,20 & 0,6137 & 0,2325 \\
\hline
\end{tabular}


Tab. C.25 Bemessungstafel für Rechteckquerschnitte mit und ohne Druckbewehrung (Normalbeton C12/16 - C50/60 | Betonstahl B500 $\mid \varepsilon_{\mathrm{L}, \text { ges, zul }}=14,5 \%$ ) (http://doi.org/10.33968/9783966270021-09-T-25)

\begin{tabular}{|c|c|c|c|c|c|}
\hline$\mu_{\mathrm{Ed}, \mathrm{L}}$ & $\omega_{\llcorner}$ & $\varepsilon_{c R 2}$ & $\varepsilon_{\mathrm{L}, \text { ges }}$ & $\xi_{L}$ & $\max . d_{s 2} / h$ \\
\hline 0,01 & 0,0101 & $-0,58$ & 14,50 & 0,0386 & \multirow{8}{*}{ 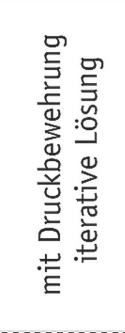 } \\
\hline 0,02 & 0,0204 & $-0,85$ & 14,50 & 0,0557 & \\
\hline 0,03 & 0,0308 & $-1,08$ & 14,50 & 0,0694 & \\
\hline 0,04 & 0,0412 & $-1,29$ & 14,50 & 0,0815 & \\
\hline 0,05 & 0,0517 & $-1,48$ & 14,50 & 0,0927 & \\
\hline 0,06 & 0,0624 & $-1,67$ & 14,50 & 0,1034 & \\
\hline 0,07 & 0,0731 & $-1,86$ & 14,50 & 0,1138 & \\
\hline 0,08 & 0,0839 & $-2,06$ & 14,50 & 0,1242 & \\
\hline 0,09 & 0,0949 & $-2,26$ & 14,50 & 0,1347 & 0,0050 \\
\hline 0,10 & 0,1060 & $-2,47$ & 14,50 & 0,1453 & 0,0172 \\
\hline 0,11 & 0,1173 & $-2,68$ & 14,50 & 0,1561 & 0,0295 \\
\hline 0,12 & 0,1286 & $-2,91$ & 14,50 & 0,1669 & 0,0420 \\
\hline 0,13 & 0,1402 & $-3,14$ & 14,50 & 0,1780 & 0,0547 \\
\hline 0,14 & 0,1519 & $-3,38$ & 14,50 & 0,1892 & 0,0676 \\
\hline 0,15 & 0,1638 & $-3,50$ & 13,80 & 0,2023 & 0,0767 \\
\hline 0,16 & 0,1759 & $-3,50$ & 12,61 & 0,2173 & 0,0823 \\
\hline 0,17 & 0,1882 & $-3,50$ & 11,55 & 0,2325 & 0,0881 \\
\hline 0,18 & 0,2007 & $-3,50$ & 10,62 & 0,2479 & 0,0939 \\
\hline 0,19 & 0,2134 & $-3,50$ & 9,78 & 0,2636 & 0,0999 \\
\hline 0,20 & 0,2263 & $-3,50$ & 9,02 & 0,2796 & 0,1059 \\
\hline 0,21 & 0,2395 & $-3,50$ & 8,33 & 0,2958 & 0,1121 \\
\hline 0,22 & 0,2529 & $-3,50$ & 7,71 & 0,3123 & 0,1183 \\
\hline 0,23 & 0,2665 & $-3,50$ & 7,13 & 0,3292 & 0,1247 \\
\hline 0,24 & 0,2804 & $-3,50$ & 6,60 & 0,3464 & 0,1312 \\
\hline 0,25 & 0,2946 & $-3,50$ & 6,12 & 0,3639 & 0,1379 \\
\hline 0,26 & 0,3091 & $-3,50$ & 5,67 & 0,3818 & 0,1447 \\
\hline 0,27 & 0,3239 & $-3,50$ & 5,25 & 0,4001 & 0,1516 \\
\hline 0,28 & 0,3391 & $-3,50$ & 4,86 & 0,4189 & 0,1587 \\
\hline 0,29 & 0,3546 & $-3,50$ & 4,49 & 0,4381 & 0,1660 \\
\hline 0,30 & 0,3706 & $-3,50$ & 4,15 & 0,4577 & 0,1734 \\
\hline 0,31 & 0,3869 & $-3,50$ & 3,82 & 0,4780 & 0,1811 \\
\hline 0,32 & 0,4038 & $-3,50$ & 3,52 & 0,4988 & 0,1890 \\
\hline 0,33 & 0,4211 & $-3,50$ & 3,23 & 0,5202 & 0,1971 \\
\hline 0,34 & 0,4391 & $-3,50$ & 2,95 & 0,5424 & 0,2055 \\
\hline 0,35 & 0,4576 & $-3,50$ & 2,69 & 0,5653 & 0,2142 \\
\hline 0,36 & 0,4768 & $-3,50$ & 2,44 & 0,5890 & 0,2232 \\
\hline 0,37 & 0,4968 & $-3,50$ & 2,20 & 0,6137 & 0,2325 \\
\hline
\end{tabular}


Tab. C.26 Bemessungstafel für Rechteckquerschnitte mit und ohne Druckbewehrung (Normalbeton C12/16 - C50/60 | Betonstahl B500 $\mid \varepsilon_{\mathrm{L}, \text { ges,zul }}=15 \%$ ) (http://doi.org/10.33968/9783966270021-09-T-26)

\begin{tabular}{|c|c|c|c|c|c|}
\hline$\mu_{\mathrm{Ed}, \mathrm{L}}$ & $\omega_{\mathrm{L}}$ & $\varepsilon_{c R 2}$ & $\varepsilon_{\text {L,ges }}$ & $\xi_{L}$ & $\max . \mathrm{d}_{\mathrm{s} 2} / \mathrm{h}$ \\
\hline 0,01 & 0,0101 & $-0,59$ & 15,00 & 0,0380 & \multirow{8}{*}{ 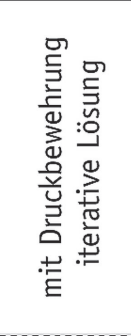 } \\
\hline 0,02 & 0,0204 & $-0,87$ & 15,00 & 0,0548 & \\
\hline 0,03 & 0,0307 & $-1,10$ & 15,00 & 0,0684 & \\
\hline 0,04 & 0,0412 & $-1,31$ & 15,00 & 0,0804 & \\
\hline 0,05 & 0,0517 & $-1,51$ & 15,00 & 0,0915 & \\
\hline 0,06 & 0,0623 & $-1,71$ & 15,00 & 0,1021 & \\
\hline 0,07 & 0,0731 & $-1,90$ & 15,00 & 0,1125 & \\
\hline 0,08 & 0,0839 & $-2,10$ & 15,00 & 0,1229 & \\
\hline 0,09 & 0,0949 & $-2,31$ & 15,00 & 0,1334 & 0,0078 \\
\hline 0,10 & 0,1060 & $-2,52$ & 15,00 & 0,1440 & 0,0200 \\
\hline 0,11 & 0,1172 & $-2,75$ & 15,00 & 0,1548 & 0,0323 \\
\hline 0,12 & 0,1286 & $-2,98$ & 15,00 & 0,1657 & 0,0448 \\
\hline 0,13 & 0,1402 & $-3,22$ & 15,00 & 0,1767 & 0,0574 \\
\hline 0,14 & 0,1519 & $-3,47$ & 15,00 & 0,1879 & 0,0703 \\
\hline 0,15 & 0,1638 & $-3,50$ & 13,80 & 0,2023 & 0,0767 \\
\hline 0,16 & 0,1759 & $-3,50$ & 12,61 & 0,2173 & 0,0823 \\
\hline 0,17 & 0,1882 & $-3,50$ & 11,55 & 0,2325 & 0,0881 \\
\hline 0,18 & 0,2007 & $-3,50$ & 10,62 & 0,2479 & 0,0939 \\
\hline 0,19 & 0,2134 & $-3,50$ & 9,78 & 0,2636 & 0,0999 \\
\hline 0,20 & 0,2263 & $-3,50$ & 9,02 & 0,2796 & 0,1059 \\
\hline 0,21 & 0,2395 & $-3,50$ & 8,33 & 0,2958 & 0,1121 \\
\hline 0,22 & 0,2529 & $-3,50$ & 7,71 & 0,3123 & 0,1183 \\
\hline 0,23 & 0,2665 & $-3,50$ & 7,13 & 0,3292 & 0,1247 \\
\hline 0,24 & 0,2804 & $-3,50$ & 6,60 & 0,3464 & 0,1312 \\
\hline 0,25 & 0,2946 & $-3,50$ & 6,12 & 0,3639 & 0,1379 \\
\hline 0,26 & 0,3091 & $-3,50$ & 5,67 & 0,3818 & 0,1447 \\
\hline 0,27 & 0,3239 & $-3,50$ & 5,25 & 0,4001 & 0,1516 \\
\hline 0,28 & 0,3391 & $-3,50$ & 4,86 & 0,4189 & 0,1587 \\
\hline 0,29 & 0,3546 & $-3,50$ & 4,49 & 0,4381 & 0,1660 \\
\hline 0,30 & 0,3706 & $-3,50$ & 4,15 & 0,4577 & 0,1734 \\
\hline 0,31 & 0,3869 & $-3,50$ & 3,82 & 0,4780 & 0,1811 \\
\hline 0,32 & 0,4038 & $-3,50$ & 3,52 & 0,4988 & 0,1890 \\
\hline 0,33 & 0,4211 & $-3,50$ & 3,23 & 0,5202 & 0,1971 \\
\hline 0,34 & 0,4391 & $-3,50$ & 2,95 & 0,5424 & 0,2055 \\
\hline 0,35 & 0,4576 & $-3,50$ & 2,69 & 0,5653 & 0,2142 \\
\hline 0,36 & 0,4768 & $-3,50$ & 2,44 & 0,5890 & 0,2232 \\
\hline 0,37 & 0,4968 & $-3,50$ & 2,20 & 0,6137 & 0,2325 \\
\hline
\end{tabular}


Tab. C.27 Bemessungstafel für Rechteckquerschnitte mit und ohne Druckbewehrung (Normalbeton C12/16 - C50/60 | Betonstahl B500 $\mid \varepsilon_{\mathrm{L}, \text { ges, zul }}=15,5 \%$ ) (http://doi.org/10.33968/9783966270021-09-T-27)

\begin{tabular}{|c|c|c|c|c|c|}
\hline$\mu_{\mathrm{Ed}, \mathrm{L}}$ & $\omega\llcorner$ & $\varepsilon_{C R 2}$ & $\varepsilon_{\mathrm{L}, \mathrm{ges}}$ & $\xi_{L}$ & $\max . \mathrm{d}_{\mathrm{s} 2} / \mathrm{h}$ \\
\hline 0,01 & 0,0101 & $-0,60$ & 15,50 & 0,0374 & \multirow{8}{*}{ 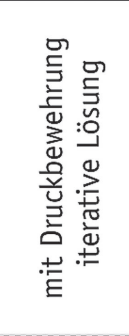 } \\
\hline 0,02 & 0,0204 & $-0,89$ & 15,50 & 0,0540 & \\
\hline 0,03 & 0,0307 & $-1,12$ & 15,50 & 0,0674 & \\
\hline 0,04 & 0,0412 & $-1,34$ & 15,50 & 0,0793 & \\
\hline 0,05 & 0,0517 & $-1,54$ & 15,50 & 0,0903 & \\
\hline 0,06 & 0,0623 & $-1,74$ & 15,50 & 0,1009 & \\
\hline 0,07 & 0,0730 & $-1,94$ & 15,50 & 0,1113 & \\
\hline 0,08 & 0,0839 & $-2,15$ & 15,50 & 0,1217 & \\
\hline 0,09 & 0,0948 & $-2,36$ & 15,50 & 0,1322 & 0,0105 \\
\hline 0,10 & 0,1060 & $-2,58$ & 15,50 & 0,1428 & 0,0226 \\
\hline 0,11 & 0,1172 & $-2,81$ & 15,50 & 0,1536 & 0,0349 \\
\hline 0,12 & 0,1286 & $-3,05$ & 15,50 & 0,1645 & 0,0473 \\
\hline 0,13 & 0,1401 & $-3,30$ & 15,50 & 0,1756 & 0,0600 \\
\hline 0,14 & 0,1518 & $-3,50$ & 15,16 & 0,1876 & 0,0711 \\
\hline 0,15 & 0,1638 & $-3,50$ & 13,80 & 0,2023 & 0,0767 \\
\hline 0,16 & 0,1759 & $-3,50$ & 12,61 & 0,2173 & 0,0823 \\
\hline 0,17 & 0,1882 & $-3,50$ & 11,55 & 0,2325 & 0,0881 \\
\hline 0,18 & 0,2007 & $-3,50$ & 10,62 & 0,2479 & 0,0939 \\
\hline 0,19 & 0,2134 & $-3,50$ & 9,78 & 0,2636 & 0,0999 \\
\hline 0,20 & 0,2263 & $-3,50$ & 9,02 & 0,2796 & 0,1059 \\
\hline 0,21 & 0,2395 & $-3,50$ & 8,33 & 0,2958 & 0,1121 \\
\hline 0,22 & 0,2529 & $-3,50$ & 7,71 & 0,3123 & 0,1183 \\
\hline 0,23 & 0,2665 & $-3,50$ & 7,13 & 0,3292 & 0,1247 \\
\hline 0,24 & 0,2804 & $-3,50$ & 6,60 & 0,3464 & 0,1312 \\
\hline 0,25 & 0,2946 & $-3,50$ & 6,12 & 0,3639 & 0,1379 \\
\hline 0,26 & 0,3091 & $-3,50$ & 5,67 & 0,3818 & 0,1447 \\
\hline 0,27 & 0,3239 & $-3,50$ & 5,25 & 0,4001 & 0,1516 \\
\hline 0,28 & 0,3391 & $-3,50$ & 4,86 & 0,4189 & 0,1587 \\
\hline 0,29 & 0,3546 & $-3,50$ & 4,49 & 0,4381 & 0,1660 \\
\hline 0,30 & 0,3706 & $-3,50$ & 4,15 & 0,4577 & 0,1734 \\
\hline 0,31 & 0,3869 & $-3,50$ & 3,82 & 0,4780 & 0,1811 \\
\hline 0,32 & 0,4038 & $-3,50$ & 3,52 & 0,4988 & 0,1890 \\
\hline 0,33 & 0,4211 & $-3,50$ & 3,23 & 0,5202 & 0,1971 \\
\hline 0,34 & 0,4391 & $-3,50$ & 2,95 & 0,5424 & 0,2055 \\
\hline 0,35 & 0,4576 & $-3,50$ & 2,69 & 0,5653 & 0,2142 \\
\hline 0,36 & 0,4768 & $-3,50$ & 2,44 & 0,5890 & 0,2232 \\
\hline 0,37 & 0,4968 & $-3,50$ & 2,20 & 0,6137 & 0,2325 \\
\hline
\end{tabular}


Tab. C.28 Bemessungstafel für Rechteckquerschnitte mit und ohne Druckbewehrung (Normalbeton C12/16 - C50/60 | Betonstahl B500 $\mid \varepsilon_{\mathrm{L}, \text { ges,zul }}=16 \%$ ) (http://doi.org/10.33968/9783966270021-09-T-28)

\begin{tabular}{|c|c|c|c|c|c|}
\hline$\mu_{\mathrm{Ed}, \mathrm{L}}$ & $\omega_{\mathrm{L}}$ & $\varepsilon_{\mathrm{CR} 2}$ & $\varepsilon$ L,ges & $\xi_{\mathrm{L}}$ & $\max . \mathrm{d}_{\mathrm{s} 2} / \mathrm{h}$ \\
\hline 0,01 & 0,0101 & $-0,61$ & 16,00 & 0,0368 & \multirow{7}{*}{ 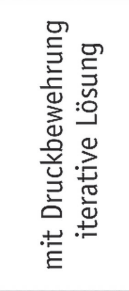 } \\
\hline 0,02 & 0,0204 & $-0,90$ & 16,00 & 0,0533 & \\
\hline 0,03 & 0,0307 & $-1,14$ & 16,00 & 0,0665 & \\
\hline 0,04 & 0,0412 & $-1,36$ & 16,00 & 0,0783 & \\
\hline 0,05 & 0,0517 & $-1,57$ & 16,00 & 0,0892 & \\
\hline 0,06 & 0,0623 & $-1,77$ & 16,00 & 0,0997 & \\
\hline 0,07 & 0,0730 & $-1,98$ & 16,00 & 0,1101 & \\
\hline 0,08 & 0,0839 & $-2,19$ & 16,00 & 0,1205 & 0,0010 \\
\hline 0,09 & 0,0948 & $-2,41$ & 16,00 & 0,1310 & 0,0130 \\
\hline 0,10 & 0,1059 & $-2,64$ & 16,00 & 0,1417 & 0,0251 \\
\hline 0,11 & 0,1172 & $-2,88$ & 16,00 & 0,1525 & 0,0373 \\
\hline 0,12 & 0,1286 & $-3,13$ & 16,00 & 0,1634 & 0,0498 \\
\hline 0,13 & 0,1401 & $-3,38$ & 16,00 & 0,1745 & 0,0623 \\
\hline 0,14 & 0,1518 & $-3,50$ & 15,16 & 0,1876 & 0,0711 \\
\hline 0,15 & 0,1638 & $-3,50$ & 13,80 & 0,2023 & 0,0767 \\
\hline 0,16 & 0,1759 & $-3,50$ & 12,61 & 0,2173 & 0,0823 \\
\hline 0,17 & 0,1882 & $-3,50$ & 11,55 & 0,2325 & 0,0881 \\
\hline 0,18 & 0,2007 & $-3,50$ & 10,62 & 0,2479 & 0,0939 \\
\hline 0,19 & 0,2134 & $-3,50$ & 9,78 & 0,2636 & 0,0999 \\
\hline 0,20 & 0,2263 & $-3,50$ & 9,02 & 0,2796 & 0,1059 \\
\hline 0,21 & 0,2395 & $-3,50$ & 8,33 & 0,2958 & 0,1121 \\
\hline 0,22 & 0,2529 & $-3,50$ & 7,71 & 0,3123 & 0,1183 \\
\hline 0,23 & 0,2665 & $-3,50$ & 7,13 & 0,3292 & 0,1247 \\
\hline 0,24 & 0,2804 & $-3,50$ & 6,60 & 0,3464 & 0,1312 \\
\hline 0,25 & 0,2946 & $-3,50$ & 6,12 & 0,3639 & 0,1379 \\
\hline 0,26 & 0,3091 & $-3,50$ & 5,67 & 0,3818 & 0,1447 \\
\hline 0,27 & 0,3239 & $-3,50$ & 5,25 & 0,4001 & 0,1516 \\
\hline 0,28 & 0,3391 & $-3,50$ & 4,86 & 0,4189 & 0,1587 \\
\hline 0,29 & 0,3546 & $-3,50$ & 4,49 & 0,4381 & 0,1660 \\
\hline 0,30 & 0,3706 & $-3,50$ & 4,15 & 0,4577 & 0,1734 \\
\hline 0,31 & 0,3869 & $-3,50$ & 3,82 & 0,4780 & 0,1811 \\
\hline 0,32 & 0,4038 & $-3,50$ & 3,52 & 0,4988 & 0,1890 \\
\hline 0,33 & 0,4211 & $-3,50$ & 3,23 & 0,5202 & 0,1971 \\
\hline 0,34 & 0,4391 & $-3,50$ & 2,95 & 0,5424 & 0,2055 \\
\hline 0,35 & 0,4576 & $-3,50$ & 2,69 & 0,5653 & 0,2142 \\
\hline 0,36 & 0,4768 & $-3,50$ & 2,44 & 0,5890 & 0,2232 \\
\hline 0,37 & 0,4968 & $-3,50$ & 2,20 & 0,6137 & 0,2325 \\
\hline
\end{tabular}


Tab. C.29 Bemessungstafel für Rechteckquerschnitte mit und ohne Druckbewehrung (Normalbeton C12/16 - C50/60 | Betonstahl B500 $\mid \varepsilon_{\mathrm{L}, \text { ges, zul }}=16,5 \%$ ) (http://doi.org/10.33968/9783966270021-09-T-29)

\begin{tabular}{|c|c|c|c|c|c|}
\hline$\mu_{\mathrm{Ed}, \mathrm{L}}$ & $\omega\llcorner$ & $\varepsilon_{c R 2}$ & $\varepsilon_{\mathrm{L}, \text { ges }}$ & $\xi_{L}$ & $\max . \mathrm{d}_{\mathrm{s} 2} / \mathrm{h}$ \\
\hline 0,01 & 0,0101 & $-0,62$ & 16,50 & 0,0363 & \multirow{7}{*}{ 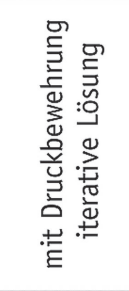 } \\
\hline 0,02 & 0,0204 & $-0,92$ & 16,50 & 0,0525 & \\
\hline 0,03 & 0,0307 & $-1,16$ & 16,50 & 0,0657 & \\
\hline 0,04 & 0,0411 & $-1,38$ & 16,50 & 0,0773 & \\
\hline 0,05 & 0,0517 & $-1,60$ & 16,50 & 0,0882 & \\
\hline 0,06 & 0,0623 & $-1,81$ & 16,50 & 0,0987 & \\
\hline 0,07 & 0,0730 & $-2,02$ & 16,50 & 0,1090 & \\
\hline 0,08 & 0,0838 & $-2,24$ & 16,50 & 0,1194 & 0,0034 \\
\hline 0,09 & 0,0948 & $-2,46$ & 16,50 & 0,1300 & 0,0153 \\
\hline 0,10 & 0,1059 & $-2,70$ & 16,50 & 0,1406 & 0,0274 \\
\hline 0,11 & 0,1172 & $-2,94$ & 16,50 & 0,1514 & 0,0396 \\
\hline 0,12 & 0,1285 & $-3,20$ & 16,50 & 0,1624 & 0,0520 \\
\hline 0,13 & 0,1401 & $-3,46$ & 16,50 & 0,1735 & 0,0646 \\
\hline 0,14 & 0,1518 & $-3,50$ & 15,16 & 0,1876 & 0,0711 \\
\hline 0,15 & 0,1638 & $-3,50$ & 13,80 & 0,2023 & 0,0767 \\
\hline 0,16 & 0,1759 & $-3,50$ & 12,61 & 0,2173 & 0,0823 \\
\hline 0,17 & 0,1882 & $-3,50$ & 11,55 & 0,2325 & 0,0881 \\
\hline 0,18 & 0,2007 & $-3,50$ & 10,62 & 0,2479 & 0,0939 \\
\hline 0,19 & 0,2134 & $-3,50$ & 9,78 & 0,2636 & 0,0999 \\
\hline 0,20 & 0,2263 & $-3,50$ & 9,02 & 0,2796 & 0,1059 \\
\hline 0,21 & 0,2395 & $-3,50$ & 8,33 & 0,2958 & 0,1121 \\
\hline 0,22 & 0,2529 & $-3,50$ & 7,71 & 0,3123 & 0,1183 \\
\hline 0,23 & 0,2665 & $-3,50$ & 7,13 & 0,3292 & 0,1247 \\
\hline 0,24 & 0,2804 & $-3,50$ & 6,60 & 0,3464 & 0,1312 \\
\hline 0,25 & 0,2946 & $-3,50$ & 6,12 & 0,3639 & 0,1379 \\
\hline 0,26 & 0,3091 & $-3,50$ & 5,67 & 0,3818 & 0,1447 \\
\hline 0,27 & 0,3239 & $-3,50$ & 5,25 & 0,4001 & 0,1516 \\
\hline 0,28 & 0,3391 & $-3,50$ & 4,86 & 0,4189 & 0,1587 \\
\hline 0,29 & 0,3546 & $-3,50$ & 4,49 & 0,4381 & 0,1660 \\
\hline 0,30 & 0,3706 & $-3,50$ & 4,15 & 0,4577 & 0,1734 \\
\hline 0,31 & 0,3869 & $-3,50$ & 3,82 & 0,4780 & 0,1811 \\
\hline 0,32 & 0,4038 & $-3,50$ & 3,52 & 0,4988 & 0,1890 \\
\hline 0,33 & 0,4211 & $-3,50$ & 3,23 & 0,5202 & 0,1971 \\
\hline 0,34 & 0,4391 & $-3,50$ & 2,95 & 0,5424 & 0,2055 \\
\hline 0,35 & 0,4576 & $-3,50$ & 2,69 & 0,5653 & 0,2142 \\
\hline 0,36 & 0,4768 & $-3,50$ & 2,44 & 0,5890 & 0,2232 \\
\hline 0,37 & 0,4968 & $-3,50$ & 2,20 & 0,6137 & 0,2325 \\
\hline
\end{tabular}


Tab. C.30 Bemessungstafel für Rechteckquerschnitte mit und ohne Druckbewehrung (Normalbeton C12/16 - C50/60 | Betonstahl B500 | $\varepsilon_{\mathrm{L}, \text { ges,zul }}=17 \%$ )

(http://doi.org/10.33968/9783966270021-09-T-30)

\begin{tabular}{|c|c|c|c|c|c|}
\hline$\mu_{\mathrm{Ed}, \mathrm{L}}$ & $\omega_{\llcorner}$ & $\varepsilon_{C R 2}$ & $\varepsilon_{L, \text { ges }}$ & $\xi_{\mathrm{L}}$ & $\max . \mathrm{d}_{\mathrm{s} 2} / \mathrm{h}$ \\
\hline 0,01 & 0,0101 & $-0,63$ & 17,00 & 0,0358 & \multirow{7}{*}{ 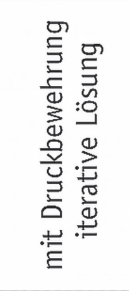 } \\
\hline 0,02 & 0,0204 & $-0,93$ & 17,00 & 0,0519 & \\
\hline 0,03 & 0,0307 & $-1,18$ & 17,00 & 0,0648 & \\
\hline 0,04 & 0,0411 & $-1,41$ & 17,00 & 0,0764 & \\
\hline 0,05 & 0,0516 & $-1,62$ & 17,00 & 0,0872 & \\
\hline 0,06 & 0,0622 & $-1,84$ & 17,00 & 0,0976 & \\
\hline 0,07 & 0,0730 & $-2,06$ & 17,00 & 0,1080 & \\
\hline 0,08 & 0,0838 & $-2,28$ & 17,00 & 0,1184 & 0,0056 \\
\hline 0,09 & 0,0948 & $-2,52$ & 17,00 & 0,1289 & 0,0176 \\
\hline 0,10 & 0,1059 & $-2,76$ & 17,00 & 0,1396 & 0,0296 \\
\hline 0,11 & 0,1171 & $-3,01$ & 17,00 & 0,1505 & 0,0418 \\
\hline 0,12 & 0,1285 & $-3,27$ & 17,00 & 0,1614 & 0,0542 \\
\hline 0,13 & 0,1401 & $-3,50$ & 16,73 & 0,1730 & 0,0656 \\
\hline 0,14 & 0,1518 & $-3,50$ & 15,16 & 0,1876 & 0,0711 \\
\hline 0,15 & 0,1638 & $-3,50$ & 13,80 & 0,2023 & 0,0767 \\
\hline 0,16 & 0,1759 & $-3,50$ & 12,61 & 0,2173 & 0,0823 \\
\hline 0,17 & 0,1882 & $-3,50$ & 11,55 & 0,2325 & 0,0881 \\
\hline 0,18 & 0,2007 & $-3,50$ & 10,62 & 0,2479 & 0,0939 \\
\hline 0,19 & 0,2134 & $-3,50$ & 9,78 & 0,2636 & 0,0999 \\
\hline 0,20 & 0,2263 & $-3,50$ & 9,02 & 0,2796 & 0,1059 \\
\hline 0,21 & 0,2395 & $-3,50$ & 8,33 & 0,2958 & 0,1121 \\
\hline 0,22 & 0,2529 & $-3,50$ & 7,71 & 0,3123 & 0,1183 \\
\hline 0,23 & 0,2665 & $-3,50$ & 7,13 & 0,3292 & 0,1247 \\
\hline 0,24 & 0,2804 & $-3,50$ & 6,60 & 0,3464 & 0,1312 \\
\hline 0,25 & 0,2946 & $-3,50$ & 6,12 & 0,3639 & 0,1379 \\
\hline 0,26 & 0,3091 & $-3,50$ & 5,67 & 0,3818 & 0,1447 \\
\hline 0,27 & 0,3239 & $-3,50$ & 5,25 & 0,4001 & 0,1516 \\
\hline 0,28 & 0,3391 & $-3,50$ & 4,86 & 0,4189 & 0,1587 \\
\hline 0,29 & 0,3546 & $-3,50$ & 4,49 & 0,4381 & 0,1660 \\
\hline 0,30 & 0,3706 & $-3,50$ & 4,15 & 0,4577 & 0,1734 \\
\hline 0,31 & 0,3869 & $-3,50$ & 3,82 & 0,4780 & 0,1811 \\
\hline 0,32 & 0,4038 & $-3,50$ & 3,52 & 0,4988 & 0,1890 \\
\hline 0,33 & 0,4211 & $-3,50$ & 3,23 & 0,5202 & 0,1971 \\
\hline 0,34 & 0,4391 & $-3,50$ & 2,95 & 0,5424 & 0,2055 \\
\hline 0,35 & 0,4576 & $-3,50$ & 2,69 & 0,5653 & 0,2142 \\
\hline 0,36 & 0,4768 & $-3,50$ & 2,44 & 0,5890 & 0,2232 \\
\hline 0,37 & 0,4968 & $-3,50$ & 2,20 & 0,6137 & 0,2325 \\
\hline
\end{tabular}


Tab. C.31 Bemessungstafel für Rechteckquerschnitte mit und ohne Druckbewehrung (Normalbeton C12/16 - C50/60 | Betonstahl B500 $\mid \varepsilon_{\mathrm{L}, \text { ges,zul }}=17,5 \%$ ) (http://doi.org/10.33968/9783966270021-09-T-31)

\begin{tabular}{|c|c|c|c|c|c|}
\hline$\mu_{\mathrm{Ed}, \mathrm{L}}$ & $\omega_{\llcorner}$ & $\varepsilon_{C R 2}$ & $\varepsilon_{\mathrm{L}, \mathrm{ges}}$ & $\xi_{\mathrm{L}}$ & $\max . d_{s 2} / h$ \\
\hline 0,01 & 0,0101 & $-0,64$ & 17,50 & 0,0353 & \multirow{7}{*}{ 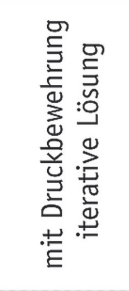 } \\
\hline 0,02 & 0,0204 & $-0,94$ & 17,50 & 0,0512 & \\
\hline 0,03 & 0,0307 & $-1,20$ & 17,50 & 0,0640 & \\
\hline 0,04 & 0,0411 & $-1,43$ & 17,50 & 0,0755 & \\
\hline 0,05 & 0,0516 & $-1,65$ & 17,50 & 0,0863 & \\
\hline 0,06 & 0,0622 & $-1,87$ & 17,50 & 0,0966 & \\
\hline 0,07 & 0,0730 & $-2,10$ & 17,50 & 0,1070 & \\
\hline 0,08 & 0,0838 & $-2,33$ & 17,50 & 0,1174 & 0,0078 \\
\hline 0,09 & 0,0948 & $-2,57$ & 17,50 & 0,1280 & 0,0197 \\
\hline 0,10 & 0,1059 & $-2,82$ & 17,50 & 0,1387 & 0,0317 \\
\hline 0,11 & 0,1171 & $-3,08$ & 17,50 & 0,1495 & 0,0439 \\
\hline 0,12 & 0,1285 & $-3,35$ & 17,50 & 0,1605 & 0,0562 \\
\hline 0,13 & 0,1401 & $-3,50$ & 16,73 & 0,1730 & 0,0656 \\
\hline 0,14 & 0,1518 & $-3,50$ & 15,16 & 0,1876 & 0,0711 \\
\hline 0,15 & 0,1638 & $-3,50$ & 13,80 & 0,2023 & 0,0767 \\
\hline 0,16 & 0,1759 & $-3,50$ & 12,61 & 0,2173 & 0,0823 \\
\hline 0,17 & 0,1882 & $-3,50$ & 11,55 & 0,2325 & 0,0881 \\
\hline 0,18 & 0,2007 & $-3,50$ & 10,62 & 0,2479 & 0,0939 \\
\hline 0,19 & 0,2134 & $-3,50$ & 9,78 & 0,2636 & 0,0999 \\
\hline 0,20 & 0,2263 & $-3,50$ & 9,02 & 0,2796 & 0,1059 \\
\hline 0,21 & 0,2395 & $-3,50$ & 8,33 & 0,2958 & 0,1121 \\
\hline 0,22 & 0,2529 & $-3,50$ & 7,71 & 0,3123 & 0,1183 \\
\hline 0,23 & 0,2665 & $-3,50$ & 7,13 & 0,3292 & 0,1247 \\
\hline 0,24 & 0,2804 & $-3,50$ & 6,60 & 0,3464 & 0,1312 \\
\hline 0,25 & 0,2946 & $-3,50$ & 6,12 & 0,3639 & 0,1379 \\
\hline 0,26 & 0,3091 & $-3,50$ & 5,67 & 0,3818 & 0,1447 \\
\hline 0,27 & 0,3239 & $-3,50$ & 5,25 & 0,4001 & 0,1516 \\
\hline 0,28 & 0,3391 & $-3,50$ & 4,86 & 0,4189 & 0,1587 \\
\hline 0,29 & 0,3546 & $-3,50$ & 4,49 & 0,4381 & 0,1660 \\
\hline 0,30 & 0,3706 & $-3,50$ & 4,15 & 0,4577 & 0,1734 \\
\hline 0,31 & 0,3869 & $-3,50$ & 3,82 & 0,4780 & 0,1811 \\
\hline 0,32 & 0,4038 & $-3,50$ & 3,52 & 0,4988 & 0,1890 \\
\hline 0,33 & 0,4211 & $-3,50$ & 3,23 & 0,5202 & 0,1971 \\
\hline 0,34 & 0,4391 & $-3,50$ & 2,95 & 0,5424 & 0,2055 \\
\hline 0,35 & 0,4576 & $-3,50$ & 2,69 & 0,5653 & 0,2142 \\
\hline 0,36 & 0,4768 & $-3,50$ & 2,44 & 0,5890 & 0,2232 \\
\hline 0,37 & 0,4968 & $-3,50$ & 2,20 & 0,6137 & 0,2325 \\
\hline
\end{tabular}


Tab. C.32 Bemessungstafel für Rechteckquerschnitte mit und ohne Druckbewehrung (Normalbeton C12/16 - C50/60 | Betonstahl B500 $\mid \varepsilon_{\mathrm{L}, \text { ges,zul }}=18 \%$ ) (http://doi.org/10.33968/9783966270021-09-T-32)

\begin{tabular}{|c|c|c|c|c|c|}
\hline$\mu_{\mathrm{Ed}, \mathrm{L}}$ & $\omega_{\mathrm{L}}$ & $\varepsilon_{C R 2}$ & $\varepsilon_{\text {L,ges }}$ & $\xi_{L}$ & $\max . \mathrm{d}_{\mathrm{s} 2} / \mathrm{h}$ \\
\hline 0,01 & 0,0101 & $-0,65$ & 18,00 & 0,0349 & \multirow{7}{*}{ 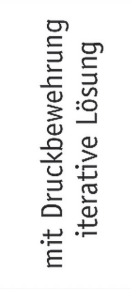 } \\
\hline 0,02 & 0,0204 & $-0,96$ & 18,00 & 0,0506 & \\
\hline 0,03 & 0,0307 & $-1,22$ & 18,00 & 0,0633 & \\
\hline 0,04 & 0,0411 & $-1,45$ & 18,00 & 0,0747 & \\
\hline 0,05 & 0,0516 & $-1,68$ & 18,00 & 0,0853 & \\
\hline 0,06 & 0,0622 & $-1,90$ & 18,00 & 0,0957 & \\
\hline 0,07 & 0,0729 & $-2,14$ & 18,00 & 0,1060 & \\
\hline 0,08 & 0,0838 & $-2,37$ & 18,00 & 0,1165 & 0,0098 \\
\hline 0,09 & 0,0948 & $-2,62$ & 18,00 & 0,1271 & 0,0217 \\
\hline 0,10 & 0,1059 & $-2,88$ & 18,00 & 0,1378 & 0,0337 \\
\hline 0,11 & 0,1171 & $-3,14$ & 18,00 & 0,1486 & 0,0458 \\
\hline 0,12 & 0,1285 & $-3,42$ & 18,00 & 0,1596 & 0,0581 \\
\hline 0,13 & 0,1401 & $-3,50$ & 16,73 & 0,1730 & 0,0656 \\
\hline 0,14 & 0,1518 & $-3,50$ & 15,16 & 0,1876 & 0,0711 \\
\hline 0,15 & 0,1638 & $-3,50$ & 13,80 & 0,2023 & 0,0767 \\
\hline 0,16 & 0,1759 & $-3,50$ & 12,61 & 0,2173 & 0,0823 \\
\hline 0,17 & 0,1882 & $-3,50$ & 11,55 & 0,2325 & 0,0881 \\
\hline 0,18 & 0,2007 & $-3,50$ & 10,62 & 0,2479 & 0,0939 \\
\hline 0,19 & 0,2134 & $-3,50$ & 9,78 & 0,2636 & 0,0999 \\
\hline 0,20 & 0,2263 & $-3,50$ & 9,02 & 0,2796 & 0,1059 \\
\hline 0,21 & 0,2395 & $-3,50$ & 8,33 & 0,2958 & 0,1121 \\
\hline 0,22 & 0,2529 & $-3,50$ & 7,71 & 0,3123 & 0,1183 \\
\hline 0,23 & 0,2665 & $-3,50$ & 7,13 & 0,3292 & 0,1247 \\
\hline 0,24 & 0,2804 & $-3,50$ & 6,60 & 0,3464 & 0,1312 \\
\hline 0,25 & 0,2946 & $-3,50$ & 6,12 & 0,3639 & 0,1379 \\
\hline 0,26 & 0,3091 & $-3,50$ & 5,67 & 0,3818 & 0,1447 \\
\hline 0,27 & 0,3239 & $-3,50$ & 5,25 & 0,4001 & 0,1516 \\
\hline 0,28 & 0,3391 & $-3,50$ & 4,86 & 0,4189 & 0,1587 \\
\hline 0,29 & 0,3546 & $-3,50$ & 4,49 & 0,4381 & 0,1660 \\
\hline 0,30 & 0,3706 & $-3,50$ & 4,15 & 0,4577 & 0,1734 \\
\hline 0,31 & 0,3869 & $-3,50$ & 3,82 & 0,4780 & 0,1811 \\
\hline 0,32 & 0,4038 & $-3,50$ & 3,52 & 0,4988 & 0,1890 \\
\hline 0,33 & 0,4211 & $-3,50$ & 3,23 & 0,5202 & 0,1971 \\
\hline 0,34 & 0,4391 & $-3,50$ & 2,95 & 0,5424 & 0,2055 \\
\hline 0,35 & 0,4576 & $-3,50$ & 2,69 & 0,5653 & 0,2142 \\
\hline 0,36 & 0,4768 & $-3,50$ & 2,44 & 0,5890 & 0,2232 \\
\hline 0,37 & 0,4968 & $-3,50$ & 2,20 & 0,6137 & 0,2325 \\
\hline
\end{tabular}


Tab. C.33 Bemessungstafel für Rechteckquerschnitte mit und ohne Druckbewehrung (Normalbeton C12/16 - C50/60 | Betonstahl B500 $\mid \varepsilon_{\mathrm{L}, \mathrm{ges}, \mathrm{zul}}=\infty \%$ ) (http://doi.org/10.33968/9783966270021-09-T-33)

\begin{tabular}{|c|c|c|c|c|c|}
\hline$\mu_{\mathrm{Ed}, \mathrm{L}}$ & $\omega_{\mathrm{L}}$ & $\varepsilon_{c R 2}$ & $\varepsilon_{L, \text { ges }}$ & $\xi_{\mathrm{L}}$ & $\max . \mathrm{d}_{\mathrm{s} 2} / \mathrm{h}$ \\
\hline 0,01 & 0,0101 & $-3,50$ & 278,37 & 0,0124 & 0,0047 \\
\hline 0,02 & 0,0202 & $-3,50$ & 136,70 & 0,0250 & 0,0095 \\
\hline 0,03 & 0,0305 & $-3,50$ & 89,47 & 0,0376 & 0,0143 \\
\hline 0,04 & 0,0409 & $-3,50$ & 65,85 & 0,0505 & 0,0191 \\
\hline 0,05 & 0,0514 & $-3,50$ & 51,67 & 0,0634 & 0,0240 \\
\hline 0,06 & 0,0620 & $-3,50$ & 42,22 & 0,0766 & 0,0290 \\
\hline 0,07 & 0,0727 & $-3,50$ & 35,46 & 0,0898 & 0,0340 \\
\hline 0,08 & 0,0836 & $-3,50$ & 30,40 & 0,1033 & 0,0391 \\
\hline 0,09 & 0,0946 & $-3,50$ & 26,45 & 0,1169 & 0,0443 \\
\hline 0,10 & 0,1057 & $-3,50$ & 23,29 & 0,1306 & 0,0495 \\
\hline 0,11 & 0,1170 & $-3,50$ & 20,71 & 0,1446 & 0,0548 \\
\hline 0,12 & 0,1285 & $-3,50$ & 18,55 & 0,1587 & 0,0601 \\
\hline 0,13 & 0,1401 & $-3,50$ & 16,73 & 0,1730 & 0,0656 \\
\hline 0,14 & 0,1518 & $-3,50$ & 15,16 & 0,1876 & 0,0711 \\
\hline 0,15 & 0,1638 & $-3,50$ & 13,80 & 0,2023 & 0,0767 \\
\hline 0,16 & 0,1759 & $-3,50$ & 12,61 & 0,2173 & 0,0823 \\
\hline 0,17 & 0,1882 & $-3,50$ & 11,55 & 0,2325 & 0,0881 \\
\hline 0,18 & 0,2007 & $-3,50$ & 10,62 & 0,2479 & 0,0939 \\
\hline 0,19 & 0,2134 & $-3,50$ & 9,78 & 0,2636 & 0,0999 \\
\hline 0,20 & 0,2263 & $-3,50$ & 9,02 & 0,2796 & 0,1059 \\
\hline 0,21 & 0,2395 & $-3,50$ & 8,33 & 0,2958 & 0,1121 \\
\hline 0,22 & 0,2529 & $-3,50$ & 7,71 & 0,3123 & 0,1183 \\
\hline 0,23 & 0,2665 & $-3,50$ & 7,13 & 0,3292 & 0,1247 \\
\hline 0,24 & 0,2804 & $-3,50$ & 6,60 & 0,3464 & 0,1312 \\
\hline 0,25 & 0,2946 & $-3,50$ & 6,12 & 0,3639 & 0,1379 \\
\hline 0,26 & 0,3091 & $-3,50$ & 5,67 & 0,3818 & 0,1447 \\
\hline 0,27 & 0,3239 & $-3,50$ & 5,25 & 0,4001 & 0,1516 \\
\hline 0,28 & 0,3391 & $-3,50$ & 4,86 & 0,4189 & 0,1587 \\
\hline 0,29 & 0,3546 & $-3,50$ & 4,49 & 0,4381 & 0,1660 \\
\hline 0,30 & 0,3706 & $-3,50$ & 4,15 & 0,4577 & 0,1734 \\
\hline 0,31 & 0,3869 & $-3,50$ & 3,82 & 0,4780 & 0,1811 \\
\hline 0,32 & 0,4038 & $-3,50$ & 3,52 & 0,4988 & 0,1890 \\
\hline 0,33 & 0,4211 & $-3,50$ & 3,23 & 0,5202 & 0,1971 \\
\hline 0,34 & 0,4391 & $-3,50$ & 2,95 & 0,5424 & 0,2055 \\
\hline 0,35 & 0,4576 & $-3,50$ & 2,69 & 0,5653 & 0,2142 \\
\hline 0,36 & 0,4768 & $-3,50$ & 2,44 & 0,5890 & 0,2232 \\
\hline 0,37 & 0,4968 & $-3,50$ & 2,20 & 0,6137 & 0,2325 \\
\hline
\end{tabular}




\section{Anhang D \\ innerer Hebelarm}

In diesem Anhang wird die Berechnung des inneren Hebelarms eines Querschnitts mit Druckbewehrung zum Zeitpunkt der Verstärkung bei linear-elastischen Spannungs-Dehnungs-Linien beschrieben. Die Betrachtung setzt voraus, dass der Querschnitt reiner Biegung unterliegt, d.h. es darf zu diesem Zeitpunkt keine Normalkraft autreten.

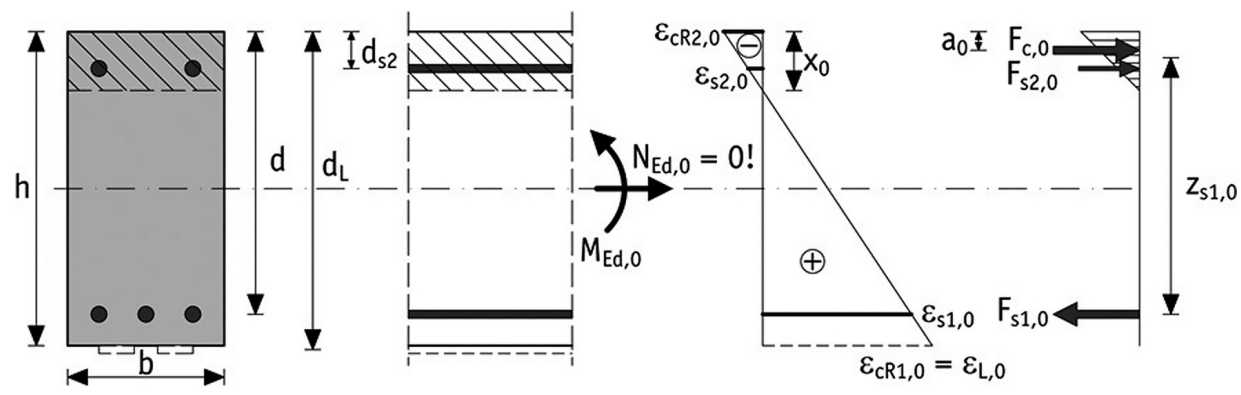

Abb. D.1 Dehnungs- und Spannungsverteilung am Stahlbetonquerschnitt bei linear-elastischem Materialverhalten (http://doi.org/10.33968/9783966270021-10-A-01)

Die resultierende Druckkraft setzt sich aus dem Anteil der Betondruckkraft und der Stahldruckkraft zusammen. Daraus kann der resultierende Hebelarm über das Verhältnis der Kräfte mit deren jeweiligen Abstand zur Nulllinie gebildet. Die zugehörige Druckzonenhöhe kann gemäß Anhang B berechnet werden.

Abstand der Betondruckkraft zur Nulllinie:

$\frac{2}{3} \cdot x_{0}$

Abstand der Stahldruckkraft zur Nulllinie:

$x_{0}-d_{s 2}$

Resultierender innerer Hebelarm: 
$z_{s 1,0}=d-x_{0}+\frac{F_{c, 0} \cdot \frac{2}{3} \cdot x_{0}+F_{s 2} \cdot\left(x_{0}-d_{s 2}\right)}{F_{c, 0}+F_{s 2}}$

Durch Einsetzen der Formeln aus Abschnitt 2.6 ergibt sich folgende Formulierung:

$z_{s 1,0}=d-x_{0}+\frac{\frac{2}{3} \cdot \frac{\varepsilon_{c R 2,0} \cdot E_{c m}}{2} \cdot b \cdot x_{0}{ }^{2}+\varepsilon_{s 2,0} \cdot E_{s} \cdot \rho_{s 2} \cdot b \cdot h \cdot\left(x_{0}-d_{s 2}\right)}{\frac{\varepsilon_{c R 2,0} \cdot E_{c m}}{2} \cdot b \cdot x_{0}+\varepsilon_{s 2,0} \cdot E_{s} \cdot \rho_{s 2} \cdot b \cdot h}$

Um die Einheitlichkeit zur übrigen Berechnung aufrecht zu erhalten, wird auch hier der Verhältniswert der E-Moduln eingeführt. Außerdem können die Dehnungen über den Strahlensatz aus der Gleichung eliminiert werden:

$\alpha_{s}=\frac{E_{s}}{E_{c m}}$

$\frac{\varepsilon_{s 2,0}}{\varepsilon_{c R 2,0}}=\frac{x_{0}-d_{s 2}}{x_{0}}$

Nach dem Einsetzen und Umformen dieser Werte ergibt sich die exakte Lösung für den inneren Hebelarm unter Annahme linear-elastischer Spannungs-Dehnungs-Linien wie folgt:

$z_{s 1,0}=d-x_{0}+\frac{\frac{2}{3} \cdot x_{0}{ }^{3}+2 \cdot\left(x_{0}-d_{s 2}\right) \cdot \rho_{s 2} \cdot h \cdot \alpha_{s}}{x_{0}{ }^{2}+2 \cdot\left(x_{0}-d_{s 2}\right) \cdot \rho_{s 2} \cdot h \cdot \alpha_{s}}$ 


\section{Anhang E \\ Beispiel Druckbewehrung}

In diesem Anhang wird anhand eines Beispiels verdeutlicht, warum Druckbewehrung bei Stahlbetonquerschnitten verwendet wird und wie sich diese auf die Wirtschaftlichkeit der Bemessung auswirkt. Sollte die Spannung der Biegezugbewehrung unterhalb der Bemessungsstreckgrenze bleiben, ist die Bemessung äußerst unwirtschaftlich, da enorm viel Bewehrung eingelegt werden müsste, um die einwirkende Zugkraft aufzunehmen. Das liegt daran, dass bei großen Einwirkungen, die Betondruckzone sehr groß werden muss, um die auftretende Betondruckkraft aufzunehmen, da die zulässige Stauchung rechnerisch begrenzt ist. Dadurch verschiebt sich die Nulllinie des Querschnitts in Richtung Biegebewehrung, deren Dehnung aufgrund der geltenden Hypothese von Bernoulli somit immer geringer würde. Die folgende Abbildung stellt dieses Verhalten eines Stahlbetonquerschnitts dar.

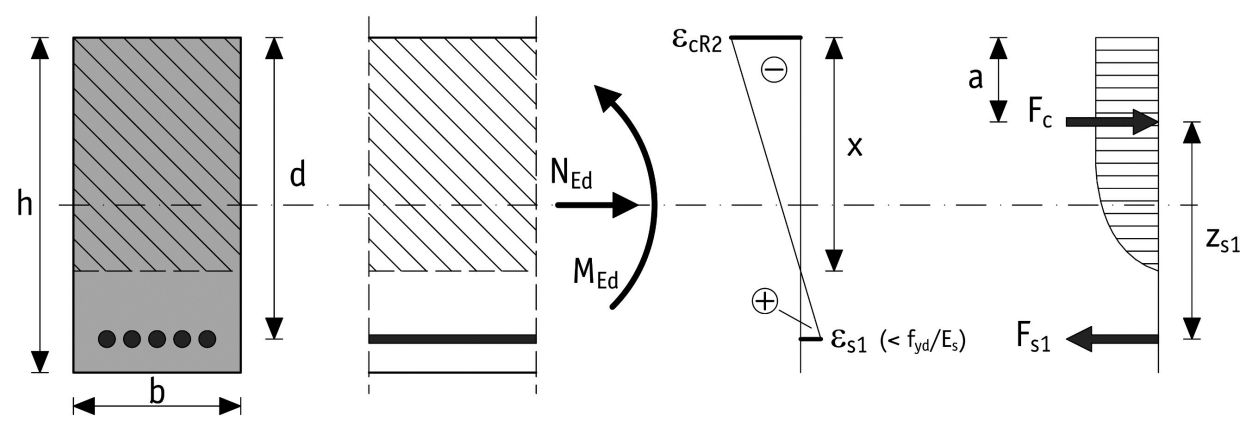

Abb. E.1 Dehnungsverteilung bei großen Einwirkungen ohne Druckbewehrung (http://doi.org/10.33968/9783966270021-11-A-01)

Wird Druckbewehrung eingelegt und die Biegebemessung damit durchgeführt, wird ein Teil der einwirkenden Druckkraft vom Stahl aufgenommen. Dadurch wird die Nulllinie nach oben verschoben, da eine geringere Druckzonenhöhe bereits genügt um die restliche Druckkraft aufzunehmen (vgl. nachfolgende Abbildung). Daraus resultiert eine größere Dehnung der Stahlzugbewehrung. 


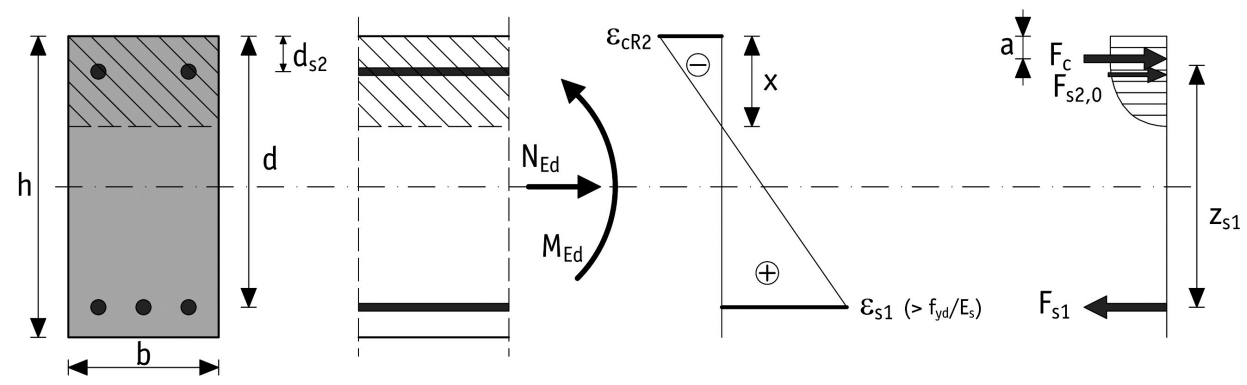

Abb. E.2 Dehnungsverteilung bei großen Einwirkungen mit Druckbewehrung (http://doi.org/10.33968/9783966270021-11-A-02)

Bei dem Beispiel handelt es sich um einen Stahlbetonbalken mit Rechteckquerschnitt, der als frei drehbar gelagerter Einfeldträger ausgeführt werden soll. Folgende Ausgangswerte werden für das Beispiel angenommen:

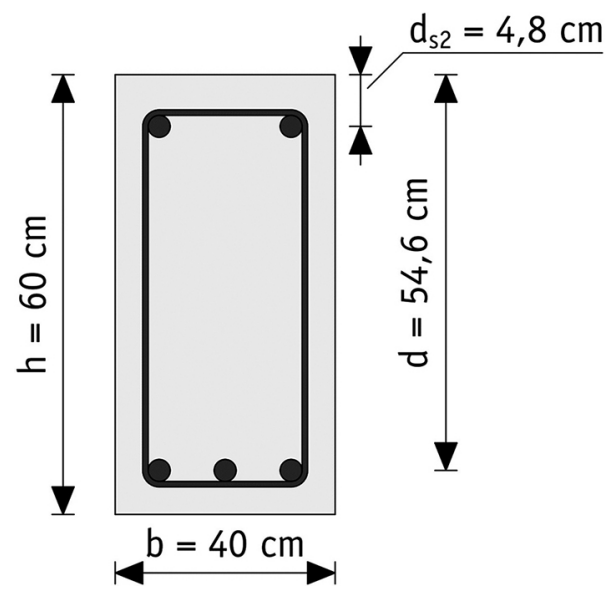

Abb. E.3 beispielhafter Stahlbetonquerschnitt

(http://doi.org/10.33968/9783966270021-11-A-03)

- $\mathrm{b} / \mathrm{h}=40 / 60[\mathrm{~cm}]$

- Betonfestigkeitsklasse C20/25

- Betonstahl B500A

- Bügel $\phi_{\mathrm{Bü}}=10 \mathrm{~mm}$

- Biegezugbewehrung $\phi_{\mathrm{s} 1}=28 \mathrm{~mm}$

- Druckbewehrung $\phi_{\mathrm{s} 2}=16 \mathrm{~mm}$

- Expositionsklasse XC1 
- Betondeckung $\mathrm{c}_{\text {nom }}=30 \mathrm{~mm}$

- keine Normalkraft

$-\mathrm{M}_{\mathrm{Ed}}=574 \mathrm{kNm}$

Die Bemessung erfolgt mit dem allgemeinen Bemessungsdiagramm für Normalbeton (vgl. bspw. [Schneider et al. 2012]).

$\mu_{E d, s}=\frac{M_{E d, s}}{b \cdot d^{2} \cdot f_{c d}}$

$M_{E d, s}=M_{E d}=574 \mathrm{kNm}$

$d=h-c_{n o m}-\phi_{B \ddot{u}}-\frac{\phi_{s 1}}{2}=60-3,0-1,0-\frac{2,8}{2} \approx 54,6 \mathrm{~cm}$

$f_{c d}=\alpha_{c c} \cdot \frac{f_{c k}}{\gamma_{C}}=0,85 \cdot \frac{20}{1,5} \approx 11,33 \mathrm{~N} / \mathrm{mm}^{2}$

$\mu_{E d, s}=\frac{574 \cdot 10^{6}}{400 \cdot 546^{2} \cdot 11,33} \approx 0,425$

Damit ergeben sich aus dem allgemeinen Bemessungsdiagramm ohne Druckbewehrung:

$\zeta=\frac{Z}{d} \approx 0,68$

$\varepsilon_{s 1} \approx 1,0 \%$

Dabei ist die Dehnung geringer als die Fließdehnung und die Stahlspannung liegt unter der Bemessungsstreckgrenze. Daher wird die erforderliche Fläche der Biegezugbewehrung sehr groß.

$\sigma_{s 1}=\varepsilon_{s 1} \cdot E_{s}=0,001 \cdot 200.000 \approx 200 \mathrm{~N} / \mathrm{mm}^{2}$

$A_{s 1}=\frac{1}{\sigma_{s 1}} \cdot\left(\frac{M_{E d, s}}{z}+N_{E d}\right)=\frac{1}{200} \cdot\left(\frac{574 \cdot 10^{6}}{0,68 \cdot 546}+0\right) \cdot 10^{-2} \approx 77,3 \mathrm{~cm}^{2}$

Im Gegensatz dazu kann mit Druckbewehrung ein deutlich wirtschaftlicheres Ergebnis erzielt werden.

$M_{E d, s, l i m}=\mu_{E d, s, l i m} \cdot b \cdot d^{2} \cdot f_{c d}=0,371 \cdot 400 \cdot 546^{2} \cdot 11,33 \cdot 10^{-6} \approx 501 \mathrm{kNm}$ 
$\zeta=\frac{Z}{d} \approx 0,75$

$d_{s 2}=c_{n o m}+\phi_{B \ddot{u}}+\frac{\phi_{s 2}}{2}=3,0+1,0+\frac{1,6}{2} \approx 4,8 \mathrm{~cm}$

$\Delta M_{E d, s}=M_{E d, s}-M_{E d, s, l i m}=574-501 \approx 73 \mathrm{kNm}$

$A_{s 1}=\frac{1}{\sigma_{s 1}} \cdot\left(\frac{M_{E d, s}}{z}+\frac{\Delta M_{E d, s}}{d-d_{s 2}}+N_{E d}\right)$

$=\frac{1}{434,78} \cdot\left(\frac{574 \cdot 10^{6}}{0,75 \cdot 546}+\frac{73 \cdot 10^{6}}{546-48}+0\right) \cdot 10^{-2}$

$\approx 35,6 \mathrm{~cm}^{2}$

$A_{s 2}=\frac{1}{\sigma_{s 2}} \cdot\left(\frac{\Delta M_{E d, s}}{d-d_{s 2}}\right)=\frac{1}{434,78} \cdot\left(\frac{73 \cdot 10^{6}}{546-48}\right) \cdot 10^{-2} \approx 3,4 \mathrm{~cm}^{2}$

Damit lässt sich bestätigen, dass in diesem Fall der Einsatz von Druckbewehrung die Wirtschaftlichkeit der Bemessung deutlich steigert. 


\section{Anhang F \\ Newton-Verfahren}

In diesem Anhang soll ein kurzer Überblick über die Vorgehensweise bei Anwendung des Newton-Verfahrens gegeben werden. Dabei wird mit einer vorgegebenen Genauigkeit näherungsweise die Nullstelle einer Funktion bestimmt. Dieses Verfahren wird in der konfigurierten Excel- Arbeitsmappe zur iterativen Lösung eines nichtlinearen mathematischen Problems durch den Solver verwendet. Voraussetzung dafür ist, dass eine differenzierbare Funktion vorliegt bzw. durch die Eingaben aufgestellt werden kann. Mit einem zu wählenden Startwert wird die differenzierbare Funktion $\mathrm{f}(\mathrm{x})$ durch die Tangente an der Stelle $\mathrm{x}$ ersetzt, die sich mittels der Ableitung wie folgt ergibt.

$t\left(x_{n}\right)=f\left(x_{n}\right)-f^{\prime}\left(x_{n}\right) \cdot\left(x-x_{n}\right)$

Der Schnittpunkt der Tangente mit der x-Achse stellt die erste Näherung $\mathrm{x}_{1}$ dar. Darauffolgend wird die Tangente der Ausgangsfunktion an der Stelle $\mathrm{x}_{1}$ betrachtet und der Schnittpunkt mit der x-Achse ergibt den nächsten Näherungswert $\mathrm{x}_{2}$. Das Verfahren wird fortgesetzt bis eine hinreichende Genauigkeit der Nullstelle erreicht ist (vgl. [Schwarz u. Köckler 2006] S.192). Für die Nullstelle der Tangente gilt:

$0=f\left(x_{n}\right)+f^{\prime}\left(x_{n}\right) \cdot\left(x_{n+1}-x_{n}\right)$

$x_{n+1}=x_{n}-\frac{f\left(x_{n}\right)}{f^{\prime}\left(x_{n}\right)}, \quad n=0,1,2, \ldots$

Die folgende Abbildung stellt diesen Vorgang beispielhaft dar. 


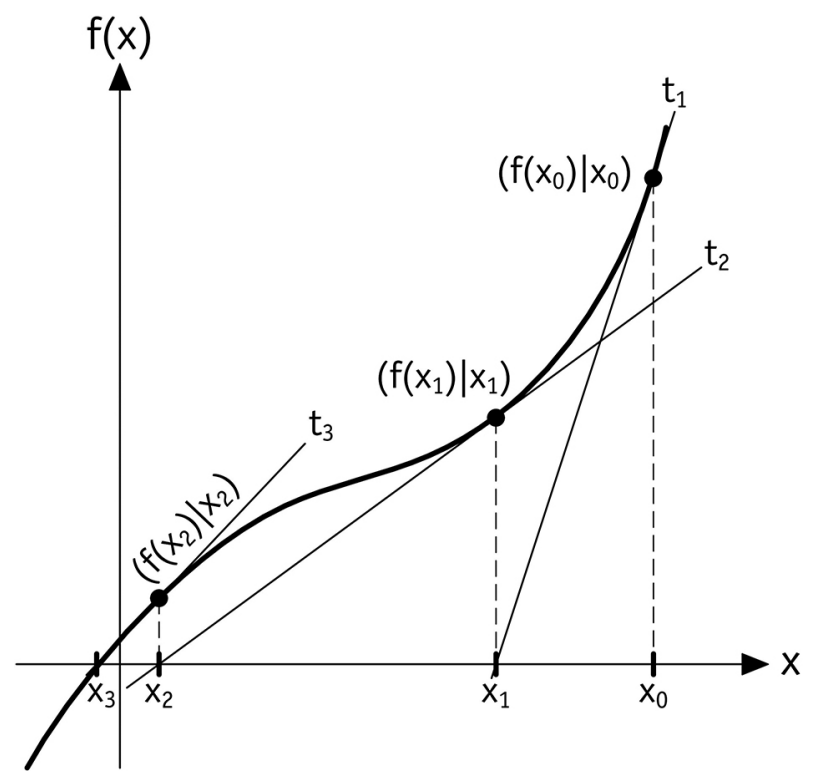

Abb. F.1 Newton-Verfahren (Quelle: Eigene Darstellung in Anlehnung an [Schwarz u. Köckler 2006] Abb. 4.4, S.192) (http://doi.org/10.33968/9783966270021-12-A-01) 


\section{Anhang G \\ VBA-Skript}

In diesem Anhang ist der gesamte Quellcode des VBA-Editors enthalten. Zum besseren Verständnis hinsichtlich der Bezeichnungen (insbesondere der Userform) wird empfohlen die Excel-Arbeitsmappe und den VBA-Editor zu öffnen. Es handelt sich hierbei lediglich um ein Modul und ein Formular. Das Modul (AutoOpen) sorgt dafür, dass die Userform startet, sobald die Excel- Tabelle geöffnet wird. Außerdem ist dieses Modul in der Schaltfläche "Eingabe starten" hinterlegt, um die Userform aus der Excel-Tabelle heraus zu starten. In "Userform1" sind alle Berechnungen und Eingaben hinterlegt.

Autoopen:

Option Explicit

Sub Auto_Open()

'Blattschutz deaktivieren um Userform zu starten

Sheets ("Eingabe"). Unprotect Password:="Masterarbeit"

'Beim Starten der Excel-Arbeitsmappe Eingabemaske anzeigen UserForm1. Show

'Erstes Tabellenblatt ("Eingabe") soll im Hintergrund aktiviert werden Worksheets("Eingabe").Activate

'Blattschutz aktivieren und Eingabe nur über Userform erlauben Sheets("Eingabe"). Protect Password:="Masterarbeit", _ userinterfaceonly: =True

End Sub

Userform 1:

Option Explicit 


\section{Private Sub UserForm_Initialize()}

'Multipage allgemein

'ohne Tabs angezeigen

MultiPage1.Style $=$ fmTabstyleNone

'Page1 "Querschnitt"

'Auf Seite 1 beginnen (VBA fängt bei $\odot$ an zu zählen)

MultiPage1. Value $=\odot$

'Startwerte: aktuelle Werte beibehalten

With Worksheets("Eingabe"). Activate

If $\operatorname{Cells}(4,2) \cdot$ Value $=100$ Then

OptionButton2. Value $=$ True

Else

OptionButton $1=$ True

End If

TextBox1. Value $=\operatorname{Cells}(4,2) \cdot$ Value

TextBox2. Value $=\operatorname{Cells}(5,2) \cdot$ Value

TextBox3.Value $=\operatorname{Cells}(8,2) \cdot$ Value

End with

'Eigengewicht anzeigen

'aus Excel Berechnung mit Wichte Stahlbeton $=25 \mathrm{kN} / \mathrm{m}^{3}$

With Worksheets("Eingabe").Activate

Label11. Caption $=\operatorname{Cells}(11,2)$. Value

End With

'Startwerte Lasten ebenfalls beibehalten

With Worksheets("Eingabe"). Activate

TextBox4.Value $=\operatorname{Cells}(12,2) \cdot$ Value

TextBox5.Value $=\operatorname{Cells}(13,2) \cdot$ Value

TextBox6.Value $=\operatorname{Cells}(14,2) \cdot$ Value

End With

'Page 3 "Beton" (Page 2 im Laufe der Bearbeitung entfallen)

'Kombinationsfeld soll nur Werte für Normalbeton zulassen

Worksheets ("Daten"). Activate

UserForm1. ComboBox1. RowSource = "A5:A13"

UserForm1.ComboBox1.Style = fmStyleDropDownList

Worksheets ("Eingabe"). Activate 
'Startwert Kombinationsfeld gemäß aktueller Auswahl

With Worksheets ("Eingabe"). Activate UserForm1.ComboBox1.Value $=\operatorname{Cells}(21,2)$. Value

End With

'Druckfestigkeit in Abhängigkeit der Festigkeitsklasse ausgeben With Worksheets("Eingabe").Activate

If UserForm1.ComboBox1.Value $<>$ Then Label35. Caption $=\operatorname{Cells}(22,2)$. Value

End If

End With

'Beiwerte für Langzeitauswirkungen standardmäßig auf $\odot, 85$ festgelegt

TextBox7. Value $=0.85$

TextBox8. Value $=0.85$

'Anzeige: 'Bemessungsdruckfestigkeit

'mittlere Druckfestigkeit

'E-Modul

'Grenzdehnung

'Oberflächenzugfestigkeit

With Worksheets("Eingabe"). Activate

Label45. Caption $=$ Round $(\operatorname{Cells}(26,2), 2)$

Label50.Caption $=\operatorname{Cells}(27,2)$

Label54. Caption $=\operatorname{Cells}(29,2)$

Label58. Caption $=\operatorname{Cells}(30,2)$

TextBox9. Value $=\operatorname{Cells}(28,2)$

End With

'Page 4 "Betonstahl"

'Startwerte: vorhandene Werte

With Worksheets("Eingabe"). Activate

'Startwert Auswahl gerippter / glatter Betonstahl

If Cells $(3,6)$.Value $=$ "gerippt" Then

OptionButton5. Value = True

ElseIf Cells $(3,6) \cdot$ Value $=$ "glatt" Then

OptionButton6. Value $=$ True

Else

OptionButton5. Value $=$ False

OptionButton6. Value $=$ False

End If 


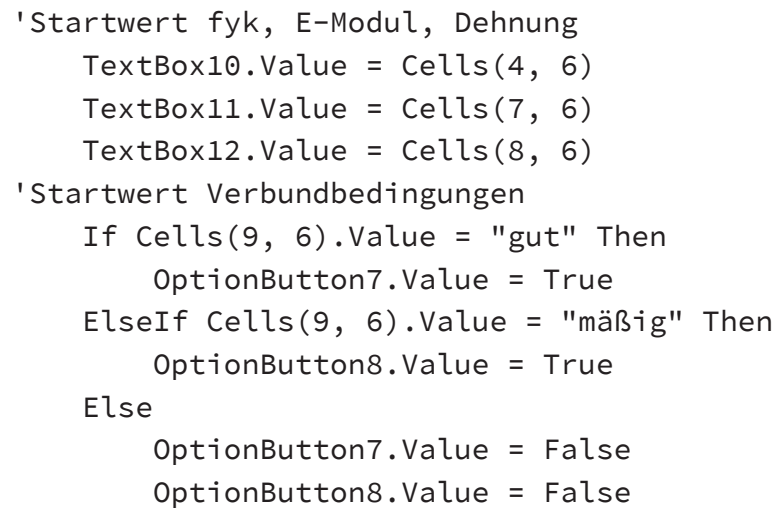

End If

End With

'Startwert Spinbuttons + in zugehörige Textboxen übernehmen With Worksheets("Eingabe"). Activate

SpinButton1. Value $=\operatorname{Cells}(21,6)$

SpinButton2. Value $=\operatorname{Cells}(35,6)$

End With

TextBox26.Value = SpinButton1. Value

TextBox28.Value = SpinButton2. Value

'Min-/Max-Werte Spinbuttons (Betonstahl Stababstände)

SpinButton1. Min $=1$

SpinButton1.Max $=100$

SpinButton2. Min $=1$

SpinButton2. Max $=100$

'Doppelstab ja/nein

If Sheets("Eingabe"). Cells $(22,6) \cdot$ Value $=2$ Then

CheckBox2. Value = True

ElseIf Sheets("Eingabe"). Cells $(22,6) \cdot$ Value $=1$ Then CheckBox2. Value $=$ False

End If

If Sheets("Eingabe"). Cells $(36,6) \cdot$ Value $=2$ Then

CheckBox3.Value = True

ElseIf Sheets ("Eingabe"). Cells $(36,6) \cdot$ Value $=1$ Then CheckBox3. Value $=$ False

End If

'Page 5 "CFK-Lamelle"

'Auswahl in Combobox2 ("System") 


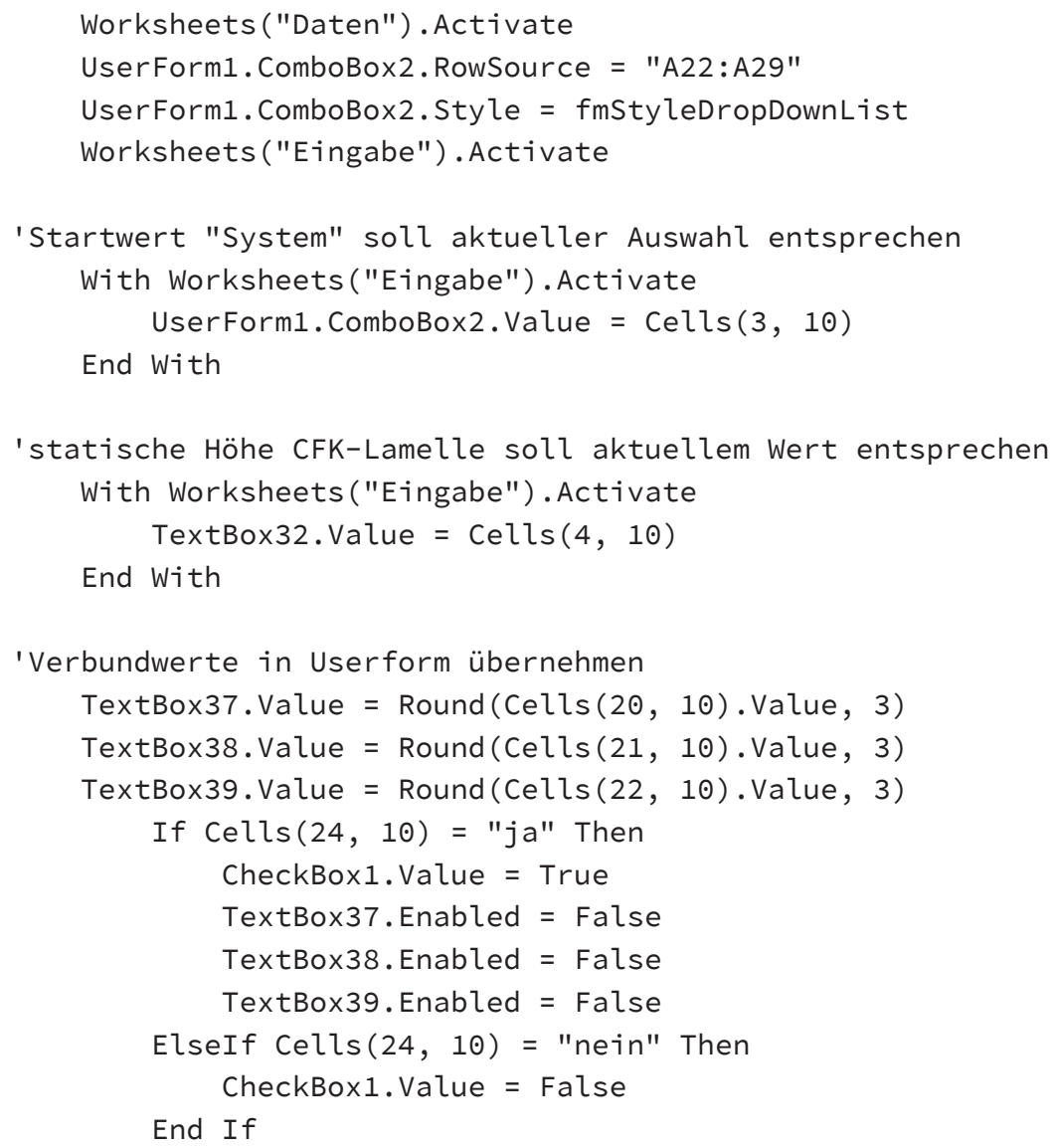

End Sub 


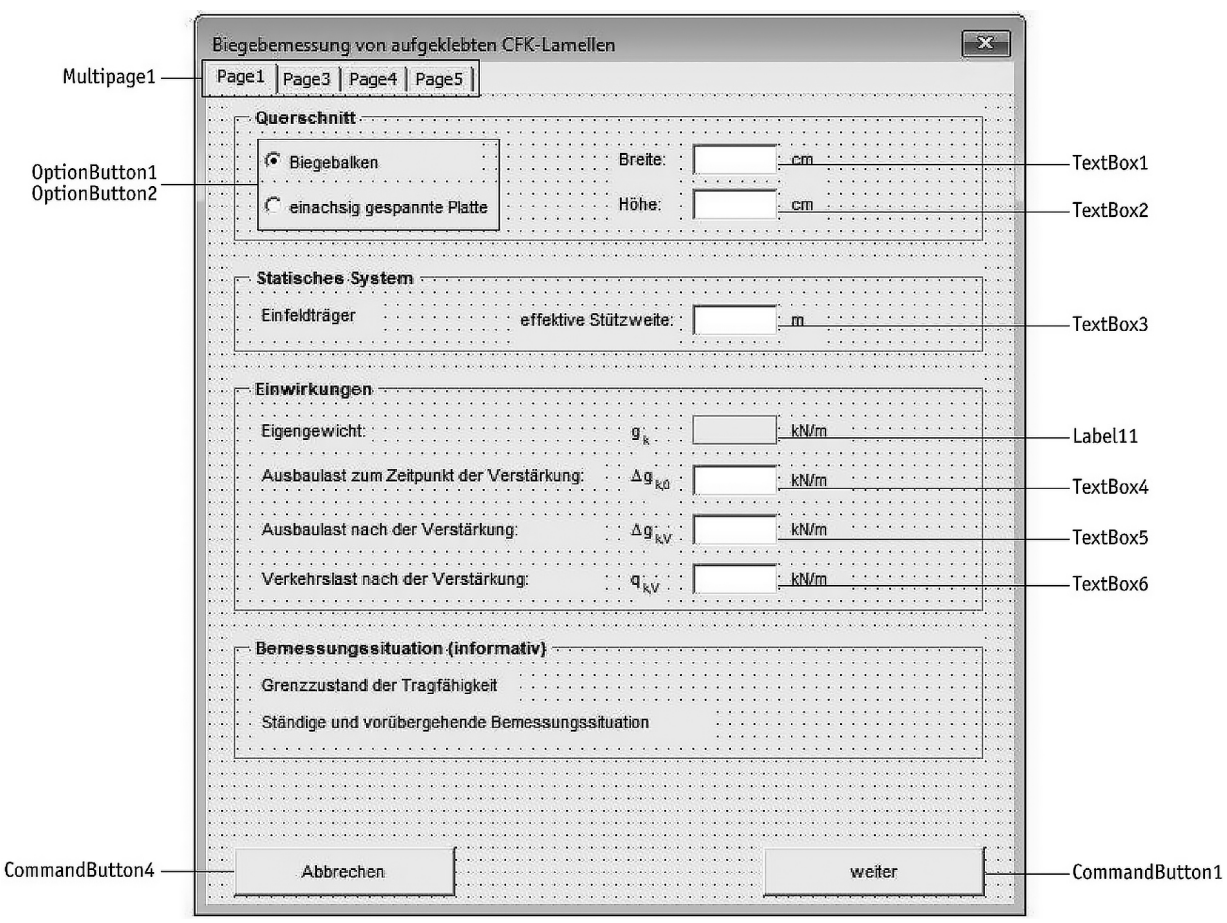

Abb. G.1 Userform Seite 1 (http://doi.org/10.33968/9783966270021-13-A-01)

\section{Private Sub OptionButton2_Click()}

'bei Auswahl einachsig gespannte Platte:

' Breite $=100 \mathrm{~cm}$

'Eingabefeld sperren

'grau hinterlegen um Sperrung zu kennzeichnen

TextBox1. Value $=100$

TextBox1. Enabled $=$ False

End Sub

\section{Private Sub OptionButton1_Click()}

'bei Auswahl Biegebalken Breite freigeben

TextBox1. Enabled $=$ True

End Sub 


\section{Private Sub TextBox1_Change()}

'Begrenzung der Textbox1 auf Zahlenwerte

If TextBox1.Value $=$ " "Then

With Worksheets("Eingabe"). Activate

$\operatorname{Cells}(4,2)=0$

End With

ElseIf Not IsNumeric(TextBox1) Then

MsgBox "Bitte geben Sie einen Zahlenwert ein.", vbInformation, _ "Hinweis"

TextBox1. Value $=40$

Else

With Worksheets("Eingabe"). Activate

Cells $(4,2)=$ TextBox1. Value $\star 1$

End With

End If

'neues Eigengewicht anzeigen

With Worksheets("Eingabe").Activate

Label11. Caption $=\operatorname{Cells}(11,2) \cdot$ Value

End with

End Sub

\section{Private Sub TextBox2_Change()}

'Begrenzung der Textbox2 auf Zahlenwerte

If TextBox2. Value $=$ " " Then

$$
\operatorname{Cells}(5,2)=0
$$

ElseIf Not IsNumeric(TextBox2) Then

MsgBox "Bitte geben Sie einen Zahlenwert ein.", vbInformation, _ "Hinweis"

TextBox2. Value $=60$

Else

With Worksheets ("Eingabe"). Activate

$\operatorname{Cells}(5,2)=$ TextBox2.Value $\star 1$

End With

End If

'neues Eigengewicht anzeigen

With Worksheets("Eingabe"). Activate

Label11. Caption $=\operatorname{Cells}(11,2)$. Value

End With

End Sub 


\section{Private Sub TextBox3_Change()}

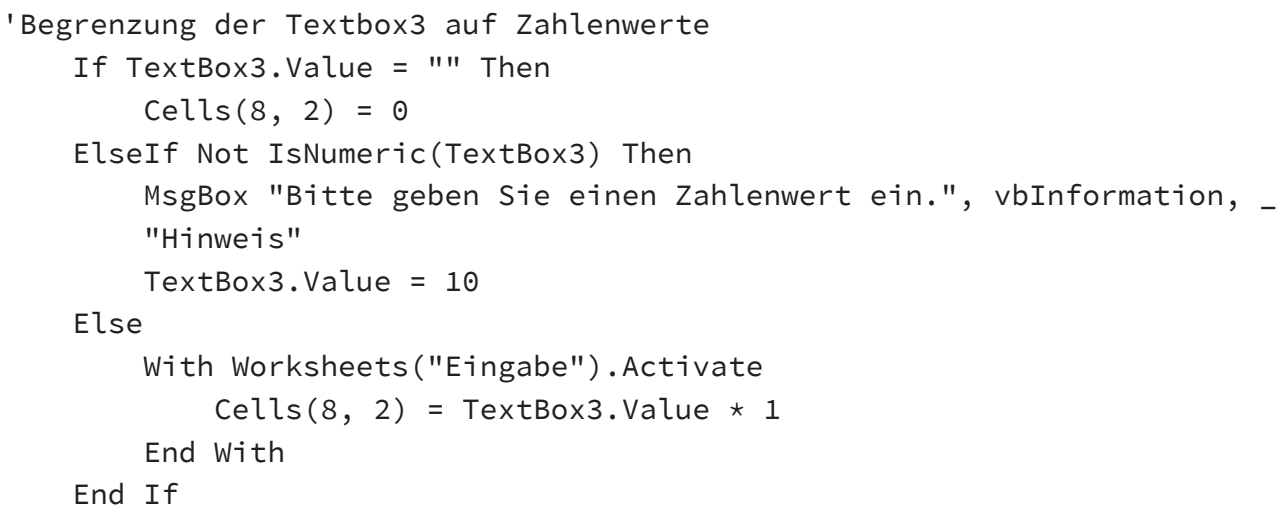

End Sub

\section{Private Sub TextBox4_Change()}

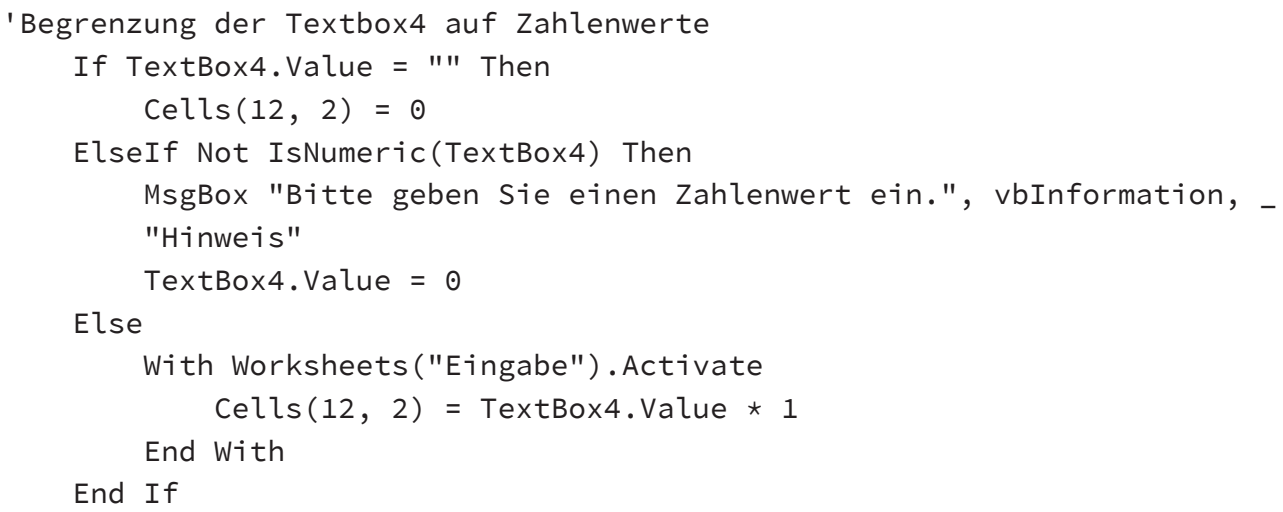

End Sub

\section{Private Sub TextBox5_Change()}

'Begrenzung der Textbox5 auf Zahlenwerte

If TextBox5. Value $=$ "" Then $\operatorname{Cells}(13,2)=0$

ElseIf Not IsNumeric(TextBox5) Then

MsgBox "Bitte geben Sie einen Zahlenwert ein.", vbInformation, _ 


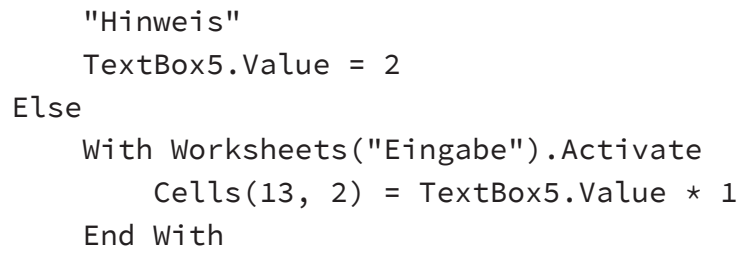

End Sub

\section{Private Sub TextBox6_Change()}

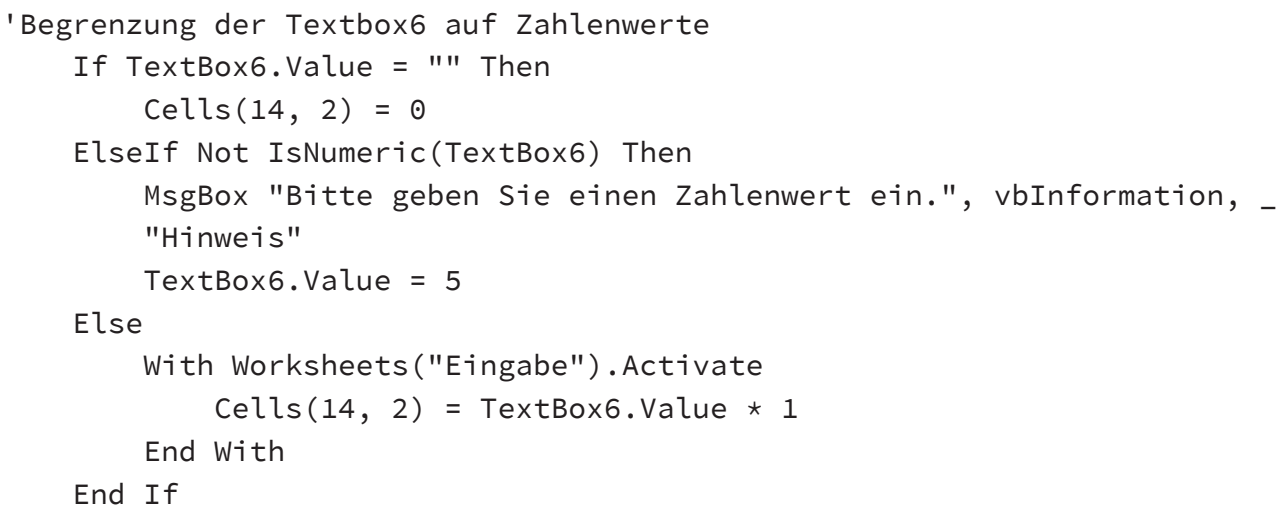

End Sub

\section{Private Sub CommandButton4_Click()}

'CommandButton4 = Abbrechen $($ Page 1$)$

Unload UserForm1

End Sub

\section{Private Sub CommandButton1_Click()}

'Page 3 "Beton" - Page 2 ist im Laufe der Bearbeitung entfallen

'Anzeige Teilsicherheitsbeiwert Beton

With Worksheets("Eingabe"). Activate

Label43. Caption $=\operatorname{Cells}(25,2)$

End With 
'weiter zur nächsten Seite

MultiPage1.Value $=$ MultiPage1.Value +1

End Sub

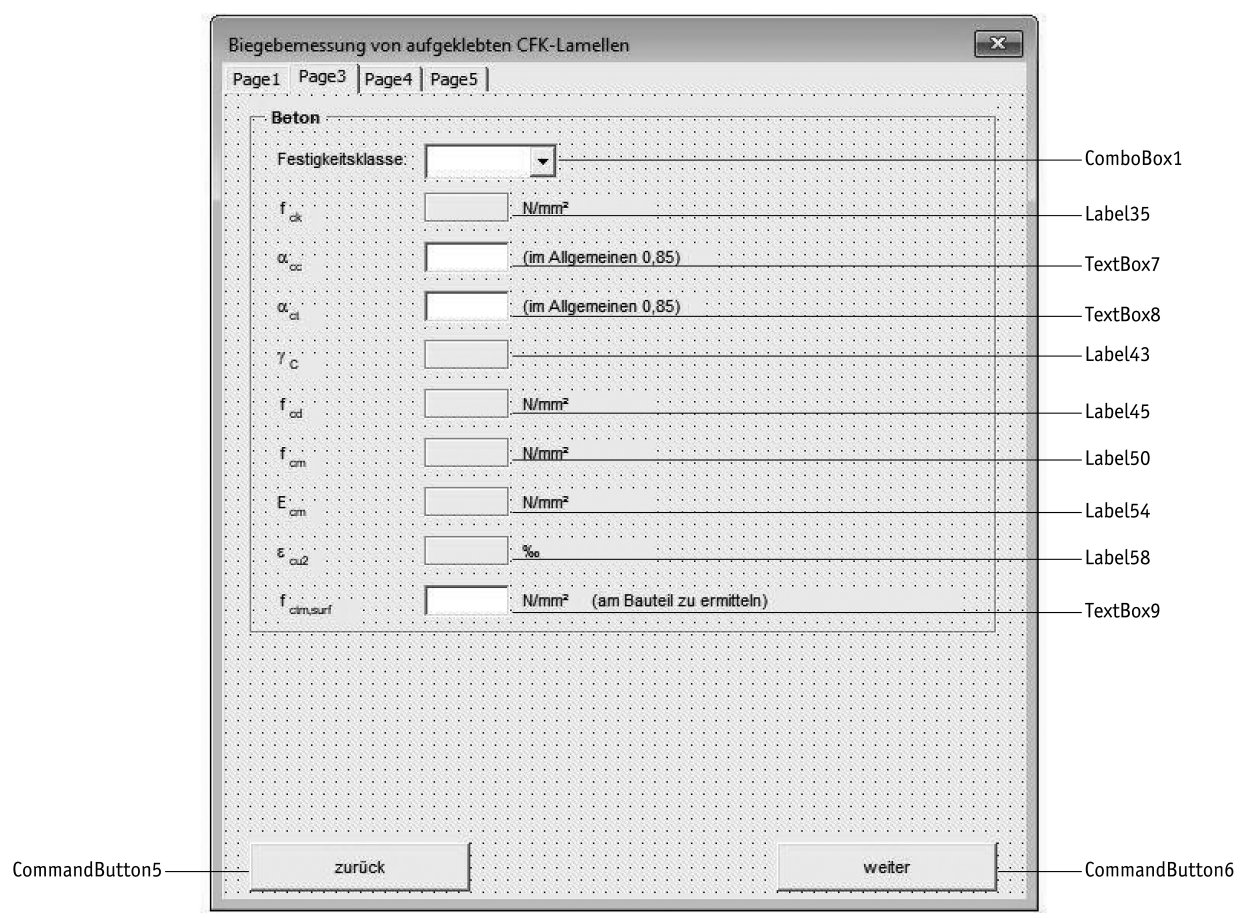

Abb. G.2 Userform Seite 2 (http://doi.org/10.33968/9783966270021-13-A-02)

\section{Private Sub ComboBox1_Change()}

'neuen Wert in Excel übernehmen

'Betondruckfestigkeit bei Änderung der Festigkeitsklasse anpassen

With Worksheets ("Eingabe"). Activate Cells $(21,2)$.Value $=$ UserForm1.ComboBox1.Value Label35. Caption $=\operatorname{Cells}(22,2)$

End With

'Druckfestigkeit etc. neu berechnen und anzeigen With Worksheets("Eingabe"). Activate 


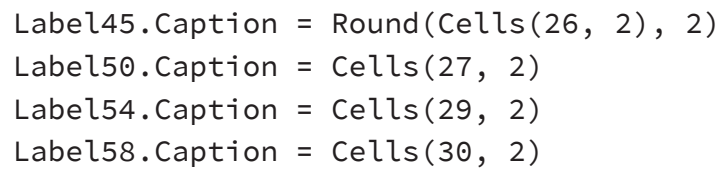

End Sub

\section{Private Sub TextBox7_Change()}

'Begrenzung der Textbox7 auf Zahlenwerte

With Worksheets("Eingabe").Activate

If TextBox7. value $=$ " "Then

Cells $(23,2) \cdot$ Value $=0$

ElseIf Not IsNumeric(TextBox7) Then

MsgBox "Bitte geben Sie einen Zahlenwert ein.", vbInformation, _ "Hinweis"

TextBox7. Value $=0.85$

Cells $(23,2) \cdot$ Value $=$ TextBox 7 . Value $\star 1$

Else

Cells $(23,2) \cdot$ Value $=$ TextBox7. Value $\star 1$

End If

End With

'Bemessungsdruckfestigkeit neu berechnen und anzeigen

With Worksheets ("Eingabe"). Activate

Label45. Caption $=\operatorname{Round}(\operatorname{Cells}(26,2), 2)$

End With

End Sub

\section{Private Sub TextBox8_Change()}

'Begrenzung der Textbox8 auf Zahlenwerte

With Worksheets ("Eingabe"). Activate

If TextBox8.Value $=$ "" Then

Cells $(24,2) \cdot$ Value $=0$ 
ElseIf Not IsNumeric(TextBox8) Then

MsgBox "Bitte geben Sie einen Zahlenwert ein.", vbInformation, _ "Hinweis"

TextBox8. Value $=0.85$

Cells $(24,2)$. Value $=$ TextBox8.Value $\star 1$

Else

Cells $(24,2) \cdot$ Value $=$ TextBox8.Value $\star 1$

End If

End with

End Sub

\section{Private Sub TextBox9_Change()}

'Begrenzung der Textbox9 auf Zahlenwerte

With Worksheets ("Eingabe"). Activate

If TextBox9.Value $="$ " Then

Cells $(28,2)$. Value $=0$

ElseIf Not IsNumeric(TextBox9) Then

MsgBox "Bitte geben Sie einen Zahlenwert ein.", vbInformation, _

"Hinweis"

TextBox9. Value $=2$

Cells $(28,2)$. Value $=$ TextBox9.Value $\star 1$

Else

Cells $(28,2)$. Value $=$ TextBox9.Value $\star 1$

End If

End with

End Sub

\section{Private Sub CommandButton5_Click()}

'Eine Seite zurück

MultiPage1.Value $=$ MultiPage1.Value -1

End Sub 


\section{Private Sub CommandButton6_Click()}

'Die Beiwerte der Langzeitauswirkungen sollen begrenzt werden.

'Langzeitauswirkungen auf die Betondruckfestigkeit

If TextBox 7 .Value $>1$ Then MsgBox "Ungültiger Beiwert für Langzeitauswirkungen", _ vbokonly + vbcritical, "Achtung!"

MultiPage1.Value = MultiPage1.Value

GoTo SubEnde

ElseIf TextBox7.Value $<0.85$ Then

MsgBox "Ungültiger Beiwert für Langzeitauswirkungen", _ vboKOnly + vbCritical, "Achtung!"

MultiPage1.Value = MultiPage1.Value

GoTo SubEnde

ElseIf TextBox7.Value $<$ ๑.85 Then

MsgBox "Im Allgemeinen ist der Beiwert für Langzeit" _

\& "auswirkungen zu 0,85 anzunehmen. Nur in " -

\& "begründeten Fällen darf hiervon abgewichen werden.", vbokonly + vbInformation, "Hinweis"

Else

'Wert liegt genau bei $\odot, 85$

End If

'Langzeitauswirkungen auf die Betonzugfestigkeit

If TextBox8.Value > 1 Then

MsgBox "Ungültiger Beiwert für Langzeitauswirkungen", _

vboKOnly + vbCritical, "Achtung!"

MultiPage1. Value = MultiPage1. Value

GoTo SubEnde

ElseIf TextBox8.Value $<0.85$ Then

MsgBox "Ungültiger Beiwert für Langzeitauswirkungen", _ vbokonly + vbCritical, "Achtung!"

MultiPage1.Value = MultiPage1.Value

GoTo SubEnde

ElseIf TextBox8.Value $<>0.85$ Then

MsgBox "Im Allgemeinen ist der Beiwert für Langzeit" -

\& "auswirkungen zu $\odot, 85$ anzunehmen. Nur in "

\& "begründeten Fällen darf hiervon abgewichen werden.", vbokonly + vbInformation, "Hinweis"

Else

'Wert liegt genau bei $\odot, 85$

End If 
'Oberflächenzugfestigkeit ist gemäß Richtlinie begrenzt auf $1, \odot-4, \odot \mathrm{N} / \mathrm{mm}^{2}$

If TextBox9.Value > 4 Then

MsgBox "Ungültiger Wert." \& vbNewLine _

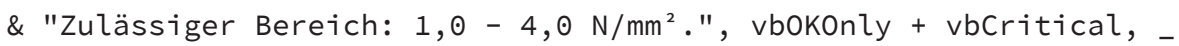
"Achtung!"

MultiPage1.Value $=$ MultiPage1. Value

GoTo SubEnde

ElseIf TextBox9.Value $<1$ Then

MsgBox "Ungültiger Wert." \& vbNewLine

\& "Zulässiger Bereich: 1, $\odot-4, \odot \mathrm{N} / \mathrm{mm}^{2} . "$, vbokonly + vbcritical, _ "Achtung!"

MultiPage1.Value = MultiPage1.Value

GoTo SubEnde

End If

'Nächste Seite der Multipage aufrufen

MultiPage1. Value $=$ MultiPage1. Value +1

'Die folgende Seite soll anzeigen:

'den Teilsicherheitsbeiwert

Label75. Caption $=\operatorname{Cells}(5,6)$

'die Bemessungsstreckgrenze

Label79. Caption $=\operatorname{Round}(\operatorname{Cells}(6,6), 2)$

'wenn Biegebalken, dann Eingabe Durchmesser + Anzahl

'wenn Platte dann Eingabe Durchmesser + Abstand

If OptionButton1. Value = True Then

MultiPage2. Value $=\odot \quad$ 'VBA beginnt bei $\odot$ zu zählen

Else

MultiPage2. Value $=1$

End If

' für angezeigte Seite (Multipage2) aktuelle Werte übernehmen

'andere Werte $=0$, da Bedingung in Excel-Berechnung eingeht With Worksheets("Eingabe"). Activate

TextBox33.Value $=\operatorname{Cells}(12,6)$

TextBox35.Value $=\operatorname{Cells}(12,6)$

TextBox34. Value $=\operatorname{Cells}(26,6)$

TextBox36. Value $=\operatorname{Cells}(26,6)$ 
If OptionButton1. Value $=$ True Then

TextBox13. Value $=\operatorname{Cells}(14,6)$

TextBox14. Value $=\operatorname{Cells}(13,6)$

TextBox15. Value $=\operatorname{Cells}(16,6)$

TextBox16. Value $=\operatorname{Cells}(15,6)$

TextBox17.Value $=\operatorname{Cells}(18,6)$

TextBox18.Value $=\operatorname{Cells}(17,6)$

TextBox19. Value $=\operatorname{Cells}(28,6)$

TextBox20.Value $=\operatorname{Cells}(27,6)$

TextBox21. Value $=\operatorname{Cells}(30,6)$

TextBox22. Value $=\operatorname{Cells}(29,6)$

TextBox23. Value $=\operatorname{Cells}(32,6)$

TextBox24.Value $=\operatorname{Cells}(31,6)$

Else

TextBox13. Value $=0$

TextBox14. Value $=0$

TextBox15. Value $=0$

TextBox16. Value $=0$

TextBox17. Value $=0$

TextBox18. Value $=0$

TextBox19. Value $=0$

TextBox20.Value $=0$

TextBox21. Value $=0$

TextBox22. Value $=0$

TextBox23. Value $=0$

TextBox24. Value $=0$

End If

If OptionButton2. Value = True Then

TextBox25.Value $=\operatorname{Cells}(20,6)$

TextBox26.Value $=\operatorname{Cells}(21,6)$

TextBox27.Value $=\operatorname{Cells}(34,6)$

TextBox28.Value $=\operatorname{Cells}(35,6)$

Else

TextBox25. Value $=0$

TextBox26. Value $=\operatorname{Cells}(21,6)$

TextBox27. Value $=0$

TextBox28.Value $=\operatorname{Cells}(35,6)$

End If

TextBox40.Value $=\operatorname{Cells}(40,6)$

End With

SubEnde:

End Sub 


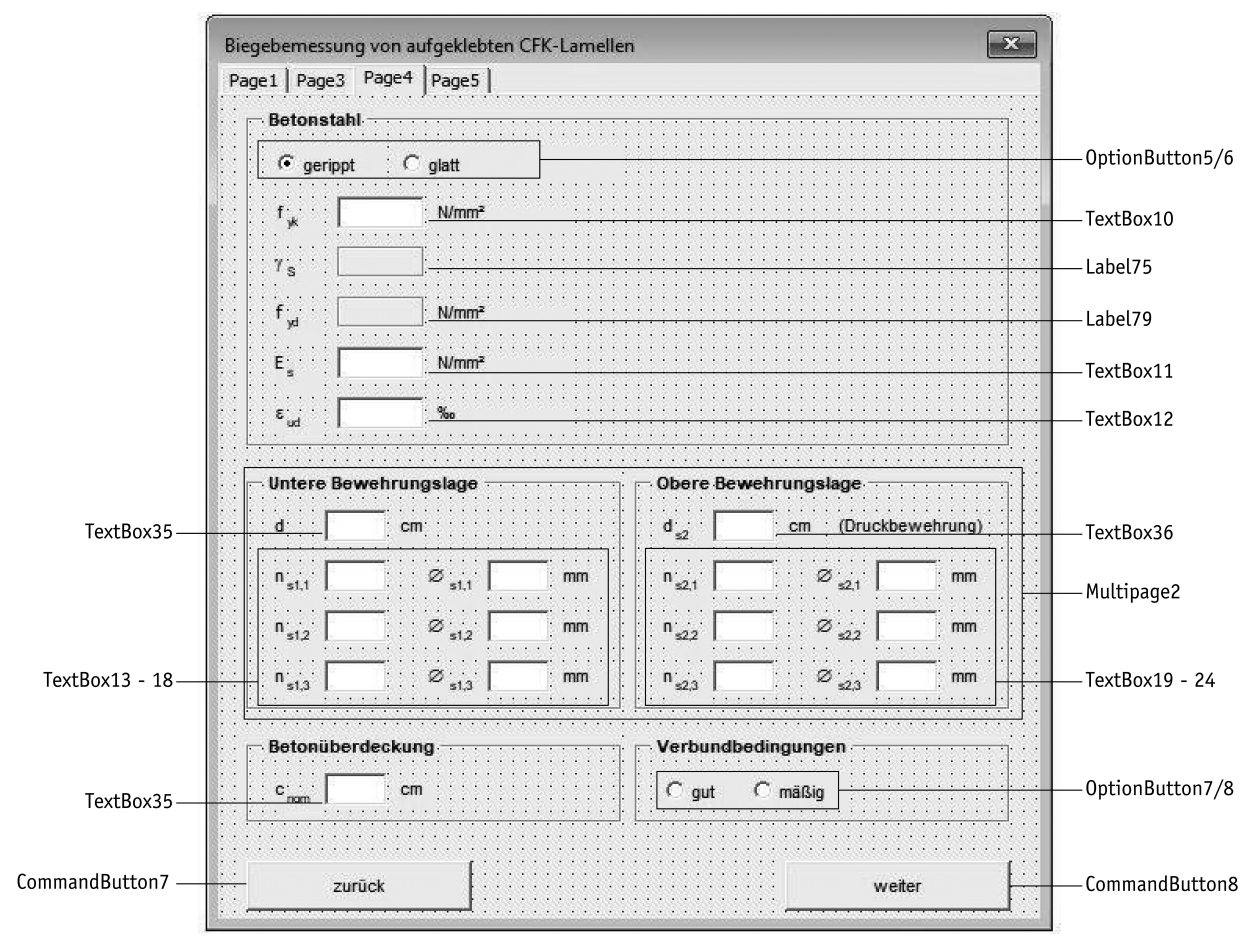

Abb. G.3 Userform Seite 3.1 (http://doi.org/10.33968/9783966270021-13-A-03) 


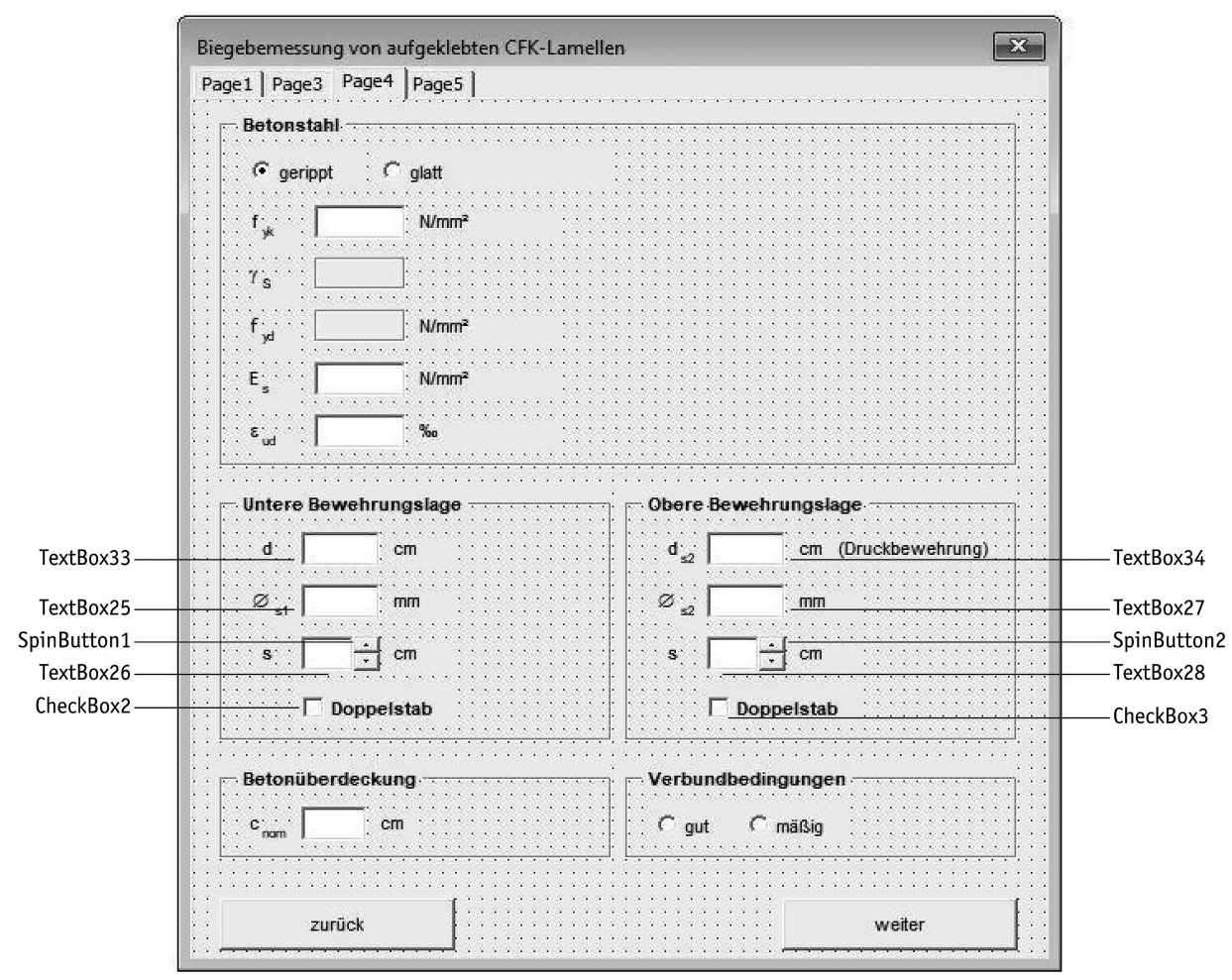

Abb. G.4 Userform Seite 3.2 (http://doi.org/10.33968/9783966270021-13-A-04)

\section{Private Sub OptionButton5_Click()}

'Bei Auswahl "gerippt", soll gerippt eingetragen werden With Worksheets("Eingabe"). Activate

$$
\operatorname{Cells}(3,6)=\text { "gerippt" }
$$

End With

End Sub

\section{Private Sub OptionButton6_Click()}

'Bei Auswahl "glatt" soll glatt eingetragen werden With Worksheets("Eingabe"). Activate

$$
\operatorname{Cells}(3,6)=\text { "glatt" }
$$

End With

End Sub 


\section{Private Sub TextBox10_Change()}

'Textbox10 auf Zahlenwerte beschränken und anschließend Werte übernehmen

If TextBox10.Value $="$ " Then

TextBox10. Value $=0$

ElseIf Not IsNumeric(TextBox10) Then

MsgBox "Bitte geben Sie einen Zahlenwert ein.", vbInformation, _ "Hinweis"

TextBox10.value $=500$

End If

With Worksheets("Eingabe"). Activate

Cells $(4,6) \cdot$ Value $=$ TextBox10.Value $\star 1$

End With

'Bemessungszugfestigkeit neu berechnen und anzeigen

With Worksheets ("Eingabe"). Activate

Label79. Caption $=\operatorname{Round}(\operatorname{Cells}(6,6), 2)$

End With

End Sub

\section{Private Sub TextBox11_Change()}

'Textbox11 auf Zahlenwerte beschränken und anschließend Werte übernehmen

If TextBox11. Value $="$ " Then

TextBox11. Value $=0$

ElseIf Not IsNumeric(TextBox11) Then

MsgBox "Bitte geben Sie einen Zahlenwert ein.", vbInformation, "Hinweis"

TextBox11. Value $=200000$

End If

With Worksheets("Eingabe"). Activate

Cells $(7,6) \cdot$ Value $=$ TextBox11. Value $\star 1$

End With

End Sub 


\section{Private Sub TextBox12_Change()}

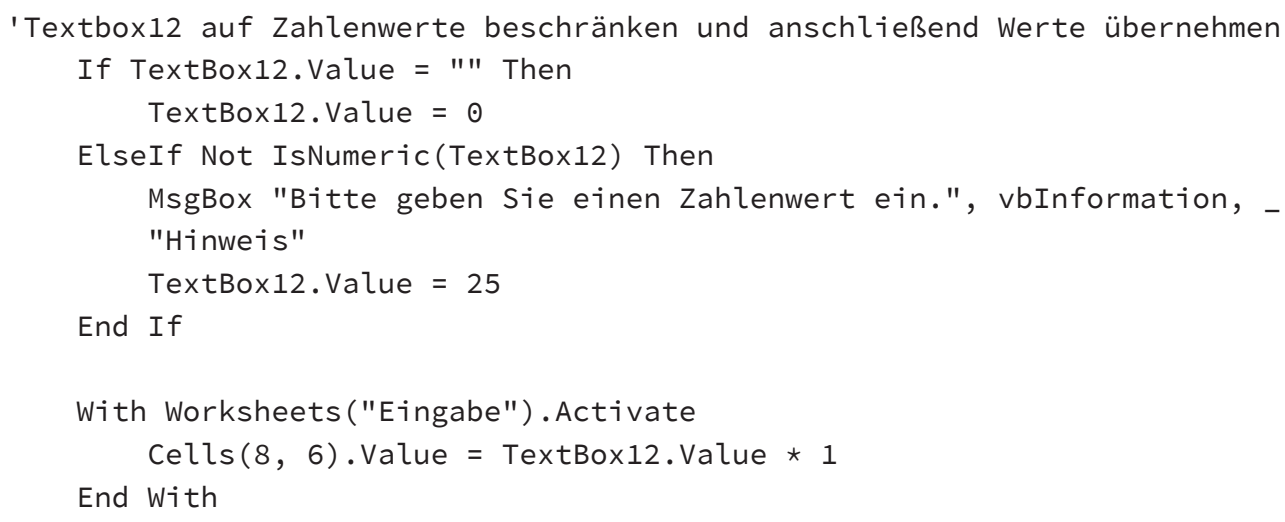

End Sub

\section{Private Sub TextBox13_Change()}

' auf Zahlenwerte beschränken (+leere Textbox $=0$ )

If TextBox13.Value $=$ " "Then

TextBox13. Value $=\odot$

ElseIf Not IsNumeric(TextBox13) Then

MsgBox "Bitte geben Sie einen Zahlenwert ein.", vbInformation, _

"Hinweis"

TextBox13. Value $=0$

End If

End Sub

\section{Private Sub TextBox14_Change()}

' auf Zahlenwerte beschränken (+leere Textbox $=0$ )

If TextBox14.Value $=$ " " Then

TextBox14. Value $=0$

ElseIf Not IsNumeric(TextBox14) Then

MsgBox "Bitte geben Sie einen Zahlenwert ein.", vbInformation, _

"Hinweis"

TextBox14. Value $=0$

End If

End Sub 


\section{Private Sub TextBox15_Change()}

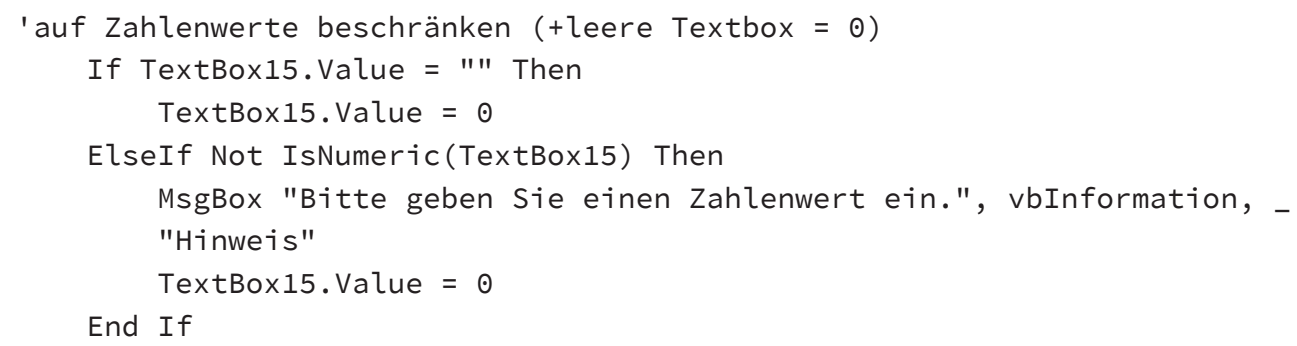

End Sub

\section{Private Sub TextBox16_Change()}

'auf Zahlenwerte beschränken (+leere Textbox $=\odot$ )

If TextBox16. Value $="$ " Then

TextBox16. Value $=0$

ElseIf Not IsNumeric(TextBox16) Then

MsgBox "Bitte geben Sie einen Zahlenwert ein.", vbInformation, "Hinweis"

TextBox16. Value $=0$

End If

End Sub

\section{Private Sub TextBox17_Change()}

'auf Zahlenwerte beschränken (+leere Textbox $=0$ )

If TextBox17. Value $=$ " "Then

TextBox17. Value $=0$

ElseIf Not IsNumeric(TextBox17) Then

MsgBox "Bitte geben Sie einen Zahlenwert ein.", vbInformation, -

"Hinweis"

TextBox17. Value $=\odot$

End If

End Sub 


\section{Private Sub TextBox18_Change()}

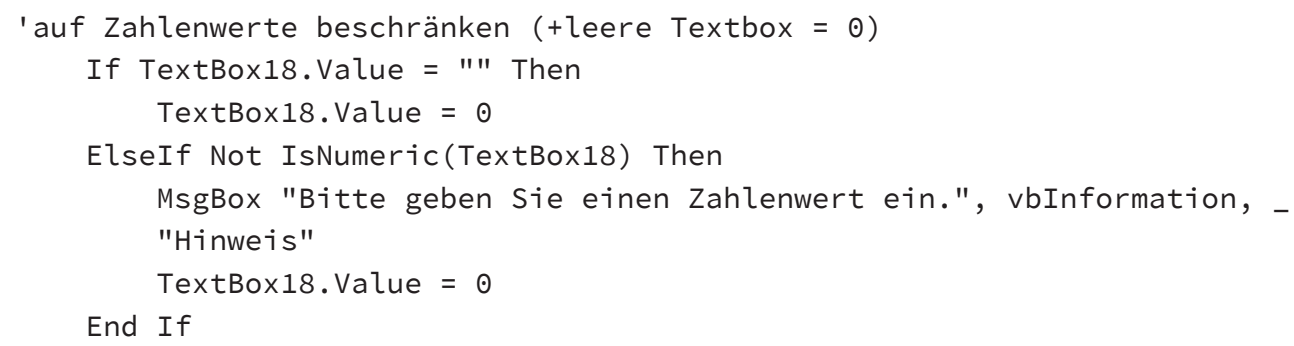

End Sub

\section{Private Sub TextBox19_Change()}

'auf Zahlenwerte beschränken (+leere Textbox $=0$ )

If TextBox19. Value $="$ " Then

TextBox19. Value $=0$

ElseIf Not IsNumeric(TextBox19) Then

MsgBox "Bitte geben Sie einen Zahlenwert ein.", vbInformation, _

"Hinweis"

TextBox19. Value $=0$

End If

End Sub

\section{Private Sub TextBox20_Change()}

' auf Zahlenwerte beschränken (+leere Textbox $=0$ )

If TextBox20.Value $="$ " Then

TextBox20.Value $=0$

ElseIf Not IsNumeric(TextBox20) Then

MsgBox "Bitte geben Sie einen Zahlenwert ein.", vbInformation, _ "Hinweis"

TextBox20. Value $=\odot$

End If

End Sub 


\section{Private Sub TextBox21_Change()}

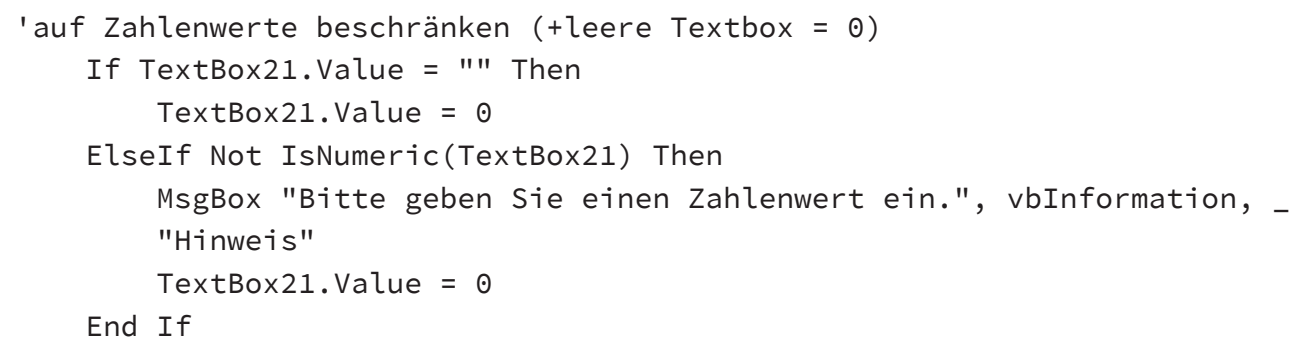

End Sub

\section{Private Sub TextBox22_Change()}

'auf Zahlenwerte beschränken (+leere Textbox $=0$ )

If TextBox22. Value $=" "$ "Then

TextBox22. Value $=0$

ElseIf Not IsNumeric(TextBox22) Then

MsgBox "Bitte geben Sie einen Zahlenwert ein.", vbInformation, _

"Hinweis"

TextBox22. Value $=0$

End If

End Sub

\section{Private Sub TextBox23_Change()}

'auf Zahlenwerte beschränken (+leere Textbox $=0$ )

If TextBox23. Value $=$ "" Then

TextBox23. Value $=0$

ElseIf Not IsNumeric(TextBox23) Then

MsgBox "Bitte geben Sie einen Zahlenwert ein.", vbInformation, "Hinweis"

TextBox23. Value $=0$

End If

End Sub 


\section{Private Sub TextBox24_Change()}

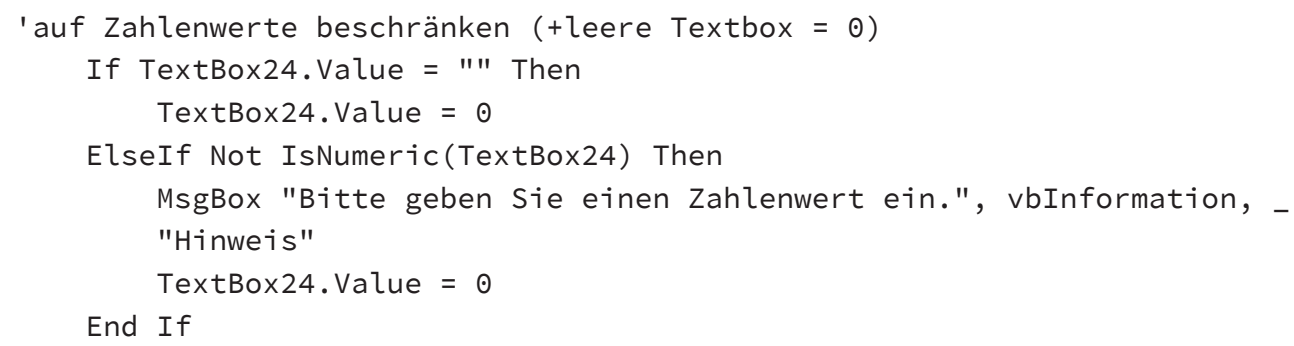

End Sub

\section{Private Sub TextBox25_Change()}

'auf Zahlenwerte beschränken (+leere Textbox $=0$ )

If TextBox25. Value $="$ " Then

TextBox25. Value $=0$

ElseIf Not IsNumeric(TextBox25) Then

MsgBox "Bitte geben Sie einen Zahlenwert ein.", vbInformation, _

"Hinweis"

TextBox25. Value $=0$

End If

End Sub

\section{Private Sub TextBox26_Change()}

' auf Zahlenwerte beschränken (+leere Textbox $=0$ )

If TextBox26. Value $=$ " "Then

TextBox26. Value $=15$

ElseIf Not IsNumeric(TextBox26) Then

MsgBox "Bitte geben Sie einen Zahlenwert ein.", vbInformation, _ "Hinweis"

TextBox26. Value $=15$

End If

End Sub 


\section{Private Sub TextBox27_Change()}

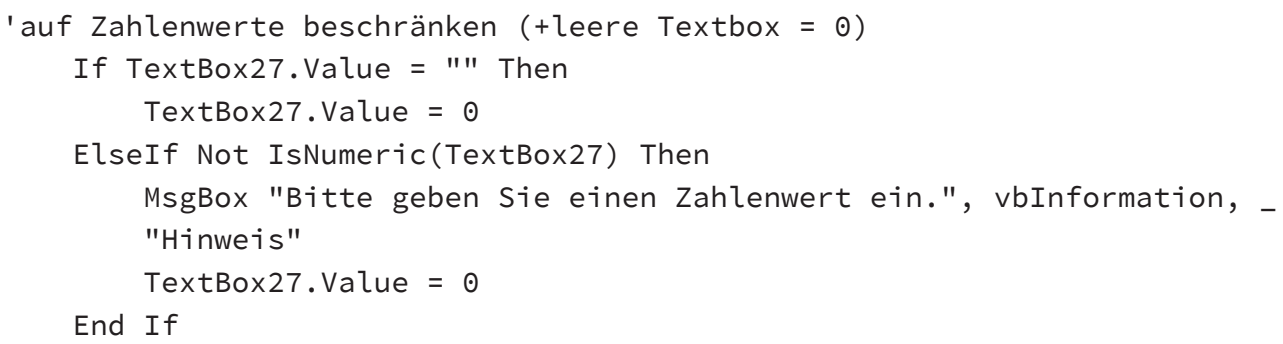

End Sub

\section{Private Sub TextBox28_Change()}

'auf Zahlenwerte beschränken (+leere Textbox $=0$ )

If TextBox28. Value $=" "$ Then

TextBox28. Value $=15$

ElseIf Not IsNumeric(TextBox28) Then

MsgBox "Bitte geben Sie einen Zahlenwert ein.", vbInformation, "Hinweis"

TextBox28. Value $=15$

End If

End Sub

\section{Private Sub TextBox33_Change()}

'auf Zahlenwerte beschränken (+leere Textbox $=0$ )

If TextBox33. Value $=$ " " Then

'nothing

ElseIf Not IsNumeric(TextBox33) Then

MsgBox "Bitte geben Sie einen Zahlenwert ein.", vbInformation, _ "Hinweis"

TextBox33.Value $=0.9 * \operatorname{Cells}(5,2)$

End If

End Sub 


\section{Private Sub TextBox34_Change()}

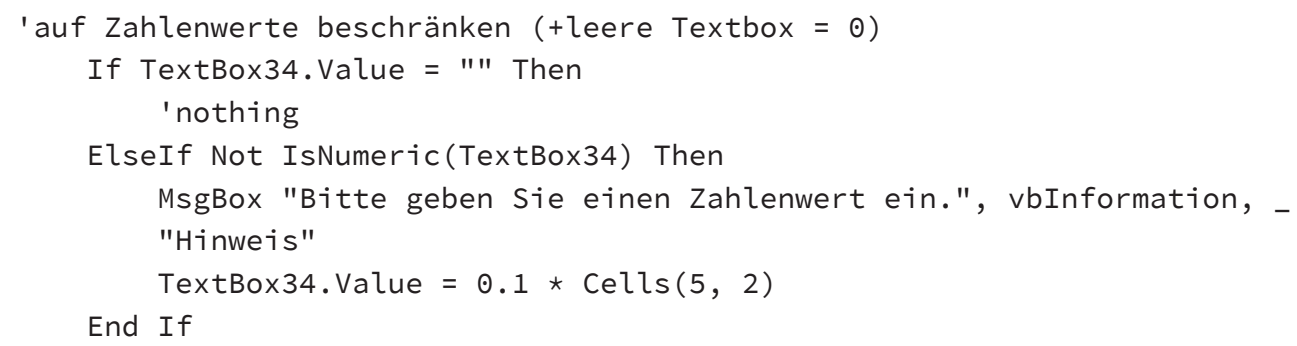

End Sub

\section{Private Sub TextBox35_Change()}

'auf Zahlenwerte beschränken (+leere Textbox $=0$ )

If TextBox35. Value $=$ " " Then

'nothing

ElseIf Not IsNumeric(TextBox35) Then

MsgBox "Bitte geben Sie einen Zahlenwert ein.", vbInformation, _ "Hinweis"

TextBox35. Value $=0.9 * \operatorname{Cells}(5,2)$

End If

End Sub

\section{Private Sub TextBox36_Change()}

'auf Zahlenwerte beschränken (+leere Textbox $=0$ )

If TextBox36. Value $=$ " "Then

'nothing

ElseIf Not IsNumeric(TextBox36) Then

MsgBox "Bitte geben Sie einen Zahlenwert ein.", vbInformation, "Hinweis"

TextBox36. Value $=0.1 * \operatorname{Cells}(5,2)$

End If

End Sub 
Private Sub TextBox40_Change()

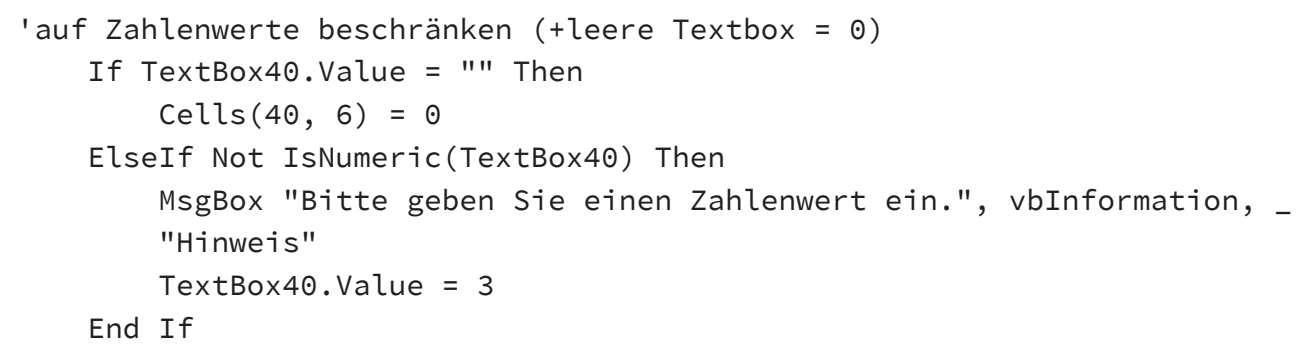

End Sub

\section{Private Sub OptionButton7_Click()}

'Bei Auswahl "gut", soll gut eingetragen werden

With Worksheets("Eingabe"). Activate

$$
\operatorname{Cells}(9,6)=\text { "gut" }
$$

End With

End Sub

\section{Private Sub OptionButton8_Click()}

'Bei Auswahl "mäßig", soll mäßig eingetragen werden

With Worksheets("Eingabe"). Activate

$$
\operatorname{Cells}(9,6)=\text { "mäßig" }
$$

End With

End Sub

\section{Private Sub SpinButton1_Change()}

'Verknüpfung Spinbutton mit Textbox

TextBox26. Value = SpinButton1. Value

End Sub 
Private Sub SpinButton2_Change()

'Verknüpfung Spinbutton mit Textbox

TextBox28.Value = SpinButton2. Value

End Sub

Private Sub CheckBox2_Click()

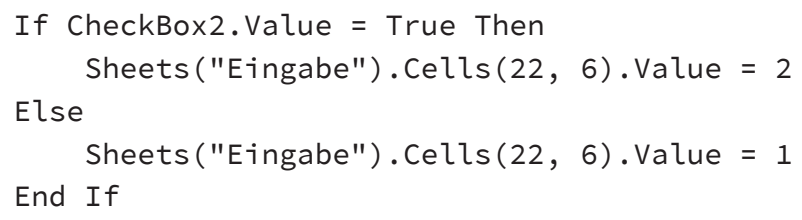

End Sub

\section{Private Sub CheckBox3_Click()}

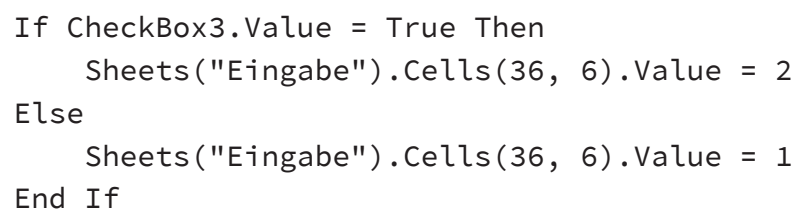

End Sub

\section{Private Sub CommandButton7_Click()}

'Eine Seite zurück MultiPage1. Value $=$ MultiPage1. Value -1

End Sub

\section{Private Sub CommandButton8_Click()}

'Werte übernehmen

With Worksheets("Eingabe"). Activate

$$
\begin{aligned}
& \text { Cells }(14,6)=\text { TextBox13.Value } \star 1 \\
& \text { Cells }(13,6)=\text { TextBox14.Value } \star 1
\end{aligned}
$$




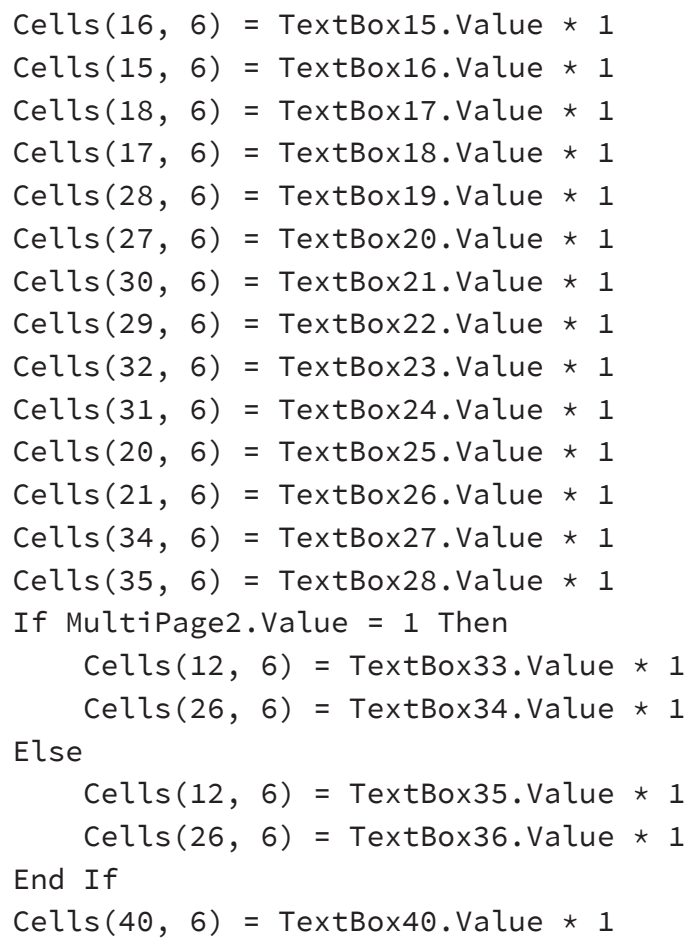

End With

'statische Höhe (Bewehrung) muss kleiner als die Querschnittshöhe sein.

'und: Nächste Seite der Multipage aufrufen

If TextBox33. Value $\star 1>\operatorname{Cells}(5,2)$. Value _

And OptionButton2.Value $=$ True Then

MsgBox _

"Die statische Höhe muss kleiner als die Querschnittshöhe sein!", _ vbExclamation, "Hinweis: Untere Bewehrungslage"

TextBox33. Value $=0.9 \star \operatorname{Cells}(5,2)$

Cells $(12,6) \cdot$ Value $=$ TextBox33. Value $\star 1$

MultiPage1. Value $=$ MultiPage1. Value

ElseIf TextBox34.Value $\star 1>\operatorname{Cells}(5,2)$. Value _

And OptionButton2. Value $=$ True Then

MsgBox _

"Die statische Höhe muss kleiner als die Querschnittshöhe sein!", _ vbExclamation, "Hinweis: Obere Bewehrungslage"

TextBox34.Value $=0.1 \star \operatorname{Cells}(5,2)$

Cells $(26,6) \cdot$ Value $=$ TextBox34.Value $\star 1$

MultiPage1. Value $=$ MultiPage1.Value

ElseIf TextBox35.Value $\star 1>\operatorname{Cells}(5,2)$. Value _ 
And OptionButton1. Value $=$ True Then

MsgBox _

"Die statische Höhe muss kleiner als die Querschnittshöhe sein!", vbExclamation, "Hinweis: Untere Bewehrungslage"

TextBox35. Value $=0.9 \star \operatorname{Cells}(5,2)$

Cells $(12,6) \cdot$ Value $=$ TextBox35. Value $\star 1$

MultiPage1. Value $=$ MultiPage1. Value

ElseIf TextBox36.Value $\star 1>\operatorname{Cells}(5,2)$. Value _

And OptionButton1.Value $=$ True Then

MsgBox _

"Die statische Höhe muss kleiner als die Querschnittshöhe sein!", _ vbExclamation, "Hinweis: Obere Bewehrungslage"

TextBox36. Value $=0.1 * \operatorname{Cells}(5,2)$

Cells $(26,6) \cdot$ Value $=$ TextBox36. Value $\star 1$

Else

MultiPage1. Value $=$ MultiPage1. Value

MultiPage1. Value $=$ MultiPage1. Value +1

End If

'Hinweis: fyd, E-Modul und zul. Grenzdehnung i.A. vorgegeben.

If TextBox10 $<500$ Then

MsgBox "Im Allgemeinen gilt für die Bemessung nach EC2 in " -

\& "Zusammenhang mit dem NA eine charakteristische Zugfestigkeit" -

\& " des Betonstahls von $500 \mathrm{~N} / \mathrm{mm}^{2}$.", vbExclamation + vbokonly, -

"Hinweis"

End If

If TextBox11 $<200000$ Then

MsgBox "Im Allgemeinen beträgt der E-Modul $200.000 \mathrm{~N} / \mathrm{mm}^{2}$ " -

\& "für die Bemessung nach EC2.", vbExclamation + vbokonly, -

"Hinweis"

End If

If TextBox12 $2>25$ Then

MsgBox "Im Allgemeinen ist die rechnerisch zulässige " -

\& "Grenzdehnung auf 25 \% zu fixieren.", -

vbExclamation + vbokonly, "Hinweis"

End If

End Sub 


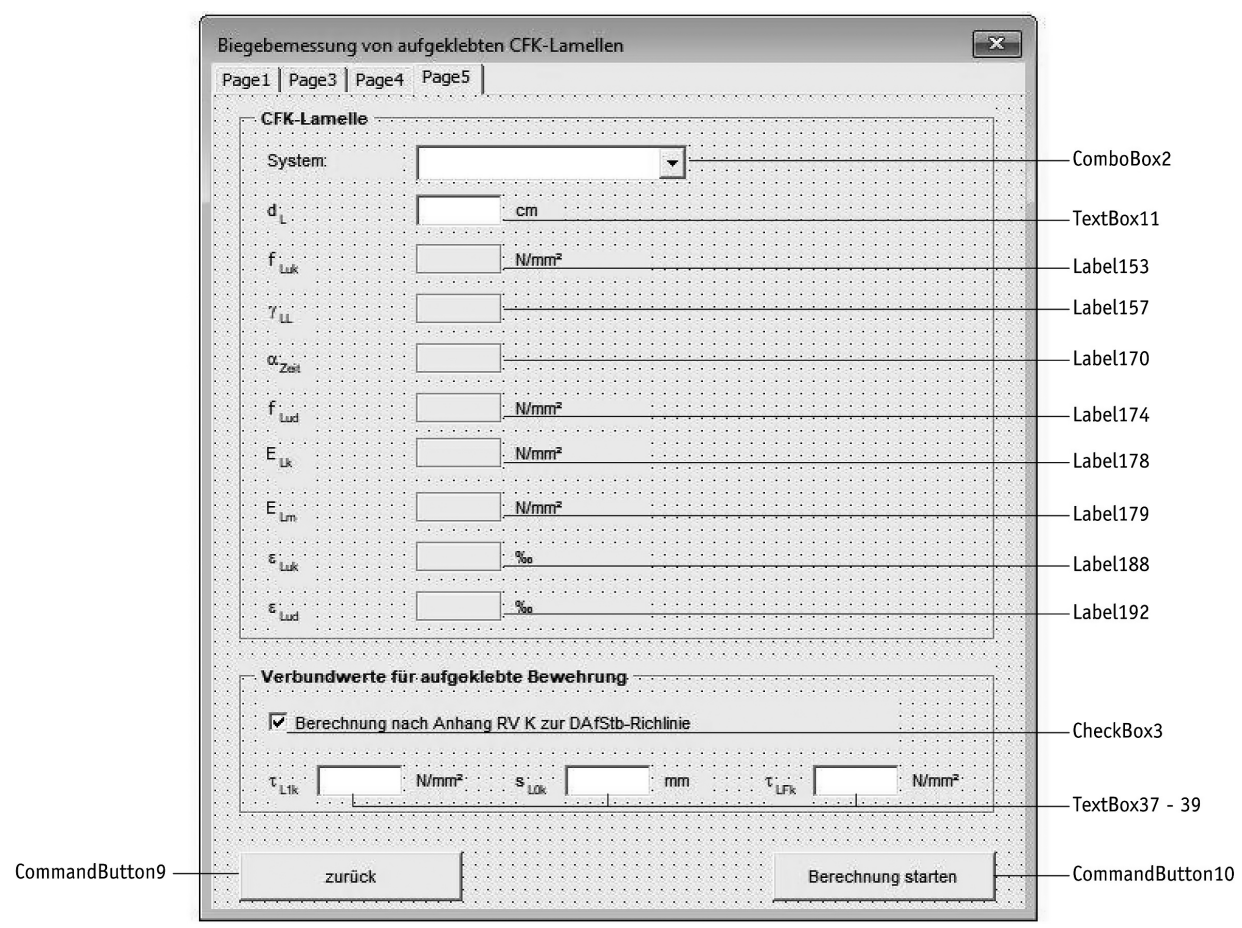

Abb. G.5 Userform Seite 4 (http://doi.org/10.33968/9783966270021-13-A-05)

\section{Private Sub ComboBox2_Change()}

'Wert übernehmen und Eigenschaften der gewählten CFK-Lamelle anzeigen Worksheets ("Eingabe"). Activate

Cells $(3,10)=$ UserForm1.ComboBox2.Value

UserForm1.Label153. Caption $=\operatorname{Cells}(5,10)$

UserForm1. Label157. Caption $=\operatorname{Cells}(7,10)$

UserForm1. Label170.Caption $=\operatorname{Cells}(6,10)$

UserForm1. Label174. Caption $=\operatorname{Round}(\operatorname{Cells}(8,10), 1)$

UserForm1.Label178. Caption $=\operatorname{Cells}(9,10)$

UserForm1.Label179.Caption $=\operatorname{Cells}(10,10)$

UserForm1. Label188. Caption $=\operatorname{Cells}(11,10)$

UserForm1.Label192. Caption $=\operatorname{Round}(\operatorname{Cells}(12,10), 1)$

End Sub 


\section{Private Sub TextBox32_Change()}

'Eingabe direkt übernehmen

With Worksheets("Eingabe"). Activate

Cells $(4,10)=$ TextBox32. Value

End With

' auf Zahlenwerte beschränken

If TextBox32. Value $=$ " " Then

'nothing

ElseIf Not IsNumeric(TextBox32) Then

MsgBox "Bitte geben Sie einen Zahlenwert ein", vbInformation, _ "Hinweis"

Worksheets("Eingabe"). Activate

TextBox32. Value $=\operatorname{Cells}(5,2)$

End If

End Sub

\section{Private Sub CheckBox1_Click()}

'bei click und true Werte nach RV $\mathrm{K}$ berechnen und Eingabe sperren

'bei click und false Werte frei eingeben mit Startwerten aus Excel

With Worksheets ("Eingabe"). Activate

If CheckBox1. Value = True Then

Range ("J2๑"). Formula $="=\odot .366 *(B 23 * B 27 \star B 24 \star B 28)^{\wedge}(\odot .5) "$

Range ("J21"). Value $=0.201$

Range ("J22"). Formula $="=1 \odot .8 * \mathrm{~B} 23 * \mathrm{~B} 27^{\wedge}(-\odot .89) "$

TextBox37. Enabled = False

TextBox38. Enabled $=$ False

TextBox39. Enabled $=$ False

$\operatorname{Cells}(24,10)=$ "ja"

ElseIf CheckBox1.Value = False Then

TextBox37. Enabled $=$ True

TextBox38. Enabled $=$ True

TextBox39. Enabled $=$ True

$\operatorname{Cells}(24,10)=$ "nein"

End If

TextBox37.Value $=$ Round $(\operatorname{Cells}(20,10)$. Value, 3$)$

TextBox38.Value $=$ Round $(\operatorname{Cells}(21,10)$. Value, 3$)$

TextBox39.Value $=\operatorname{Round}(\operatorname{Cells}(22,10)$. Value, 3$)$

End With

End Sub 


\section{Private Sub TextBox37_Change()}

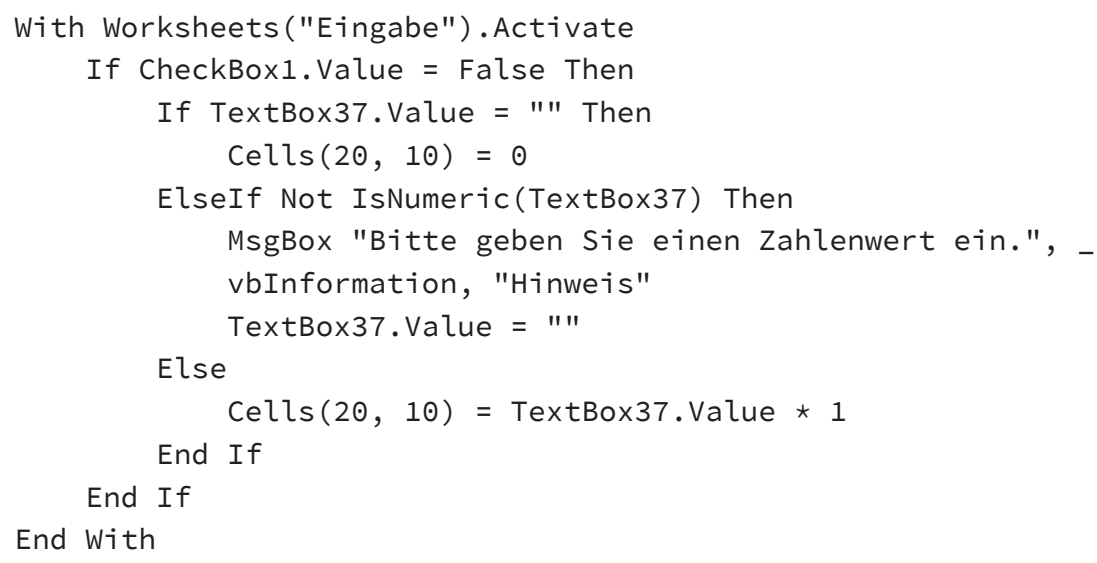

End Sub

\section{Private Sub TextBox38_Change()}

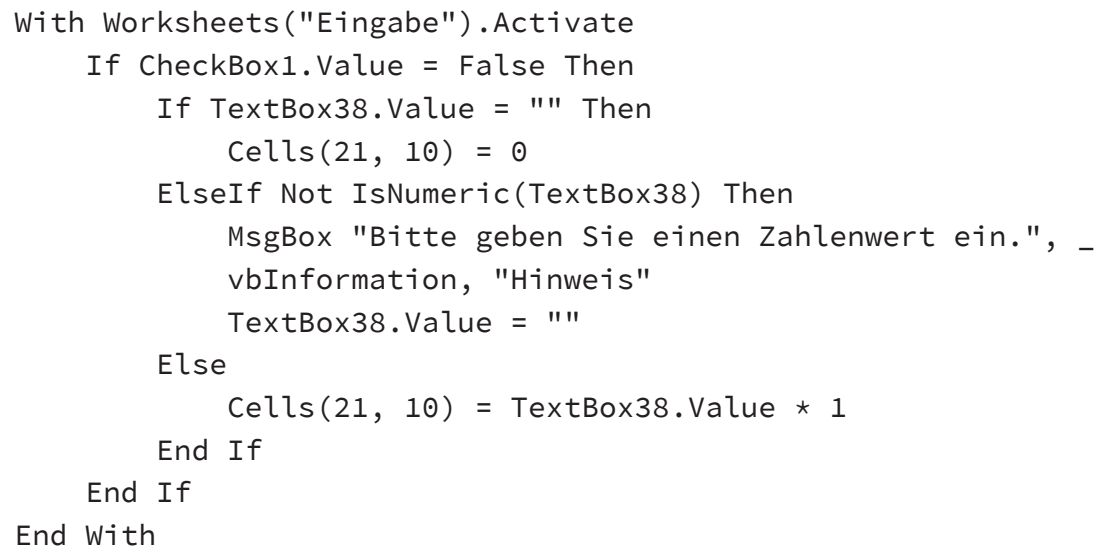

End Sub

\section{Private Sub TextBox39_Change()}

With Worksheets("Eingabe"). Activate

If CheckBox1.Value = False Then

If TextBox39.Value $=$ " "Then

$\operatorname{Cells}(22,10)=0$ 


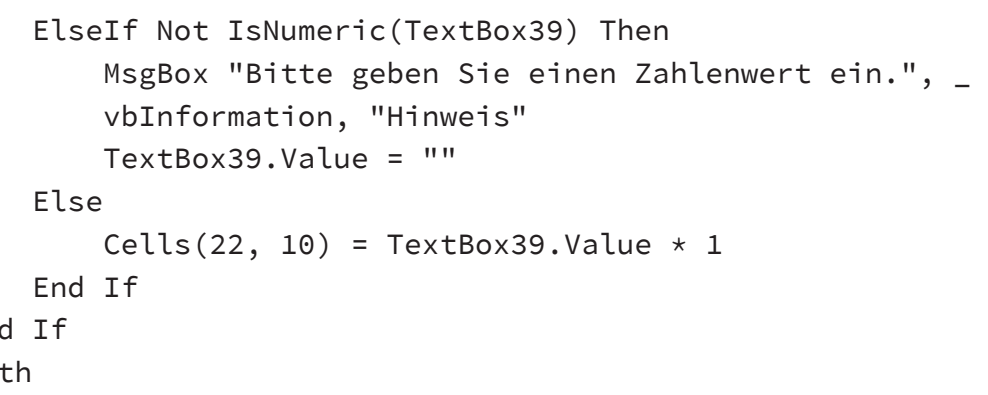

End Sub

\section{Private Sub CommandButton9_Click()}

'Eine Seite zurück MultiPage1. Value $=$ MultiPage1. Value -1

End Sub

\section{Private Sub CommandButton10_Click()}

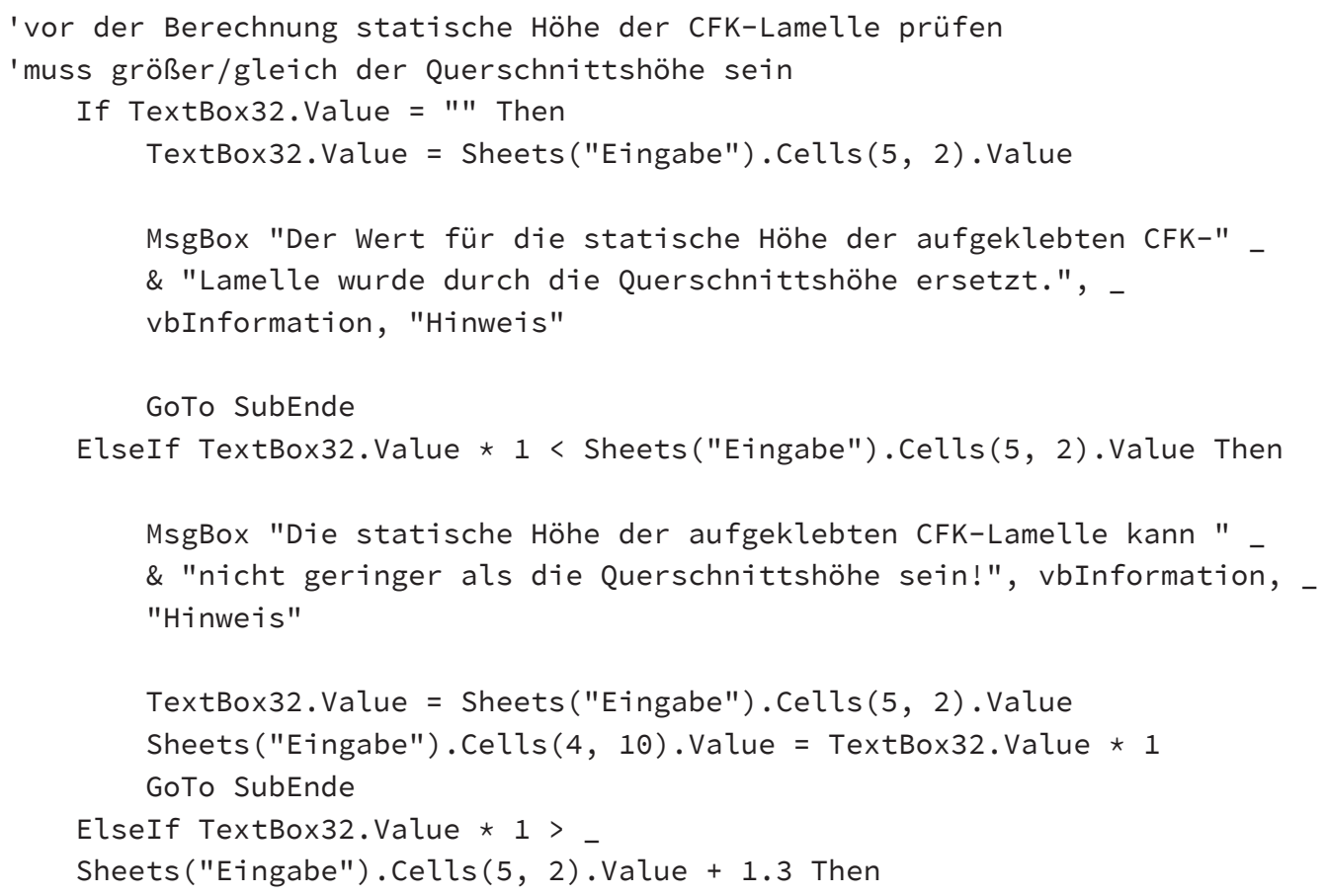


$1+1.3=$ maximale Lamellendicke +2 Lagen Kleber $(j e \max 0,5 \mathrm{~cm})$

MsgBox "Bitte prüfen Sie die statische Höhe der CFK-Lamelle." \& _ vbNewLine \& "maximale statische Höhe: " -

\& Sheets("Eingabe").Cells $(5,2)$. Value +1.3 , vbInformation, "Hinweis"

GoTo SubEnde

Else

End If

'Information, dass die folgende Berechnung ein paar Minuten dauern kann MsgBox "Die Berechnung des genaueren Nachweises der "

\& "Lamellenkraftänderung am ZRE wird nach bestätigen der Schaltfläche" \& " 'OK' durchgeführt. Dieser Vorgang kann einige Minuten dauern.", vbInformation, "Information"

'Arbeitsblätter entsperren

Sheets ("Biegenachweis"). Unprotect Password:="Masterarbeit"

Sheets("Rissabstand") .Unprotect Password:="Masterarbeit"

Sheets ("Genauerer_NW"). Unprotect Password:="Masterarbeit"

'1. vorhandene Tragfähigkeit MRd, $\odot$ berechnen

With Worksheets("Biegenachweis"). Activate

'A) Stahlversagen (Betondehnung iterieren)

Range ("A11") Value = Range ("H6") Value

Range ("C11").Value = Range ("K4") .Value

SolverReset

SolverOk SetCell:="\$A11", MaxMinVal:=1, Value0f:=0, _

ByChange:="\$A $\$ 11$ ", Engine:=1, EngineDesc:="GRG Nonlinear"

'Nebenbedingungen

SolverAdd CellRef: $=$ "\$K\$11", Relation: $=2$, FormulaText: $=" \odot "$

SolverAdd CellRef:="\$A $\$ 11$ ", Relation:=1, FormulaText:="\$H\$6"

SolverAdd CellRef:="\$A $\$ 11$ ", Relation:=3, FormulaText:="๑"

SolverOk SetCell:="\$A\$11", MaxMinVal:=1, Value0f:=๑, _

ByChange:="\$A11", Engine:=1, EngineDesc:="GRG Nonlinear" SolverSolve (True)

'B) wenn kein Stahlversagen, dann Betonversagen (Stahldehnung iterieren) 


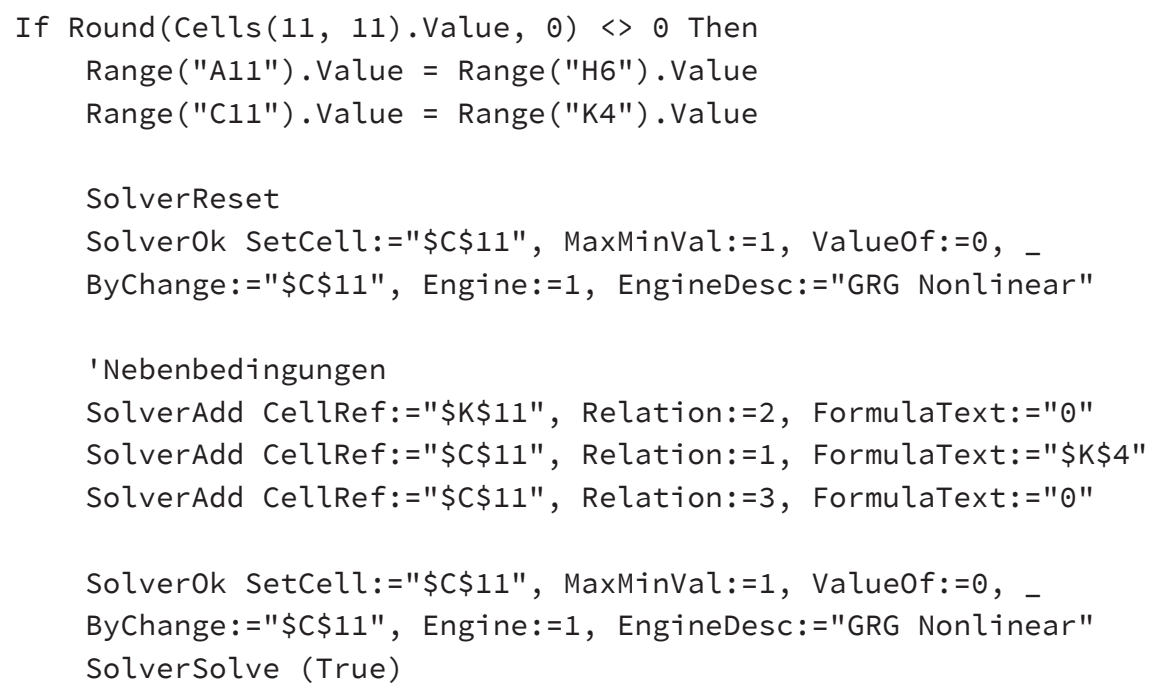

End If

End With

'2. prüfe: Einwirkung größer Widerstand?

With Sheets ("Biegenachweis")

If $\operatorname{Cells}(4,4)<=\operatorname{Cells}(11,12)$ Then

MsgBox "Die vorhandene Biegtragfähigkeit ist ausreichend." \& " Eine Verstärkungsmaßnahme ist nicht notwendig.", _ vbInformation, "Information"

GoTo SubEnde

End If

End With

'3. Biegenachweis (Lamellenfläche für einwirkendes Moment)

With Worksheets("Biegenachweis"). Activate

'A) Lamellenversagen (Betondehnung iterieren)

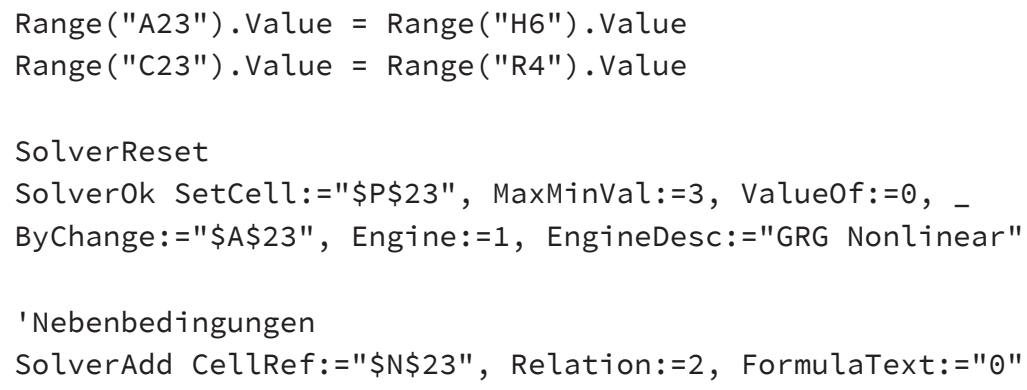


SolverAdd CellRef:="\$A $\$ 23 "$, Relation:=1, FormulaText:="\$H\$6" SolverAdd CellRef:="\$A $\$ 23 "$, Relation:=3, FormulaText:="๑"

Solverok SetCell:="\$P\$23", MaxMinVal:=3, Value0f:=e, _ ByChange:="\$A23", Engine:=1, EngineDesc:="GRG Nonlinear" SolverSolve (True)

'B) Betonversagen (Lamellendehnung iterieren) If Round(Range("P23"). Value, $\odot)<>\odot$ Then Range ("A23") .Value = Range $(" \mathrm{H6} ") \cdot$ Value Range ("C23") .Value = Range ("R4") . Value

SolverReset

Solverok SetCell:="\$P\$23", MaxMinVal:=3, Value0f:=e, _ ByChange: $=$ "\$C\$23", Engine: $=1$, EngineDesc:="GRG Nonlinear"

'Nebenbedingungen

SolverAdd CellRef: $=" \$ N \$ 23 "$, Relation:=2, FormulaText:="๑" SolverAdd CellRef: $=$ "\$C $\$ 23 "$, Relation:=1, FormulaText: ="\$R $\$ 4 "$ SolverAdd CellRef:="\$C\$23", Relation:=3, FormulaText:="๑"

SolverOk SetCell:="\$P\$23", MaxMinVal:=3, Value0f:=0, _ ByChange: $=$ "\$C23", Engine: $=1$, EngineDesc:="GRG Nonlinear" SolverSolve (True)

End If

If Round(Range ("C23") . Value, 4) $=0$ And Round(Range("P23").Value, 2) $<>$ Then

MsgBox "Die Einwirkung ist zu groß. Eine Verstärkungs" \& "maßnahme mit aufgeklebten CFK-Lamellen lässt sich" _ \& " für diese Einwirkung nicht nachweisen.", vbcritical, "Nachweis nicht möglich!"

GoTo SubEnde

End If

End With

14. Startwert Lamellenbreite und -dicke

'minimale und maximale Abmessungen berücksichitgen

'roundup $(\ldots, \odot / 5) \star 5$ rundet auf ganzzahlige $5 \mathrm{~mm}$

Sheets ("Eingabe").Range("J16"). Value = 


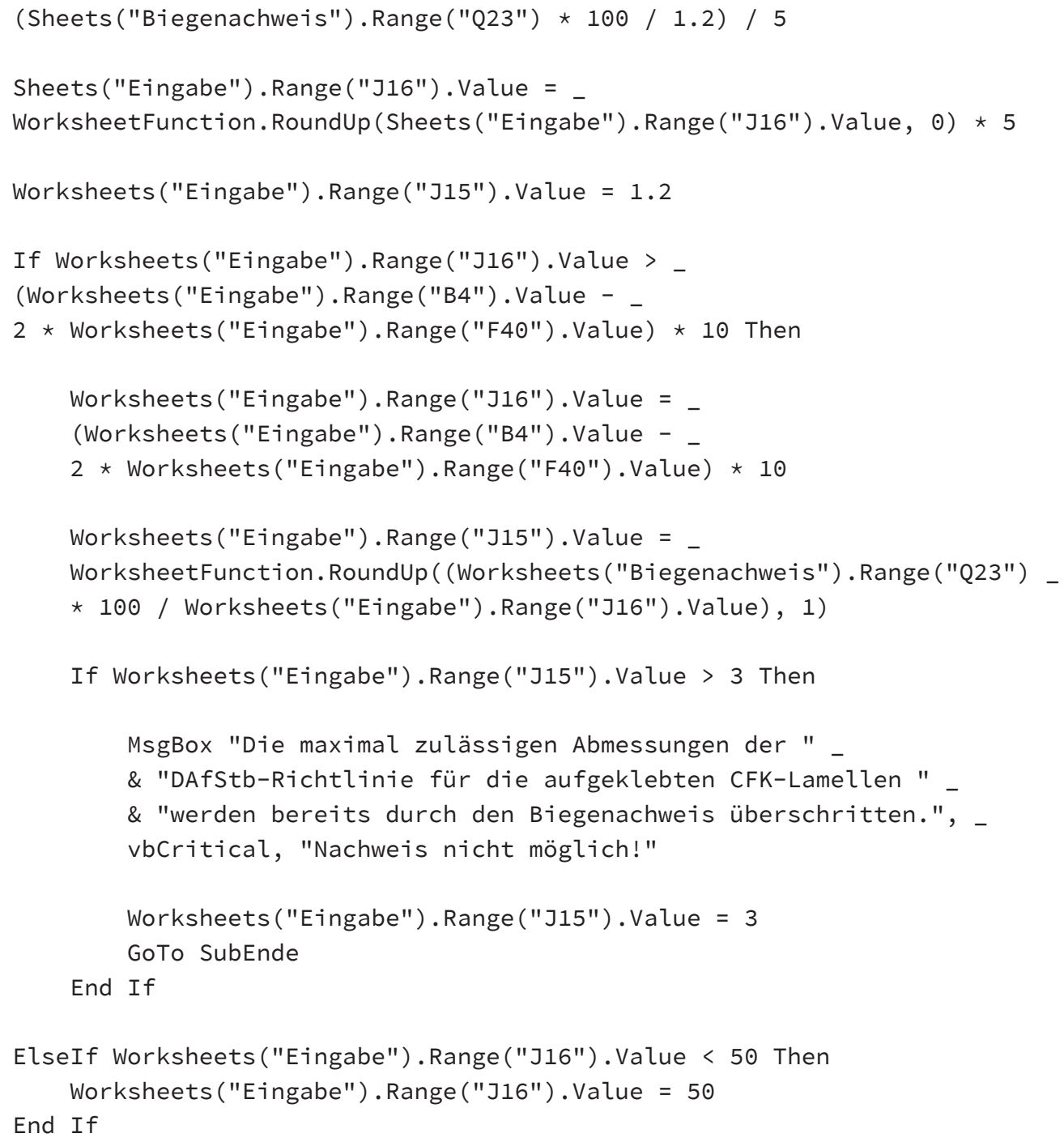

'5. Verbundnachweis mit kontinuierlicher Steigerung der Lamellenbreite

RunAgain1:

With Worksheets("Genauerer_NW"). Activate

' löschen der vorhandenen Werte

If Range("A9") < Cells $(4,3) * 100 / 2-\operatorname{Cells}(4,26)$ Then Rows("9:9"). Delete Shift:=xlup

GoTo RunAgain1

Else

'1.Zeile mit Solver lösen 
RunAgain2:

$$
\begin{aligned}
& \text { Range ("J10") } \cdot \text { Value }=25 \\
& \text { Range ("K10"). Value }=3.5
\end{aligned}
$$

SendKeys "\{Enter $\} "$, True

SolverReset

Solverok SetCell:="\$X\$10", MaxMinVal:=3, -

Value0f: $=\odot$, ByChange: $=$ " J $\$ 10: \$ K \$ 10 "$,

Engine:=1, EngineDesc:="GRG Nonlinear"

'Nebenbedingungen

SolverAdd CellRef:="\$W10", Relation:=2, FormulaText:="๑"

SolverAdd CellRef:="\$J\$10", Relation:=1, FormulaText:="\$K\$4"

SolverAdd CellRef:="\$J\$10", Relation:=3, FormulaText:="๑"

SolverAdd CellRef:="\$K\$10", Relation:=1, FormulaText:="\$H\$6"

SolverAdd CellRef:="\$K\$10", Relation:=3, FormulaText:="๑"

SolverOk SetCell:="\$X $\$ 10 "$, MaxMinVal: $=3$,

Value0f: $=\odot$, ByChange: $=$ "\$J\$10:\$K\$10", _

Engine:=1, EngineDesc:="GRG Nonlinear"

SolverSolve (True)

If $\operatorname{Round}(\operatorname{Cells}(1 \odot, 23), \odot)<>\odot$.

Or Round (Cells $(10,24), \odot)<>\odot$ Then

'teilweise findet Solver bei diesem Wert keine Lösung

If Round(Range("J10").Value, 3) $=2.174$ Then

Range ("J10") $\cdot$ Value $=25$

End If

GoTo RunAgain2

End If

'2.Zeile mit Solver lösen

Range ("J9"). Value $=25$

Range ("K9") . Value $=3.5$

RunAgain3:

SolverReset

SolverOk SetCell:="\$X\$9", MaxMinVal:=3, _

Value0f: $=\odot$, ByChange: $=$ "J \$9:\$K\$9", _

Engine:=1, EngineDesc:="GRG Nonlinear"

'Nebenbedingungen

SolverAdd CellRef:="\$W\$9", Relation: $=2$, FormulaText: $=" \odot "$

SolverAdd CellRef:="\$J\$9", Relation:=1, FormulaText:="\$K\$4" 


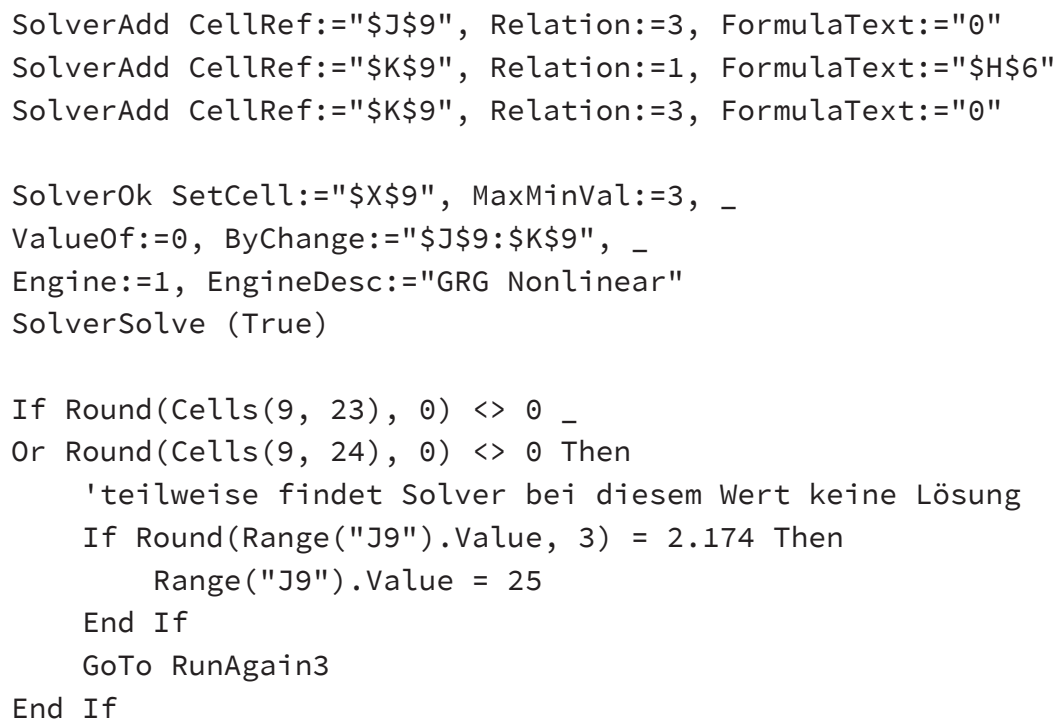

RunAgain4:

'einfügen und lösen bis zum Auflager $(x=0)$

Rows ("9:9"). Select

Selection. Insert Shift:=xlDown

Range ("A10:AI10"). Copy

Range("A9"). Select

Activesheet.Paste

Application.CutCopyMode = False

RunAgain5:

SolverReset

SolverOk SetCell:="\$X\$9", MaxMinVal:=3,

Value0f: $=0$, ByChange: $=$ "J\$9:\$K\$9", _

Engine:=1, EngineDesc:="GRG Nonlinear"

'Nebenbedingungen

SolverAdd CellRef:="\$W\$", Relation:=2, FormulaText:="๑"

SolverAdd CellRef: $=$ "\$J9", Relation: =1, FormulaText:="\$K\$4"

SolverAdd CellRef:="\$J9", Relation:=3, FormulaText:="๑"

SolverAdd CellRef:="\$K\$9", Relation:=1, FormulaText:="\$H

SolverAdd CellRef:="\$K\$9", Relation:=3, FormulaText:="๑"

SolverOk SetCell:="\$X\$9", MaxMinVal:=3, _

Value0f: $=\odot$, ByChange: $=" \$ J \$ 9: \$ K \$ 9 "$,

Engine:=1, EngineDesc:="GRG Nonlinear"

SolverSolve (True) 


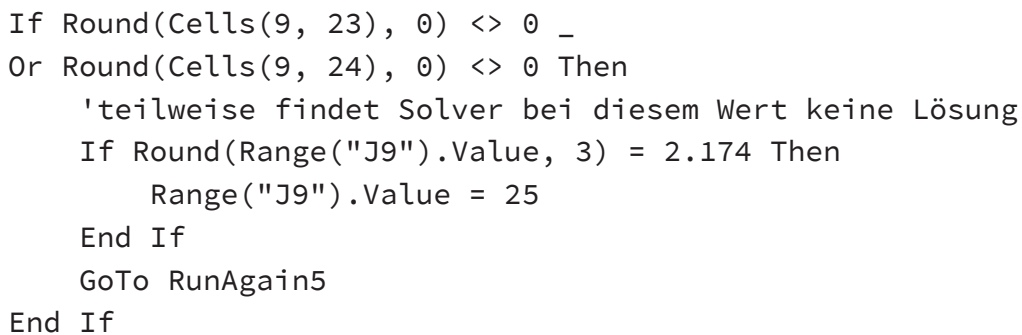

' in jeder Zeile prüfen, ob Verbundnachweis erfüllt ist 'sonst Lamellenbreite erhöhen und neue Berechnung starten 'wenn maximale Lamellenbreite erreicht ist, Lamellendicke steigern 'wenn $b L, \max =b-2 \star c n o m$ und $t L, \max =3,0 \mathrm{~mm} N W$ nicht erfüllt If Worksheets("Genauerer_NW").Cells(4, 43) > 1 Then

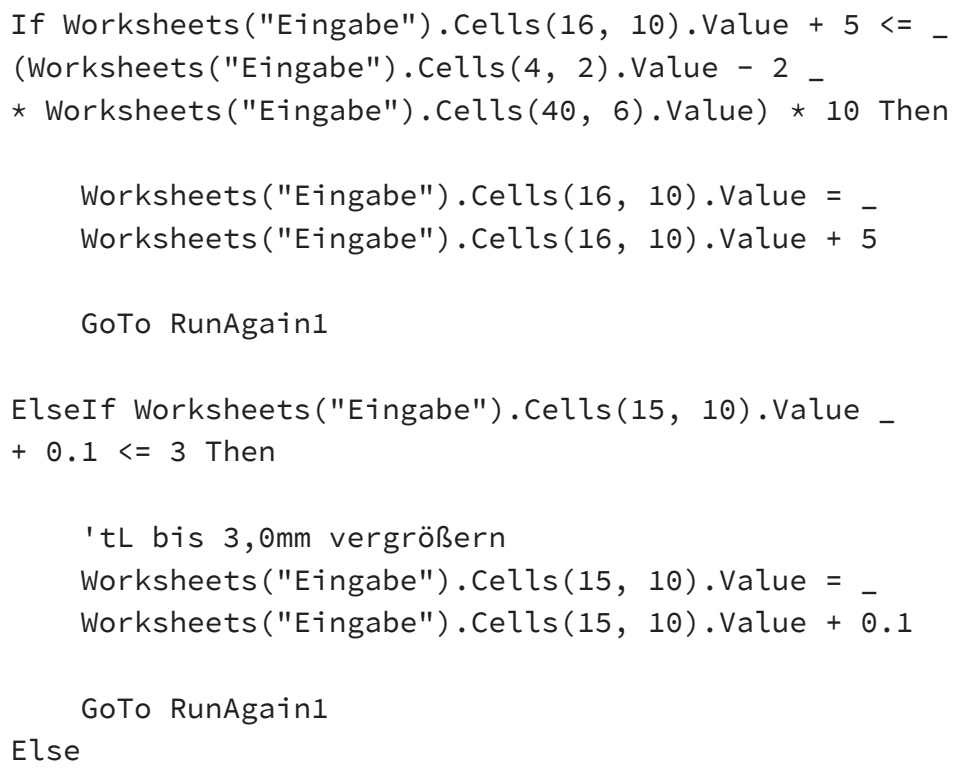




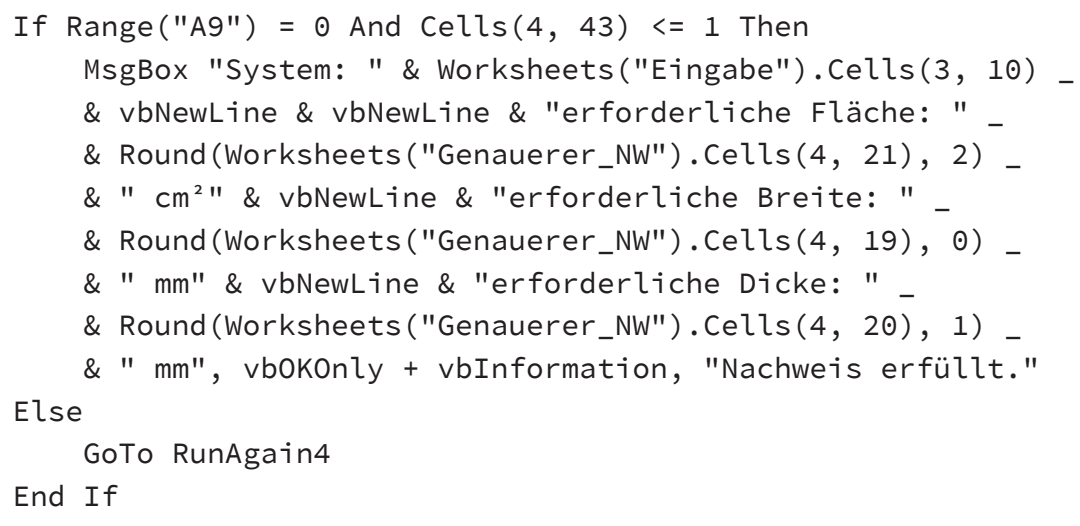

End If

End With

Unload UserForm1

SubEnde:

'Arbeitsblätter sperren

Sheets("Biegenachweis"). Protect Password:="Masterarbeit"

Sheets ("Rissabstand") . Protect Password:="Masterarbeit"

Sheets ("Genauerer_NW") . Protect Password:="Masterarbeit"

End Sub 



\section{Anhang $\mathrm{H}$ \\ Fehlerbehebung Excel-Arbeitsmappe}

\section{Makros aktivieren}

Für die Nachweisführung in Verbindung mit VBA in Excel sind im Voraus einige grundlegende Einstellungen vorzunehmen. Ansonsten wird während der Berechnung möglicherweise eine Fehlermeldung erscheinen. In diesem Anhang soll dem Anwender eine Hilfestellung für die Lösung der möglichen auftretenden Fehlermeldungen geliefert werden, um eine uneingeschränkte Anwendung der Excel-Arbeitsmappe zu ermöglichen. Dabei werden die Fehlerursachen betrachtet, die während der probeweisen Berechnungen aufgetreten sind. Es besteht jedoch die Möglichkeit, dass weitere Fehlermeldungen erscheinen, die zum jetzigen Zeitpunkt noch unbekannt sind. Für alle bekannten Fehlermeldungen wird im Folgenden lediglich ein möglicher Lösungsweg aufgezeigt, auch wenn es mehrere zielführende Wege gibt.

Eine grundlegende Voraussetzung wurde bereits in Kapitel 3.3.2.2 geschildert. Um die Funktion der Excel-Arbeitsmappe überhaupt nutzen zu können, müssen die hinterlegten Makros zugelassen werden. Dazu muss beim Starten der Arbeitsmappe lediglich die Schaltfläche „Inhalt aktivieren“ betätigt werden.

\section{Solver Add-In installieren}

Sofern die Inhalte aktiviert sind, startet das Makro „AutoOpen“ die Eingabemaske. Dabei sind während der probeweisen Berechnungen keine Probleme aufgetreten. Alle Pop-Up-Fenster, die während der Eingabe erscheinen, dienen zur Begrenzung der Eingabewerte und sind durch den Anwender zu beheben, indem Werte im jeweils zulässigen Bereich eingegeben werden. Nachdem alle Eingaben getätigt wurden und die Berechnung startet, kann eine Excel-Fehlermeldung aufgrund des fehlenden Solver-Add-Ins auftreten. Diese kann mit „OK“ bestätigt werden. 


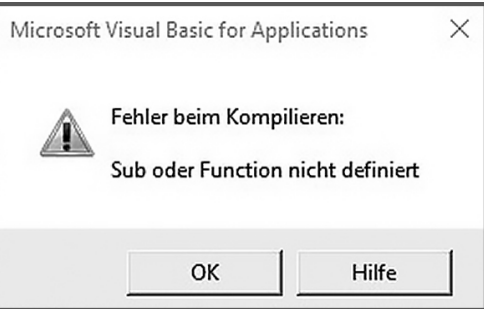

Abb. H.1 Fehlermeldung (Solver Add-in nicht installiert) (http://doi.org/10.33968/9783966270021-14-A-01)

Da das Solver Add-In zwar von Excel mitgeliefert wird, aber nicht automatisch installiert ist, muss dies vor der ersten Anwendung durch den Nutzer durchgeführt werden. Über die Menüschaltflächen Datei $\rightarrow$ Optionen $\rightarrow$ Add-Ins werden die bereits installierten Add-Ins angezeigt. Durch Bestätigen der Schaltfläche „Los“ im unteren Teil des Fensters werden die verfügbaren Add-Ins angezeigt. Dabei ist zu beachten, dass in dem Auswahlfenster („Verwalten:“) die Excel-Add-Ins ausgewählt sind.

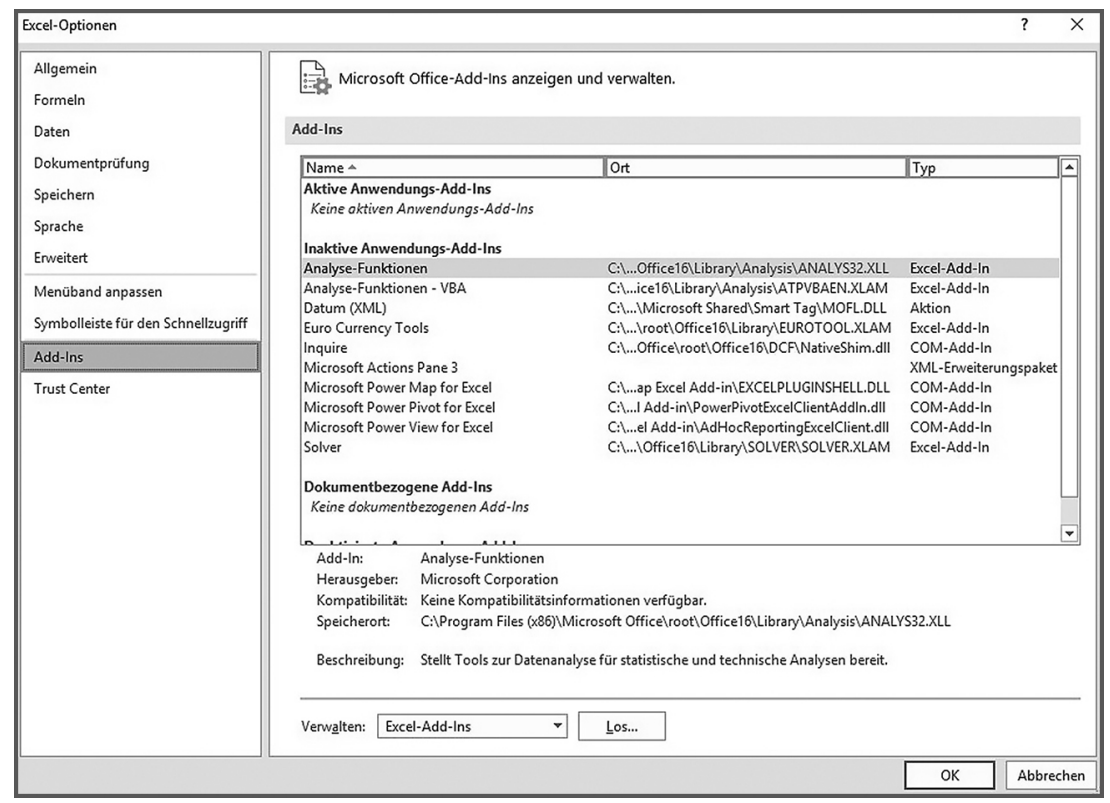

Abb. H.2 Excel-Add-Ins (http://doi.org/10.33968/9783966270021-14-A-02) 
Hier muss bei dem Eintrag „Solver“ der Haken gesetzt werden. Anschließend kann mit „OK“ bestätigt werden. Der Solver ist jetzt installiert und im oberen Menüband der Excel-Arbeitsmappe unter dem Reiter „Daten“ verfügbar.

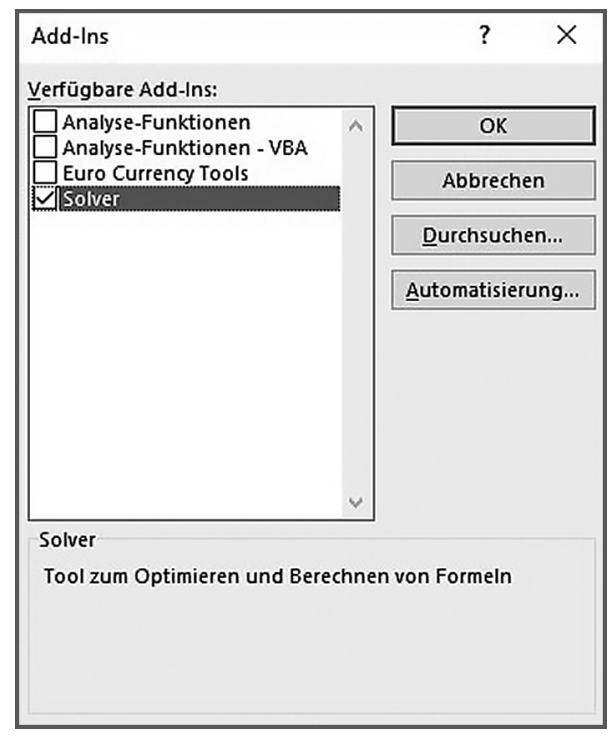

Abb. H.3 Solver aktivieren (http://doi.org/10.33968/9783966270021-14-A-03)

\section{VBA Solver-Verweis}

Ist der Solver installiert, können prinzipiell die iterativen Berechnungen in der Nachweisführung von der Excel-Arbeitsmappe durchgeführt werden. Sofern die Eingaben per Hand in den Solver eingetragen werden, tritt auch keine weitere Fehlermeldung auf. Da die Berechnung aber mittels Makros automatisiert ablaufen soll, muss auch VBA auf den Solver zugreifen können. Dazu muss ein Verweis auf die Solver-Datei im VBA-Editor erzeugt werden, denn sonst wird wieder folgende Meldung auf dem Bildschirm erscheinen: 


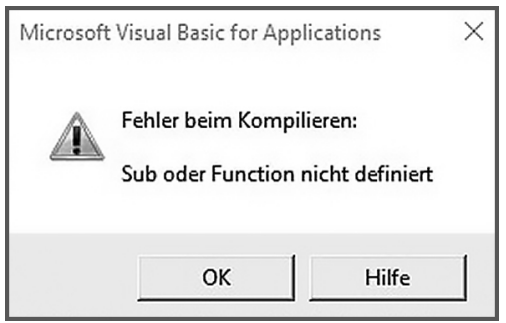

Abb. H.4 Fehlermeldung (VBA Solver-Verweis fehlt)

(http://doi.org/10.33968/9783966270021-14-A-04)

An dieser Stelle kann der Vorgang mit „OK“ bestätigt werden. Um den Verweis zu setzen, muss der VBA-Editor gestartet werden. Eine Möglichkeit dazu besteht mit der Tastenkombination ALT + F11. Als nächstes muss der Vorgang gestoppt werden, da der VBA-Editor sonst keine Änderung in den Verweisen zulässt. Dies kann über das blaue Quadrat in der Symbolleiste erfolgen.

Microsoft Visual Basic for Applications - Verbundnachweis_aufgeklebte_CFK-Lamellen - Kopie.xlsm [Unterbrechen] - [UserForm1 (Code)]

Datei Bearbeiten Ansicht Einfügen Format Debuggen Ausführen Extras Add-Inns Fenster ?

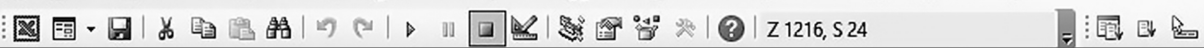

Abb. H.5 Makro stoppen (http://doi.org/10.33968/9783966270021-14-A-05)

Über den Menüpunkt „Extras“ können die verfügbaren Verweise geöffnet werden.

\begin{tabular}{|c|c|c|c|}
\hline \multicolumn{4}{|c|}{ Microsoft Visual Basic for Applications - Verbundnachweis_aufgeklebte_CFK-Lamellen - Kopie.xlsm - [UserForm1 (Code)] } \\
\hline Datei Bearbeiten Ansicht Einfügen & Format Debuggen Ausführen & Extras Add-Ins Fenster ? & \\
\hline 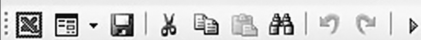 & 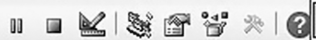 & Verweise... & Ev \\
\hline Projekt - VBAProject & CommandButton10 & Zusätzliche Steuerelemente... & \\
\hline 图目回 & & $\underline{\text { Makros... }}$ & \\
\hline 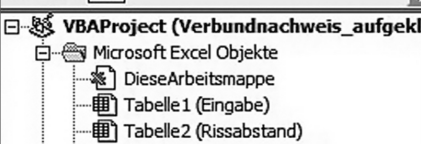 & $\begin{array}{l}\text { 'Information, dass } \\
\text { MsgBox "Die Ber } \\
\& \text { "Lamellenkraf } \\
\& \text { " 'OK' durchg } \\
\text { vbInformation, }\end{array}$ & $\begin{array}{l}\text { Optionen... } \\
\text { Eigenschaften von VBAP roject... } \\
\text { Digitale Signatur... } \\
\text { "Information" }\end{array}$ & $\begin{array}{l}\text { ar } \text { Min } \\
\text { es } \text { der } \\
\text { tätige: } \\
\text { Minute: }\end{array}$ \\
\hline
\end{tabular}

Abb. H.6 VBA-Verweise öffnen (http://doi.org/10.33968/9783966270021-14-A-06)

Anschließend muss der Haken beim Solver gesetzt und die Auswahl mit „OK“ bestätigt werden. Sollte das Solver-Add-In noch nicht installiert sein, ist der Solver hier noch nicht zu finden. Dann muss zuerst der Solver, wie vorab beschrieben, installiert werden. 


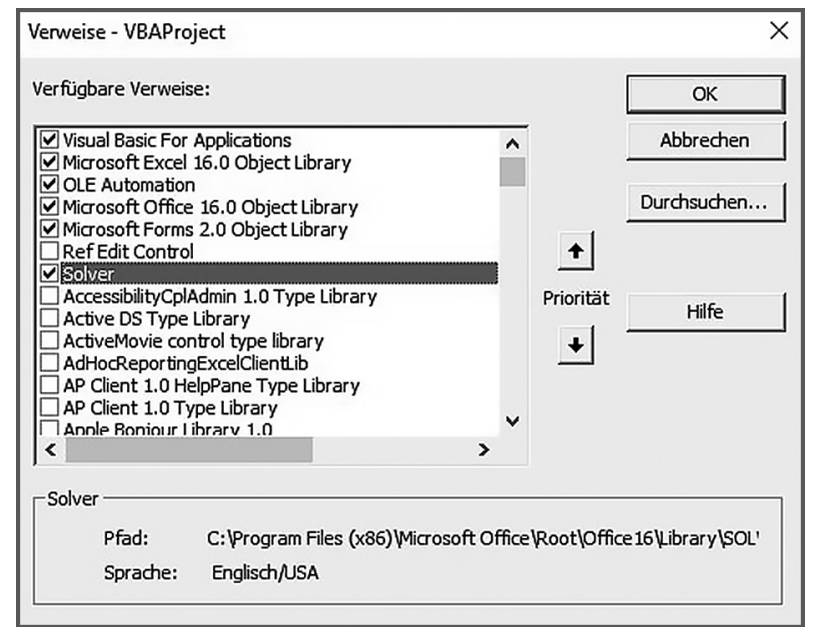

Abb. H.7 Solver-Verweis setzen (http://doi.org/10.33968/9783966270021-14-A-07)

Sobald der Verweis auf den Solver gesetzt ist kann der VBA-Editor geschlossen und mit der Berechnung begonnen werden. Die Berechnung sollte nun unproblematisch durchgeführt werden können.

\section{Einstellungsänderungen durch Makros}

Aufgrund der Vorgehensweise der Makros kann es teilweise auch zu unerwünschten Änderungen an grundlegenden Einstellungen der Arbeitsmappe kommen, die aber keine Auswirkung auf die Berechnung haben. Teilweise wird während der Ausführung der Makros die automatische Berechnung des aktiven Excel-Arbeitsblatts zurückgesetzt, sodass erst nach dem Speichern die Werte neu berechnet und ausgegeben werden. Um die automatische Anzeige wiederherzustellen, muss die entsprechende Auswahl in den Optionen getroffen werden. Wann und ob dieser Fehler auftritt und worin dessen Ursache liegt, ist zum jetzigen Zeitpunkt nicht genau bekannt. Da dadurch aber keine ausschlaggebende Einschränkung der ExcelArbeitsmappe herbeigeführt wird und dieser Fehler vergleichsweise selten auftritt, bleibt die Ursachenforschung an dieser Stelle unberücksichtigt. 


\begin{tabular}{|c|c|c|c|c|c|}
\hline Excel-Optionen & & & & $?$ & $\times$ \\
\hline Allgemein & \multirow{2}{*}{\multicolumn{4}{|c|}{ 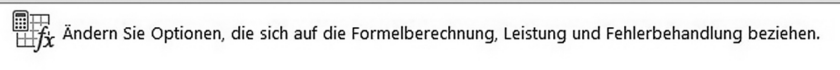 }} & $\Delta$ \\
\hline Formeln & & & & & \\
\hline Daten & \multicolumn{5}{|l|}{ Berechnungsoptionen } \\
\hline Dokumentprüfung & \multirow{5}{*}{$\begin{array}{l}\text { Arbeitsmappenberechnung }(i) \\
\text { Automatisch } \\
\text { Automatisch außer bei Datentabellen } \\
\text { Manuell } \\
\square \text { Vor dem Speichern die Arbeitsmappe neu } \\
\text { berechnen }\end{array}$} & \multicolumn{3}{|c|}{$\square$ Itterative Berechnung aktivieren } & \\
\hline Speichern & & \multirow{4}{*}{$\begin{array}{l}\text { Maximale Iterationşzahl: } \\
\text { Maximale Änderung: }\end{array}$} & $100 \div$ & & \\
\hline Sprache & & & 0,001 & & \\
\hline Erweitert & & & & & \\
\hline Menüband anpassen & & & & & \\
\hline
\end{tabular}

Abb. H.8 automatische Arbeitsmappenberechnung aktivieren (http://doi.org/10.33968/9783966270021-14-A-08)

Außerdem kann es vorkommen, dass die „numlock“-Taste unbeabsichtigt durch die Ausführung der hinterlegten Makros aktiviert bzw. deaktiviert wird. Da der Solver bei der ersten Iteration die Fehlermeldung ausgibt, dass die Zielzelle auf dem aktiven Arbeitsblatt liegen muss, wurde ein Befehl in dem Makro formuliert, der die Taste „Enter“ zur Bestätigung an Excel sendet, sodass der Nutzer diese Fehlermeldung nicht nach jedem Berechnungsvorgang bestätigen muss. 


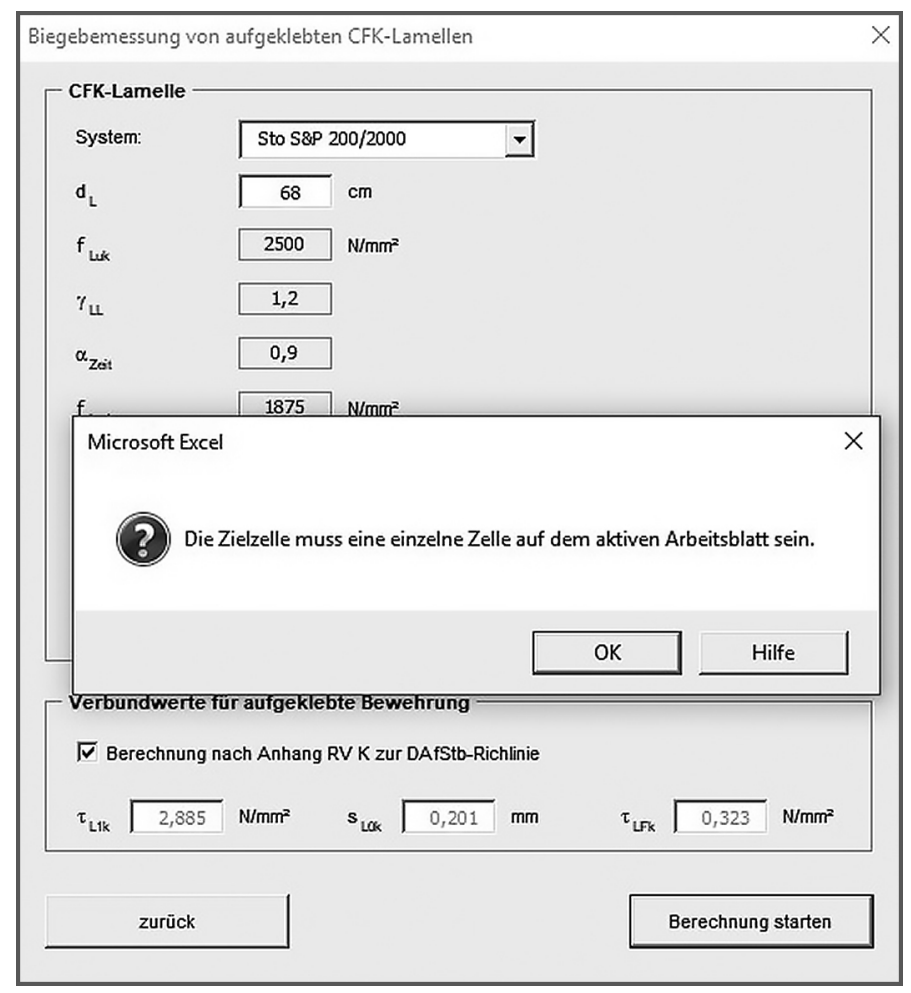

Abb. H.9 Fehlermeldung Zielzelle (http://doi.org/10.33968/9783966270021-14-A-09)

Vermutlich tritt der Fehler an dieser Stelle auf, denn dabei werden jedes Mal die Tastatureinstellungen abgefragt. Da diese Einstellung mit äußerst geringem Aufwand wieder in den gewünschten Zustand zu bringen ist und die Anwenderfreundlichkeit durch den integrierten Befehl deutlich zunimmt, wird dieser Fehler an dieser Stelle akzeptiert. 
